\title{
STORIED POSSESSIONS: POST-HOUSEHOLD DISBANDMENT OLDER ADULT PLACEMAKING THROUGH MEANINGFUL BELONGINGS
}

A Dissertation
presented to
the Faculty of the Graduate School
at the University of Missouri-Columbia
In Partial Fulfillment
of the Requirements for the Degree
Doctor of Philosophy
HEATHER CARLILE CARTER
Dr. Ruth Tofle, Dissertation Supervisor
DECEMBER 2018


(C) Copyright by Heather Carlile Carter 2018

\author{
All Rights Reserved
}




\section{STORIED POSSESSIONS}

The undersigned, appointed by the Dean of the Graduate School at the University of Missouri - Columbia, have examined the dissertation entitled

STORIED POSSESSIONS: POST-HOUSEHOLD DISBANDMENT OLDER ADULT LATE-LIFE PLACEMAKING WITH MEANINGFUL BELONGINGS

presented by Heather Carlile Carter, a candidate for degree of Doctor of Philosophy and hereby certify that, in their opinion, it is worthy of acceptance.

Ruth Tofle, $\mathrm{PhD}$

Benyamin Schwarz, $\mathrm{PhD}$

Jacquelyn Benson, $\mathrm{PhD}$

Stephen Jeanetta, $\mathrm{PhD}$ 
STORIED POSSESSIONS

\section{Dedication}

My brilliant mother, a mathematician and technology geek, passed away while I was finishing this research. She was born decades too early, a digital native before the digital age. One year she bought my husband and me a bedside, atomic alarm clock. It has a swivel arm that projects the time onto the ceiling with red light visible in the dark. Although it is designed to synchronize to local time, our clock does not register to the zone where we live. Instead, the time zone of her childhood and entrance into her career is illuminated. When I wake in the night, I must mentally add two hours to the numbers on the ceiling. Sometimes, in my sleepy haze, I cannot immediately recall if I need to add or subtract the two hours. I smile at the irony of this gift from a mathematician. It is so like my mother to make me calculate in my sleep. After she died, I became more attached to this geeky, non-synchronizing clock. When I wake, I look for the time on my ceiling. It is a known stable thing. "Good morning, Mom. Thank you for loving me," I say. Thus, I dedicate this research, on the embedded meaning of possessions, to my mother - the smartest person in the room projecting her love through the dark.

\section{Irene Carlile}

March 6, 1933-May 1, 2018

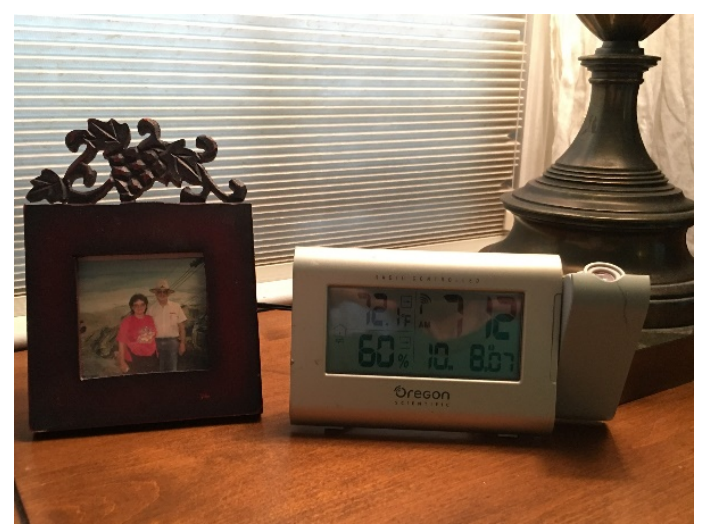




\section{Acknowledgements}

Thank you, Dr. Ruth Tofle. As my dissertation supervisor, your leadership was superb. I always knew you had my best interest in mind, not just as a student and researcher, but also as a human being. I appreciate the skill with which you headed the Architectural Studies department, particularly the Ph.D. program. Thank you for joining me in the pursuit of a research topic that continues to fuel my curiosity and passion for deeper understanding. Also, at a crucial time in my dissertation process, Dr. Schwarz and you provided kindness, guidance, and support after my mother's death — it was a lifeline that allowed me to continue my research.

Thank you, Dr. Benyamin Schwarz. Your deep thought processes and passion for meaningful research challenged me to excellence. I appreciate that you did not settle for good enough but authentically demonstrated the pursuit of impactful knowledge.

Thank you to my other committee members: Dr. Jacquelyn Benson and Dr. Stephen Jeanetta. You went above and beyond, adjusting schedules and contributing your unique perspectives that benefitted my research.

Thank you to my fellow Ph.D. students and candidates in the University of Missouri Architectural Studies Program. I appreciate the consistent encouragement of Dr. Elke Altenburger and Dr. Greg Galford as we moved together through the dissertation process. Our writing group, under the leadership of Dr. Laura Cole, provided delightful weekly accountability that I needed. My deepest appreciation for all the participants who are scattered throughout the U.S. and their intellectual conversation and humor.

Finally, thank you to my editor, Jennifer Bortz. Your logic and writing inspire me. My best to all. 


\section{Table of Contents}

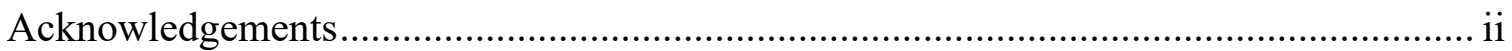

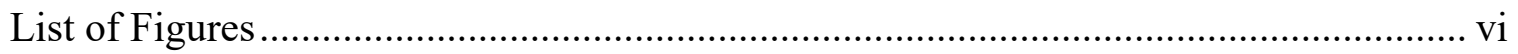

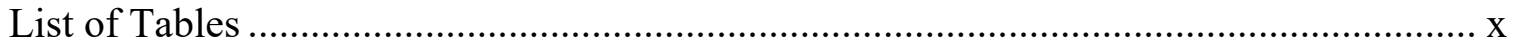

Academic Abstract................................................................................................. xii

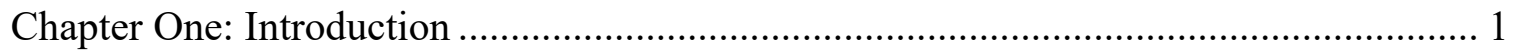

Research Questions .................................................................................

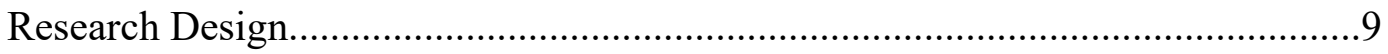

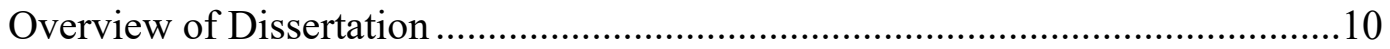

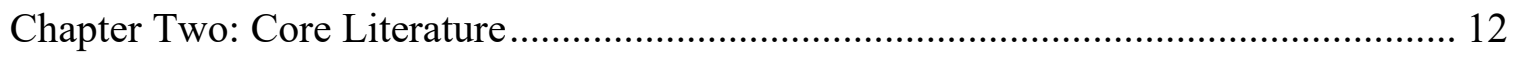

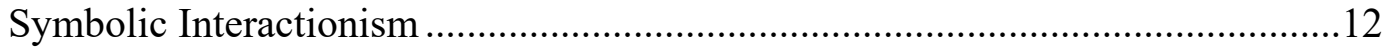

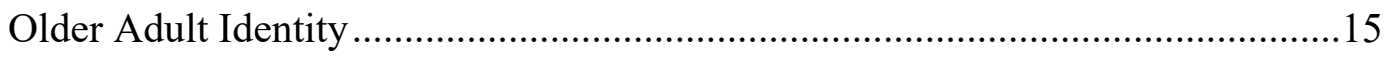

Embedded Meanings in Possessions .............................................................24

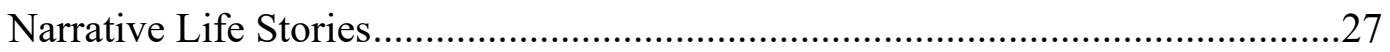

Late-Life Place Making ..............................................................................29

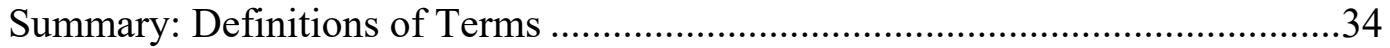

Chapter Three: Research Methods....................................................................... 39

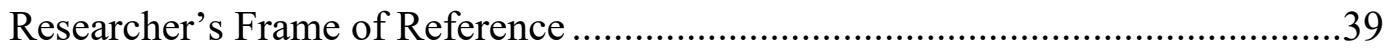

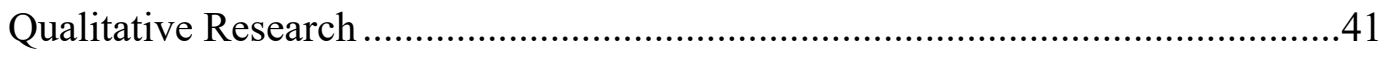

Multiple-Case Holistic Case Study ....................................................... 42

Research Participants .............................................................................46

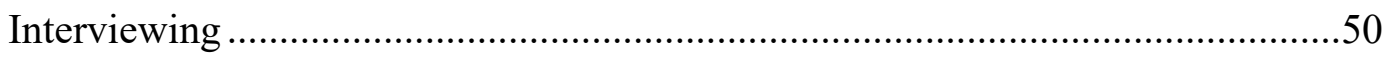

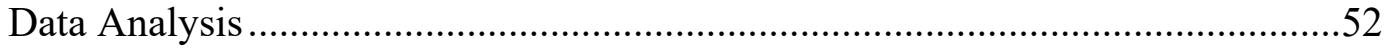




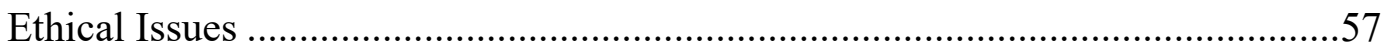

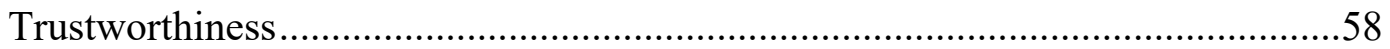

Chapter Summary: Interactive Research Design ..........................................6

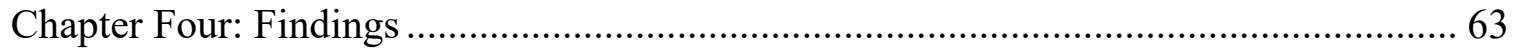

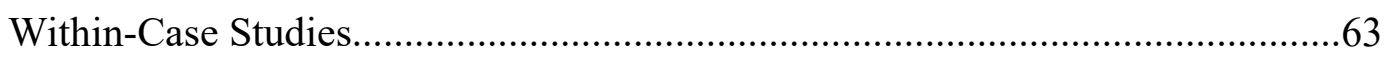

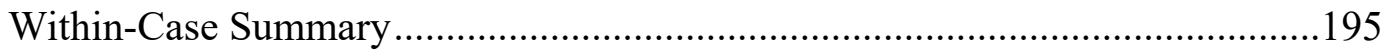

Cross-Case Themes: Embedded Family Meanings and Storied Possessions ......199

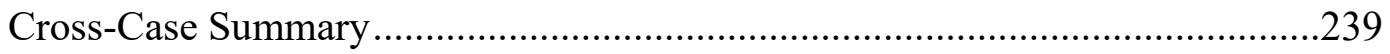

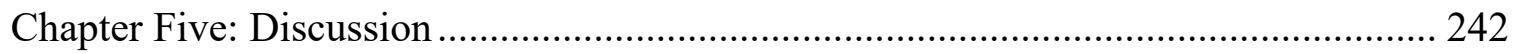

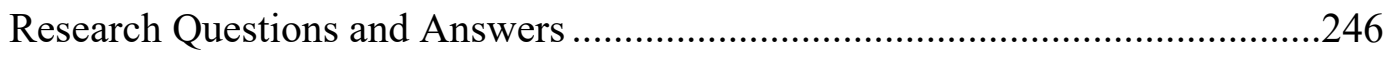

Conceptual Framework — Storied Possessions Model ....................................250

Interior Design Knowledge....................................................................252

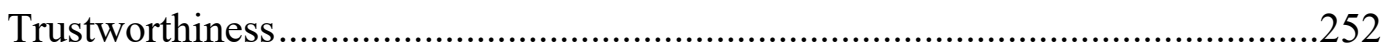

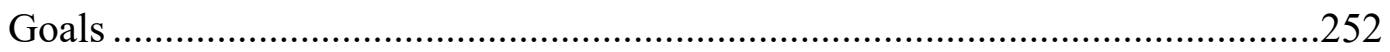

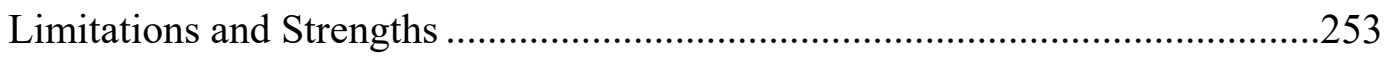

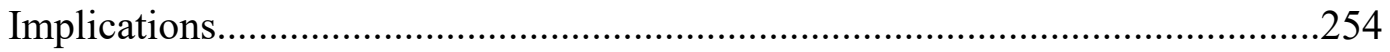

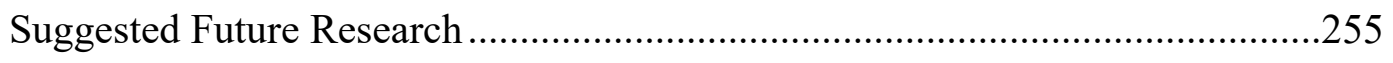

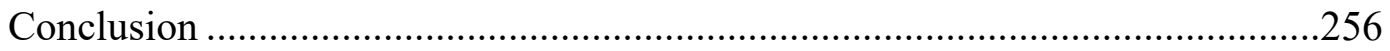

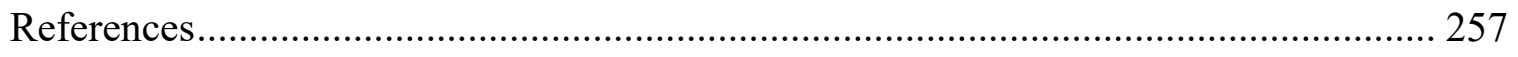

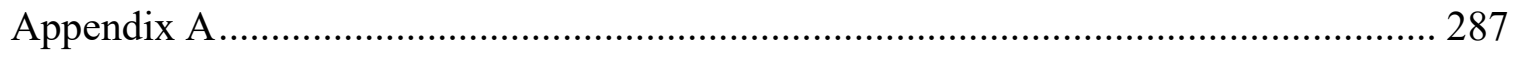

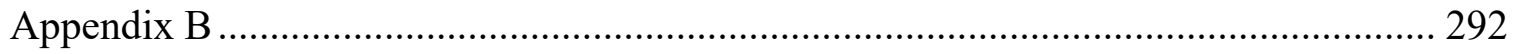

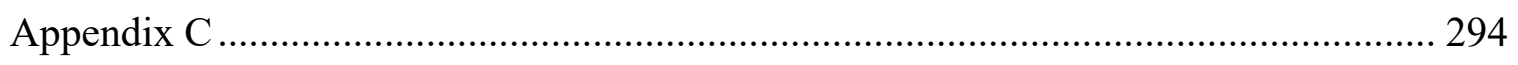

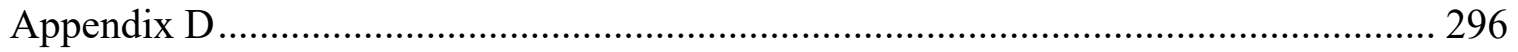




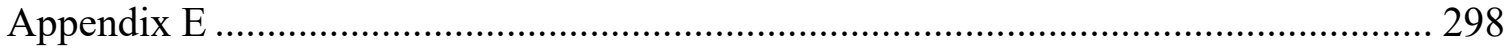

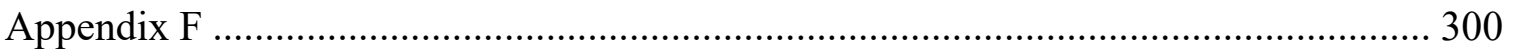

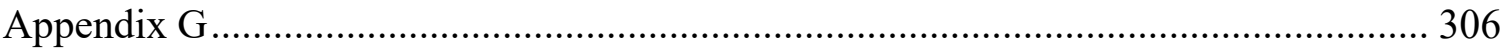

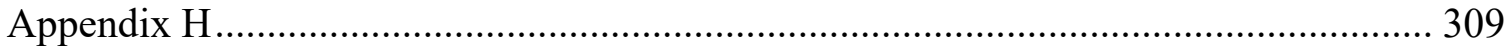

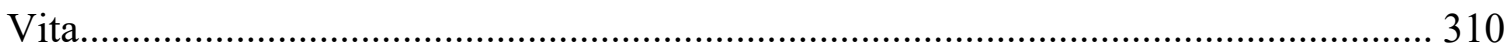




\section{List of Figures}

Figure

Page

1. Lawton and Nahemow's Competence-Press Model

2. Adapted from Maxwell, J. A. (2012). Qualitative Research Design: An Interactive Approach: SAGE Publications ..................................................................... 10

3. Generalized extent of home range incorporates shrinkage with old age \& other attributes. Adapted from Home and Identity in Late Life: International Perspectives (p. 355), by G. D. Rowles, 2006, NY: Springer Publishing Company. Copyright 2006 by Springer Publishing Company, Inc.

4. Yin, Robert K. Case Study Research and Applications: Design and Methods (Kindle Location 2112). SAGE Publications. Kindle Edition

5. Positioning of household types within multiple-case holistic case study matrix adapted from Yin's graphic (2017)

6. The four elements of this study's research process that inform one another. Adapted from The Foundations of Social Research: Meaning and Perspective in the Research Process (p.4), by Michael Crotty, 1998, Thousand Oaks, CA: Sage. Copyright 1998 by Michael Crotty.

7. Life Story Possession Analysis (LSPA) template. .56

8. Maxwell's interactive model of research design completed for the current study. Adapted from Maxwell, 2005, p.5. Qualitative Research Design: An interactive approach. Thousand Oaks, CA: Sage Publications

9. Cole Life Story Possession Analysis (LSPA \#1)

10. Photographs of Cole's storied possessions: upper left - toolbox; upper rightceramic houses from electric train village with children's drawing; lower leftframed family photographs; lower right — airplane poster \& balsa wood airplane model.

11. Elaine Life Story Possession Analysis (LSPA \#2).

12. Photographs of Elaine's storied possessions: left-family photographs, painting,

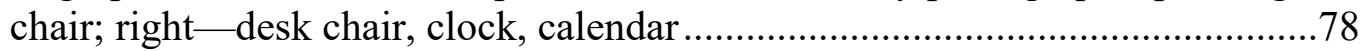

13. George and Tillie Life Story Possession Analysis (LSPA \#3) 
14. Photographs of George \& Tillie's storied possessions: upper left—candlestick phone; upper right — stained glass \& sea shells; lower left - mother's vanity dresser set; lower right_-Planters cookie jar and nut bowls.

15. Lance and Monica’s Life Story Possession Analysis (LSPA \#4)

16. Photographs of Lance \& Monica's storied possessions: upper left-second bedroom with quilt, rocker, family photographs; upper right_-farm clock, mother's farm drawing, family photographs; lower left - book shelf with books \& plaques; lower right — wedding portrait, chest of drawers made by father .....96

17. Fern Life Story Possession Analysis (LSPA \#5) 104

18. Photographs of Fern's storied possessions: upper left-illustrations of WWII aircraft \& bookcase; upper right — computer, desk, \& family photographs; lower left — 90th birthday celebration book; lower right — womb chair \& ottoman, WWII aircraft illustration

19. Bridgette and Leon Life Story Possession Analysis (LSPA \#6)

20. Photographs of Bridgette and Leon's storied possessions: upper left-jewelry box and small green chair and table in closet; upper right - son's cinerary urn; lower left_Leon's curio cabinet with Lion's and Blue Angel Navy pins; lower rightliving room showing books, TV, DVDs, and Longaberger umbrella basket ....114

21. Grayson Life Story Possession Analysis (LSPA \#7)

22. Photographs of Grayson's storied possessions: upper left—desk with small figurines, fraternity needlepoint, computer, bear, Greek pottery, model plane; upper right - Rufus figurine; lower left — mountain photograph; lower rightSanta figurine, fraternity award, Provence illustration.

23. Mary Life Story Possession Analysis (LSPA \#8)

24. Photograph of Mary's storied possessions: family photos, end table, recliner, and paintings by Mary

25. Pauline and Paulo's Life Story Possession Analysis (LSPA \#9).

26. Pauline and Paulo's storied possessions: upper left—father's childhood mahogany corner chair with get-well bear from granddaughter; upper right-signed armoire and Lladró and Limoges figurines; lower left-Paulo's childhood treasure chest

27. Robert and Elsie's Life Story Possession Analysis (LSPA \#10) ..... 
28. Robert and Elsie's storied possessions: upper left-great-uncle's handcrafted map case; upper right —Elsie in her chair with antique tables and painting; lower left-Robert's chair with antique tables and bookcase

29. Gina Life Story Possession Analysis (LSPA \#11).

30. Gina's storied possessions: upper left—refurbished sofa and fine art; upper rightrefurbished chair, cuttings from plants, lavender; lower left -mother's crystal and tea pot; lower right - refurbish desk and chest of drawers, books. 154

31. Claire Life Story Possession Analysis (LSPA \#12)

32. Photographs of Claire's storied possessions: upper left—painting by boss, mother's china; upper right - living room with drapery from daughter and furniture from house, painting; lower left—computer, books; lower right — photograph, Lladró figurines

33. Donna's Life Story Possession Analysis (LSPA \#13) 168

34. Photographs of Donna's storied possessions: upper left-photo collection of family during 80th birthday celebration; upper right - angel cinerary urn; lower leftson's dragonfly metal work; lower right—wall hangings with inspirational words

35. Nina and Oliver's Life Story Possession Analysis (LSPA \#14)

36. Photographs of Nina and Oliver's storied possessions: upper left—sofa with pillows from previous houses, 20-year-old plant; upper right-hall tree with Oliver's hats; lower left_-Parador from Philippines, Korean chest, mother's doily; lower right - Magdalena Armoire....

37. Susan's Life Story Possession Analysis (LPSA \#15)

38. Photographs of Susan's storied possessions: upper left—Susan's chair, Pot Belly Bear, photograph albums, and publish policy written by Susan; upper right$\mathrm{PhD}$ diploma, study books, painted eggs; lower left—sponge and sea shells, family photo; lower right — beach painting, furniture

39. Bernard and Abbie's Life Story Possession Analysis (LSPA \#16)

40. Photographs of Bernard and Abbie's storied possessions: upper left - acrylic grapes in compote dish; upper right — mother's painted hurricane lamp without broken globe; lower left — mother's plant on plant stand; lower right - dog sculpture from collection

41. Coding map of collective within case identity themes based on Life Story Possession Analysis (LSPA) identity types 
42. Excerpt from Lance and Monica's photo journal............................................205

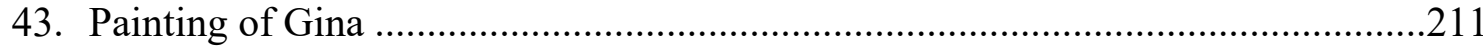

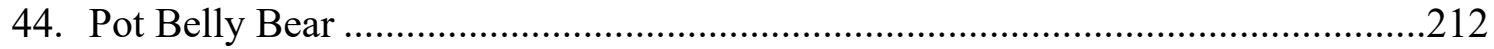

45. Map of layered family meanings with four themes -low points, turning points, high points, and ordinary events ...................................................................240

46. Storied possessions model with interactions contributing to meaningful place.....251 


\section{List of Tables}

Table

Page

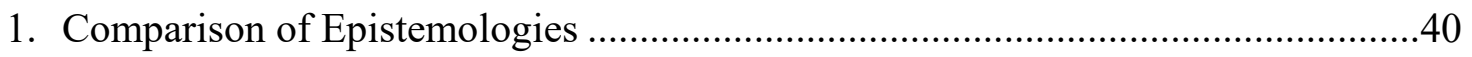

2. Participant Demographics ................................................................................. 48

3. Adult Children Participants and Their Contributions .........................................49

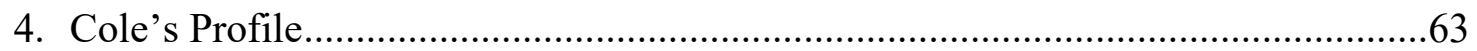

5. Cole's Objects Identified in Narrative ...........................................................67

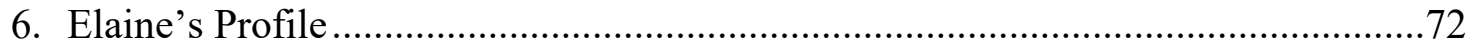

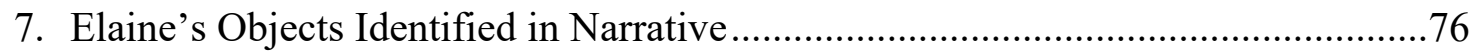

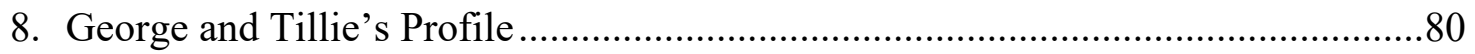

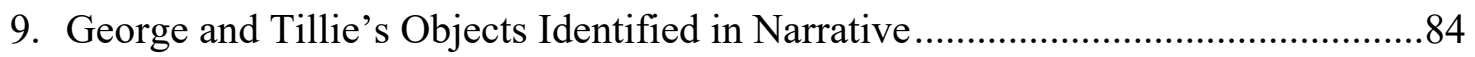

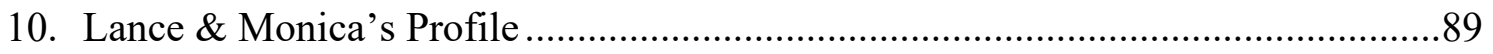

11. Lance \& Monica’s Objects Identified in Narrative ...........................................92

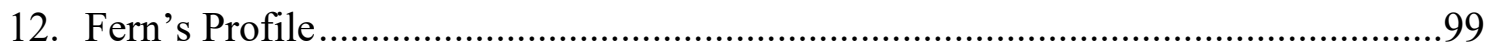

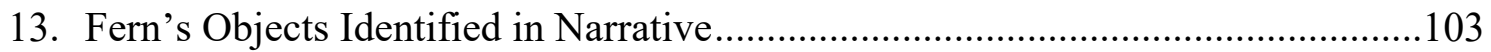

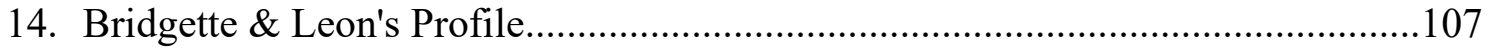

15. Bridgette \& Leon's Objects Identified in Narrative ......................................111

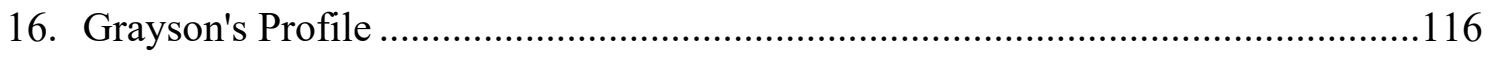

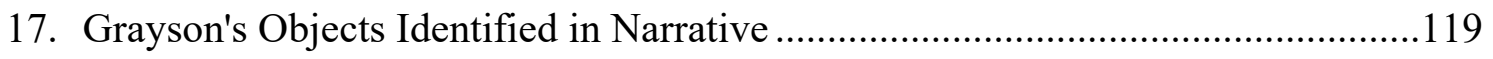

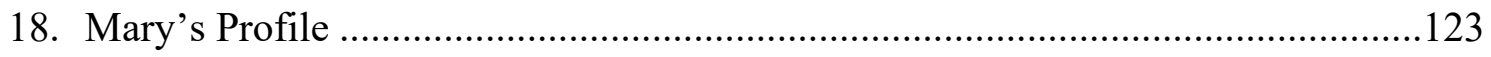

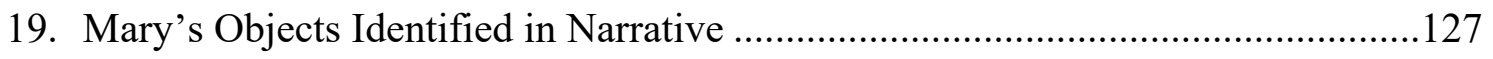

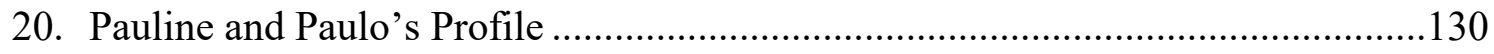

21. Pauline and Paulo's Objects Identified in Narrative .........................................134

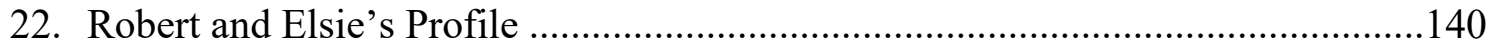

23. Robert and Elsie's Objects Identified in Narrative ........................................144 


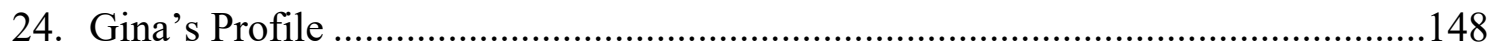

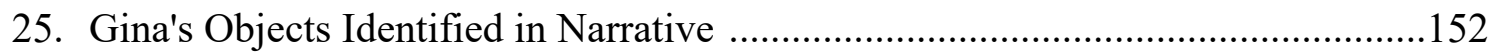

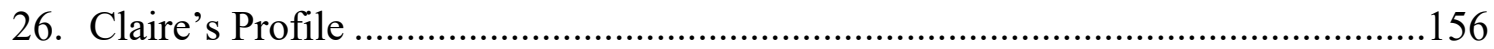

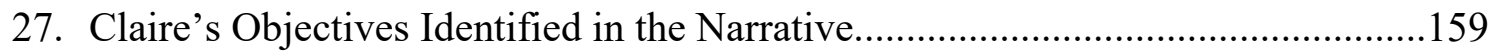

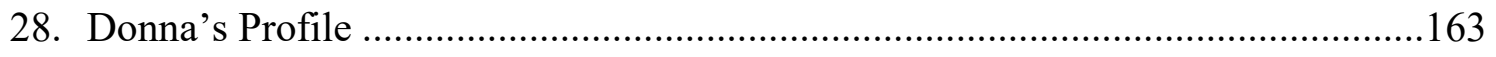

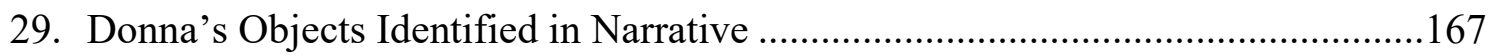

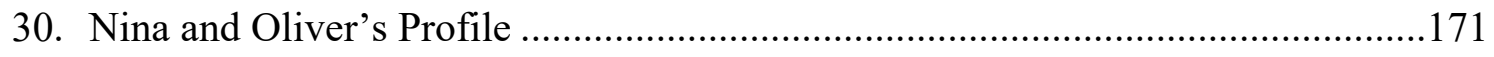

31. Nina and Oliver's Objects Identified in the Narrative ...........................................174

32. Susan's Profile

33. Susan's Objects Identified in Narrative ………...................................................183

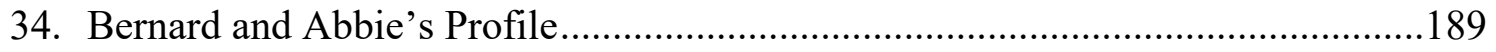

35. Bernard and Abbie's Objects Identified in Narrative............................................192

36. Collective Themes Identity Statement Analysis ...................................................198 


\section{Academic Abstract}

If older adults do not age-in-place, one of their last residential moves involves significant downsizing referred to as household disbandment. During this process, older adults divest themselves of possessions, change lifestyles, and move into smaller spaces. There is increased social and anthropological research on household disbandment. Less is known from environment and behavior and interior design theoretical perspectives about the subsequent process of reestablishing a meaningful place for post-disbandment older adults. Focusing on belongings brought from disbanded residences, a goal of this study is to understand how older people make place through their personal possessions to answer the research questions: "What identity meanings, related in life span stories, are embedded in the possessions older people move to their new residences?" and "How do post-disbandment older people embed the meaning of family when making place?"

Participants are post-disbandment retirees $(70+)$ whose moves occurred within three years of initial researcher contact and five of their adult-children. A variety of residential housing types are included. Multiple-case holistic case study research methods are used to analyze sixteen household cases that include twenty-three older adult participants. Within-case findings suggest post-disbandment older adults, in their new residential environments, incorporate possessions embedded with personal, social, and collective identity meanings related to events in their life stories. Multiple layers and diversity of embedded meanings exist within solitary possessions. Cross-case findings suggest participants integrate family into their new residences by engaging with possessions connected to storied points in their lives and embedded with their meanings of family. The incorporation into their residences of storied possessions embedded with 
ordinary, low, high, and turning point family meanings suggests these older adults actively engage with their authentic perspectives of current reality and either willfully make or willfully do not make the place of home. Implications suggest disbandment and the subsequent placemaking process need to be considered as a holistic event rather than two distinct episodes, and older adult agency needs to be privileged for placemaking to be successful. Contributions of this study to existing knowledge include an analytic tool to evaluate granular level meanings within possessions and a conceptual Model of Storied Possessions depicting symbolic interactions of self-identity, others, narrativity, life events, and storied possessions that lead to meaningful place. 


\section{Storied Possessions: Post-Household Disbandment Older Adult Placemaking through Meaningful Belongings}

\section{Chapter One: Introduction}

Dwelling is in the very nature of our being. To dwell is to learn how to be at home on the earth, to cultivate places for ourselves (Heidegger, 1971). It is a process that occurs throughout the individual life span up until the moment the human body ceases to breathe. Dwelling involves the creation of meaning. Menin (2004) suggests, "we invest phenomena with meaning by engaging with them, and there can be little if any material that has no meaning" (p. 1).

The process of dwelling is enacted on objective and subjective levels and is at once philosophical, practical, and theoretical (Bille, Bjerregaard, \& Sørensen, 2015; Menin, 2004); it is the overarching issue under which my research problem lays. I am interested in understanding how older adults, who have disbanded their households and moved to smaller spaces due to health concerns, use personal possessions to make places as they approach the end of their lives. By disbanding, I mean disassembling and downsizing both place and possessions (Ekerdt \& Baker, 2014b; Ekerdt, Luborsky, \& Lysack, 2012b).

I have a variety of motives for increasing my understanding of household disbandment. The phenomenon is personally intriguing because of the disparity of choices older adults in my life have made. In my family of origin, there are older adults who have significant attachment to place and possessions such that they choose not to disband their own houses, even at the expense of wellbeing. Juxtaposed with these are the 
older adults of my acquaintance who elected household disbandment as a viable residential transition.

These two choices are highlighted in society as the process of downsizing and disbandment and a focus on minimalism are of increasing interest, demonstrated in a recent Dallas Morning News article. The author lauds her eighty-two-year-old mother's downsizing experience. Emptying the house she occupied for fifty-six years, her mother "without remorse" easily let go of negligees, pasta machines, sympathy cards, and hundreds of recipe cards (Casey, 2018). Her story echoes the message promoted in the New York Times best seller The Life-Changing Magic of Tidying Up: The Japanese Art of Decluttering and Organizing (Kondo \& Zeller, 2015). Ten million copies of the book have been published and sold in over forty countries - its message, let go of joyless possessions, has been so thoroughly embraced the author calls it a global phenomenon (Kondo, 2018).

Yet attention paid to this trend is in stark contrast to the number of older people with whom I discuss my ongoing research. When I tell them that my topic is about older adults making place after household disbandment, they typically react with negativity. One person responded, "Well, that's depressing." I find it compelling to try to understand a phenomenon that results in such a polarization of feelings.

On another level, as a professional interior designer, the process of using possessions, which are essentially elements of material culture, to construct place has been anecdotally evident to me over many years. As a researcher, I am drawn to understand the phenomenon I see being enacted. Similar to Tischleder (2005), "it is the inside of "materialism" rather than its conspicuousness that interests me here-a 
materialism that is intimate rather than public, moral rather than fetishistic, idiosyncratic rather than narcissistic" (p. 97).

My final motive lies in a concern germane to the older adult. "Western conceptions of dwelling are based on notions of stability, permanency, belonging to and being rooted in place" (Kiliçkiran, 2004, p. 99), but sense of home is often researched as a place attachment process that takes considerable time to achieve (Low \& Altman, 1992; Raymond, Kyttä, \& Stedman, 2017). Home is a secure, true north compared to other, less comfortable and external social worlds. It is a created atmosphere as well as a physical place of belonging (Bille et al., 2015). McCracken (2005) suggests, "We invest in our homes... because they are transformational opportunities. We make them to make ourselves" (p. 21). As is true for other population groups, home is a place that gives older adults a sense of identity, a place in which they can be themselves. They experientially dwell in the places they cultivate (Sherman \& Dacher, 2005), spending more than $80 \%$ of their time there (Low \& Altman, 1992; Oswald \& Wahl, 2013). With these concepts in mind, I question the possibility of making meaningful places that contribute to the older adult's sense of home at the end of a life span when time is short.

Apart from personal motivations, this research has philosophical, theoretical, and practical relevancy. As mentioned above this occurs at both objective and subjective levels. On the objective level, understanding the meaning of dwelling within placemaking occurs by referencing people, situations, and environments in the concrete, physical world. Contrarily, when dwelling is approached subjectively, people, situations, and environments are viewed abstractly using symbolic representations and meanings that belong entirely to the mental world of the older person. It is important to understand that 
the philosophical, theoretical, and practical relevancy of research concerning late life residential transitions occurs at both these objective and subjective levels; I will use the philosophical context below to illustrate the reason for this importance.

Philosophically, Donahoe (2011) suggests human bodies are inseparable from the space in which they exist by the very nature of embodiment. They exist in created places, inhabiting them in their lived bodies. It follows that personal wellbeing is closely associated with place, and typically, home is the most meaningful place that people idealize and hope to create. Understanding how older adults make place and create a sense of home is important because placemaking is an aspect of older adult wellbeing (Chaudhury \& Oswald, 2018; Koss \& Ekerdt, 2016; Rowles, 2017), and older adult wellbeing is an indicator, for some, of society's humanity and goodness (Buck, 2013; Gott \& Ingleton, 2013; Humphrey, 1976; McCormack, 2017).

Approaching this philosophical insight from a purely objective perspective might suggest that specific types of furniture — a bed, dresser, table, and chair — are required for the older adult's embodiment to be appropriately accommodated. Although this is accurate in American culture, it ignores the subjective level that provides insights as to which specific pieces of furniture contain symbolic representations and meanings of home for the older adult. Because sense of being at home improves wellbeing, ignoring the subjective aspect becomes problematic. As the home place is the older adult's lifesphere and the environment in which they predominately operate, the need for meaningful home places for older people is clear, which includes meaningful possessions. 
There is a symbiotic relationship between humans and their possessions. Using Belk's words, possessions are extensions of self(1988). Pearce notes, "Objects are our other selves; the better we understand them, the closer we come to self-knowledge" (Belk, 2013, p. editor's note). The relationship between possessions as extensions of ourselves can be seen when possessions are eliminated from our environments. Galford (2018) found that inmates who were moved to solitary confinement felt the loss of belongings that created their sense of home within their general population cells. "When you don't have anything in your cell, it's like it really hits you that you're all alone. That there's nobody that cares for you. You can't have your personal letters or none of that from your property" (Galford, 2018, p. 136).

The human-possession relationship does not diminish with age (Ekerdt \& Baker, 2014b). This extension of self exists beyond our mortality. In the film Stand Up Guys, the following statement is made, "You die twice. You die once, when you do die, but the second time you die is when your name isn't spoken anymore" (Swinburn, 2013). One important meaning of personal possessions is their connections to people and events past. They extend the speaking of names and memories, bringing those who have died into current, everyday places and staving off the second death.

For instance, participants in the study, Abbie and Bernard, have a small stool with a caned seat Bernard's Grandmother Ryan built by hand. Her name along with the date, 1925 , is stamped on one of the stool's legs. "These are the kinds of things that to us are family treasures. That's how we named our son Ryan... That is part of family." Grandmother Ryan's personhood has been extended beyond her mortality through this cherished belonging. The physical energy she used creating the stool is embedded in it as 
firmly as is her name on its leg (Csikszentmihalyi \& Rochberg-Halton, 1981). An additional layer of meaning was added to the stool with the naming of Abbie and Bernard's son, Ryan. The stool is a storied possession, part of their family. The speaking of Grandmother Ryan's name brings her memories into everyday places, staving off her second death.

Departing from the philosophical and turning to practical relevancy, the older adult population is burgeoning. Senior housing is and will continue to be a pressing issue (Eisenberg, 2014; Joint Center for Housing Studies of Harvard University, 2015). Most people desire to and do age in place; i.e., they continue to live in the residences they occupied prior to encountering the physical and mental infirmities of old age (Farber, Shinkle, Lynott, Fox-Grage, \& Harrell, 2011; Rantz et al., 2013; Stafford, 2016). However, this study is concerned with the growing subset of the older adult population who relocate to smaller spaces to mediate their current or anticipated health issues (Golant, 2015; Lindley \& Wallace, 2015). When this occurs, they disassemble their current residences. As mentioned previously, this process is known as household disbandment (Ekerdt \& Baker, 2014b; Ekerdt et al., 2012b). The demands on these older people are so physically and mentally extreme that outside assistance is often necessary. Assistance comes in the form of family, social networks, and professional and trade organizations (i.e., attorneys, estate managers and sellers, auctioneers, donation agencies, senior-move managers, self-storage operators, and retirement community managers) (Ekerdt, Sergeant, Dingel, \& Bowen, 2004).

These practical issues can also be discussed in terms of their theoretical relevancy. Lewin (1939) influenced environmental gerontology with his field theory 
ideas. Field theory's central premise is that "people and their surroundings and conditions depend closely on each other" (Neumann, 2008, para. 1). Lewin believed that understanding or predicting behavior required that the person and corresponding environment had to be considered as one group (field) of interdependent factors (Lewin, 1939). Field was seen as everything involving the individuals in relationship with their surroundings and the conditions that looked like they were influencing the specific behaviors and developments of concern at the time in question (Neumann, 2008). This led to the concept of person-environment fit $(P-E)$ and the equation $B=f(P, E)$, which reads behavior is a function of a person's interactions with his/her environment. This suggests the importance of considering the placemaking process for older adults as a relationship with their possessions rather than a purely linear, temporal, and spatial progression.

Lewin's theory directly informs Lawton and Nahemow's Ecological Model (1973), also known as the Competence-Press Model, another important theoretical resource. The model, Figure 1, graphically demonstrates P-E fit as seen through an individual's ability, his/her competence, to meet the environmental requirements, its press (Oswald \& Wahl, 2013).

The model indicates that both overly challenging and nonchallenging environments result in negative effect. When older adults relocate to environments that mediate for health issues, it is important that these environments continue to positively stimulate them intellectually, physically, emotionally, and spiritually.

Within the remainder of this dissertation, I illustrate the importance of understanding how older adults' residential places are created through subjective and 
objective interactions that intertwine identity, family, social circles, and the material culture of possessions. Interactions are demonstrated with narratives in which the older adult participants talk about life stories that contribute to the meanings of their things and create their storied possessions.

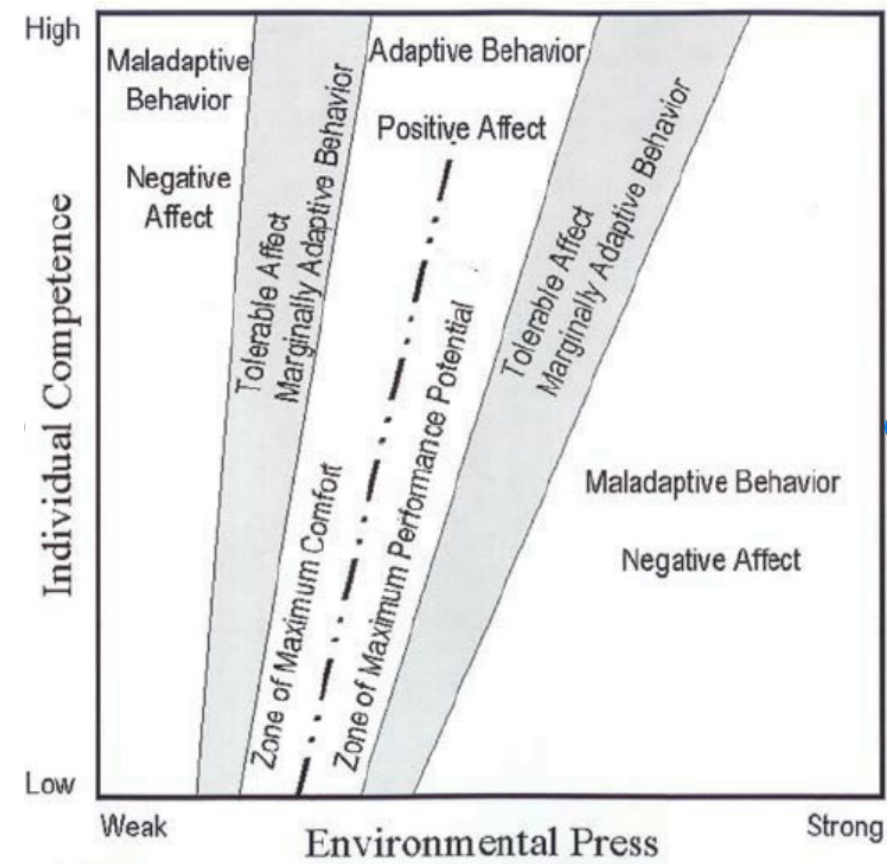

Figure 1. Lawton and Nahemow's Competence-Press Model. From Eisdorfer and Lawton (eds) 1973, pp. 619-74. Psychology of Adult Development and Aging. Washington, DC: American Psychological Association.

\section{Research Questions}

My research assumes the symbolic interactionist perspective that suggests our lived-world is not built on objective/material reality alone, but it also incorporates our interpretation of physical reality intertwined with our constructed social world and the meanings we create when we engage with it. We know from Boschetti (1995), Eshelman and Evans (2002), Lovatt (2016), and Marcoux (2001) that older adults are able to 
effectively alter the place meanings of their residential spaces by personalizing them with possessions. We also know from Csikszentmihalyi and Rochberg-Halton (1981) that there is an active cultivation of meanings in things and from Ekerdt et al. (2012b) that meanings of possessions are recrafted in the disbandment process.

In considering the personal meaning of identity items in older adult placemaking and how these items occupy space in the older adults' new residences, I intend to benefit individuals who are associated practically and assist with older adult post-disbandment relocation experience and interior designers interested in the theory of the same. I use multiple-case holistic case study research (described fully in Chapter 3) to answer the following questions:

- What identity meanings, related in life span stories, are embedded in the possessions older adults move to their new residences?

- How do post-disbandment older adults embed the meaning of family when making place?

\section{Research Design}

I relied on Maxwell's (2012) interactive model for the design of my research study, Figure 2, below. Maxwell's (2012) model highlights the central prominence of research questions: they bring awareness to the relevance of connecting and mutually informing all elements of the designs. The upper triangle of the model illustrates the design's integrated components. My research questions are related to my goals which were informed by what was previously known about post-disbandment older adult placemaking including theoretical concepts and models that could be applied to my 
study. Simultaneously, my determinations about what relevant theory and knowledge to use depended on my goals and research questions.

Likewise, there is an integrated triangle at the bottom of the model. The methods I used allowed me to answer my research questions and address the trustworthiness of my research design. My questions were structured with reference to the capability of my methods and the importance of maintaining the trustworthiness of the research design. Assurance of trustworthiness relied on the structured questions and methods.

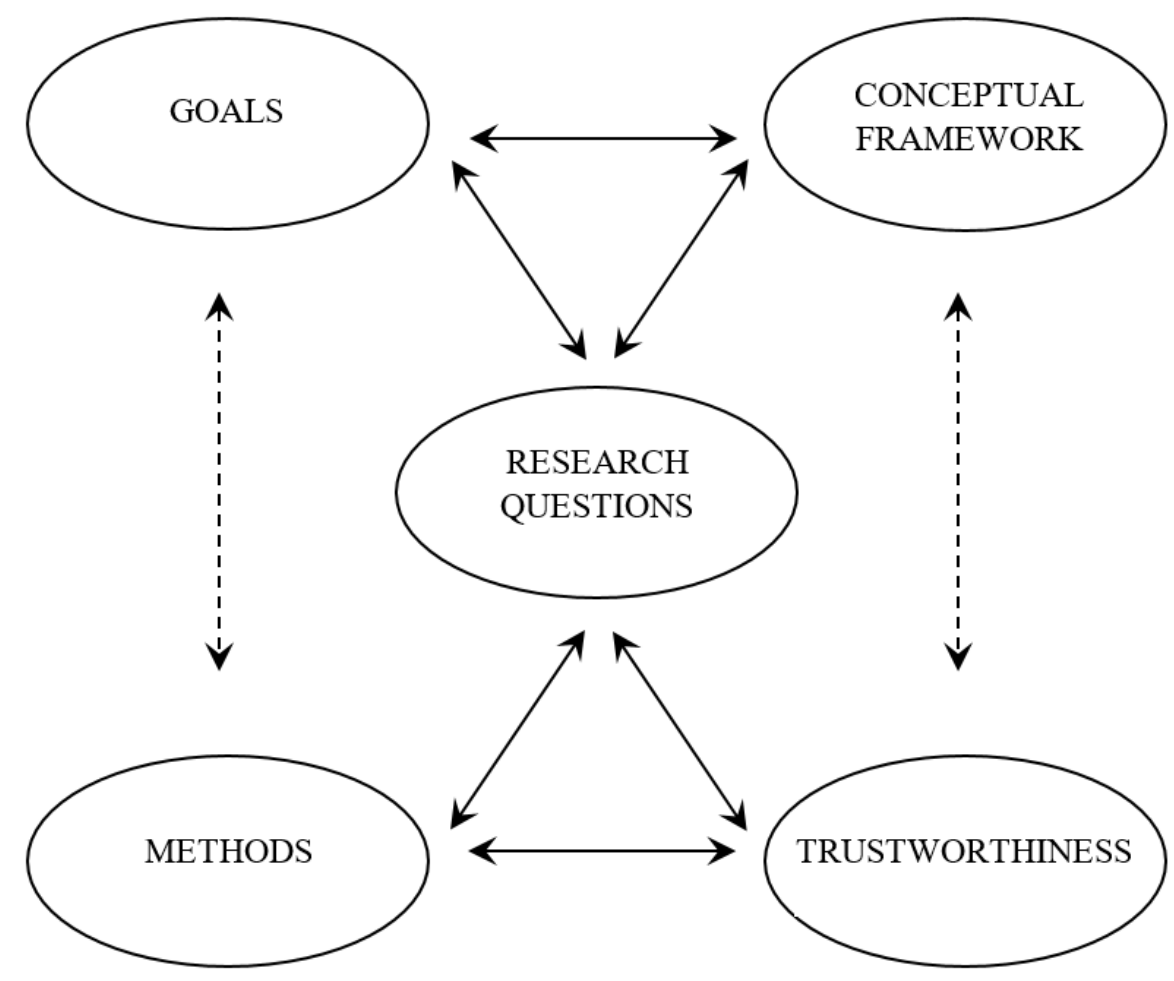

Figure 2. Adapted from Maxwell, J. A. (2012). Qualitative Research Design: An Interactive Approach: SAGE Publications.

\section{Overview of Dissertation}

Following this introduction, Chapter 2 is a review of the core literature that informs my conceptual framework, and Chapter 3 is an articulation of my methods. 
Chapter 4 is a revelation of my findings, and Chapter 5 is a discussion about the relevance and implications of these findings. 


\section{Chapter Two: Core Literature}

This study centers on the meanings embedded in older adult possessions which have been used to make place after household disbandment. I identify four concepts to situate my research based on my pilot study on older adult household disbandment and previous literature reviews. These concepts include older adult identity, embedded meaning in possessions, narrative life stories, and late-life place making. All these concepts can be viewed through the lens of symbolic interactionism.

\section{Symbolic Interactionism}

Symbolic interactionism is a micro-level, sociological theory that tries to make sense of the distinction between the self and the social. To understand the theory, it is helpful to break up the term symbolic interaction into its two component (Campbell, 2010, June 30).

Symbolic. Although both symbols and signs are used to communicate symbolic meaning, Jung (1964) distinguished between the two. What is known as a symbol may be any familiar object; a name, term, or image. Similar to signs these objects possess conventional and obvious meanings. A symbol, however, is also imbued with an additional "something vague, unknown, or hidden from us.... thus, a word or an image is symbolic when it implies something more than its obvious and immediate meaning. It has a wider unconscious aspect that is never precisely defined or fully explained" (Jung, 1964). Alternatively, signs have attached symbolic meaning that is more concretized.

Through deliberate usage, signs (meaningless in themselves) denote the objects to which they are attached (Jung, 1964). Once learned, signs have obvious meanings for the groups that use them. Philosopher George Berkeley’s (2009) ideas on direct and indirect 
perception have been used to explore how sign meanings contribute to symbolic interaction (Campbell, 2010, June 30). Berkeley maintained that when we initially receive data through our senses (seeing, hearing, touching, smelling, and tasting), we directly perceive the real object associated with that sense data. These sensed objects depend on the rational mind for meaning. Once such meaning is supplied, through interaction with others, the objects are perceived indirectly (Bettcher, 2008).

Reading illustrates this process. Until we learned to read, the symbols that made up letters were sensed through sight (or touch in the case of Braille) as shapes: lines and circles systematically assembled. After we learned that shapes were combined to create letters with associated sounds, we stopped perceiving those objects directly as shapes. Letters, grouped together, became words. It is through this process that societies from antiquity have used written words to express the meanings they want to convey (Campbell, 2010, June 30; Jung, 1964). Within our digital society, emojis (ideograms and smileys) are contemporary examples of signs that have symbolic meaning. Symbols are used in the context of interaction.

Interaction. The basic building block of the social world is the self (Cast \& Stets, 2016). The self is our essential, though invisible, embodied nature that experiences life internally and externally. It environmentally engages both subject and object, and in the process, it mediates relationships and meanings between itself, others, and the material culture (Glas, 2006; Rubinstein \& de Medeiros, 2005, p. 48). The social is a network of interaction between selves (Campbell, 2010, June 30). In the symbolic interactionist perspective, an individual can only make sense of self through collective interactions with other selves. Differentiating myself from others requires both a 
subjective reference to self (I) and an objective reference (me) (Carter \& Fuller, 2016). My recognition of my own self is only possible within social interactions. Initially, I arrive at my self-concept through interactions with my primary social group which is generally my family. Through these interactions, I also come to understand that I am not these others.

We receive values from of our social group. These values are social norms the group adopts. Socialization occurs, during interactions, when one's behavior is compared against transmitted values and is judged acceptable or unacceptable. In this way, we are socialized, i.e., appropriately fitted for community interaction with others. This is a lifelong process that may be replicated in future generations. For instance, in a study of household disbandment, Addington and Ekerdt (2014) found that multigenerational families used socialized gender norms to decide who completed specific tasks and who received certain items: females generally receive domestic items such as china and hope chests; males receive tools.

Our perception of self is also informed by collective groups. These groups can be religious, national, and cultural. Unlike the family and other social groups by which we were originally socialized, collective groups are often of our own choosing. We seek out groups that have the identity markers we want to associate with our sense of self; collective groups are reference groups we appeal to for identification; i.e., our collectiveidentity (Harmeling, Palmatier, Fang, \& Wang, 2017).

We mirror or reflect our sense of self on other people in our social and collective groups to validate our perceptions of self, a concept referred to as the looking glass self (Carter \& Fuller, 2016; Hagestad \& Settersten, 2017). “A sense of self is created and 
maintained through social mirrors, in webs of interdependent lives that span family generations and historical time" (Hagestad \& Settersten, 2017, p. 136). The perception I have of my-self, my self-identity, is only valid when it is reflected to me by others through interactions.

In summary, humans initially interact with the natural world, objects, and other human beings at the level of direct perception for the briefest of times. Once we learn the significance of the world (society) and ourselves by using symbols and interactions, we continue interpreting our world through meaning. Society can be viewed as the network of interactions through which we attain, maintain, and change meaning (Campbell, 2010, June 30). This occurs continuously through language, gestures, behavior, and material culture. Symbolic interactionism suggests we make sense of ourselves and create meaning within the world through this ongoing process.

Using a lens of symbolic interactionism, I now explore more thoroughly the concepts announced at the beginning of this chapter: older adult identity, embedded meaning in possessions, narrative life stories, and late-life place making. These concepts create a framework through which further analysis is done in the methods chapters.

\section{Older Adult Identity}

Identity is a complex concept that describes a range of phenomena (Fowler, 2010; Vignoles, Schwartz, \& Luyckx, 2011). It is the name or definition of one's self. Identity clothes the invisible self.

Jørgensen (2010), from the perspective of psychology, suggested four different layers of identity: ego identity, personal identity, social identity, and collective identity. The first layer, ego identity, is the basic structural operating mechanism that maintains 
integrity and equilibrium for the core self (Livesley \& Larstone, 2018; Wheeler, 2017). The remaining three layers (personal, social, and collective) are phenomenological manifestations of identity.

Personal identity. Personal identity is a conscious recognition that one's self is unique and separate from others. As discussed previously in symbolic interactionism, personal identity is developed through interactions with others and is a presentation showing how one wants to be known. "Your outer identity, your persona, is the result of the interaction, or friction, between your inner and outer experiences.... It's how you want others to see you — as friendly, intimidating, modest, competent, helpless, nice, honest, powerful, sexy, or wounded" (Wheeler, 2017, p. 7). It is constructed through unique traits, values, goals, achievements, and the way we make place (Jørgensen, 2010).

Traits include unique distinguishing factors that can be revealed through one's body, thinking, and personality (Colman, 2015b). Physical traits are primarily unchangeable characteristics with which we are born such as height, body type, race, and natural eye and hair color. Some physical and cognitive abilities and disabilities are part of our genetic code and alter with age. This can lead to change in an older adult's personal identity as the elements by which it is constructed alter with age. Physical and cognitive declines often change participation in activities that provide older people with experiences of personal meaning and importance (Young, 2017). These changes differ substantially between individuals (Bennett, Clarke, Kowalski, \& Crocker, 2017; Gale, Ritchie, Cooper, Starr, \& Deary, 2017; Phoenix \& Sparkes, 2009; Schwaba \& Bleidorn, 2018). 
Another aspect of personal identity is personality. Although personality is unique to the individual, there are six personality factors that have been replicated throughout world cultures (Ashton, Lee, \& De Vries, 2014). These six dimensions capture important personality differences (Ashton et al., 2014) and include honesty-humility, emotionality, extroversion, agreeableness, openness to new experiences, and conscientiousness (Boyle, Matthews, \& Saklofske, 2008; Estroff Marano \& Yusim, 2018; Stephan, Sutin, Bosselut, \& Terracciano, 2017). Significant physical and cognitive decline can lead to personality changes; however, this may be mitigated in older adults with secure identities (Schwaba \& Bleidorn, 2018) In addition to unique personal traits, older adults' personal values also contribute to their identities.

Personal values. Personal values are defined as the material and nonmaterial things older adults consider important in life now and in the past (Fegg, Wasner, Neudert, \& Borasio, 2005; Heisler, 2017). Values are preferences that help us decide what to do when we have choice (Beckett \& Maynard, 2011). Although values may be explored and personally assumed, the symbolic interactionist perspective suggests that society and culture shape and impact them.

In a recent study concerning older adult health and wellbeing, six interrelated value-areas emerged that were seldom communicated in isolation. These included guiding principles, relationships with others, engagement in emotionally meaningful experiences, physical or mental competency, activities, and meaningful possessions and places (Heisler, 2017; Young, 2017).

Personal values change as individuals approach their own mortality (Carstensen, 2006). Fegg et al. (2005) found self-transcending values (benevolence, self-direction, and 
universalism) were more important for patients with life-threatening illnesses than selfenhancement values (power, achievement, and stimulation).

Personal goals and achievements. Older person late-life goals and achievements relate to values. "One cannot state a value without stating the goal being served" (Costanza \& Folke, 1997, p. 49). Unlike values, however, goals are bound by time. The Socioemotional Selectivity Theory predicts that as people approach their own demise, their goals change (Carstensen, Isaacowitz, \& Charles, 1999). Older people are more motivated to achieve short-term goals, such as sense of wellbeing, that result in positive emotions (Bauer, King, \& Steger, 2018). Short-term goals also focus on improving current relationships rather than pursuing new ones (de Lange, Van Yperen, Van der Heijden, \& Bal, 2010; Giasson, Liao, \& Carstensen, 2018).

In addition to liminality, older adults' goals are impacted by their memories. When they are retrieved, recollections about the past incorporate personal meaning into current day goals (McAdams, 2008). Memories also remind older people of past lessons and act as motivational adjustments in the pursuit of goals (Luchetti \& Sutin, 2018). Important late-life goals tend to be specific and attainable (Waldersen et al., 2017). In order to make them attainable, older adults adjust their goals to fit their agerelated abilities (Sneed \& Whitbourne, 2001). Two specific methods of adjusting goals are through changing one's thinking (accommodative strategies) and changing one's actions (assimilative strategies) (Brandtstädter \& Greve, 1994; Golant, 2015). Adjusted goals contribute to self-care, domestic life, general tasks and demands, community, social and civil life, major life areas, interpersonal interactions and relationships, 
communication, body functions, products and technology, and mobility. (Nurmi, 1992; Waldersen et al., 2017).

Goals help older adults clarify tasks that lead to achievements (Kennedy \& Mitchell, 2017). Achievements are often accomplished using courage, special abilities, or above average effort. All achievements, however, are not linked directly to previously identified goals. There are also serendipitous achievements or secondary achievements that are appreciated but unplanned (Inclezan, Zhang, Balduccini, \& Israney, 2018; Pickett, 2016). To summarize, older adult goals and achievements are tied to their values and impacted by liminality, memories, and attainability. From here we continue exploring personal identity and move to another aspect of same, one's personal beliefs.

Personal beliefs. Beliefs are propositions that are accepted as true without conclusive evidence. Although not as strong as items of knowledge, they are stronger than baseless opinions. Beliefs are convictions, faith based concepts, or confidences in things not immediately susceptible to rigorous proof (Colman, 2015a). Older adult beliefs may contribute to enabling mind-set, social response, and future actions (D. Rose, 2018; Winterrowd, Canetto, \& Benoit, 2017). Spiritual and faith-based beliefs are often relied upon during the traumas that are encompassed in aging (Silverstein \& Bengtson, 2018).

Older adults' beliefs, goals and achievements, personality, physical, and cognitive traits, and values are identity aspects, as discussed above, that make up personal identity. As mentioned, Jørgensen (2010) recognized four different layers of identity that can be visualized as broadening outwards. Ego identity, the first, is the hub of the wheel around which the other more phenomenally manifested layers are structured. Personal identity is the next most interior layer. The final two layers involve people. They are categorized in 
two groupings: the primary group identity and the secondary group identity. Although both primary and secondary groups are contextualized in social interactions (Fowler, 2010), for the purpose of this study, social identity will refer to the primary group and collective identity will refer to the secondary group.

Social identity. Social identity is developed through interactions with one's family (nuclear, extended, and chosen), friends, and acquaintances. While personal identity is the story about me, social identity is the story of $u s$, and is defined by the primary group's attributes and expected behavior. Social identity promotes pride or shame depending on its standing within the greater social community at large (Fearon, 1999).

Family identity. For participants, the family is regarded as the basic social unit. The nuclear family consists of a couple and their dependent children, whereas the extended family broadens to include other genetic or legal relatives such as aunts, uncles, grandparents and in-laws. "Family relationships are obligatory, based on notions of family responsibility and duty" (Chatters, Taylor, Nicklett, \& Taylor, 2018, p. 1.2).

For the three generations represented in this study (the Greatest Generation-born 1924, silent generation_-born 1925-1945; and baby boomers-born 1946-1964), the societal ideal of nuclear families was not always attainable or desirable, and the nuclear family experienced significant decline from 1960-1990 (Popenoe, 1993). Older adults incorporated other individuals into their primary group to fill the vacant roles. These people are known as chosen family. Rather than legal or genetic, these bonds are emotional (Gabrielson, 2018). In addition to family (chosen, extended, and nuclear), 
friends and acquaintances make up the primary group. Research suggests that friends supports older adults' identities differently than family (Chatters et al., 2018).

Friendship identity. Friends are the individuals older adults know and with whom they have voluntarily chosen bonds of mutual affection based on similar age, interests, and life experiences (Chatters et al., 2018). Friendships are developmentally important throughout one's life as cognitive and affective resources that support ongoing socialization, mutual interests, sense of wellbeing, and increased self-esteem (Hartup \& Stevens, 1997). Although young people see their friends more often, when older people are able to visit with their friends, they report higher levels of satisfaction (Nicolaisen \& Thorsen, 2017). Friends support each other differently than family members (Chatters et al., 2018).

Technology assists with interactions when older people are not in the same physical locale as their friends (Quan-Haase, Mo, \& Wellman, 2017). When older adults facilitate social interactions by using technology, it increases their sense of power and protects them from digital exclusion (Hill, Betts, \& Gardner, 2015). Digital exclusion can negatively impact social identity and contribute to ageism (Diehl \& Wahl, 2014). Research suggests that social media sites increase the frequency with which older adults visit with their friends, family, and acquaintances (Sinclair \& Grieve, 2017). Although online relationships do not replace face-to-face interactions, access to both technology and Internet connectivity may reduce social isolation among older adults (Czaja, Boot, Charness, Rogers, \& Sharit, 2017).

Acquaintance identity. Acquaintances are associates, past-work colleagues, contacts, allies, and connections who volunteer together. They are more formal in their 
relationships than friends. Even so, acquaintances, such as neighbors, are able to provide important physical, social, and emotional support; social connection helps older people feel they confidently and comfortably belong to a larger community than their family and friends offer (Bergman, 2007; Buys et al., 2015). Among acquaintances, older adults perceive there to be more similarity with others who are their same age (Lin, Ankudowich, \& Ebner, 2017). In this context, having the social identity of reliability is important to older people. They need others on whom they can rely in emergencies, and they want to think of themselves as reliable (Buys et al., 2015). This is part of their social identity which is an amalgamation of all the social roles they perform such as grandmother, mother, daughter, father, and volunteer. From acquaintances, older adults' social circles expand to include the secondary group that contributes to their collective identity.

Collective identity.The secondary group is a collective reference group, to which the self looks for socially transferred knowledge about religion, nation, and culture. Collective identity is established and maintained through membership rules, appropriate group behavior, required assets, and valued characteristics. Membership is translated into pride, shame, honor, etc. (Fearon, 1999). Altheide (2000) suggests it is critical to view identity as a "social production and not an individual property" (p. 3); e.g., what an older adult thinks of himself is relevant, but identity claims require the agreement of other people, who require evidence. This evidence comes in both material and non-material forms.

Religious and spiritual identity. Religion, from the perspective of this study, is an organized and identifiable system of faith and worship. Although non-material culture is 
a significant aspect of religion (e.g., beliefs, ethics, morals, ideas about worship), material culture reinforces religious culture. Crucifixes, menorahs, mezuzahs, ketubahs, icons, crosses, prayer mats, the Bible, the Qur'an, the Bhagavad Gita, and the Torah are embedded with spiritual meaning (Peteet, Zaben, \& Koenig, 2018).

Spirituality and religion may overlap for some older adults but not necessarily for all. There are older adults who reject organized religion in favor of less prescriptive avenues for the pursuit of spirituality. The term spirituality refers to individual subjective experiences that may also involve collective identity groups. Examples are Alanon Family Groups, Alcoholics Anonymous, and yoga groups. Spirituality promotes qualities and perceptions such as serenity, mindfulness, and centeredness. As a human phenomenon, spirituality provides guidance and power for many older adults (Emlet, Harris, Pierpaoli, \& Furlotte, 2018; Srivastava, 2017) and is also supported by material culture. Religious and spiritual identity is a complex integration of these concepts, beliefs, and behaviors (Margolis, 2018).

National identity. Nations are governed groups of people associated with geographic territories. National identity, rather than being essential and timeless, is often constructed during times of national crisis when collective action is required for the survival of the government, geographic territory, and citizens (Wendt, 1994). This occurred in the United States for the Great Generation, silent generation, and baby boomers during the Great Depression, WW2, the Korean War, and the Vietnam War. During these times there was a valorization of male soldiers (Cornish \& Saunders, 2013). Edensor (2002) suggests that national identity may be the most important entity around 
which some older adults' identities are formed. Active military service may play a part in this type of identity establishment for some participants.

Cultural identity. Culture shapes the meaning older adults make of their lives and their progression through the life course (Merriam \& Mohamad, 2000). Cultural identity is seen as the emotional significance and sense of belonging that older adults attach to larger cultural groups (Ting-Toomey \& Dorjee, 2018). These groups and organizations construct their own cultural identity (Gagliardi, 2017). Affiliation to cultural groups can be demonstrated with personal possessions such as team paraphernalia (Kelly, 2018). Cultural groups may include ethnic groups, sport teams, alma maters, fraternities and sororities, regional geographies (e.g., Midwest, Southern), and organizations (e.g., Service Corps of Retired Executives - SCORE, Dairy Farmers of America).

\section{Embedded Meanings in Possessions}

Csikszentmihalyi and Rochberg-Halton (1981) suggest that American culture is based on owning things. Ames (1995) highlights our intense attachment to possessions writing, "Americans have invested goods with powerful meanings. Goods matter to them. Owning things, living with things, experiencing things, longing for things years ago became normal and accepted parts of American life" (p. 233). For some, this is seen as materialism, which is "a preoccupation with or stress upon material rather than intellectual or spiritual things" (Merriam-Webster, 2018e). McCracken (2005) suggests that materialism is not an evil of American society but rather an important medium that acts as a template for the self and objects in which our public and private meanings are stored, i.e., embedded. 
Material culture describes physical elements created or used by people through which individuals and groups interactively define their culture while that culture simultaneously defines its members' perceptions and behaviors (Ray, 2018). This type of symbolic interactionism is known as the trajectory perspective. It is a framework within consumer culture research that suggests individuals and groups construct meanings in objects and, through ownership, transfer those meanings to their own identities (McCracken, 1986). Tilley (2006) stated, "Material forms do not simply mirror preexisting social distinctions, sets of ideas or symbolic systems. They are instead the very medium through which these values, ideas and social distinctions are constantly reproduced and legitimized, or transformed" (p. 61). Just as older people adhere to different philosophies of living, the objects used to transfer identity meanings vary. Jean Paul Sartre suggests we know who we are by what we have, and having things increases the sense of who we are (Belk, 1988; Nisan, 1999). Sartre's views are foundational to Belk's (1988) concept of the extended self. Belk suggests we use our possessions to maintain the many selves that make up our identity in a hierarchy of levels. Although there may be a variety of levels, the construct is built upon the first —our individual self. Family, community, and group may be added in successive levels (Belk, 1988; Csikszentmihalyi \& Rochberg-Halton, 1981). "Possessions central to self may be visualized in concentric layers around the core self, and will differ over individuals, over time, and over cultures that create shared symbolic meanings for different goods" (Belk, 1988, p. 152). Owning objects enhances our sense of control, increases self-confidence, strengthens self-concept, and provides us with feelings of protection and security (Belk, 1992). In this way, possessions “extend the self” (Belk, 1988, p. 140). 
Possessions help us master transitions through the life course and store the past for us (Belk, 1990). They are not, however, a random selection of things that recall the past; rather they represent the highlights of one's life. One possession will not represent all aspects of the owner's identity, and older adults may grow more attached to possessions with embedded experiences when they lose the ability to participate in those experiences (Belk, 1988).

Csikszentmihalyi and Rochberg-Halton (1981) conducted seminal research on the meaning of household objects with eighty-two families, comprising three generations. Categories of meaningful objects varied by generation and gender. An object provided significant and deeply felt comfort for one person but no specific attachment to another. The central concept that emerged from their ethnographic study was cultivation. They found that all three generations used household possessions to cultivate meanings that moved them toward "the ultimate goals of one's existence" (Csikszentmihalyi \& Rochberg-Halton, 1981, p. xi).

The attention necessary for an individual to engage in the process of cultivation is referred to as psychic energy (Csikszentmihalyi \& Rochberg-Halton, 1981). It is that investment of attention or psychic energy that creates the initial person-object bond, charging the object with the energy of the person, embedding it with meaning. This can happen when someone creates an object, such as a piece of pottery or a quilt, or when they invest money they earned in the object. Older adults have invested significant amounts of their attention over the course of their lives into large objects, for example, cultivating a farm, a business, or a household. It is a significant loss when they no longer have the object of their life's energy (Csikszentmihalyi \& Rochberg-Halton, 1981). 


\section{Narrative Life Stories}

Narrating their own life stories is a method by which people make sense of challenging and significant events within their lives (Lal, Suto, \& Ungar, 2012). Bruner (1991) suggests that we construct and represent "the rich and messy domain of human interaction" (p. 4) through narrative construction, i.e. storytelling. The stories we tell are not just vehicles by which we disseminate knowledge and share our experiences. Mental storytelling is a type of cognition that allows us to understand our world and our place in it. Asking participants to share their life stories allows them to share their versions of reality. Because we all lead storied lives, inquiry aimed at understanding an older adult's narrative had the potential to reveal meaning-making experiences associated with the belongings at their new residences (Connelly \& Clandinin, 2006). "The autobiographical storytelling self continues to make sense of life, and its efforts may even improve with age" (McAdams, 2008, p. 252).

There are varying methods by which a person's life is parsed into meaningful segments. From a literary perspective, Shakespeare, in As You Like It, suggests there are seven stages in a man's life: infant, schoolboy, lover, soldier, justice, Pantalone, and old age (Hedges, 2017). Life-span perspective prioritized the temporal developmental order of life stages using eight age ranges (infancy: birth-18 months, toddlerhood 18 months- 3 years, preschool: 3-5 years, childhood: 5-13 years, adolescence: 13-21 years, young adulthood: 21-39 years, middle adulthood: 39-65 years, and older adulthood: $65+$ ) (Dunkel \& Harbke, 2017).

Life course perspective includes developmental aspects but also emphasizes social-role expectations at different ages and transitions between them (Bengtson \& 
Allen, 2009; Gilleard \& Higgs, 2015; Moschis, 2007). These phases (age-graded periods) can include infancy, toddlerhood, childhood, "tween" years (i.e., between childhood and adolescence; ages 12-14), adolescence, emerging adulthood, early adulthood, adulthood, midlife, late life, and oldest old. Their quality and essence are socially constructedmodernization and population aging has led to more in depth distinctions within the phases resulting in an increased number (Hutchison, 2014). However, diversity is also present in these phases, as people have personal control and decision-making power.

Events and roles do not proceed in the same chronological order for everyone, but an individual's life course is the summation of all personal experiences at a given moment and these experiences impact the future (Ferraro \& Wilmoth, 2013; Ponzetti, 2003). Old age, therefore, is viewed within the larger context of the life course (Settersten, 2018). The life course perspective can illuminate how society communicates social and personal meanings to the passage of time, specifically as it relates to aging (Hendricks \& Cutler, 2018).

Distillation of life story events. As well as everyday events, narratives about one's life contain self-defined high points, low points, and turning points (McAdams, 2008; Thomsen \& Pillemer, 2017). High points are positive in nature and remembered for their emotional content of excitement, love, and joy; low points are negative and encapsulate feelings of anger, fear, guilt, sadness, and shame (McAdams, 2008). Because older adults in their study rated all types of life events more highly than younger adults, Umanath and Berntsen (2017) suggested older adults may have an overall greater appreciation of life events. Turning points may be either specific positive, negative, or everyday events that trigger directional changes in life (Enz \& Talarico, 2016). Everyday 
events are the normalized routines and practical problems that occur every day. Although mundane, these events represent the social homeostasis that allows for comfortable functioning (Berger, 1997).

\section{Late-Life Place Making}

Esoterically, place is a geographic location having material form and invested with specific meanings (Gieryn, 2000) as well as a psychical force that shapes older adult lives with the remembrance of people and events temporally anchored (Schieffelin, 2018). Practically, Fuller and Atkinson (2016) view place as an "integration of physicality, functionality, community and spirituality and given an enacted/enacting form as place-making” (p. 233). Rowles (2018) suggests the meaning of a place comes with a blending of the physical location and older adult identity.

Home is one of many place meanings that occurs in residential locations. Older adults' identity formation has been linked to their sense of home (Gram-Hanssen \& BethDanielsen, 2004; Leonard, Perkins, \& Thorns, 2004; Low \& Altman, 1992; Miller \& Schlitt, 1987; Vollmer, Schulze, \& Chebra, 2005). Rubinstein and de Medeiros (2005) suggest this identity is tied to familiarity with home elements including objects and symbols that induce memories. They delimited their concept of home as "including the residence itself, personal objects, and microenvironments therein; home as memory; and home routines or rituals" (Rubinstein \& de Medeiros, 2005, p. 47). Being at-home for late-life older adults can be seen as being able to be one's self while being connected to others (Saarnio, Boström, Gustavsson, \& Öhlén, 2016).

Place Attachment. Place attachment has similar characteristics to the attachments older adults have to possessions with embedded meaning; these attachments are often 
strong, multi-faceted, emotionally complex, and they change temporally with older adult identity (Kleine \& Baker, 2004). Place attachment is an integrating concept that involves different personal bonding aspects. These aspects are affective (affect, emotion, feeling), cognitive (thought, knowledge, \& belief), and active (behavior \& action) and create a relational bond with an individual to a place (Low \& Altman, 1992).

Attachment to place integrates interrelated and inseparable aspects of older adult life course experiences. The origins of personal place attachments which initially develop early in life come from a variety of sources that are biological, environmental, psychological, and sociocultural (Low \& Altman, 1992, p. 8). Older people's place attachments contribute to how they view themselves as authentic, whole people. In addition to contributing to self-identity, place attachment provides security, control, predictability, and the ability for exploration (Low \& Altman, 1992), For older adults, attachment to former places organizes and accesses life events that occurred during one's entire life (Rubinstein \& Parmalee, 1992).

Philosophically, Bachelard (1969) suggested that our first house, the place in which we grew up (residence for those who grew up in a different type of structure), became the template for our future dwelling and the making of home. It was our first place attachment. Donahoe (2011) argues that the patterning of home, about which Bachelard (1969) writes, applies to both pleasant and unpleasant experiences of home. She suggests that learning to be at home is a normative experience, "a foundational standard to which other places are compared in terms of our embodied constitution of the world" (Donahoe, 2011, p. 25). The normative experience being at home creates a default that if negative, must be mentally switched for perhaps the remainder of our lives. 
An older adult's attachment to place integrates interrelated and inseparable aspects of their life course that signify their experiences (Low \& Altman, 1992). Rubinstein and Parmalee (1992) suggest, "the crucial role of personal experience of space, or the individually defined life course in relation to space, in development of both a sense of place and affective attachment to that place" (p. 146).

Household disbandment. Initializing household disbandment is complicated and impacts not only elders but also their family members. Ekerdt et al. (2004) studied household disbandment from a life course perspective. Older adults are statistically less likely to reduce their belongings than younger generations (Ekerdt \& Baker, 2014a). A national study revealed that during the year of measure, $30 \%$ of septuagenarians did not give away anything, and $80 \%$ did not sell any of their belongings. Too many possessions can make aging in place more difficult, but it can also make it more difficult to move (Ekerdt \& Baker, 2014a). Family members are aware of these difficulties and have opinions on what should happen. Unfortunately, advice literature on senior downsizing addresses older adults and their families as two separate groups. Advice to the elders is deferential to the connections people have with their belongings, whereas advice for family members negates the sentimental attachment to things (G. V. Smith \& Ekerdt, 2011).

Once these issues are resolved, however, household disbandment can be done quickly, although it can extend over several months (Ekerdt et al., 2004). Objects are disposed of in a sequence beginning with gifts to family and friends of significant items and pieces of furniture. Remaining objects are sorted to keep, sell, provide additional gifts, donate, or discard (Ekerdt et al., 2004). The task involves the spiraling of meaning: 
memories of the disbandment process will add a new layer of meaning to that already embedded in the object (Ekerdt et al., 2004). With the added meaning attributed to the dispersed objects, family dynamics are represented and rearticulated and new memories are interwoven with old ones (Sergeant \& Ekerdt, 2008).

Family traditions and meanings, which extended family members associate with household objects, are passed from one generation to the next. Social customs reinforce the necessity for older adults to provide a safe passage for these types of possessions when the objects cannot move with the current owner. This occurs in three phases: 1) the owner finds a new recipient for artifacts who will appreciate them;2) the artifact's story continues with the new recipient; 3) a legacy is created because, "the placement is thought to project the values, personality or identity of the giver" (Ekerdt et al., 2012b).

Legacy is an important concept in disbandment as it gives some amount of immortality to the older adult through the object. Older adults do not want to be forgotten - they want to live on through the items they give to others (Ekerdt \& Sergeant, 2006; Linda L Price, Eric J Arnould, \& Carolyn Folkman Curasi, 2000). Bequeathing personal belongings allows a new construction of the self for the older person, and although difficult, can be cathartic and commemorative. Contrarily, if an older person does not have family or friends who can or will take their possessions, the objects vanish, emphasizing the alienation and demise of the person (Marcoux, 2001). "In taking a thing, they [family members] affirm what the elder is doing and what the gesture means" (Ekerdt, Addington, \& Hayter, 2011, p. 39). Just as these types of patterns occur within the household disbandment process, there are also patterns within reiterated relocations. 
Contraction of home range. Rapoport (2005) suggests that, when we are born, our material world is a crib. That is our home range, and it expands over the life course, reaching maximum range around middle age. During old age, with iterative downsizing, the home range shrinks, even more so with frailty. At the time of our deaths, our place is again very small — the bed upon which we die as shown in Figure 3.

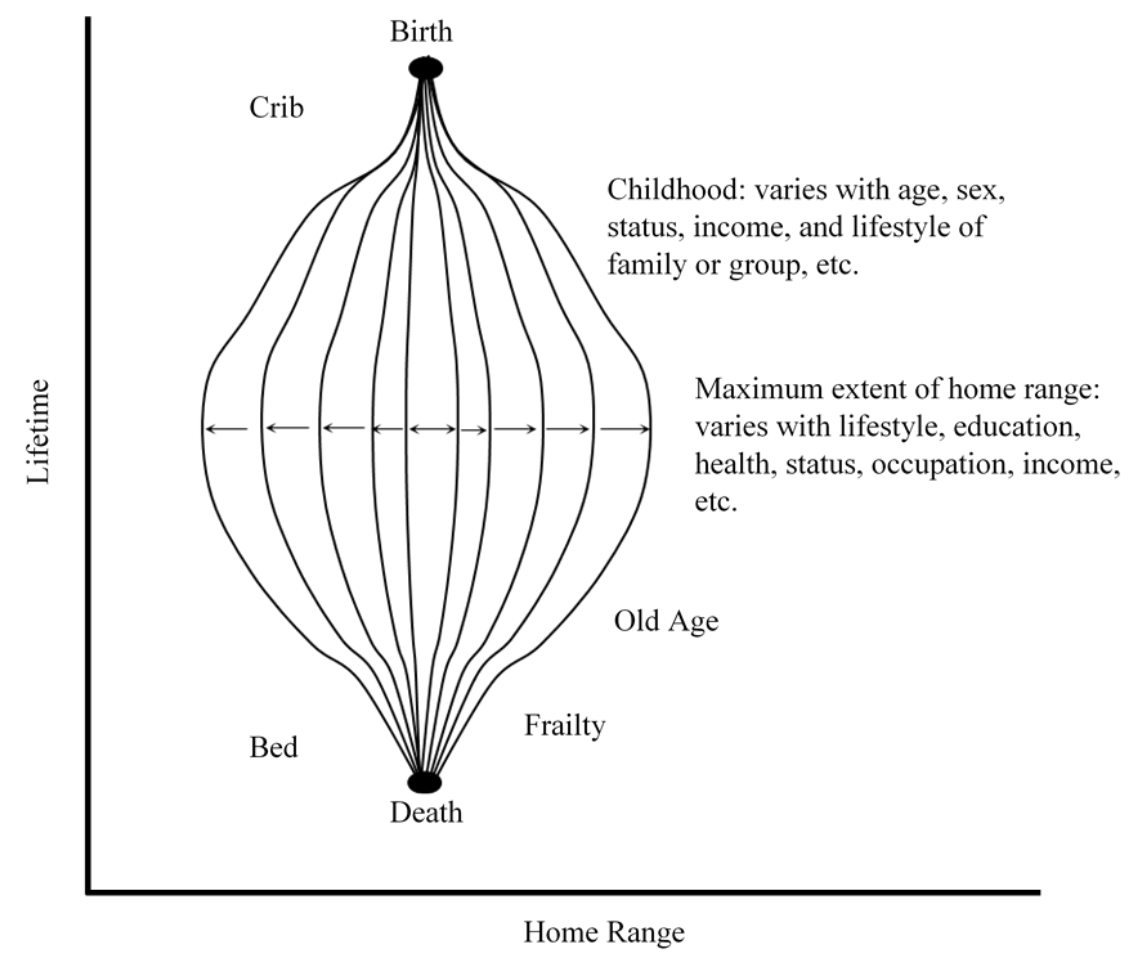

Figure 3. Generalized extent of home range incorporates shrinkage with old age \& other attributes. Adapted from Home and Identity in Late Life: International Perspectives (p. 355), by G. D. Rowles, 2006, NY: Springer Publishing Company. Copyright 2006 by Springer Publishing Company, Inc. 


\section{Summary: Definitions of Terms}

The above concepts were used to create a rubric which serves as an analytic instrument, Life Story Possession Analysis (LSPA), and is fully discussed in the methods chapter. Terms, which are encompassed in the concepts explored above, are used in the rubric. Brief definitions of these terms are given below in alphabetical order.

- Achievements - personal accomplishments experienced by the older adult which elicit pride and pleasure

- Acquaintances - people with whom the older adult is or has been casually familiar

- Ancestors - people who are in the older adult's genetic lifeline but who might not have been known personally

- Beliefs - a personal confidence, opinion, or trust in something that is not necessarily provable but which the older adult holds true

- Belongings - objects the older adults possess; used interchangeably with possessions

- Childhood - the initial period of the older adult's life span when other people were legally responsible for care; articulated by older adults as a loose concept of time rather than as specific chronological years of age

- Chosen family — although not legally acknowledged, a person or group of people who fills/fill the roles of traditional family members and is identified as chosen by the older adult

- Cognitive traits - self indicated, personal intellectual abilities of the older adult throughout the life-span 
- Collective-large combined social groups of people in which the older adult has been embedded during a lifetime

- Command central chair - the primary piece of furniture in which the older adult sits during the day; the position from which activities of daily life can occur

- Continuum of care - continuum of senior care typically begins with independent living and progresses through the following: assisted living, skilled nursing \& memory care; required assistance increases along the facility continuum

- Distillation of life story events - older adult recitations of events or series of events seen as high points, low points, turning points, or simple every day events in life stories.

- Embedded meaning - meaning that is incorporated as an integral part of a possession

- Everyday event - a mundane event or routine in the older adult's life

- Extended family - the older adult's kinship group that encompasses the nuclear family along with multiple generations, including ancestors

- Family - group of people related to the older adults through birth or legal process

- Frailty - the period during which the older adult requires daily help from another due to decreased health, strength, or memory loss; articulated by older adults or their children as a loose concept of time rather than a chronological range

- Friends - individuals with whom the older adult has emotional and social ties and who will not cause intentional harm

- Goals - time constrained personal objectives of the older adult 
- High point — a positive life experience that established a pleasant memory for the older adult

- High school - the time during which the older adult's dependence upon parents or guardians culminated, highlighted by preparation for higher education, a career, personal nuclear family, or a military stint; articulated by older adults as a loose concept of time rather than a chronological range

- Household disbandment — a significant life event during which the older adult's residence is sold or the lease not renewed, and most of her belongings/possessions are sold, given away, or discarded; subsequent residences are smaller. For the purposes of this study household disbandment occurred due to actual or impending age-related health issues.

- Identity aspects - Three layers of identity (personal, social, and collective) that when combined are phenomenologically manifested in an individual

- Life Story Possession Analysis (LSPA)_Analytic tool developed to evaluated older adult possessions

- Low point - a negative life experience that established an unhappy or painful memory for the older adult

- Meaningful -worthwhile, valid, substantial, relevant, useful, consequential, essential, important, deep, purposeful, eloquent, expressive

- Midlife - the period during the life of an older adult when they have established their careers and families and are continuing to work toward personal success in these areas; articulated by older adults as a loose concept of time rather a chronological range 
- Nuclear family - a social unit comprising the older adult, spouse, and any children

- Older adult - for this study, a retired person sixty-five years or older (also older person)

- Parents - biological or adoptive mother and father of older adult

- Personal identity - the person one believes oneself to be and shows to others that is an amalgamation of elements that differentiate one's self from another

- Personality traits - combination of six factors including honesty-humility, agreeableness, conscientiousness, emotionality, extroversion, openness to new experiences

- Physical traits - traits that describe the older adult's bodily appearance and abilities (height, weight, strength, eye color, etc.) throughout life-span

- Placemaking - within this research, focuses on older adults' creation of meaningful residences

- Post-household disbandment_-describes either older adults or residential places after the household disbandment experience

- Religious group - from the perspective of this study, is an organized and identifiable group with a professed system of faith and worship that is a reference group for the older adult's identity

- Retirement — time during which the older adult ceased working full-time; articulated by older adults as a loose concept of time rather than a chronological range 
- Social identity - the self made visible to the communities in which one actively engages

- Spiritual group -collective identity group that promotes qualities and perceptions such as serenity, mindfulness, and centeredness; examples are Alanon Family Groups, Alcoholics Anonymous, and yoga groups

- Storied possessions - older adult possessions (of all types) that are embedded with stories that convey personal life histories and are often accompanied with a narrative

- Time when possession was received - the remembered period in the older adult's life when a specific object was received

- Turning point — events in the older adult's life that triggered a directional change, could be interior personal change or external transitional change

- Values - ideals, customs, institutions, etc. of a society toward which the older adult has an affective regard; may be positive or negative: evaluated based on relative worth, merit or importance of something in terms of the amount of other things for which it can be exchanged or in terms of some medium of exchange import or meaning force, significance; liking or affection; favorable regard.

- Young adult — the period in the older adult's life when high school was finished, and formal adult life began characterized by advent of career, military service, higher education, and/or marriage; articulated by older adults as a loose concept of time rather than a chronological range 


\section{Chapter Three: Research Methods}

Transparency is a basic requirement of qualitative research. It showcases the quality of the research to assist in the trustworthiness of the findings. As a criterion for writing, presenting, and disseminating the findings, transparency requires the researcher to be clear and unambiguous about the processes (Ahmed, Opoku, \& Aziz, 2016; Creswell \& Miller, 2000; Hiles, 2008).

Mindful of the need for transparency, I begin this chapter with a broad review of my frame of reference followed by an explanation of my choice of qualitative methods. The focus is then narrowed to the specific type of qualitative methods and procedures I followed. I conclude with an application of Maxwell's (2012) interactive research design to my study.

\section{Researcher's Frame of Reference}

Crotty (1998) discussed three different epistemologies from which researchers arrive at their frame of reference: objectivist (also referred to as positivist), subjectivist, and constructionist. A major distinguishing point of each is its assertion about the origin of meaningful reality. In the objectivist epistemology, meaning resides solely within the object, and it is free of values. It is immutable and cannot be changed by the perspective of the subject. The researcher looks to investigate and explain this meaning. In opposition, subjectivist epistemology sees meaning as being imposed on the object by the subject, consciously or subconsciously. The object has no elemental meaning. The researcher intellectually interprets the meaning assigned to the object by the subject.

Constructionism. Constructionism resides within the dynamic tension formed by objectivist and subjectivist epistemologies. It posits that the object is independent of the 
subject, but the meaning of the object is made through a relationship between the subject and object. Crotty (1998) summarized the central idea of constructionism as, "all knowledge, and therefore all meaningful reality as such, is contingent upon human practices, being constructed in and out of interaction between human beings and their world and developed and transmitted within an essentially social context” (p. 42). The researcher, then, theorizes a social context for the object's meaning which has been derived from the relationship between the object and the subject.

A comparison of these epistemologies is graphically displayed below in Table 1. Although various concepts, theoretical perspectives, and theories (developed beneath the umbrella of each of these epistemologies) offer insight into complexities of late-life wellbeing (Meyer \& Daniele, 2016), my frame of reference is predicated on the constructionist epistemology.

\section{Table 1}

Comparison of Epistemologies

\begin{tabular}{llll} 
Epistemology & Objectivism (positivism) & Constructionism & Subjectivism \\
\hline Origin of & Inherent in the object - & Constructed through & Created \& imposed \\
meaning & discoverable, & relationship between & on object by \\
& independent of & object \& subject & subject \\
& experience \& & (person) & \\
consciousness & &
\end{tabular}

Symbolic interactionism. Within constructionism, our social world is viewed from both top-down (macro-level) and bottom-up perspectives (micro-level) (Haslam, 
Cornelissen, \& Werner, 2017; Pattinson, Nicholson, \& Lindgreen, 2017; Samanta, 2017). Micro-level theories analyze societal small scale structures and processes such as interactions between individuals (Crotty, 1998). Symbolic interactionism is a micro-level, sociological perspective that tries to make sense of the distinction between the self and the social. (For a more thorough discussion of symbolic interactionism, please refer to Chapter 2.) It is the lens through which I view the meanings of older adults' possessions on their late life placemaking experiences.

\section{Qualitative Research}

Qualitative research focuses on understanding the construction of meaning associated with relational interactions (Creswell, 2009). The focus on understanding meaning versus reporting statistical facts is based on an ontological assumption that the social world differs from the physical world of natural science. For instance, the physical properties of natural light are not a product of human action so colors in the visible spectrum of light can be discovered and factually investigated.

Contrary to the light spectrum and other objects of physical reality, social reality is constructed through human action and interaction (Noonan, 2008). This reveals a constructed reality that is multidimensional and assumes participants' subjective evidence counts as knowledge. This assumption impacts the three questions basic to epistemology: "What is knowing? What is the known? What is knowledge?" (Stone, 2008, p. 265). Constructionism is an epistemology that assumes meaning (i.e., social knowledge that contributes to sense-making) is constructed rather than discovered (Crotty, 1998).

Understanding this construction and the resultant meaning requires research that is different than statistical assessment. Qualitative research meets this challenge by 
delving deeply into the human aspects of a social phenomenon in order to avoid superficial findings (Padgett, 2016). “Thick descriptions are deep, dense, detailed accounts.... Thin descriptions, by contrast, lack detail, and simply report facts" (Denzin as cited by Creswell \& Miller, 2000, p. 128).

Researchers spend time with participants to understand the data they present. The data is then analyzed for meaning. Qualitative findings are rooted in the data generated by the participants. Theory generation occurs when understanding regarding societal meanings emerges from the collaboration of researchers and participants.

Answering my research questions required understanding of the lived-experiences of the older adult participants; I anticipated this could only be done by looking deeply into the topic and developing thick descriptions as demonstrated by previous researchers on similar topics (Luborsky, Lysack, \& Van Nuil, 2011; Nord, 2013; Linda L Price, Eric J Arnould, \& Carolyn Folkman Curasi, 2000). I chose multiple-case holistic case study research as the method by which I would systematically investigate these experiences.

\section{Multiple-Case Holistic Case Study}

Many qualitative procedural methods are used to explore human environmental interactions (Charmaz, 2011; Lal et al., 2012). Case study research is one such method. It is an approach by which the researcher explores a real-life, contemporary situation that is bounded by place and time (Creswell, 2013). The post-disbandment household meets this criteria. Yin (2017) suggests case study research is appropriate when research questions 1) seek to understand how a contemporary phenomenon works and 2) need a rich, extensive description of that phenomenon. Aligning with Yin's criteria, my research questions 1) seek to understand how the meanings of possessions contribute to post- 
household disbandment placemaking and 2) need rich, extensive descriptions of the meanings embedded in older adult possessions to get to the understanding.

Within case study research there are four different types of investigations that may be pursued depending on the number of sites (contexts) in which the specific bounded case is being explored and number of phenomena (units) being explored within that same case. Regarding number of sites: if one site is being explored, it is a single-case design; if there are more than one, it is a multi-case design. I explored sixteen different contexts with post-disbandment households, so my research falls into multiple-case design.

Regarding number of phenomena: when there is one unit being investigated within the case, it is a holistic analysis. When there are multiple units, it is embedded analysis. I researched a single phenomenon, the meaning of possessions. I had a single unit of analysis, so it was holistic. Consequently, my research was a multiple-case holistic case study (Creswell, 2013).

Yin's graphic (2017) depicting these different types of case studies is adapted and displayed in Figure 4. I include it to situate Figure 5, my multiple-case holistic case study. Figure 5 illustrates the specific types of dwelling-contexts in which the sixteen household cases, with the twenty-three older adult participants, exist. Participant pseudonyms are used within each of the contexts. Additional information regarding the research participants is provided in the following section. 


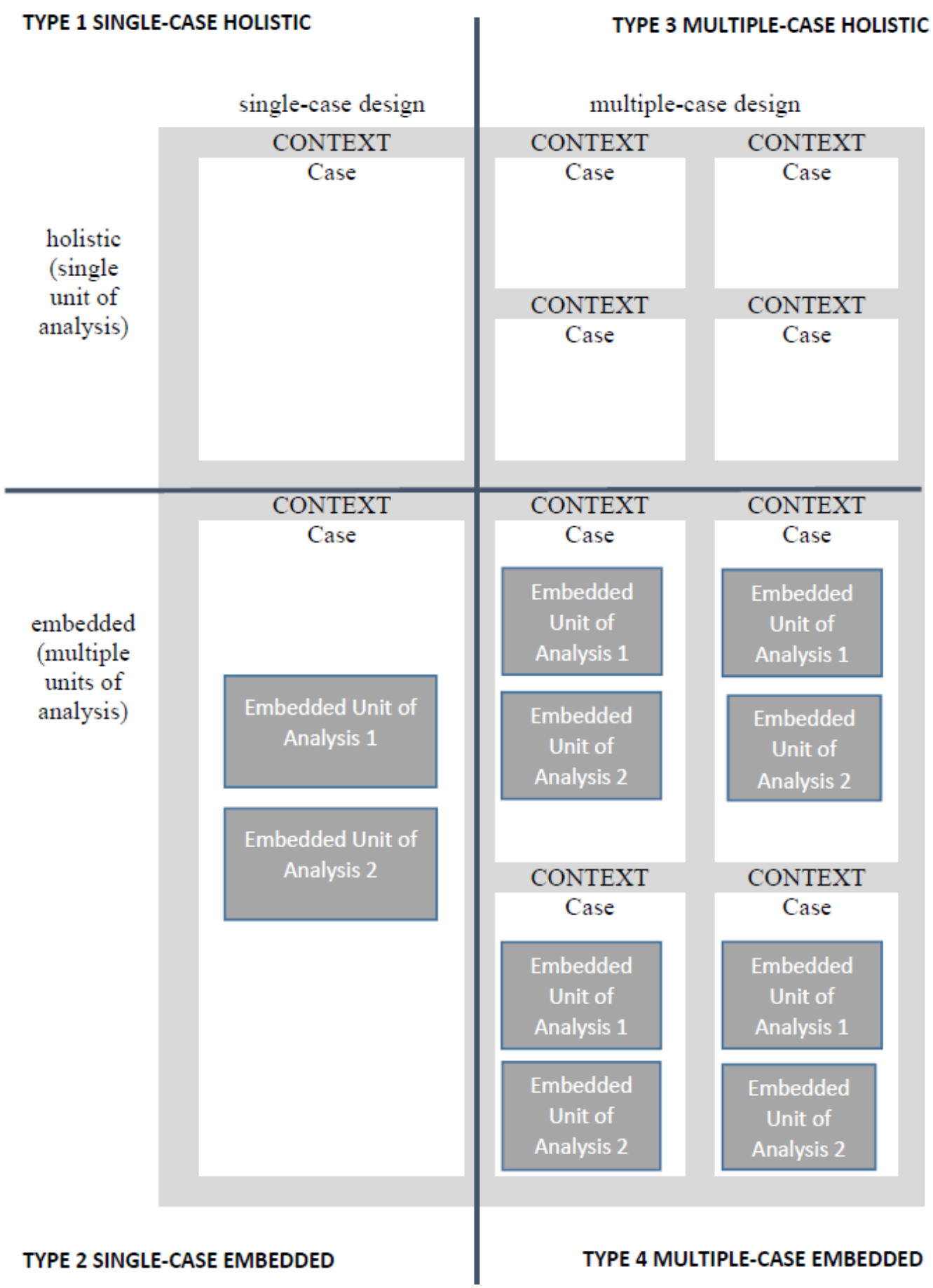

Figure 4. Yin, Robert K. Case Study Research and Applications: Design and Methods (Kindle Location 2112). SAGE Publications. Kindle Edition. 


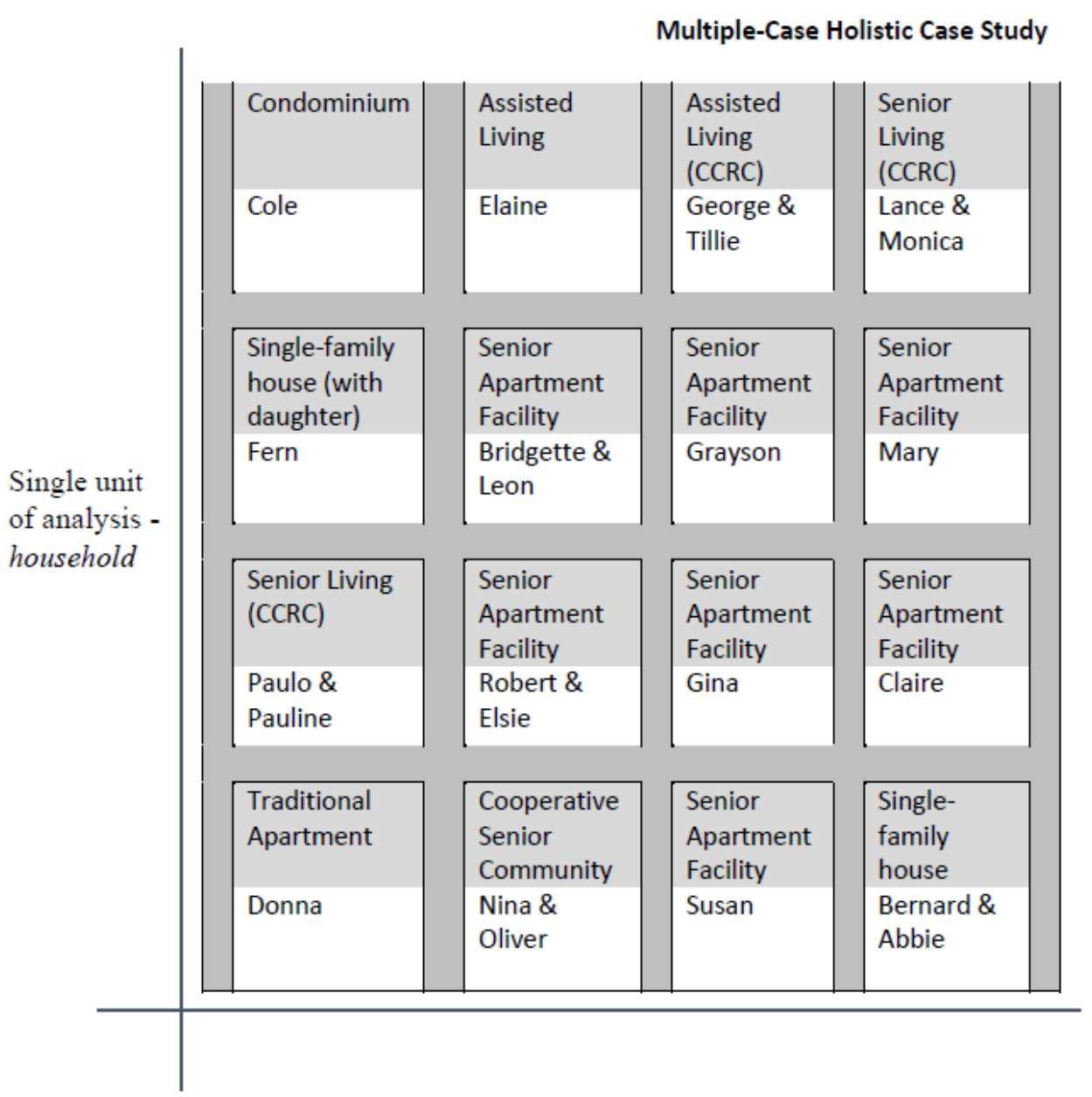

Figure 5. Positioning of households types within multiple-case holistic case study matrix adapted from Yin's graphic (2017).

I have broadly reviewed my frame of reference as anchored in constructionism and the micro-level perspective of symbolic interactionism. I discussed my reasons for choosing qualitative methods and then narrowed to the specific type of qualitative method I used, multiple-case holistic case study research. An adaptation of Crotty's (1998) diagram illustrating the alignment of my frame of reference including the 
epistemology, theoretical perspective, research methods, and research procedures is seen in Figure 6. The remainder of the chapter reviews the specific procedures I followed.

\section{Epistemology: constructionism}

\section{Theoretical perspective:} symbolic interactionism

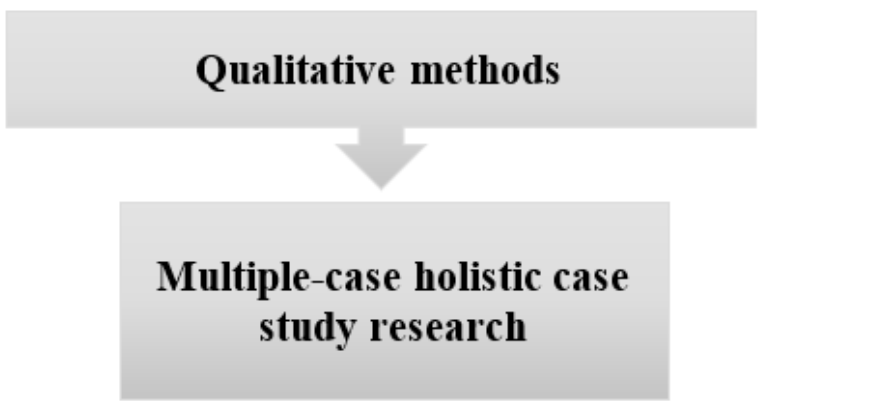

Figure 6. The four elements of this study's research process that inform one another. Adapted from The Foundations of Social Research: Meaning and Perspective in the Research Process (p.4), by Michael Crotty, 1998, Thousand Oaks, CA: Sage. Copyright 1998 by Michael Crotty.

\section{Research Participants}

In choosing participants, I used purposeful selection (Maxwell, 2005), a technique used in qualitative studies to locate people who have rich information that aids in understanding the research problem and the main phenomenon being studied (Creswell, 2013; Palinkas et al., 2013). Initially I looked for retired adults who moved into smaller 
residential space and downsized their belongings. The adults were ages 65 or older, had age-related limitations (anticipated or actual), and had moved within three years of the onset of this study. These criteria met the three features that characterize late life household disbandment: "necessary, comprehensive, and liminal to mortality all at the same time" (Ekerdt et al., 2004, p. S266).

I also contacted several gatekeepers: individuals who were members of or who had "insider status" to potential participants (Creswell, 2013, p. 154). An executive director of a recently built senior living apartment facility agreed to help by placing an advertisement in its community newsletter and posting a sign-up sheet in the front office. Nine older adults (five single people and two couples) agreed to participate from that site.

Recruitment was also conducted by distribution of a poster describing the study to acquaintances, coworkers, and Facebook contacts. Additionally, as I visited with people about my research, I asked if they knew anyone who might be interested. Four people suggested I contact their parents. This type of purposeful selection resulted in a total of twenty-three older-adult participants and five adult children. See Table 2 for additional demographic information for the older adult participants. Table 3 lists pseudonyms of the five adult children and their contributions.

Although most of my participants lived in some type of senior apartment, I included an older adult who lived in a traditional apartment and a couple who purchased a house substantially smaller than what they previously owned; additionally, one of the nonagenarians lived with her adult daughter in a single-family house and another lived independently in a condominium near his son. All the residential sites were in midsized to large urban areas within Texas and Kansas. 
Table 2

Participant Profiles

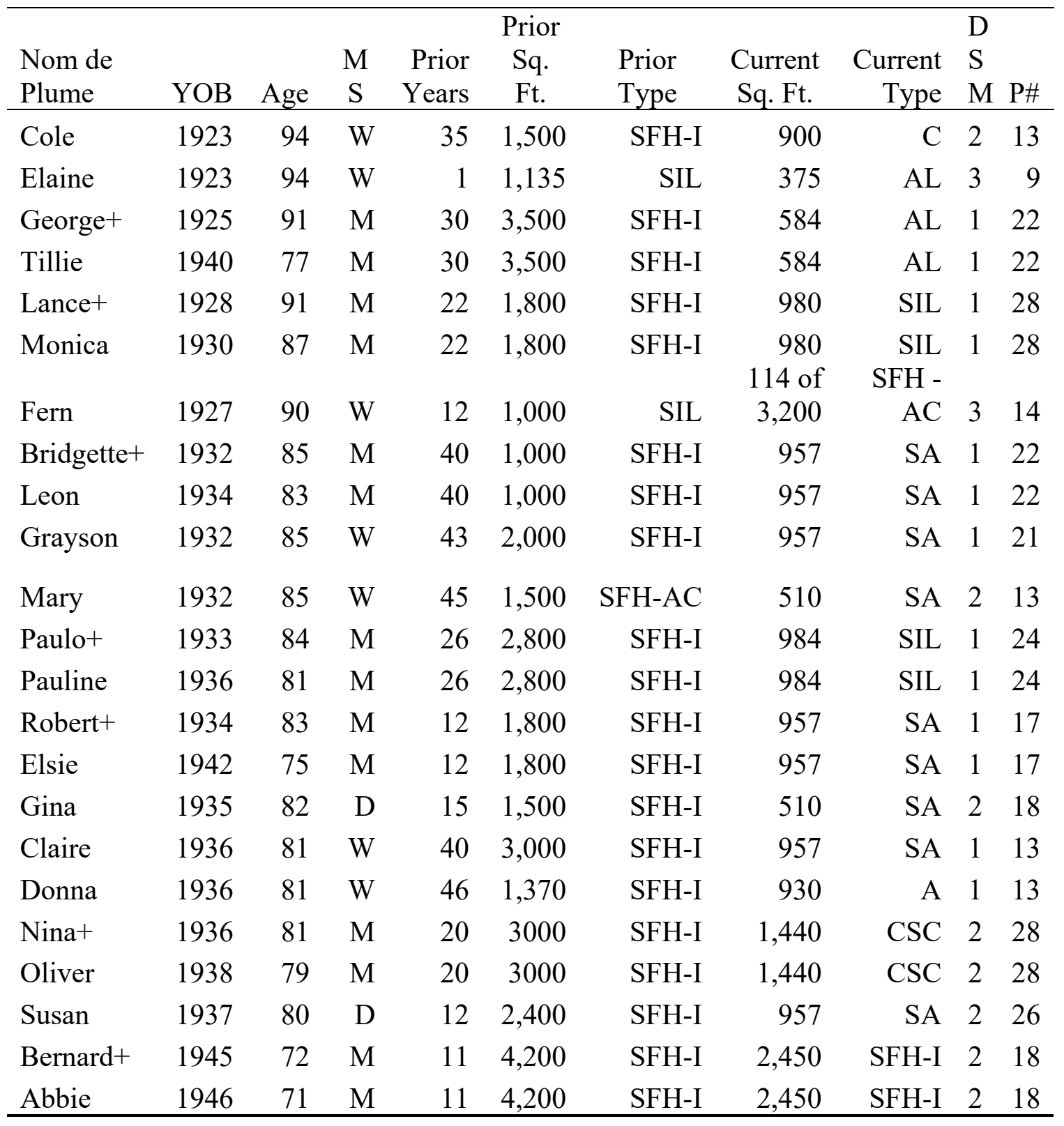

Note. Abbreviations in order of occurrence - YOB = year of birth; MS = Marital status ( $\mathrm{D}=$ divorced, $\mathrm{M}=$ married, $\mathrm{W}=$ widowed); Sq. Ft. = square feet; Prior type: $\mathrm{A}=$ apartment, $\mathrm{AL}=$ assisted living, $\mathrm{C}=$ condominium, $\mathrm{CSC}=$ cooperative senior community, $\mathrm{SA}=$ senior apartment, $\mathrm{SIL}=$ senior independent living, $\mathrm{SFH}-\mathrm{AC}=$ single family house with adult child, SFH-I = single family house independently; DSM = downsizing moves; $\mathrm{P} \#$ = number of possessions discussed as important; + in first column $=$ married to participant on next row 
Table 3

Adult Children Participants and Their Contributions

\begin{tabular}{|c|c|c|c|}
\hline $\begin{array}{l}\text { Participant } \\
\text { Nom de } \\
\text { Plume }\end{array}$ & $\begin{array}{l}\text { Adult Child } \\
\text { Nom de } \\
\text { Plume }\end{array}$ & Relationship & Contribution \\
\hline Cole & Barry & son & $\begin{array}{l}\text { Barry was present during all three } \\
\text { of my interviews with Cole, who } \\
\text { has hearing loss. }\end{array}$ \\
\hline Elaine & Tori & $\begin{array}{l}\text { daughter-in- } \\
\text { law }\end{array}$ & $\begin{array}{l}\text { I recorded and transcribed a } \\
\text { telephone call with Tori who } \\
\text { provided context about Elaine's } \\
\text { move to assisted living. }\end{array}$ \\
\hline Fern & Leah & daughter & $\begin{array}{l}\text { Leah was present during my } \\
\text { interactions with Fern, who has } \\
\text { hearing loss. }\end{array}$ \\
\hline $\begin{array}{l}\text { Paulo \& } \\
\text { Pauline }\end{array}$ & Daniel & son-in-law & $\begin{array}{l}\text { Daniel is Paulo and Pauline's } \\
\text { interior designer. He spoke to me } \\
\text { regarding furniture culling and } \\
\text { placement. }\end{array}$ \\
\hline $\begin{array}{l}\text { Nina \& } \\
\text { Oliver }\end{array}$ & Merida & daughter & $\begin{array}{l}\text { Merida was present during two of } \\
\text { my three interviews with Nina } \\
\text { and Oliver. She contributed } \\
\text { insights into their life style and } \\
\text { furniture choices. }\end{array}$ \\
\hline
\end{tabular}

I attempted to visit with each older adult participant at least twice. The first meeting occurred over the phone or in person. During the first interview, I discussed the 
parameters of the investigation and verified their desire to participate. In addition to verbal inquiry, I incorporated photo-elicitation into the interview process. If the older adults were willing and able to contribute to the photo-elicitation, we reviewed the parameters during this first meeting. (Both photo-elicitation and the parameters for this study are detailed more fully in subsequent paragraphs). At the end of our first meeting, I scheduled an interview time.

Creswell (2013) suggests that case study exploration occurs by gathering data from a variety of sources that may include interviews, visual material, documents, and/or observations. The methods I used to follow such exploration are below.

\section{Interviewing}

All participants gave me permission to audio record the interview. Each interview was completed in the older adult's residence using a predetermined list of broad questions or probes specifically related to their relocation and possessions as seen in Appendix F. These questions were based on insights from existing literature, my pilot study, and questions about the photographs that participants sent me (see further explanation below). I also asked participants to tell me their life stories.

Narrating their own life stories is a method by which people - in this study the older adult participants — can make sense of challenging and significant events within their lives such as household disbandment (Lal et al., 2012). Bruner (1991) suggests that we construct and represent "the rich and messy domain of human interaction" (p. 4) through narrative construction, i.e. storytelling. The stories we tell are not just vehicles by which we disseminate knowledge and share our experiences. Mental storytelling is a type of cognition that allows us to understand our world and our place in it. Asking 
participants to share their life stories with me allowed them to share their versions of reality. Because we all lead storied lives, inquiry aimed at understanding an older adult's narrative had the potential to reveal meaning-making experiences associated with the belongings at their new residences (Connelly \& Clandinin, 2006). "The autobiographical storytelling self continues to make sense of life, and its efforts may even improve with age" (McAdams, 2008, p. 252).

Interviews lasted from one to two hours in length. If a participant appeared to be getting tired, I asked if we needed to continue the interview later. Audio recording was done with my mobile phone and subsequently transcribed by a transcription service.

Photo-elicitation. Photo-elicitation (also known as photo interviewing, photovoice, and photo-feedback) is a qualitative research method that integrates photographs into the interviewing process (Shaw, 2013). It has been successfully used in a range of older adult studies (Loeffler, 2018; Swank, Smith - Adcock, \& Puig, 2017; Williamson, Lyle, Darton, Griffiths, \& Lamb, 2017). I chose to use photo-elicitation to establish rapport and collaboration between older adults and myself (Bignante, 2010; G. Rose, 2014). I had a concern, however, about the implications of asking older adults, who were essentially strangers to me, to take photographs of their belongings. In an era of illegal scams targeting senior citizens, I was skeptical about how potential participants might receive my request (Burnes et al., 2017; Lee, Johnson, Fenge, \& Brown, 2017). My suspicion was confirmed early in my data collection process when I met with a Holocaust survivor who had been part of the French Resistance during World War II. She agreed to participate, but when I mentioned the photo-elicitation she became hesitant and said she would no longer do so. The declination validated the need for sensitivity to the signs of 
hesitancy; I adjusted the way in which photo-elicitation was presented, verifying that the older adults knew they did not need to send me photographs prior to interviews in order to participate in the research.

Eighteen of the twenty-three participants said they felt comfortable taking and sending photographs. I gave them a sheet of instructions in photographic techniques (Appendix E) and offered disposable cameras (Fuji Film Quicksnap ${ }^{\circledR}$ single-use cameras with 27 exposures) and a self-addressed postage-paid envelope. Sixteen of the eighteen used these cameras. Two participants preferred to use their cell phones; one of the two emailed me the digital photographs, and the other sent the photographs in a text message. The participants completed journals recording the location, date, time, and a brief description of the objects in the photographs.

I created two sets of prints for our second meeting. At the end of the verbal interview, each participant was asked to use the photographs to select ten of their most prized possessions (Clark-Ibáñez, 2004). Once completed, I asked them to narrow the photographs down to their top five, then top three, and finally their primary prized possession. During the interviews, all participants allowed me to take photographs of their belongings in the context of their residences.

\section{Data Analysis}

Initial analysis. Data from interview transcripts, participant journals, and photographs were compiled into chronological narratives for each household. I titled these Life Story Narratives. I also input all transcripts into NVivo software. I analyzed the life story narratives by hand and coded the interview transcripts in the software. My initial analysis revealed the benefit of creating an analytical instrument specific to this 
research that could visually display several fields of meaning at the same time. Yin (2017) refers this case study analytic strategy as an organized descriptive framework.

Descriptive framework. I define fields of meaning as the different areas that contribute to the embedded meaning in an object. Three fields of meaning emerged from the initial data analysis: those associated with a particular time frame, those associated with identity; and those associated with the intensity of events. Possessions were received at different times throughout a participant's lifespan and carried meanings associated with that time period (Ekerdt, Luborsky, \& Lysack, 2012a). Additionally, identity meanings were associated with participants' possessions (Ekerdt, 2014). Those associated with the intensity of specific life story events were also contributors. Using this information, I created a descriptive framework entitled, Life Story Possession Meaning Analysis (LSPA) by which I could evaluate object meaning. See Figure 7. Application of the three fields of meaning to the LSPA follow.

Time frames of possession. I analyzed the data to find time frames by which participants organized their lives. As guidelines I began with Erik Erikson's Stages of Psychosocial Development (Brown \& Lowis, 2003) and the stages of life from life course perspective work (Halfon \& Hochstein, 2002); participants, however, did not relate their information to me in these academic or psychologically bounded decades or developmental spans. Their time frames were associate with memories, life course events, and their approximate age: I was a child, sometime after we retired, and we met in high school are typical ways that time information was given.

I incorporated the general time frames used by participants in the LSPA. These time frames are childhood, high school, young adult, midlife, retirement, and frailty. 
Ancestors and parents were also included as codes to demonstrate the heritage of some belongings.

Identity aspects. In my literature review, I discuss Livesley and Larstone's (2018) layers of identity. The LSPA includes three layers and their concomitant parts of the older adult's identity reflected in their possessions: personal, social, and collective. (Jaspers \& Pieters, 2016; Stobart \& Rothery, 2014; White \& Beaudry, 2009).

Event intensity. Event intensity can be studied using different intensities of events presented in the life story (Brockmeier, 2009; Luchetti \& Sutin, 2018; McAdams, 2008). I included four specific types of events that participants related: 1) high points, 2) low points, 3) turning points, and 4) everyday engagements. Explanations for each of these terms is given in Summary: Definitions of Terms located at the end of Chapter Two.

The procedures detailed below in the secondary analysis section and the format of the findings in the next chapter follow the description of data analysis for multiple-case holistic analysis in (Creswell, 2013):

When multiple cases are chosen, a typical format is to provide first a detailed description of each case and themes within the case, called a within-case analysis, followed by a thematic analysis across the cases, called a cross-case analysis, as well as assertions or an interpretation of the meaning of the case. (p. 101)

Secondary analysis. I used the LSPA to perform within-case analyses of the sixteen households. The resultant meanings from each case are used to answer my first research question, "What identity meanings, related in life span stories, are embedded in the possessions older adults move to their new residences?" The findings are presented as 
within-case studies with a narrative, list of possessions, completed LSPA, and the themes that emerged within the case.

Tertiary analysis. As suggested by Creswell (2013) I conducted an additional cross-case analysis regarding family identity.

Family identity. I isolated the rows on the LPSA that incorporate family identity for all sixteen households. I thematically analyzed the four event categories (high point, low point, turning point, and everyday engagements) to answer my second research question, "How do older adults use their possessions to create places imbued with the meaning of family after household disbandment?" The cross-case analysis findings follow the within-case reports in the findings chapter. 


\begin{tabular}{|c|c|c|c|c|c|}
\hline & \multicolumn{5}{|c|}{ Distillation of Life Story Events } \\
\hline & Identity Aspects & high point & low point & turning point & every day \\
\hline \multirow{5}{*}{ 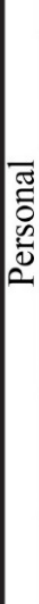 } & $\begin{array}{l}\text { personality } \\
\text { traits }\end{array}$ & & & & \\
\hline & $\begin{array}{l}\text { physical \& } \\
\text { cognitive } \\
\text { traits } \\
\end{array}$ & & & & \\
\hline & values & & & & \\
\hline & $\begin{array}{l}\text { goals \& } \\
\text { achievements }\end{array}$ & & & & \\
\hline & beliefs & & & & \\
\hline \multirow{5}{*}{$\begin{array}{l}\frac{\pi}{8} \\
0 \\
0\end{array}$} & nuclear & & & & \\
\hline & 를 & & & & \\
\hline & chosen & & & & \\
\hline & friends & & & & \\
\hline & acquaintances & & & & \\
\hline \multirow{3}{*}{ 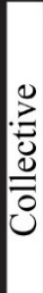 } & $\begin{array}{l}\text { religion/ } \\
\text { spiritual } \\
\text { communities }\end{array}$ & & & & \\
\hline & nation & & & & \\
\hline & culture & & & & \\
\hline \multirow[t]{2}{*}{ 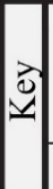 } & \multicolumn{4}{|c|}{$\begin{array}{l}\text { Time when Possession was Received } \\
\square=\text { ancestors } \triangle=\text { parents }\end{array}$} & $\begin{array}{l}=\text { childhood } \\
=\text { frailty }\end{array}$ \\
\hline & \multicolumn{4}{|c|}{ Other Symbols } & $=$ photos \\
\hline
\end{tabular}

Figure 7. Life Story Possession Analysis (LSPA) template. 


\section{Ethical Issues}

Responsible, ethical research requires a minimum of harm and risk to participants and a maximum of benefits, respect for human dignity, autonomy, and privacy, and the special care of vulnerable populations (Resnik, 2011). To comply with these requirements, I ensured there were no conflicts of interest between my study and my professional or personal contacts.

Per federal and institutional regulations at the University of Missouri (IRB, 2018), any study in which data is collected from human participants must be approved through the Institutional Review Board (IRB). I submitted the appropriate documentation for this study, and it was approved. Per IRB requirements, a written informed consent (see Appendix H) was given to older adult participants prior to participation. I stated at the beginning of the interview that it could be terminated at any time and that participation was voluntary.

In addition to these practical safeguards, I engaged in reflection about the interviews both during and after the collection process to increase my self-awareness and reduce the chances of harming the interviewee (Sabar \& Sabar Ben-Yehoshua, 2017). I considered possible ethical dilemmas that might arise during our interactions and how I would respond to them (Mason, 2002). I was particularly concerned about three items. First, I wanted to be as alert as possible to the older adults' contemporaneous feelings and desires about the discussion and respond appropriately to any distress that might arise. Although household disbandment and relocation were positive experiences for some participants, for others, they were difficult and needed to be approached with extra care (Mason, 2002; Ritchie, Lewis, Nicholls, \& Ormston, 2013). No participants became 
agitated during the interviews, but when it became evident that they did not want to continue discussing an issue, I steered the conversation in a different direction. Second, I wanted to be sensitive to items that might be shared that were not necessary to my research but might make the participant feel vulnerable later. This was difficult because, as my research related to life stories, I was not sure if the topic being discussed was incidental. My mental procedure was to listen until I strongly suspected we were off topic. At that point, I steered the conversation back to the topic. Third, I determined in advance that if I suspected elder abuse in any of the residences I visited, I would contact my advisor to discuss the situation while maintaining the anonymity of my participant. Fortunately, this did not occur.

\section{Trustworthiness}

Qualitative researchers establish trustworthiness during each phase of research. "It involves an infusion of science with what is outside science-human life as lived, as well as a conversation among multiple, mutually critical perspectives.... In these relationships, no one set of interests and values is exclusively privileged" (Wertz et al., 2011, p. 399).

Four aspects that promote trustworthiness are credibility, transferability, dependability, and confirmability (Lincoln \& Guba, 1985a). Credibility concerns the believability of the data, analysis, and results. Data from different sources (triangulation) justified the coherent themes and contributed to believability of my results (Creswell, 2013; Ewens, Hendricks, \& Sundin, 2017). As mentioned, my data sources included interviews, photo-elicitation, and floor plan analysis. Additionally, my reflexivity documentation is available for readers to evaluate the inclusion of my biases in my knowledge construction (see Appendix A). 
Transferability is the degree to which my results or theoretical framework apply to other settings. It is used in qualitative methods rather than the concept of generalizability that is used in quantitative methods. The notion of transferability is linked to a constructivist perspective because it assumes 1) research results are only frameworks that might legitimately be expected to happen when similar methods are used in similar circumstances and 2) only readers of the study are qualified to decide if the results might be transferable to other situations (Given, 2008). For this reason, the precise details of my methods (data collection procedures and the data analysis) are provided along with rich descriptions in my findings. This type of description "incorporates the cultural framework and meanings of the actors, their codes of signification, providing an emic account grounded in the actors' cultural context" (Given, 2008).

Dependability describes the degree to which the results are consistent with the data reported. Evaluation of dependability requires the adequate documentation of procedure including field context (Silverman, 2015). Documentation of this type is referred to as an audit trail and for this study included:

- Procedures for data collection and coding

- Theoretical and field notes, memos

- Concurrent process notes discussing pursuit of trustworthiness

- Coding scheme (including categories, definitions, and relationships), findings, and integration of existing literature

- Researcher reflexivity (Flick, 2013)

Confirmability is the additional research process work that confirms my findings 1) make sense and 2) contribute to existing knowledge. "In interpretive research, meaning 
is disclosed, discovered, and experienced. The emphasis is on sensemaking, description, and detail" (Bhattacharya, 2008, p. 465). Because my research is about meanings embedded in older adult possessions, the meanings I discuss in my findings should make sense to the owners of the possessions. Additionally, these findings should provide continuity to existing material culture and environmental gerontology research.

Confirmability also verifies that two research goals of qualitative methods are met: 1) the phenomenon under investigation is understood from the participants' perspectives and 2) the meanings people give to their experiences are understood by others (Given, 2008). The confirmability of my research is expressed by the degree my findings demonstrate these goals were pursued over my own biases, i.e., my results should demonstrate the meanings older adults have about their belongings rather than the meanings I have about their belongings or the meanings I think they should have about them.

Techniques I used for confirmability include seeking participant perspectives by listening to recorded interviews of their life stories, viewing photographs they took of possessions that were meaningful to them, and incorporating participants' journals during data analysis. Additionally, I asked five participants to review my findings to see if they made sense to them, and I presented findings at the Caring for the Frail Elderly Annual Conference in 2017 and the Environmental Design Research Association (EDRA) Annual Conference 2018 to get feedback. Throughout my research process I journaled reflectively about biases that arose for me to distinguish them from participant perspectives (Lincoln \& Guba, 1985b). 
Reflexivity is a process involving transparency that speaks to the challenge of not making the data say what the researcher, as the main instrument, wants it to say. Therefore, the awareness of the ways in which the researcher impacts the process must be kept at the forefront of awareness. To ensure I adequately answered this challenge, I reviewed Appendix A throughout my research and evaluated my involvement in further discussions with other researchers (McGhee, Marland, \& Atkinson, 2007). I recorded my reflections and supplied authentic resolutions to the questions detailed in the appendix.

\section{Chapter Summary: Interactive Research Design}

In this chapter, I addressed my goals, conceptual framework, research questions, methods, and trustworthiness. By way of concluding the chapter, I graphically display the connections between these elements in Figure 8. I introduced a simplified version of the graphic in the introduction chapter. The following figure is also an adaption of Maxwell's interactive model of research design, which he designed as "a model of as well as for research" (2012, p. 3).

The elements of the study are displayed in rectangles, and the ways in which they affected each other are displayed in two type of lines. The six solid lines represent the most important integral relationships among the five components. The two dashed lines, on the other hand, indicate relationships that are less emphasized within research models, but their existence needs to be acknowledged and evaluated for relational consistency (Maxwell, 2012). Maxwell (2005) posited that qualitative research design requires an interactive model that is not linear, but rather iterative with a back and forth relationship between the different elements of the design. The model helped me plan the structure of my study and execute it while maintaining connections between the elements. 


\section{Goals}

- Understand how precious belongings were used in late-life placemaking

- Understand the perspective (feelings \& opinions) of older adults after household disbandment about their senior apartments

- Understand how older adults used their possessions to extend their identity within new environments to create meaningful places

- Add research that informs interior design theory

\section{Conceptual \\ Framework}

- Background as a Professional residential interior designer

- Older adult identity

- Personal possessions

- Making place

- Narrative life stories

- Pilot research

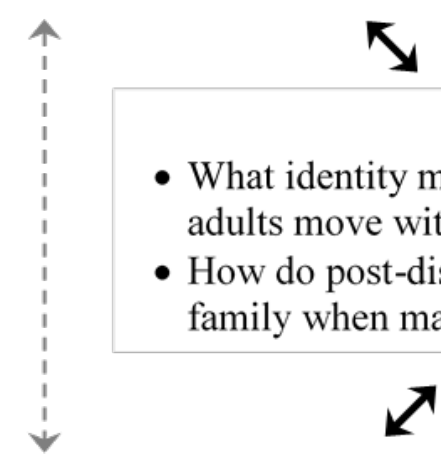

Multiple-Case Holistic Case

\section{Study Research}

- Data Collection

- Open-ended interviews

- Observation of older adult senior residences

o Photograph-elicitation

- Journal notes by participants

○ Field notes \& journals

- Floor plans of residences

- Data Analysis

- Interview transcription

- Initial Coding/NVivo

- Descriptive Framework LSPA

○ Memo writing

\section{Research Questions}

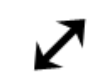

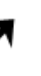

ossessions older 


\section{Chapter Four: Findings}

\section{Within-Case Studies}

To follow are sixteen within-case analyses of the in-depth exploration of each household as a stand-alone entity ("Encyclopedia of Case Study Research," 2010). To gain an intimate familiarity with each particular case and discern the identity themes revealed, every household has a narrative based on interviews, a list of storied possessions, the life story possession analysis, and case by case themes to answer the research question: "What identity meanings, related in life span stories, are embedded in the possessions older adults moved to their new residences?"

\section{Household case study \#1: Cole.}

Cole moved from living independently in single-family house (SFH-I) to a condominium (C) within a short walk from is son. It was his second downsizing move (DSM) as seen in Table 4. Below is Cole's life story.

Table 4

Cole's Profile

\begin{tabular}{|c|c|c|c|c|c|c|c|c|c|c|}
\hline $\begin{array}{l}\text { Nom } \\
\text { de } \\
\text { Plume }\end{array}$ & YOB & Age & MS & $\begin{array}{l}\text { Prior } \\
\text { Years }\end{array}$ & $\begin{array}{c}\text { Prior } \\
\text { Sq. } \\
\text { Ft. }\end{array}$ & $\begin{array}{l}\text { Prior } \\
\text { Type }\end{array}$ & $\begin{array}{l}\text { Current } \\
\text { Sq. Ft. }\end{array}$ & $\begin{array}{r}\text { Current } \\
\text { Type }\end{array}$ & DSM & $\mathrm{P} \#$ \\
\hline Cole & 1923 & 94 & W & 35 & 1,500 & $\begin{array}{r}\text { SFH- } \\
\text { I }\end{array}$ & 900 & C & 2 & 13 \\
\hline
\end{tabular}

Cole's parents worked in Yellowstone National Park. Black and white photographs of erupting geysers, bighorn sheep, bison, grizzly bear, moose, and elk are featured in Cole's albums. During the Great Depression, this idyllic lifestyle changed. His family lost their house to the bank. After that, a desperate family odyssey began, first to Seattle and then to Ohio, as month after month his father searched for work. 
For a time, they stayed on a farm in Ohio. Cole had no friends. "I was a sorry boy, I'll tell you. I remember it raining one time walking to school, and then I remember the onion smells and the filth." He helped earn living expenses by picking onions. His family bathed in the creek along with other migrant workers. Cole was mortified when he failed school. The only pleasant memory he has of that time is of two farm dogs.

About a year after they arrived on the farm, his father was hired as a grocery store manager in Detroit. "Boy that saved his life. It saved our lives. Things got better from then on." The entire family worked in the store though only his father was paid. They lived off his pay and ate unwanted cracked eggs and old potatoes. "We ate a lot of potatoes; they could clean up, and those onions - we loved onions too." Eventually, the family was able to get a house and a dog. Cole became an avid reader and still reads daily from a poetry book he bought in high school.

On weekends in high school, Cole and his friends roller-skated all over the city even as far as Walled City, a celebrity night club. "We'd get out where the big bands played. I remember they'd shoo us away. They wouldn't allow us to stay near, but we'd go out there anyway. Boy, that was great!’ Even though Cole's hearing was impaired in his advanced old age, he kept his phonograph, "It's fun. I love my records. Music is enjoyable and reminds me of places, things, and people."

Cole became a Navy fighter pilot over the South Pacific during World War II. Air battles required intense focus. "You had to be a gung-ho to survive: they were shooting at you!" Often when they were flying blind in bad weather, he would see a hole in the clouds and dive through it, the other planes following their leader. During one mission, a bullet penetrated his plane and lodged in the parachute he was wearing. Cole shot down 
the enemy plane and saved the bullet from his own parachute. During our interview, Cole looked through dresser and desk drawers to show it to me, but he could not find it.

Following the war, Cole came home and stole his friend's beautiful, tall girlfriend, Annie, after meeting her at a square dance. They married and had four children. Cole flew with the Navy Reserve on weekends and worked as a salesman during the week. "Flying is the best thing in the world. We had a party every single Saturday. God. I'm telling you, we had parties. I flew all day. At night, I would invite Annie out to the base, and then we would party." Dancing to a jukebox at the Oak Club with other pilots and their wives was "a ball!" The photo albums he kept in his old age are filled with reminders of his war and Navy Reserve adventures, his friends, and family. Showing off one photo, Cole said, "That's a priceless, perfect picture. See the planes coming back, and they're all spread out? They didn't have far to go, they just took off, and within 15 minutes they were fighting. To me it's priceless."

He loves woodworking, miniature trains, and music boxes. "After the war I got into these crazy music boxes, and boy that was really fun. We had a club, and other people made them like I did, and we traded them and had meetings." Annie and he collected over one-hundred music boxes. They enjoyed traveling internationally with MBS, the Musical Box Society. They vacationed yearly in Florida and bought an additional house there after they retired.

After sixty-four years of marriage, Annie died, and Cole began living in Florida all year. His daughter "worked like hell" to disband and sell the Michigan house. Cole did not participate in the process. Later, Cole's children became concerned about his memory. They asked him to move closer to one of his sons, Barry, who could visit him 
daily. Cole moved into a one-bedroom condominium down the street from his son. Sparsely furnished, he decorated it to his liking. Magazine advertisements with photographs of dogs are taped on the walls, along with an advertisement for stiletto heels modeled by a woman's long leg. At the insistence of Barry, Cole added framed family photographs to his everyday life display.

A balsa wood model airplane hangs from the ceiling. Across from his chair is a poster of fighter planes. On the floor is his tool chest, his most prized possession because he still wants "to build stuff, to keep stuff repaired." After his move, reassembling the train track through the village scene proved too much for Cole, and he became frustrated. The set is packed away, but a miniature house reminds him that the train set still exists. One of his music boxes sits in the middle of the room on an occasional table. His photo and music albums are on the bookcase across the room, and Cole's book of poetry lies on the table next to his chair. When Cole sits in the chair, his dog is always at his feet. 


\section{Table 5}

Cole's Objects Identified in Narrative

\begin{tabular}{lll} 
ITEM \# & TYPE & OWNERSHIP \\
\hline 1 & phonograph & Cole-young adult onward \\
2 & photo albums & Cole-throughout life \\
3 & model air planes & Cole- high school onward \\
4 & framed photos & Cole-young adult onward \\
5 & books & Cole- high school onward \\
6 & train set houses & Cole-young adult onward \\
7 & tools & Cole-young adult onward \\
8 & sewing machine & Cole's wife-retirement \\
9 & DustBuster & Cole-retirement \\
10 & music boxes & Cole and his wife- midlife onward \\
11 & school pennant \& pins & Cole- high school \\
13 & travel bag & Cole-young adult onward \\
12 & Cole-young adult onward
\end{tabular}




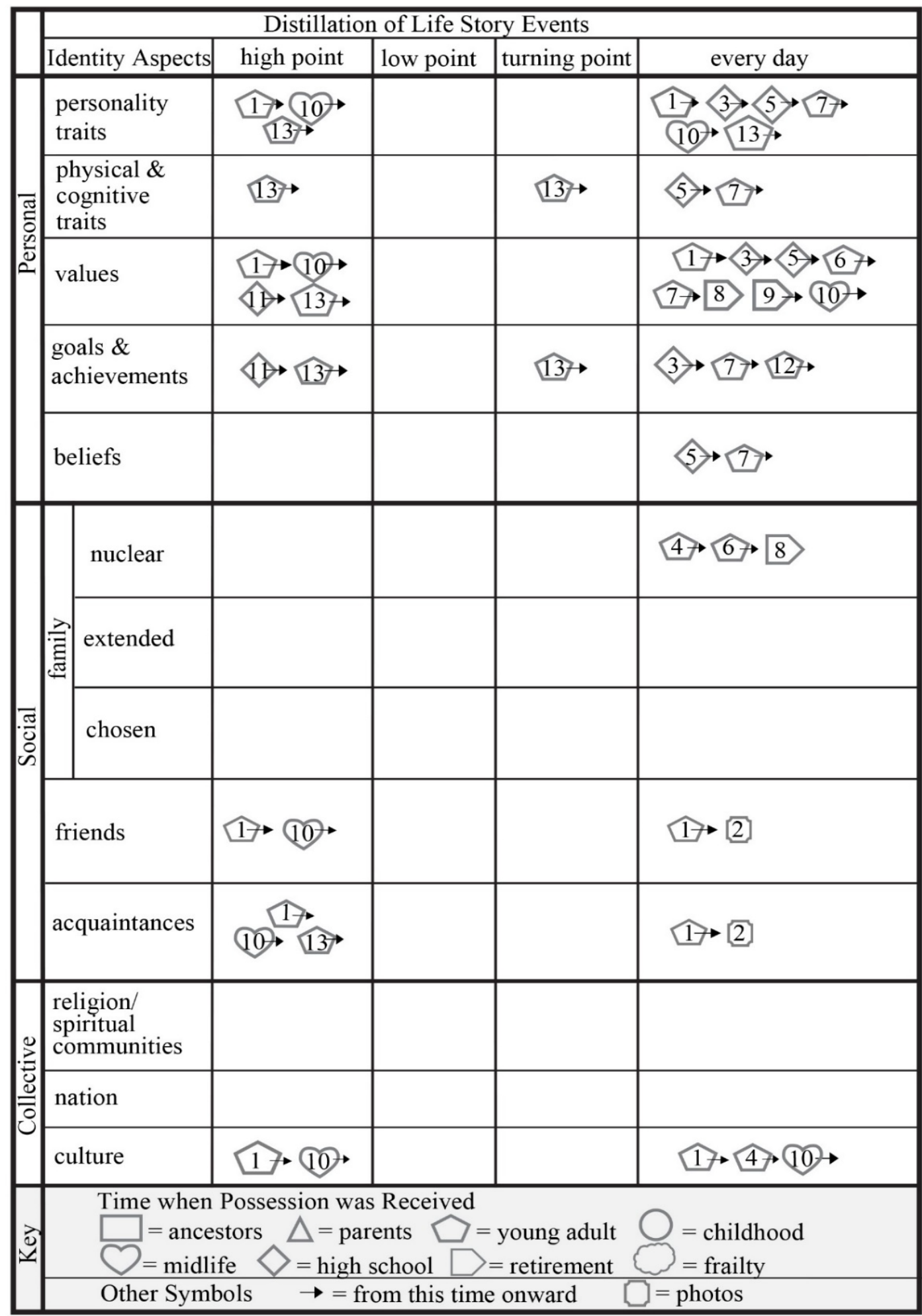

Figure 9. Cole's Life Story Possession Analysis (LSPA \#2). 

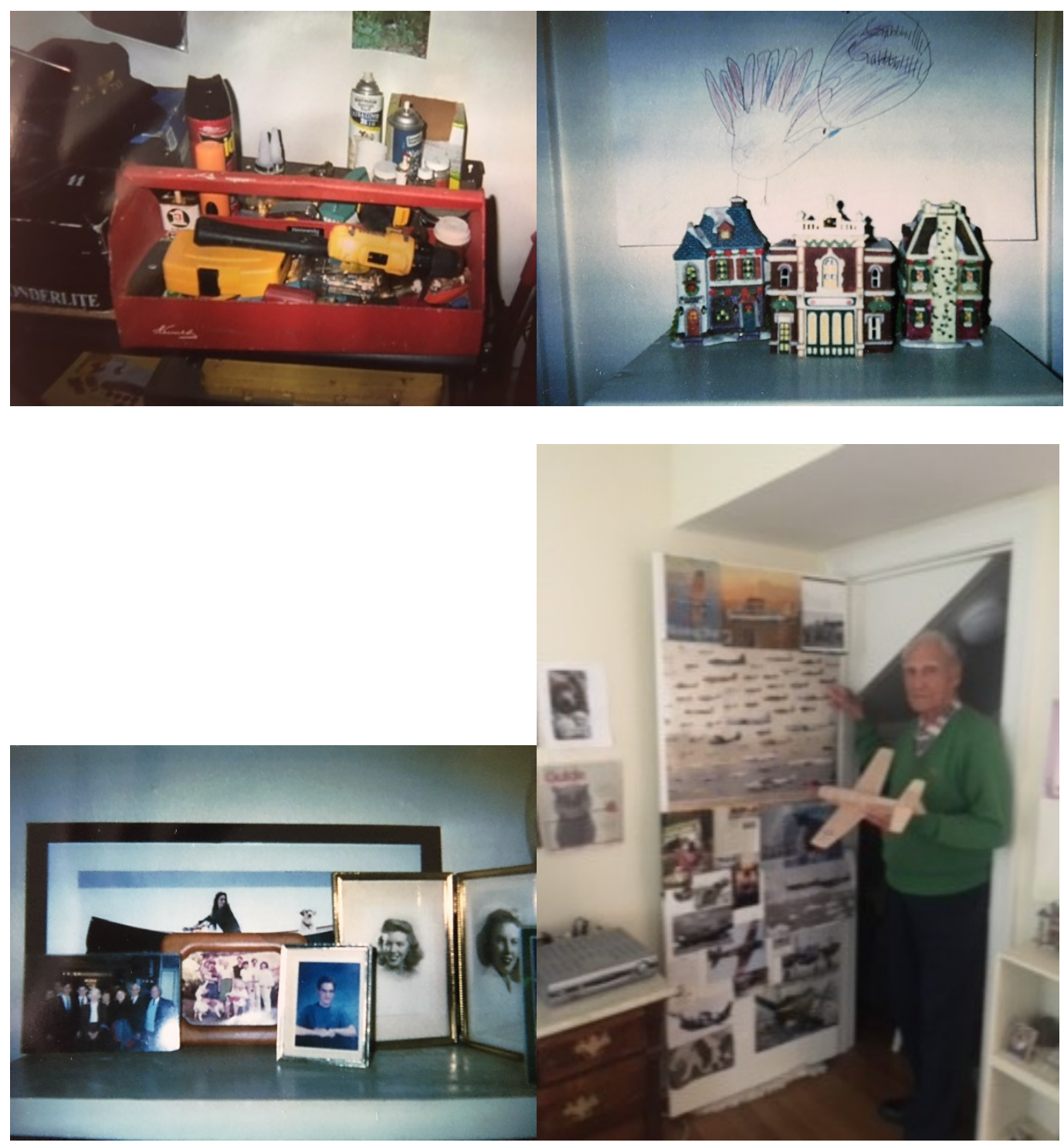

Figure 10. Photographs of Cole's storied possessions: upper left—-toolbox; upper right— ceramic houses from electric train village with children's drawing; lower left-framed family photographs; lower right — airplane poster \& balsa wood airplane model.

Identity meanings, related in life span stories, embedded in the possessions

Cole moved to his new residence. There are four themes of meaning embedded in the 
possessions Cole and his son moved to his condominium: 1) work is life, 2) remembering the fun and glory, 3) family and friends, and 4) living routines.

Work is life. Cole's most precious possession is his tool box. The effect of the Great Depression on his childhood is a constant reminder that the ability and possession of work brings life. He kept belongings that would allow him to maintain his place and his belongings. Hand tools, such as claw hammers, incorporate stories of work, "I got a big kick out of that. You had to seat a nail on oak flooring, seating it - the first blow seats it - and then you had to pound the hell out of it."

Remembering the fun and glory. Although he is no longer able to hear the music, Cole kept his phonograph albums and turntable. They incorporate his love of music and embed the stories of Officers' Club dance parties and Detroit teenage roller-skating adventures. Likewise, the village house, from his electric train set, recalls the time when the train set was a constant fixture in his home as well as recalling the fun in assembling things. The airplane poster is embedded with the adrenaline of being a fighter pilot and the glory of flying machines. His balsa wood model planes combine his joy of woodworking and assembling with the joy of flying, and his flying bag incorporates his travels. "I got the flying bag in 1942 and sewed patches on it: Australia, Texas, Bermuda, Belize - a beautiful island. You can smell how musty it is. We swam and snorkeled there."

Family and friends. Cole actively uses his photo albums to remember his life. Each photograph is a story. Many of the black and white images capture events and people that only Cole remembers. No other person is still living who can recall these happenings with him. The photograph has become the happening. This was evidenced 
when I asked him about a specific event during the depression, and Cole responded, "I can't tell you, I don't know... no one can tell you [emphasis mine]. Don't even remember friends, no. I remember we were by a creek, and that's how we washed. You'd go down on the creek, and sit on the rocks, and wash. I remember that." Without the photographs, items that Cole cannot remember no longer exist because no one else can fill in the memory gaps. For Cole, the value of these links to his past life are inestimable, "The [photograph albums] are from the 40s, 50s. They're all—-they're everything. These are priceless, priceless." Cole's music box is imbued with the gatherings his wife and he attended throughout the world with other music box club members.

Living routines. Cole's book of poetry allows him to maintain a routine he established in high school and which provided mental grounding during his time as a fighter pilot. His tools and sewing machine allow him to continue creating even without his workshop. Speaking about the sewing machine, Cole's son said, "When he got here, he wanted to sew things. He would look for stuff to do, so he would patch a towel, sew his pants, things like that." Cole did not have possessions with low point meanings in his life. Many of his possessions embedded meanings from more than one of the life story event themes. For instance, the airplane poster, around which he created a vignette, had meanings of pinnacle events (successfully surviving air battles), readjustment points (becoming the squadron leader), and everyday engagements (a consistent interest in the mechanical assembly and performance of specific planes). 
Household Case Study \#2: Elaine. Elaine moved from a senior independent living (SIL) apartment to an assisted living (AL) studio apartment. It was her third downsizing move (DSM) as seen in Table 6. Below is Elaine's life story.

Table 6

Elaine's Profile

\begin{tabular}{|c|c|c|c|c|c|c|c|c|c|c|}
\hline $\begin{array}{l}\text { Nom } \\
\text { de } \\
\text { Plume }\end{array}$ & YOB & Age & MS & $\begin{array}{l}\text { Prior } \\
\text { Years }\end{array}$ & $\begin{array}{c}\text { Prior } \\
\text { Sq. } \\
\text { Ft. }\end{array}$ & $\begin{array}{l}\text { Prior } \\
\text { Type }\end{array}$ & $\begin{array}{l}\text { Current } \\
\text { Sq. Ft. }\end{array}$ & $\begin{array}{r}\text { Current } \\
\text { Type }\end{array}$ & DSM & $\mathrm{P} \#$ \\
\hline Elaine & 1923 & 94 & W & 1 & 1,135 & SIL & 375 & $\mathrm{AL}$ & 3 & 9 \\
\hline
\end{tabular}

Elaine was born in a small, Midwestern college town. As a child, she loved cats and had an affinity for music. She sang and practiced the piano diligently. Unlike other children, this passion did not fade when she graduated from high school. It was a constant in her life, as was the admiration for her father embodied in her hope chest. He made it for her by hand, investing both his time and money.

After high school, Elaine's love of music went with her to college where she received a degree in voice and music. It was there she met Jeff, a veteran of WWII. They married and had four children in close proximity. Elaine gave up her dreams of a music career to teach high school. She collected small, porcelain pianos, though, and continued playing on her own piano and organ throughout her life. Jeff worked in the automobile industry, and they relocated to four different states as he moved up the corporate ladder. The hope chest always came with them. Elaine was never able to indulge her desire for a pet cat, as Jeff had forbidden them. He hated the smell. However, as a gesture of love from one cat lover to another, a friend of Elaine's gave her a life-size one of the porcelain variety. 
Their moves stopped when they decided their children needed to stay in the same high school and church congregation. Family and church were very important to them. Their family entertained often, participated in sports, played bridge and card games, sang around the campfire, and told stories. After retirement, Elaine and Jeff took cruises and traveled to all 50 states. They had 17 grandchildren and 14 great-grandchildren.

Elaine and Jeff were original participants in my pilot study. At that time, they were disbanding their patio-house to relocate into a senior living apartment due to Jeff's failing health. Although they knew they needed to relocate, they did not do so until their children forced the issue. Jeff was unhappy, but the children felt trapped between wanting independence for their parents and knowing Elaine was concerned about remaining in the patio-house. She often broke down and cried when talking with her daughter-in-law. During disbandment, they gave away or sold most of their things. Finding a new place for the beloved organ and piano was particularly difficult. No one wanted them anymore. Neither were in vogue, and floor space was not available. This disappointed Elaine, but Jeff and she maintained that they weren't really attached to material things. Elaine made sure to hang on to the hope chest, though, forgoing a washer and dryer in order to have a space for the chest. The porcelain cat came as well.

Less than a year after they moved, Jeff died, age 92. They had been married for seventy-years. After disbanding her household to the bare essentials, Elaine moved once again into an assisted living studio closer to one of her children. It was an emotionally wrenching and ultimately debilitating move.

Elaine's daughter-in-law, Tori, gave me the remaining information through a telephone interview. Tori and Elaine's son, Preston, were experiencing their own health 
crisis the year Jeff died. Tori's had surgery for metastasized cancer. She went into a coma and came close to dying. Additionally, a different one of Elaine's sons moved out-ofstate to be closer to his children. This left only Preston to assume Elaine's ongoing care. After Jeff's death, Elaine was very vocal about wanting to live with Preston and Tori, but Tori was unable to take that responsibility. Preston took Elaine to five different assisted living facilities before she chose one, but she was very angry about not being able to live with them. She said she could not believe she had three children and none of them would take her in.

During the senior living apartment disbandment, Elaine sat in a chair while her family members brought her items to decide upon. Her most prized possession, her hope chest, went to her granddaughter. Tori thought she was in denial through most of the disbandment process.

During the first disbandment, Elaine told me photographs and photo albums were important to her because they represented family and friends. They'd lost a son to cancer, and his photographs reminded her how much she missed him every day. She and Jeff had kept photographs and a few paintings given to them by friends to take to their senior living apartment. However, after moving into her studio apartment, Elaine did not personalize her space. She routinely asked her children how long she had to stay there. Preston, in an effort to convince her that the studio apartment was now her home, brought a hammer and nails and hung the family photographs, the paintings, and a clock from her alma mater.

When I visited, I noticed the lift chair Elaine had proudly showed me in an earlier disbandment. It had been moved to the studio with another chair, a dresser, and a desk 
chair. She had a new twin bed because her larger bed did not fit. Her children were frustrated with the tight space; it made visiting awkward. They had wanted her to get a one-bedroom apartment, but true to her values, Elaine did not want to spend the extra money. The porcelain cat, however, moved with her and occupied a spot next to her bed. 
Table 7

Elaine's Objects Identified in Narrative

\begin{tabular}{lll} 
Item \# & Type & Ownership \\
\hline 1 & photographs & $\begin{array}{l}\text { Elaine-children and } \\
\text { grandchildren }\end{array}$ \\
2 & paintings & Elaine from midlife \\
3 & porcelain cat & Elaine from midlife \\
4 & alma mater clock & Elaine from young adult \\
5 & calendar & Elaine current \\
6 & desk chair & Elaine from midlife \\
7 & lift-chair & $\begin{array}{l}\text { Elaine-recent purchase to replace } \\
\text { previous }\end{array}$ \\
8 & dresser & Elaine from midlife \\
9 & twin bed & Elaine new for assisted living
\end{tabular}




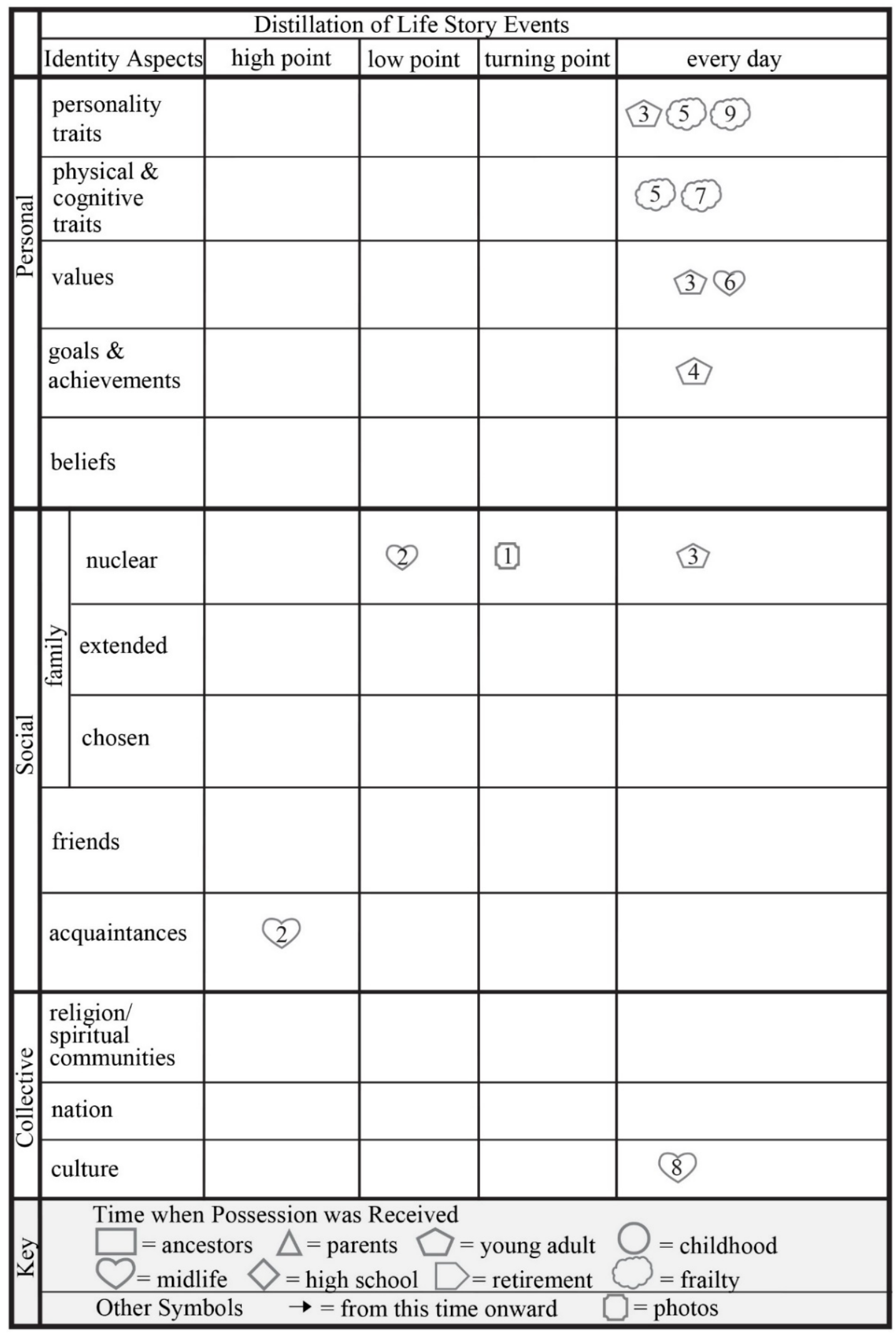

Figure 11. Elaine's Life Story Possession Analysis (LSPA \#2). 

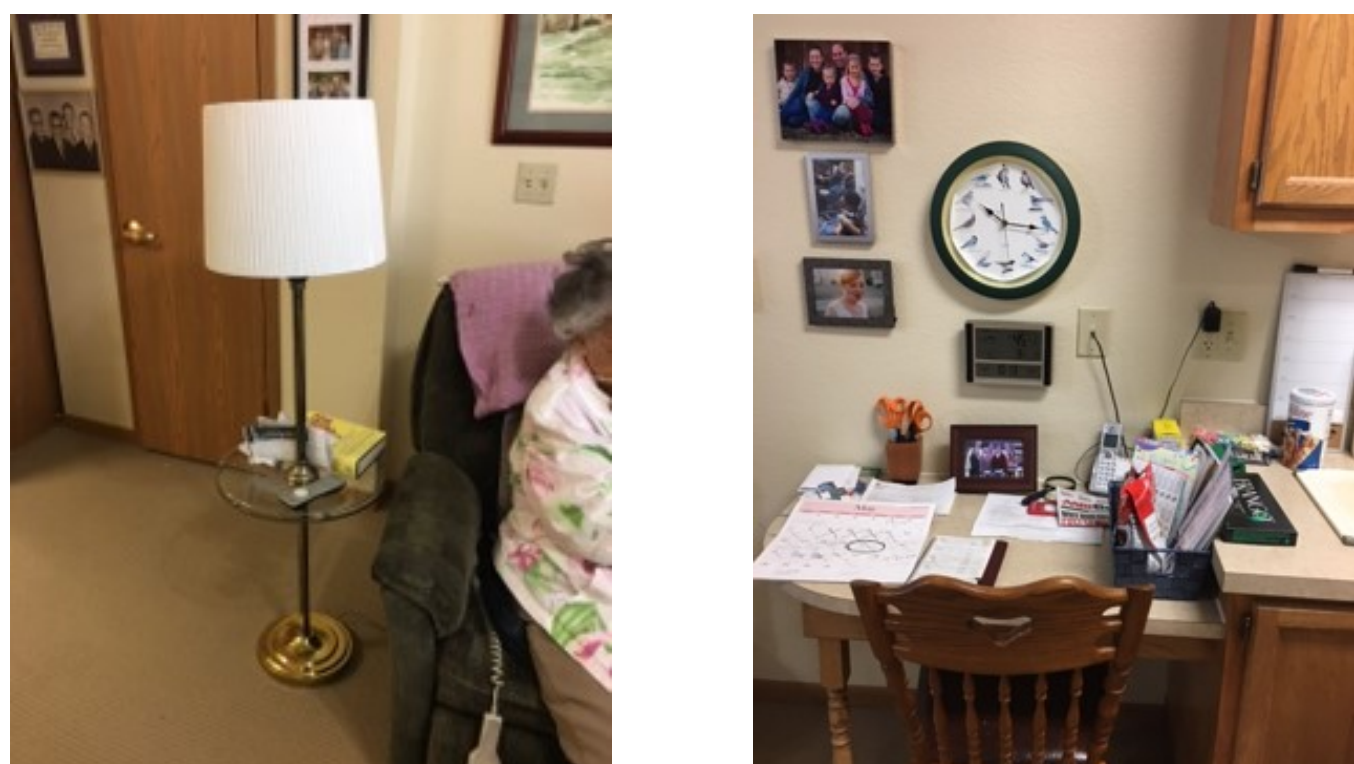

Figure 12. Photographs of Elaine's storied possessions: left—family photographs, painting, chair; right—-desk chair, clock, calendar.

Identity meanings, related in life span stories, embedded in the possessions

Elaine moved to her new residence. I only identified one theme of meaning embedded in Elaine's remaining possessions. Perhaps this is because the move to assisted living was a turning point for Elaine. She and Jeff had previously maintained that they were not really attached to material things, but at this point in her life she turned away from the comfort of embedded meaning in her possessions.

Resisting rejection. The first time I interviewed Elaine, her husband was still living, and we discussed their first disbandment experience for my pilot study. There was a marked change with the second disbandment after Jeff's death. The theme of meaning associated with the subsequent disbandment was resisting rejection. Elaine's resistance was demonstrated by her refusal to personalize her space with family photographs and paintings from her previous residences. Feeling rejected by her family, she resisted attempts to create a sense of home. She routinely asked her children how long she had to stay in assisted living. Elaine's anger was not abated by her oldest son's effort to 
personalize the studio apartment by hanging the photographs, paintings, and a clock. Her possessions fall into the representations of adjustment theme because they are placed in an environment that is a permanent change in her life direction, exemplified in her statement, "I don't miss my stuff. I miss my life."At the time of Elaine's first disbandment, she told me her photographs were one of her most precious possessions because they represented family. During our second disbandment interview, however, she discussed one of the only decorative objects in the room: the life-sized porcelain cat her friend made years ago. She was pleased with the way she had gotten around her late husband's no-cats mandate saying, "So, I have a cat that doesn't have a smell." The cat became a storied possession of her resistance to others trying to make home for her. While I was writing up my findings, Elaine's health declined further. She died shortly after entering hospice care. The end of Elaine's life with her possessions reflects suggestions by Rapoport (2005), as mentioned in Chapter Two, that our home range expands over the life course, begins shrinking with old age, and becomes very limited frailty. 
Household Case Study \#3: George and Tillie. George and Tillie moved from living independently in a single-family house (SFH-I) to an assisted living (AL) onebedroom apartment. It was their first downsizing move (DSM) as seen in Table 8. Below is George and Tillie's life story.

Table 8

George and Tillie's Profile

\begin{tabular}{lrrrrrrrrrr}
\hline $\begin{array}{l}\text { Nom de } \\
\text { Plume }\end{array}$ & YOB & Age & MS & $\begin{array}{r}\text { Prior } \\
\text { Years }\end{array}$ & $\begin{array}{c}\text { Prior } \\
\text { Sq. } \\
\text { Ft. }\end{array}$ & $\begin{array}{c}\text { Prior } \\
\text { Type }\end{array}$ & $\begin{array}{c}\text { Current } \\
\text { Sq. Ft. }\end{array}$ & $\begin{array}{r}\text { Current } \\
\text { Type }\end{array}$ & $\begin{array}{r}\text { DS } \\
\text { P\# }\end{array}$ \\
\hline George+ + & 1925 & 91 & M & 30 & 3,500 & SFH-I & 584 & AL & 1 & 22 \\
Tillie & 1940 & 77 & M & 30 & 3,500 & SFH-I & 584 & AL & 1 & 22 \\
\hline
\end{tabular}

Tillie grew up in the farmhouse her grandparents built it in 1903 and in which her eight brothers and sisters were born. With the help of her nine children, Tillie's mother maintained a half-acre garden, canning enough vegetables to feed their family through the winter. There were three metal stars on the exterior of the house. Tillie was grieved, years later, when their farmhouse was destroyed in a fire. A newspaper article about the fire was framed in a shadowbox with one of the metal stars from the house. The stoneware crock that Tillie, her grandmother, and mother used to make sauerkraut and pickles was in the apartment living room. In addition to cooking and baking, Tillie's mother taught her daughters to sew. Tillie kept a quilt that her mother, aunt, and sisters blocked, embroidered, and appliqued as well as her own high school sewing box.

After high school, Tillie taught school, had three children, and divorced her first husband of twenty-five years. She moved with furniture, household items, and 
memorabilia several times before she met George. They married after meeting while working at the phone company, and she moved the stuff into their house.

Twelve years older than Tillie, George, an only child, was born during the Great Depression and moved from one apartment to another. He did not have his own room until he was sixteen years old. George's father managed grocery stores. At one of them, he had a candlestick phone on his desk. His friends also had candlestick phones in their houses. George's favorite possessions were two candlestick phones that he adapted for landline use. Their grandchildren enjoyed using them to call friends.

After high school, George served in the Navy for ten years. Later he worked for the telephone company. He lost his first wife to polio, leaving him a single father of two very young children. One day, before his wife contracted polio, his three-year-old son asked if he could have one of the neighbors' new kittens. Although she said no, she was surprised later when she reached into the cookie jar and touched a kitten. Startled, she threw the cookie jar lid, and it broke in two. George kept it. Years later, Tillie and he repaired the lid, which had a large ceramic apple on it, and gave the cookie jar to his son as a gift. George also kept his mother's Franciscan Apple stoneware boxed in the basement. After Tillie discovered it, she insisted they use the stoneware. Throughout their marriage they enjoyed collecting additional pieces together.

After getting married, they sold their individual houses to buy one house. It was very plain and located on land outside of town. Until their household disbandment, neither George nor Tillie systematically culled their belongings. They were comfortable amidst their meaningful clutter. 
While George was in the hospital, Tillie had an auction with the help of their children. Disbandment was a traumatic experience, and the things they kept were very important to them. Tillie rented a one-bedroom apartment and moved what furniture would fit. In hindsight, she and George would have rather had two bedrooms. They feel crowded in the seven-hundred square feet, but they also have storage in the facility's basement where they put Christmas decorations. A daughter, Lori, and granddaughter helped arrange photographs and objects on the walls of the apartment. There is a photograph of George's 90th birthday with all their family. They also have a framed photograph of the Navy carrier George served on. The photograph had been in the auction, but Tillie's little brother, who was also in the Navy, rescued it. He framed and gave it to George knowing he would want to keep it.

George and Tillie still listen to CDs. George enjoys Glenn Miller and big band music. Although he has some of his favorite books, including a dictionary and Bible, George misses his extensive collection. Tillie feels badly about the Franciscan Apple stoneware collection she sold, but she kept eight place-settings and serving pieces and the oak dining room table, four chairs, and china hutch, along with her heavy aluminum cookware. Years ago, she burned the food she cooked in other pans. The aluminum was tried and true.

Although George had many beautiful clocks, they only kept an oak grandfather clock—a Christmas present from Tillie many years before. A handmade stained-glass window, a wedding present from a friend, hands on the wall. Tillie has antique glassware, cookie cutters in old fruitcake tins, and old jars above the kitchen cupboards. They have a large Planters Peanuts nut bowl set that included small individual bowls. They use them 
when they play bridge with other couples. Torrie's son made the small oak cabinet with a lower shelf that they hung on the kitchen wall and in which they store coffee and tea.

George and Tillie's previous king-sized furniture would not fit in their new bedroom, so they kept his parent's queen-sized suite. A daughter used family photographs to create a three-dimensional star that hung on the bedroom wall; Tillie is thinking about moving it into the living room, so more people will see it. A family tree was created with photographs that were taken during Tillie's parents fiftieth wedding anniversary celebration.

George considers the apartment home, although he does not "like" it. However, in accordance with the pragmatic life understanding revealed in our interviews, he finds some good; he enjoys the view out the apartment's window. 
Table 9

George and Tillie's Objects Identified in Narrative

\begin{tabular}{|c|c|c|}
\hline Item \# & Type & Ownership \\
\hline 1 & oak hutch, dining table, \& chairs & Tillie-midlife \\
\hline 2 & Franciscan Apple dishes & George's mother onward \\
\hline 3 & Rollator carts & George \& Tillie_frailty \\
\hline 4 & 90th birthday family photo & George-frailty \\
\hline 5 & grandfather clock & George \& Tillie—midlife \\
\hline 6 & candle stick phones (2) & George's father onward \\
\hline 7 & framed photo of navy airline carrier & George-young adult \\
\hline 8 & lift-chairs (2) & George \& Tillie-retirement \\
\hline 9 & George Miller CDs & George-young adult onward \\
\hline 10 & Planters Peanut collection & George \& Tillie-midlife on \\
\hline 11 & sunflower objects collection & Tillie-midlife on \\
\hline 12 & bedroom furniture & George's parents \\
\hline 13 & photographic family tree & Tillie_parents onward \\
\hline 14 & photo in beautiful frame & George's mother \\
\hline 15 & yellow and gray bedding & Tillie-frailty \\
\hline 16 & photo of previous old house & George \& Tillie-midlife on \\
\hline 17 & shell object collection & George \& Tillie-midlife on \\
\hline 18 & artifacts from Tillie's ancestral home & Tillie's grandparents onward \\
\hline 19 & Tillie's mother's vanity dresser set & Tillie's mother \\
\hline 20 & sewing box & Tillie_-high school \\
\hline 21 & Christmas decorations & Tillie \& George — midlife on \\
\hline 22 & handcrafted quilt & Tillie's extended family \\
\hline
\end{tabular}




\begin{tabular}{|c|c|c|c|c|c|}
\hline & \multicolumn{5}{|c|}{ Distillation of Life Story Events } \\
\hline & Identity Aspects & high point & low point & turning point & every day \\
\hline & $\begin{array}{l}\text { personality } \\
\text { traits }\end{array}$ & & & & $9 \rightarrow$ \\
\hline ช్ & \begin{tabular}{|l} 
physical \& \\
cognitive \\
traits \\
\end{tabular} & & 7 & & 3 \\
\hline 2 & values & $2 .(5)(17)$ & (16) & & $\begin{array}{c}112 \rightarrow 10 \rightarrow 11 \\
17 \rightarrow\end{array}$ \\
\hline & $\begin{array}{l}\text { goals \& } \\
\text { achievements }\end{array}$ & 4. & (16) & & \\
\hline & beliefs & & & & \\
\hline \multirow{5}{*}{ 管 } & nuclear & (5) & & & \\
\hline & extended & 13.1922 & & $18 \rightarrow$ & (6) 121 \\
\hline & chosen & & & & \\
\hline & friends & & & & (6) \\
\hline & acquaintances & & & & \\
\hline \multirow{3}{*}{ 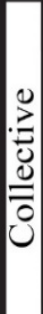 } & $\begin{array}{l}\text { religion/ } \\
\text { spiritual } \\
\text { communities }\end{array}$ & & & & \\
\hline & nation & & & & \\
\hline & culture & (21) & & & $9 \rightarrow$ \\
\hline \multirow[t]{2}{*}{ 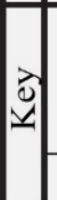 } & $\begin{array}{l}\text { Time when } \\
\begin{array}{|l}\square=\text { ances } \\
Y=\text { midli }\end{array}\end{array}$ & $\begin{array}{l}\text { Possession w } \\
\text { stors } \Delta=\text { p } \\
\text { fe } \Delta=\text { high }\end{array}$ & $\begin{array}{l}\text { s Received } \\
\text { cents } \square= \\
\text { school } \square=\end{array}$ & $\begin{array}{l}\text { young adult } \\
\text { retirement }\end{array}$ & $\begin{aligned} & =\text { childhood } \\
& =\text { frailty }\end{aligned}$ \\
\hline & Other Symb & $\rightarrow=$ & om this tim & onward & $=$ photos \\
\hline
\end{tabular}

Figure 13. George and Tillie's Life Story Possession Analysis (LSPA \#3). 

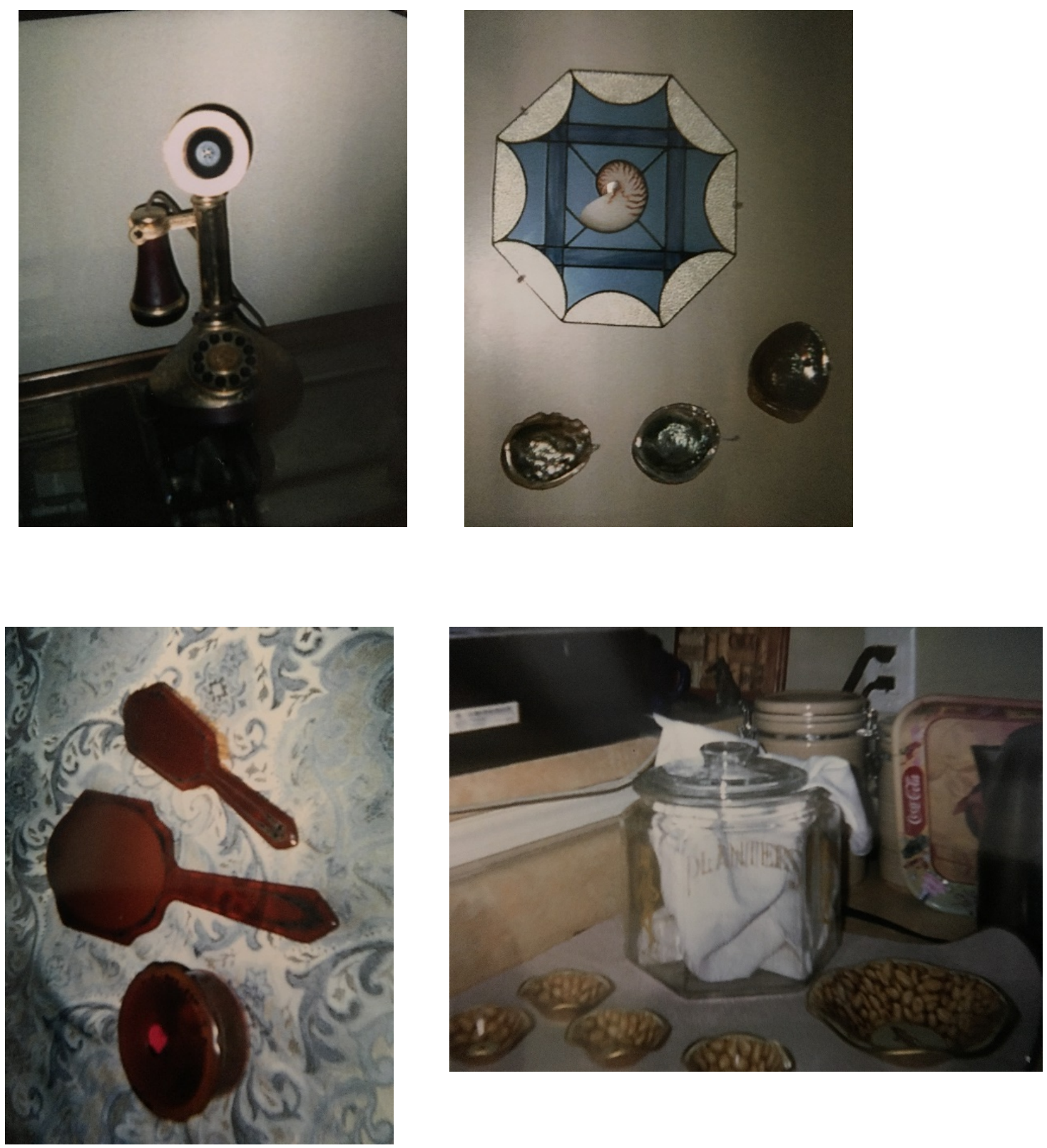

Figure 14. Photographs of George \& Tillie's storied possessions: upper left—candlestick phone; upper right—stained glass \& sea shells; lower left—mother's vanity dresser set; lower right—Planters cookie jar and nut bowls. 


\section{Identity meanings, related in life span stories, embedded in the possessions}

George and Tillie moved to their new residence. There are four themes of meaning embedded in the possessions George and Tillie moved to their new one-bedroom senior apartment in assisted living: 1) expandable, 2) collectors, 3) organization is less important than abundance, and 4) active and adaptable.

Expandable. Tillie grew up in a large rural family and has three children. George grew up as an only child and has five children. George and Tillie are people who expand themselves to take in people and things. The statement "less is more" has no relevance for them. They spent their life together adding more possessions to what they already loved and thought beautiful. Beauty for them was magnified through quantity. When family members passed away, George and Tillie took in their possessions. They expanded the footprint of their house to incorporate antiques from relatives. Disbandment was traumatic for them. Even though they auctioned most of their items, the items remaining fill the new apartment to overflowing. Expandable, as an identity, is embedded in the gestalt of possessions. Downsizing their possessions was a health-related requirement rather than a turning point in their lives.

Collectors. One of the ways Tillie and George expanded their possessions was through collecting, an activity they enjoyed doing together over many years. They traveled looking for antiques and began collections of many different types of items. The identity of collector is embedded in many of their possessions. Collections are nested in collections. Above kitchen cabinets is a tin container collection. Inside one of the tins are Mr. Peanut nut cups. Inside another is a collection of cookie cutters. George and Tillie are 
no longer able to travel and purchase items. By keeping smaller collections, they are able to keep the identity of collector, an area of companionship throughout their marriage.

Organization is less important than abundance. George and Tillie do not live in abject disorganization, but they have more items than they have access to storage. Horizontal surfaces are covered, and prized possessions are stacked one on top of the other. George does not like the clutter, but both he and Tillie prefer to live in disorganization than give away possessions.

Active and adaptable. Music and activity still matter to George and Tillie. His Glen Miller collection is within easy reach of his chair. Lift chairs help them to stand making movement less painful. They bought a new car after their auction which allows them to put their Rollators in the back seat. They can continue grocery shopping with the walker-cart combination. Although they are able to entertain using their Franciscan apple china collection and dining table, they generally go to the dining hall. The ability to entertain is more important that entertaining. 
Household Case Study \#4: Lance and Monica. Lance and Monica moved from living independently in a single-family house (SFH-I) to an assisted living (SIL) twobedroom apartment. It was their first downsizing move (DSM) as seen in Table 10. Below is Lance and Monica's life story.

Table 10

Lance and Monica's Profile

\begin{tabular}{lrrrrrrrrrr}
\hline $\begin{array}{l}\text { Nom } \\
\text { de } \\
\text { Plume }\end{array}$ & YOB & Age & MS & $\begin{array}{r}\text { Prior } \\
\text { Years }\end{array}$ & $\begin{array}{c}\text { Pq. } \\
\text { Ft. }\end{array}$ & $\begin{array}{l}\text { Prior } \\
\text { Type }\end{array}$ & $\begin{array}{c}\text { Current } \\
\text { Sq. Ft. }\end{array}$ & $\begin{array}{r}\text { Current } \\
\text { Type }\end{array}$ & $\begin{array}{c}\text { M } \\
\text { P\# }\end{array}$ \\
\hline Lance+ & 1928 & 91 & M & 22 & 1,800 & SFH-I & 980 & SIL & 1 & 28 \\
Monica & 1930 & 87 & M & 22 & 1,800 & SFH-I & 980 & SIL & 1 & 28 \\
\hline
\end{tabular}

Lance's father was a cowboy born on a ranch. During the Great Depression, he got a job in the post office. He didn't get paid much, but he got paid weekly. Lance's mother was a school teacher. When they decided to marry in 1925, Lance's father picked up his mother on a Friday after school, and they went to the blacksmith's. The blacksmith was a Baptist preacher, and he married them in the car. Lance's father said it was the first drive-in wedding. His parents had four boys and a girl. They stayed in Texas, where Lance was born and raised.

Lance first started out in law, but after a while, he and his family decided that law school was not for him, and he went into ministry. Lance met Monica on a Greyhound Bus coming back from a student conference.

Monica's grandfather came out west on a covered wagon. She still has his rocking chair as seen in Figure 16. Both her parents grew up on ranches. Her father became a pharmacist then a pharmaceutical sales representative. He was hearing impaired, and 
Monica's mother had ongoing anxiety about his ability to hear trains when he traveled. During her childhood, Monica and other children could ride the bus to town and go to the movies without worry. After high school, Monica looked at several colleges, but her mother wanted her to go to a local college in case something happened to her father.

Monica studied journalism, and when she was a junior, she went to work for the Dallas Times Herald. She and Lance married after she graduated in September of 1951. Lance became a college minister, and Monica, embracing the social attitude of the time, chose not to continue in her career after she had children.

At Lance's second appointment, during Senator Joe McCarthy's interrogation of suspected communists, Lance was asked by the school to sign a loyalty oath. He conscientiously wrote a letter saying he would sign the loyalty oath, but it was illegal and improper. Deciding he couldn't do the same the following year, they moved to a third campus appointment after friends helped create a job for him. He became a Bible teacher and Director of Student Activities. Those friends remained dear and valued. After four years, they moved northeast for Lance's graduate degree, a very different environment from their southwestern roots. Their third son was born the year it snowed 88 inches. It was a difficult and financially lean time. They thought it was heaven to move back to the southwest after a year in the harsh weather. Eventually, Lance got an appointment at their alma mater, and he served as campus minister until his retirement.

When Lance and Monica started encountering age-related physical declines, they decided to move. They wanted to make the change before they had to stop driving or were no longer able to communicate with others, something they had seen happen to their parents. They used senior move managers who suggested what furniture would fit in the 
new residence they had selected, and Lance and Monica told them what they most wanted to keep. An estate saleswoman sold their remaining possessions.

Lance and Monica believe they have everything they need, but she misses the little things. Somewhere in the move her mother's and grandmother's wedding rings were lost. So was a small vase that her aunt and given her. It had been a wedding present of her grandmother's. It was just a little thing, but she feels its loss. Still, Monica knows she has plenty of souvenirs. The things that family or friends gave Lance and Monica are most valuable to them. Photographs of friends and family are displayed. Their beloved books fill their bookcases. Even more photographs and books are stored in their closets.

The only big mistake Monica and Lance believe they made concerns a couch. The senior move managers told them their old one would not fit-what they meant was it would not fit with their understanding of what the room ought to look like. They replaced it with a smaller one, but after they moved, Monica and Lance realized there would have been physical space. It would have been tight but that would not have mattered. Having a comfortable place to nap in the living room would have been better.

Their apartment feels like home mostly. Their phone is important. It gives them a digital printout of the conversation, so they know what is being said. It helps Monica stay in communication with others. They regret there is no place for children and friends to sleep when they come to visit, but that does not happen very often. Lance and Monica believe the place would not be as good without their things; but they do not think it would be too bad. Monica likes to think that she could adapt to it, but she likes having her things. If none of them were there, it would be strange; but she thinks they could make it. 
Table 11

Lance \& Monica's Objects Identified in Narrative

Item \# Type Ownership

\begin{tabular}{|c|c|c|}
\hline 1 & $\begin{array}{l}\text { drawing by Lance's mother of } \\
\text { family farm \& clock }\end{array}$ & Lance's mother \\
\hline 2 & curio cabinet for figurine collection & Monica - young adult on \\
\hline 3 & $\begin{array}{l}\text { technology -TV, DVD players, } \\
\text { radio, tape player }\end{array}$ & Lance \& Monica retirement \\
\hline 4 & family photographs & Lance \& Monica childhood on \\
\hline 5 & $\begin{array}{l}\text { quilt made by Lance's sister after } \\
\text { 50th anniversary }\end{array}$ & Lance \& Monica retirement \\
\hline 6 & alma mater symbol crest & important to Lance \& Monica \\
\hline 7 & rocking chair from prominent ranch & Monica's grandfather's \\
\hline 8 & painting by long term colleague & Lance \& Monica midlife \\
\hline 9 & $\begin{array}{l}\text { numbered print illustration "Bronc } \\
\text { for Breakfast" bought by Monica at } \\
\text { Charlie Russell's museum }\end{array}$ & Lance - midlife \\
\hline 10 & collection of figurines & Monica - young adult \\
\hline 11 & $\begin{array}{l}2 \text { paintings from Alaska where } \\
\text { relatives live }\end{array}$ & Lance \& Monica retirement \\
\hline 12 & inherited table & Monica's parents \\
\hline
\end{tabular}


13

14

16

17

18

19 molas hand-stitched by women of small Caribbean island

4
bookcase with books copy of alma mater bronze bench

plaque dedicated with tree to Lance

for his work

6

$$
\text { file \& map case }
$$

Japanese statue - owned by

sociology teacher friend with whom

Lance played tennis; family gave

him statue when she died.

desk brought from Kentucky by

covered wagon in 1875 by Lance's

great-grandfather

lamp from prominent ranch -

formerly coal oil - converted to

electric

plates - contributions from both

sides of the family

plaque- awarded to Lance when a

Peace \& Justice Fellowship was

established
Lance \& Monica midlife

Lance \& Monica childhood on

Lance retirement

Lance \& Monica midlife

Lance midlife

Lance great-grandfather

Monica's grandfather's

Lance \& Monica ancestors

Lance midlife 
needle-points done by German

great-grandmother

23

24

26

27 cedar chest

tennis bag

chest of drawers made by Monica's

father

pantry

closet/pantry: Lance's tool chest,

books, Monica's tote bags, 5

elephant book ends, slow-cooker,

etc.

Monica's wedding photo above
Monica ancestor

Lance's grandmother

Lance played

Monica parent

known as the place the china cabinet

almost fit!

Lance \& Monica - retirement

Monica-young adult 


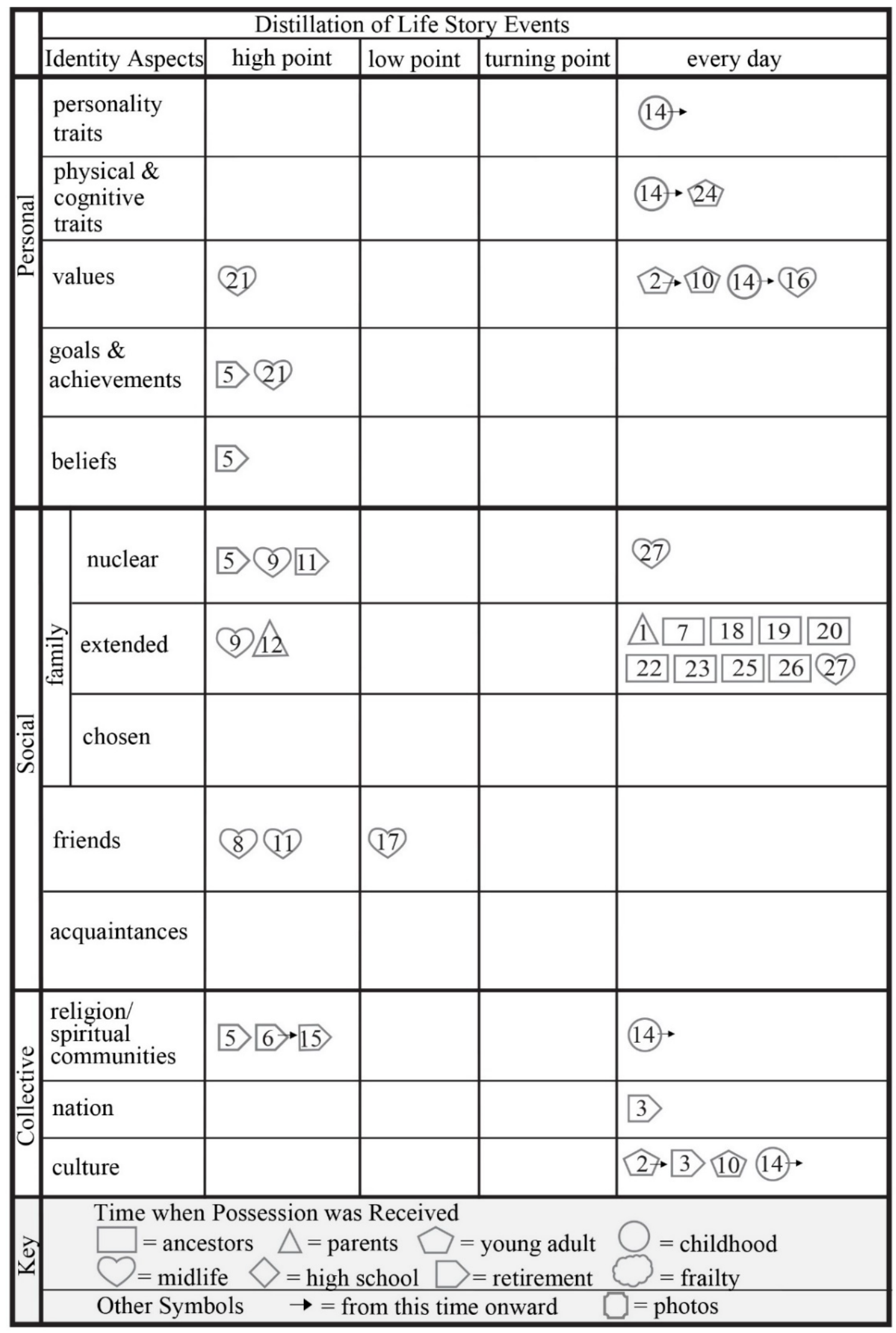

Figure 15. Lance and Monica's Life Story Possession Analysis (LSPA \#4). 

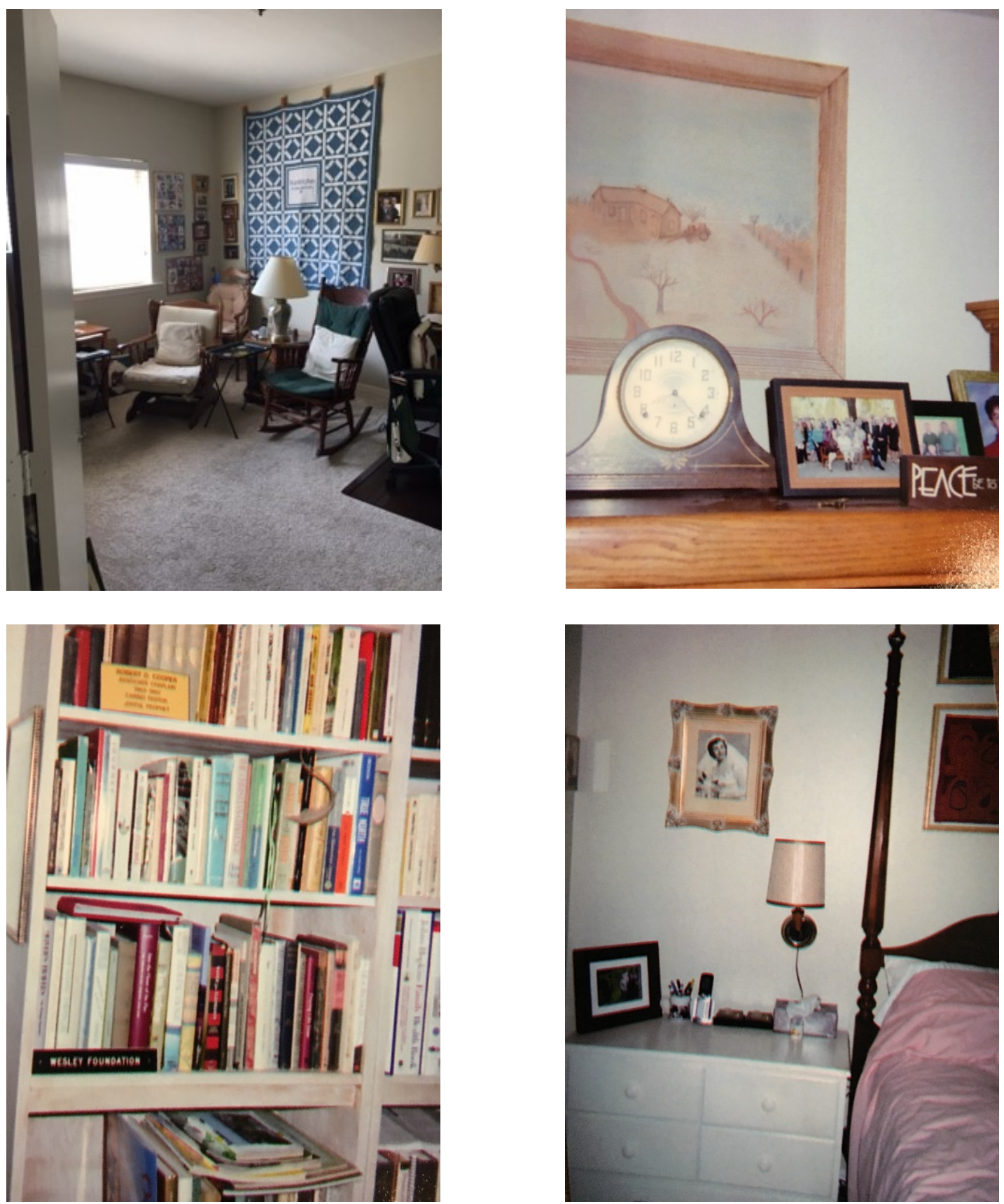

Figure 16. Photographs of Lance \& Monica's storied possessions: upper left—second bedroom with quilt, rocker, family photographs; upper right—-farm clock, mother's farm drawing, family photographs; lower left—book shelf with books \& plaques; lower right— wedding portrait, chest of drawers made by father. 


\section{Identity meanings, related in life span stories, embedded in the possessions}

Lance and Monica moved to their new residence. There are four themes of meaning embedded in the possessions Lance and Monica moved to their new two-bedroom apartment in the senior living facility of a continuing care retirement community: 1) relationships matter, 2) family matters, and 3) books matter.

Relationships matter. Lance and Monica embedded layered meanings into possessions that demonstrate investment of time and energy in relationships with people throughout their ministry career. These meanings support gendered social mores. Monica invested in raising their children and supporting Lance's ministry. He received the accolades that are represented by possessions. Together they spent time with other people which is demonstrated in prized life-long relationships and gifts given to them by these people. These gifts are both signs and symbols of their investments. Monica's support is demonstrated by the fiftieth anniversary quilt, which is Lance's most prized possession. The current acquisition of the phone that enables Monica to communicate better demonstrates Lance's support of Monica and their relationships.

Family matters. Generous displays of photographs surrounding the fiftieth anniversary quilt create a sign meaning that family matters to Lance and Monica. Throughout their apartment are other photographs. Fine and folk art also demonstrate embedded family meanings that extend the mortality of parents, grandparents, and great grandparents.

Books matter. Reading is a shared activity between the couple. Although they sorted and gave away books, the apartment has large spaces donated to the books they 
kept including books secreted away in their closet because they do not fit in the bookcases. 
Household Case Study \#5: Fern. Fern moved from a senior independent living (SIL) apartment into a bedroom in her daughter and son-in-law's single-family house (SFH-AC). It was her third downsizing move (DSM) as seen in Table 12. Below is Fern's life story.

Table 12

Fern's Profile

\begin{tabular}{|c|c|c|c|c|c|c|c|c|c|c|}
\hline $\begin{array}{l}\text { Nom } \\
\text { de } \\
\text { Plume }\end{array}$ & YOB & Age & MS & $\begin{array}{l}\text { Prior } \\
\text { Years }\end{array}$ & $\begin{array}{c}\text { Prior } \\
\text { Sq. } \\
\text { Ft. }\end{array}$ & $\begin{array}{l}\text { Prior } \\
\text { Type }\end{array}$ & $\begin{array}{l}\text { Current } \\
\text { Sq. Ft. }\end{array}$ & $\begin{array}{r}\text { Current } \\
\text { Type }\end{array}$ & $\begin{array}{c}\mathrm{D} \\
\mathrm{S} \\
\mathrm{M}\end{array}$ & $\mathrm{P} \#$ \\
\hline Fern & 1927 & 90 & W & 12 & 1,000 & SIL & $\begin{array}{r}114 \text { of } \\
3,200\end{array}$ & $\mathrm{SFH}-\mathrm{AC}$ & 3 & 14 \\
\hline
\end{tabular}

Carrying her slight 4'6" frame with grace and dignity gives Fern a Yoda-like appeal. Her daughter said she sometimes gets cranky, and when bored she worries, but that is not her public persona. As part of her ninetieth birthday celebration, Fern sang "I Got You Babe" at a karaoke bar with a female impersonator, "Cher." Fern's clothes are upbeat and stylish. Her hair is coiffed, and her nails manicured and pedicured.

Born just before the Great Depression, Fern was the fourth of five siblings. Her oldest brother and sister are still living. His brother calls Fern and her sister weekly. Fern has photographs of her siblings that are precious to her. When she looks at the pictures of their young family, she acknowledges they didn't have much, “But we didn’t know. I was too young, and I didn't know we were poor." Their mother died when Fern was four.

Their father, JW, told the older children to take care of the younger ones, which they did.

When Fern was twelve, the Depression had fully engulfed the US. Her father fell ill. He asked her older brother, then 18 , to find families to adopt the two youngest children. Fern was adopted by a family who could provide her with a good education. 
The adoptive family did not care for her in the way her family of origin expected. Her adoptive father was a pedophile. After high school, Fern attended college classes, dated, and knit socks for boyfriends. She met a man named Simon through a mutual friend. Simon, six years her senior, was career military. When he found out about her living situation, he wanted to get married, so they did. Fern has no possessions from her adoptive family because of the unhappiness associated with them. She considers herself "pretty darn lucky" to have a family of origin that helped her to be strong during this time.

Simon and Fern traveled with the military for thirty-one years. He was an Army pilot. After they retired from the military, Simon taught at a university, and she worked for the city. "We loved our small town and took part in everything." They built a house and finally had their own place to display the items they collected on their world travels. They became very involved with their religious community, even hosting a world-famous leader at their dining room table as they worked together to help others around the world. Fern worked for the city for ten years. When she retired, the city had "Fern Day" in appreciation for all her work.

Simon and Fern continued traveling for pleasure. They often went to air shows to watch planes with their daughter, Leah, and their son-in-law, Joel. They stopped traveling when Simon was diagnosed with terminal cancer. While having chemotherapy, he became depressed and decided he was too tired to continue the treatments. Fern refers to their marriage as good while acknowledging that she and Simon were not perfect people. Fern says that she learned to view love as unconditional. "When I look at a picture of him, I could never, never remarry. Never." 
A couple of years ago, Fern began to spiral downward emotionally and physically. She was in pain. "I was getting depressed, losing my friends, and I knew I couldn't help them." Leah and Joel, who live in a nearby town, suggested she sell the house and move in with them. As their house was already fully furnished, it meant that Fern needed to get rid of most of her belongings. She made a choice to sell the house and virtually everything in it to a single woman who Fern believed was in need and worthy.

The walls in Fern's new bedroom are covered with items from her life with Simon. She has two chairs. In the morning she knits quietly by herself and enjoys a cup of coffee. Her wedding ketubah is directly across from her chair. Simon's photograph is on her bedroom table. At the foot of her bed is another chair next to a TV and DVD player. She uses this area of her room to exercise along with a DVD. At the head of her bed are framed fans given to Simon and her when he taught in Taiwan. There are paintings on another wall. The artist is Sammy Davis, Jr.'s wife. The paintings originally belonged to Fern's sister-in-law who was a friend of the artist.

Throughout the rest of the house are framed illustrations and photographs of different planes in flight; some of them were flown both by Simon and Joel when they were in the Army. On the fireplace mantel is a menorah Simon and Fern bought in Israel. Fern's candelabras are in the dining room so that she can do her Friday night blessings and holidays. She also has all the pieces for Passover Seder. Leah and Fern mingle their cookbooks and photographs. Leah has a business office in the house, and Fern has a computer and desk opposite to Leah's. Fern communicates with friends and family using Facebook and email. 
Fern enjoys her life with Leah and Joel. 'I'm very, very happy. I really am.” Fern travels with Joel and Leah, and she contributes to Leah's business with knitted scarves for Leah's clients. "I knit in the car." When I suggest that may be the secret to aging well, Fern responds, "I'm having a ball!" 
Table 13

Fern's Objects Identified in Narrative

Item \# Type Ownership

photographs

Fern-childhood on

2

computer

Fern-frailty

3

Original fine art

Fern—midlife

4

photograph of her beloved late-

Fern—midlife

husband

5

richly ornamented ketubah

Fern-young adult

6

bedroom chairs

Fern-frailty

chair (living room)

daughter purchased for Fern - frailty

8

chair (master bedroom)

daughter purchased for Fern-frailty

9

cookbooks

Fern-young adult on

two closets filled with clothes

Fern-frailty

11

DVD player

Fern-frailty

12

prints of aircraft

daughter, son-in-law young adult on

13

Shabbat candelabras

Fern-midlife on

14

knick-knacks

Fern— - gifts from friends, midlife on 


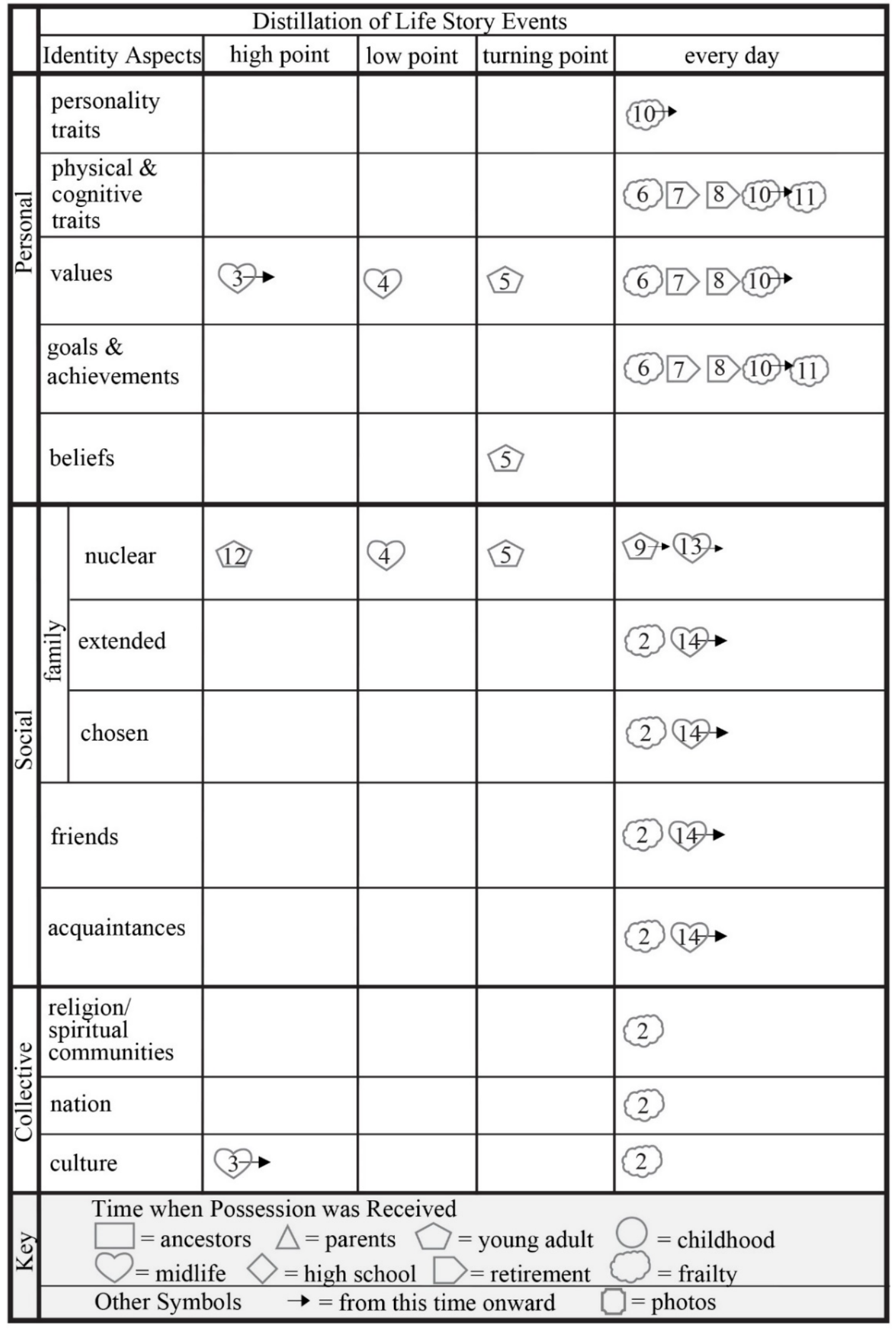

Figure 17. Fern Life Story Possession Analysis (LSPA \#5). 

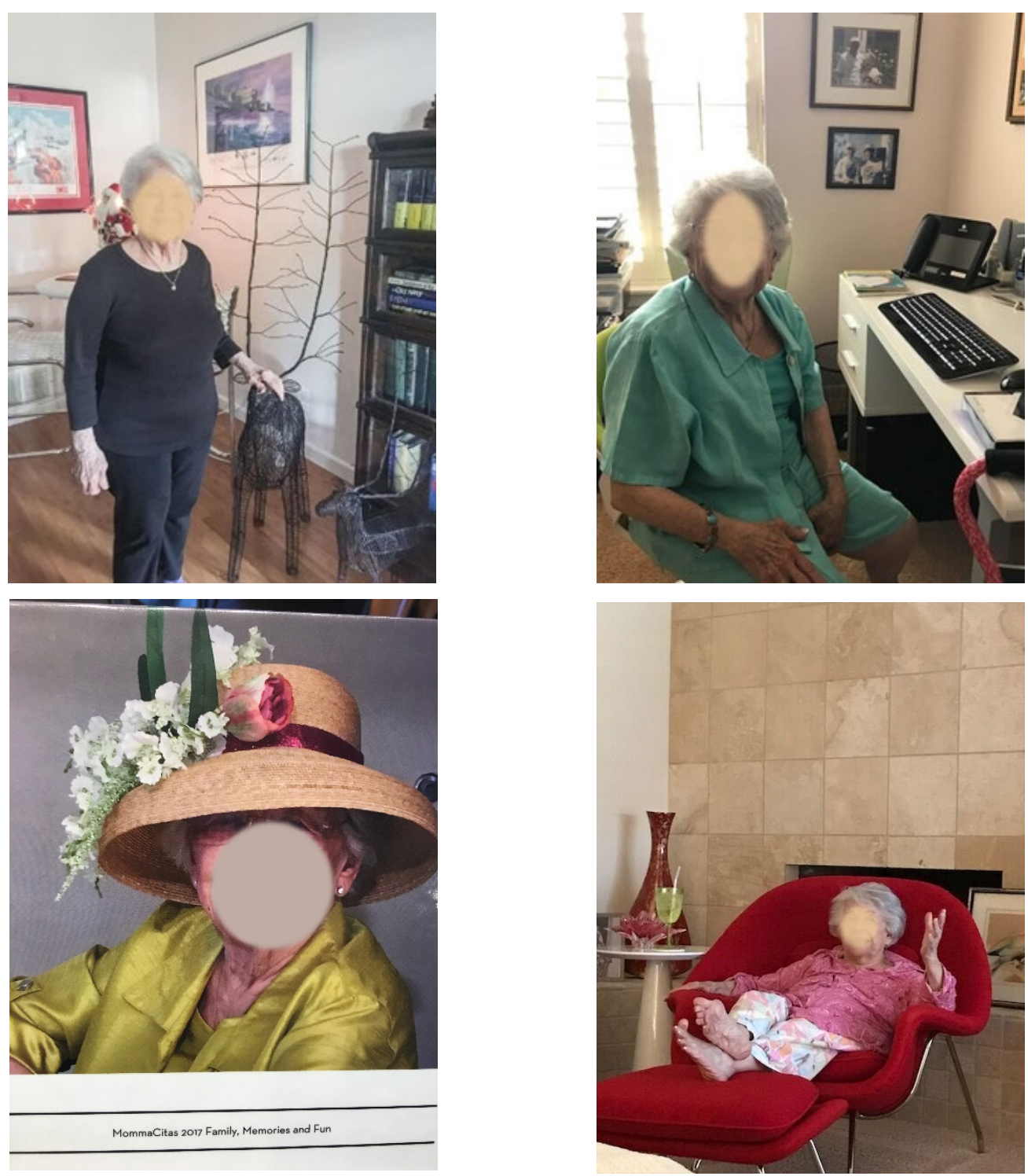

Figure 18. Photographs of Fern's storied possessions: upper left—illustrations of WWII aircraft $\&$ bookcase; upper right — computer, desk, \& family photographs; lower left $-90^{\text {th }}$ birthday celebration book; lower right — womb chair \& ottoman, WWII aircraft illustration.

Identity meanings, related in life span stories, embedded in the possessions

Fern moved to her new residence. There are three themes of meaning embedded in the 
possessions Fern moved into her daughter and son-in-law's house: 1) engages the present, 2) remembers the past, and 3) erases baggage.

Engages the present. Fern's decision to engage with every new day is demonstrated in the photographs she keeps of her karaoke performances with Cher, her two red chairs positioned throughout the house so that she can be participate fully with her family, and her computer desk arrangement that allows her to communicate with friends and family at the same time her daughter is conducting business. The womb chairs as a modern element have sign meanings that she is stylish and contemporary. Her knitting and exercise chairs demonstrate she is active.

Remembers the past. Fern's photographs of her late-husband and late-sons extend their mortality, help her remember them, and are embedded with the meaning that she sacrificially loved one man and was the mother of sons. This meaning is echoed in her ketubah. Photographs of her family of origin contain meanings of overcoming extreme grief and surviving. Small knickknacks and fine art are also embedded with meanings of family members and friends who are no longer living but whose relationships were important to her.

Erases baggage The absence of any possessions from her adopted family demonstrate her intentionality to remove emotional baggage from her life. 
Household Case Study \#6: Bridgette and Leon. Bridgette and Leon moved from living independently in a single-family house (SFH-I) a two-bedroom senior apartment facility (SA). It was their first downsizing move (DSM) as seen in Table 14. Below is Bridgette and Leon's life story.

Table 14

Bridgette and Leon's Profile

\begin{tabular}{|c|c|c|c|c|c|c|c|c|c|c|}
\hline \multicolumn{11}{|c|}{ Prior } \\
\hline $\begin{array}{l}\text { Nom de } \\
\text { Plume }\end{array}$ & YOB & Age & $\mathrm{MS}$ & $\begin{array}{r}\text { Prior } \\
\text { Years } \\
\end{array}$ & $\begin{array}{l}\text { Sq. } \\
\text { Ft. }\end{array}$ & $\begin{array}{l}\text { Prior } \\
\text { Type }\end{array}$ & $\begin{array}{l}\text { Current } \\
\text { Sq. Ft. }\end{array}$ & $\begin{array}{r}\text { Current } \\
\text { Type }\end{array}$ & $\begin{array}{r}\mathrm{DS} \\
\mathrm{M} \\
\end{array}$ & $\mathrm{P \#}$ \\
\hline Bridgette+ & 1932 & 85 & M & 40 & 1,000 & SFH-I & 957 & SA & 1 & 22 \\
\hline Leon & 1934 & 83 & M & 40 & 1,000 & SFH-I & 957 & SA & 1 & 22 \\
\hline
\end{tabular}

Bridgette's father was a trucker, something she is proud of. She has a photograph of her father and other truck drivers standing by a group of trucks lined up in an arc. As a child she loved roller-skating and met Leon at a neighborhood roller skating rink after she graduated from high school.

She was a legal secretary, and Leon was enrolled in college after having served four years in the Navy. They married and went to Niagara Falls for their honeymoon and came back to live in an apartment above a garage. Leon had a friend, Tom, who noticed Bridgette could not reach the upper cabinets in the apartment, and he built a stool that she still treasures. It never had a loose screw, and their children carried it around the house and brushed their teeth on it. She thinks of Tom every time she uses it.

After college, Leon became a mechanic like his father. He also remained in the Navy Reserve for twenty-six years. Their marriage was fruitful. They had one daughter and three sons, but while they were in the disbandment process, their middle-son died in 
a motorcycle accident. Their grief delayed Leon and Bridgette's move, and they still attend a grief support group in their current senior apartment facility.

I arrived at their two-bedroom apartment for their interview during the holidays; a wreath with miniature hand crocheted Santa socks decorated the entry door. Children's Christmas books lined the breakfast bar. A Christmas tree was decorated with ornaments, and a baseball batting Santa figurine displayed. The figurine is special because Leon gave it to Bridgette. The nativity set was out. Of the twenty-five they owned, it is the only one they kept. Bridgette explained it is called a pencil set because the figures are tall and weird looking - the uniqueness has value to them.

Leon's bedroom is larger than Bridgette's and has a larger attached bathroom. The smaller bedroom, however, had the larger closet Bridgette wanted. She gave away clothes to get the things she wanted to fit in the closet. She put a chest-of-drawers from her bedroom suite into it, along with a child's table and chair that she said was so ugly it was cute. She kept puzzles, paper dolls, balls, jacks, and crayons in her closet. The toys were gifts from Leon or their children. Although she wanted some of them for their greatgrandchildren, Bridgette, herself, enjoys coloring and doing puzzles. She and other residents recently put together a two thousand piece Gone with the Wind puzzle on a table outside their apartment.

Bridgette keeps her favorite books in her bedroom bookcase. On the wall is a frame with photographs of Bridgette at four and Leon at three. They lost most of their photographs in a basement flood years ago. Bridgette made albums with the surviving photos for children and grandchildren. She has a small pencil collection and a chair that 
Leon traded a Volkswagen pickup truck to get. Bridgette named her bed and their couch as two of her most prized possessions.

Leon said he had fun creating his library by putting his bookcase in his bathroom. His books had notable themes: the sinking of the Indianapolis, aviation-related World War II, Henry Ford, The Spirit of St Louis with Lindbergh, and Volkswagen cars. A book Bridgette gave to Leon in 1967 is one of his favorites.

Once, when Leon and Bridgette were in Arizona babysitting their grandchildren, they went to a PTA carnival, and Leon paid a dollar to have a caricature of them drawn on butcher paper. He had it framed, and it is now on their bedroom wall. On an old City Hall table sits a curio cabinet filled with small engines Leon made from scrap metal, Blue Angel Navy wings, and Lions Club pins. His dresser top holds Bridgette's baby sister's bronzed shoe; she died from whooping cough before she was two-years-old. Their late son's cinerary urn is next to it, along with a photograph of him with his baby brother. Another photograph of a much younger Bridgette and a clock given them for their 50th wedding anniversary are also present.

In the living room, Bridgette and Leon trade ends on the sofa to watch TV or something from their extensive DVD collection. They share Leon's stool as their foot rest. They have a small kitchen table and chairs from their former house. An umbrella basket from a Longaberger party sits next to the table. Their daughter-in-law bought the basket. Bridgette wryly acknowledged the basket never had a wet umbrella in it.

A storage unit houses out-of-season clothes, handcrafted things made by Bridgette, seasonal decorations, another steam engine built by Leon, and Bridgette's LuRay pottery. 
The day before the interview, Leon and Bridgette were running errands. Bridgette told me, "Yesterday I said, 'When we go home, we need to do so-and-so and so-and-so,' and I thought when we go home, it'll be a different place, but when we go home now, this is where we come." 
Table 15

Bridgette \& Leon's Objects Identified in Narrative

\begin{tabular}{|c|c|c|}
\hline Item \# & Type & Ownership \\
\hline 1 & little stool & Bridgette-young adult \\
\hline 2 & Longaberger umbrella basket & Bridgette-midlife \\
\hline 3 & $\begin{array}{l}\text { children's table and chair a nasty } \\
\text { shade of green }\end{array}$ & Bridgette—midlife \\
\hline 4 & paper dolls \& crayons & Bridgette - midlife on \\
\hline 5 & bureau & Bridgette—midlife \\
\hline 6 & Luray pottery & Bridgette-young adult on \\
\hline 7 & little clock & Bridgette \& Leon—retirement \\
\hline 8 & kitchen bowls & Bridgette-young adult on \\
\hline 9 & baseball batting Santa & Bridgette-retirement \\
\hline 10 & pencil nativity weird looking pieces & Bridgette \& Leon — midlife on \\
\hline 11 & gal drew our caricatures for a dollar & Leon-retirement \\
\hline 12 & little steam engine & Leon-retirement \\
\hline 13 & abacus & Leon—midlife \\
\hline 14 & Blue Angel Navy airplane pins & Leon-young adult on \\
\hline 15 & Lion's Club pins & Leon-midlife one \\
\hline 16 & book collection & Leon—high school on \\
\hline 17 & urn with son's ashes & Bridgette \& Leon—frailty \\
\hline 18 & rectory table & Leon-midlife \\
\hline 19 & photograph of young Bridgette & Leon-young adult \\
\hline
\end{tabular}


photographs of sons

21

bed

ladder back oak chair

22
Leon-midlife

Bridgette-midlife

Bridgette-retirement 


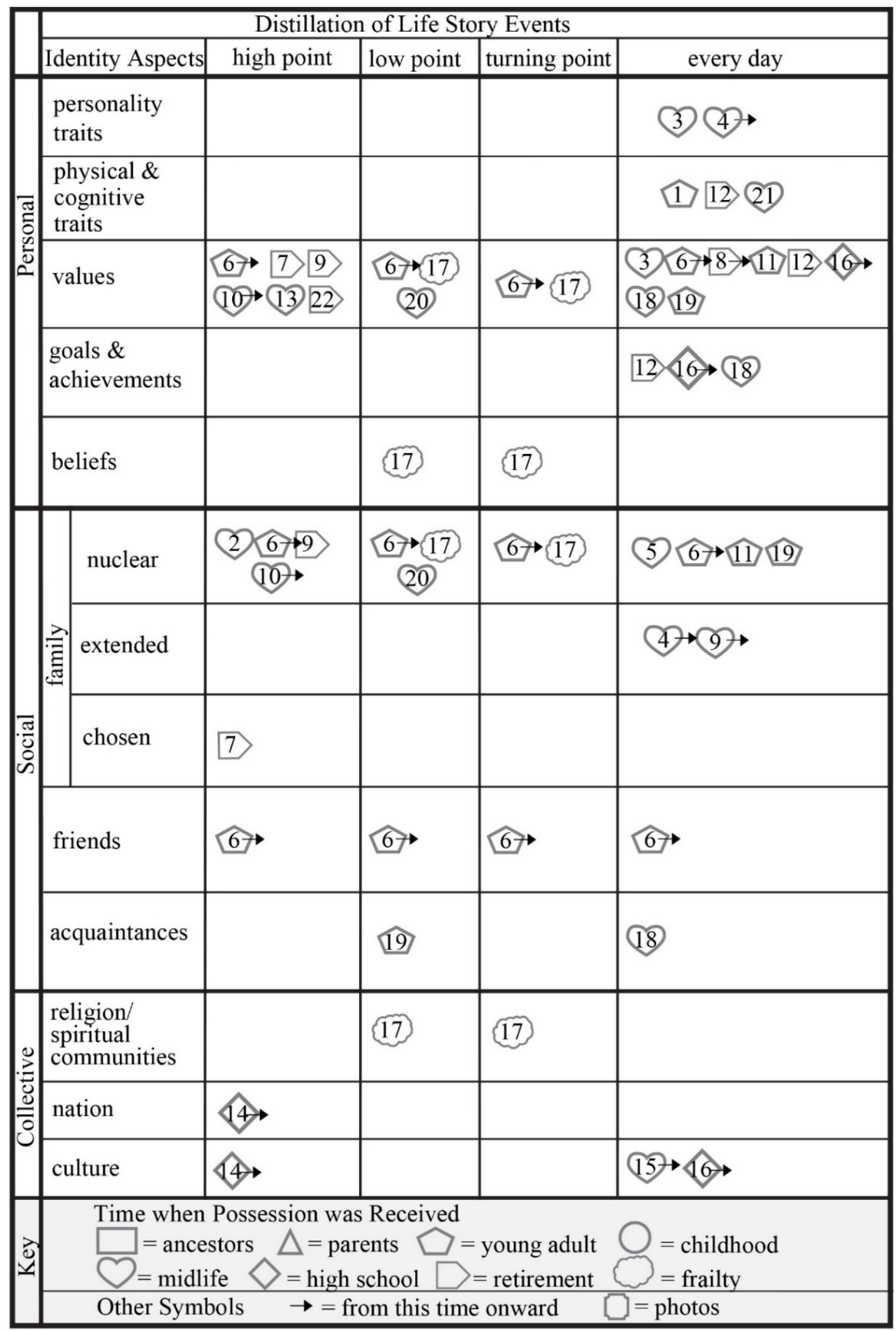

Figure 19. Bridgette and Leon Life Story Possession Analysis (LSPA \#6). 

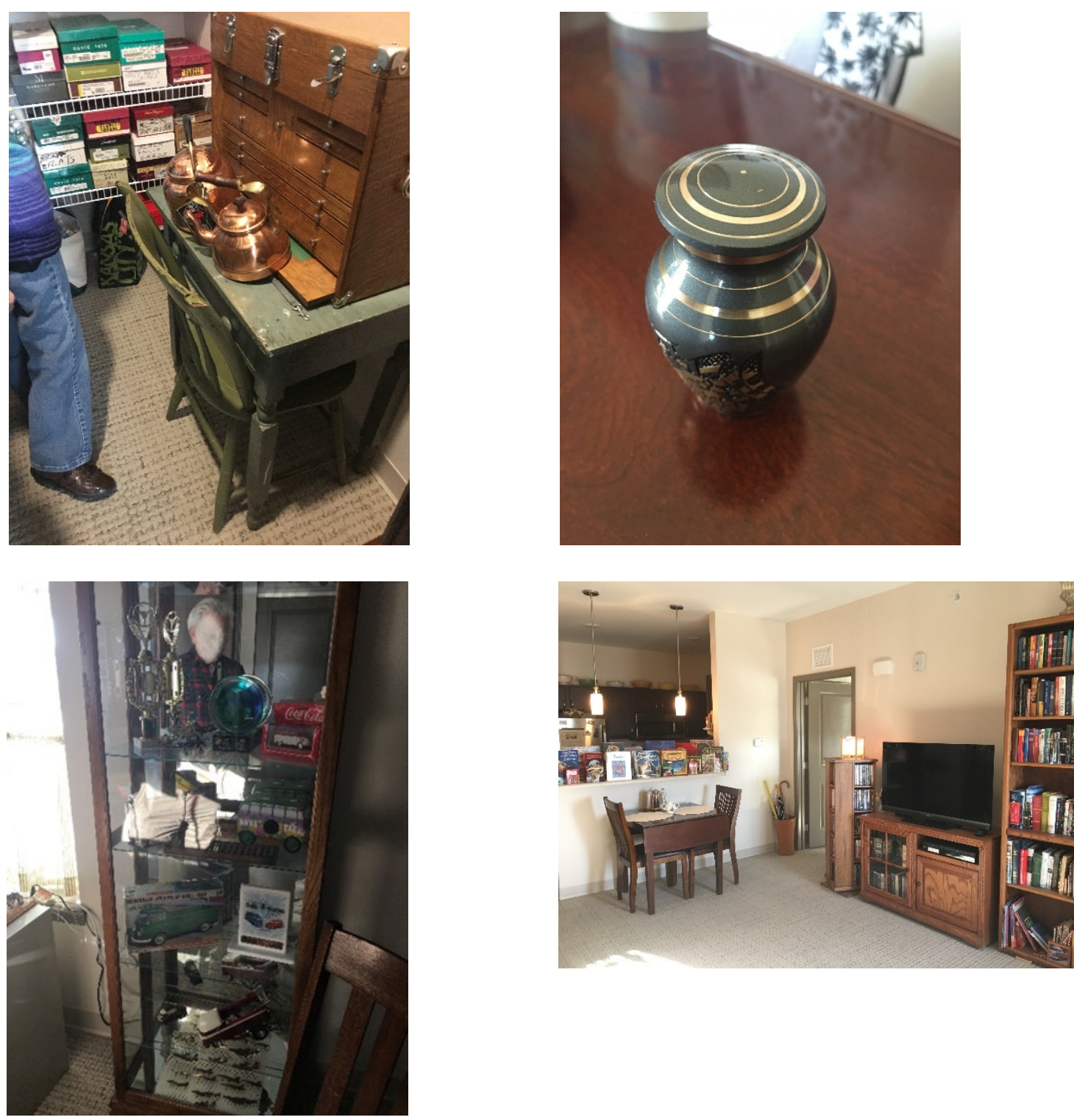

Figure 20. Photographs of Bridgette and Leon's storied possessions: upper left—jewelry box and small green chair and table in closet; upper right—-son's cinerary urn; lower left— Leon's curio cabinet with Lion's and Blue Angel Navy pins; lower right—living room showing books, TV, DVDs, and Longaberger umbrella basket.

Identity meanings, related in life span stories, embedded in the possessions

Bridgette and Leon moved to their new residence. There are three themes of meaning embedded in the possessions Bridgette and Leon moved into their senior apartment: 1) 
woven interests, 2) family, and 3) joy in the unique.

Woven interests. Possessions are embedded with their own personal identities but are woven together throughout their space. The weaving of the possessions creates a gestalt that demonstrates their investment in each other.

Family. Meanings of poignant grief and family unity are embedded in their possessions as seen in photographs, folk art, and décor. Possessions incorporate chosen family.

Joy in unique. Possessions they consider odd or weird are embedded with meanings that embrace the different, unique, and unusual. 
Household Case Study \#7: Grayson. Grayson moved from living independently in a single-family house (SFH-I) to a two-bedroom senior apartment (SA). It was his first downsizing move (DSM) as seen in Table 16. Below is Grayson's life story.

Table 16

Grayson's Profile

\begin{tabular}{|c|c|c|c|c|c|c|c|c|c|c|}
\hline \multicolumn{11}{|c|}{ Prior } \\
\hline $\begin{array}{l}\text { Nom de } \\
\text { Plume }\end{array}$ & YOB & Age & MS & $\begin{array}{l}\text { Prior } \\
\text { Years }\end{array}$ & $\begin{array}{l}\text { Sq. } \\
\text { Ft. }\end{array}$ & $\begin{array}{l}\text { Prior } \\
\text { Type }\end{array}$ & $\begin{array}{l}\text { Current } \\
\text { Sq. Ft. }\end{array}$ & $\begin{array}{r}\text { Current } \\
\text { Type }\end{array}$ & DSM & P\# \\
\hline & & & & & & SFH- & & & & \\
\hline Grayson & 1932 & 85 & W & 43 & 2,000 & I & 957 & SA & 1 & 21 \\
\hline
\end{tabular}

Grayson grew up as a Kansas farm boy. After graduating high school, he flew B47s during the Cold War, in that brief span of time, when the Korean conflict took a nap and Vietnam had not yet fully drawn the attention of the United States. He knew the mass and weight of that war plane.

When I met him, it had been seven years since his wife, Sadie, had died. Grayson's friends, neighbors, and family know his grief was deep, but they thought he was healing. "How does a gutted animal heal," he pondered. But he continued as best he could without his wife. He did not quit.

Today he still serves his college-pledged, national fraternity. He has received their highest award for service, a lead crystal vase etched with their emblem and his name, one of his prized possessions. "I don't mind bragging about it." He is now, in the language of the fraternity, a Silver Gray: an older man who can lead, inspire, correct, and encourage younger men. When he himself was the young man, growing up in hill country with farm boys, it felt natural to pledge a brotherhood built on principles of mutual assistance, intellectual growth, trust, responsible conduct, and integrity. Grayson's beliefs were 
forged in part through this fraternity alliance. He came to fully believe that men were mutually obligated to help others work to achieve higher goals. To do this he devoted time cultivating his mind not just in college but for the rest of his life. He is a voracious reader of science, business, and theology, and fiction. He and Sadie both loved books. Four decades into their marriage, they spent hours together reading the fantastical antics of Harry Potter. They were delighted by his life in Gryffindor, a fraternity-like house in Hogwarts School of Witchcraft and Wizardry.

Unlike Harry Potter, however, Grayson could not craft a spell to get himself out of the grief of living without Sadie. Looking around their house, he knew the home they built was solid. Her heritage, laughter, energy, and artistry filled every crevice. Sadie spent hours laboring over photo albums. He watched in pleasure as she created a needlework honoring his national fraternity role. It embodied their union: her artistry, his endeavors - all stitched together. "It's a beautiful thing. I'm just so pleased to have it."

Neighbors were like extended family at the house he had shared with Sadie for over forty years. He had been a boy scoutmaster at the school where the kids played sports. Even so, they did discuss leaving. Sadie's health and mobility were failing. They knew they could not stay forever. When she died, Grayson knew staying was not what he wanted to do. He needed his own place. "After my wife died, I moved and didn't want to try to duplicate our house. I largely sold everything and started brand-new."

Grayson researched and decided upon a new neighborhood, an apartment complex built for seniors. His daughter assisted as needed, but Grayson remained in control. After giving his children free reign to take what they wanted, he simply left the rest to an estate sale. He took very little. "I brought things that interested me." 
Walking through the house before the sale, he saw alien things dispersed throughout his own. There were stuffed dolls on every shelf in his garage. Just that quickly, it was no longer his house. Instead, the senior community became his Hogwarts, his apartment, Gryffindor. "This is my home-I plan on being here so long as it's acceptable." On moving day, he hung Sadie's fraternity needlework on the wall beside her photograph. 


\section{Table 17}

Grayson's Objects Identified in Narrative

\begin{tabular}{|c|c|c|}
\hline Item \# & Type & Ownership \\
\hline 1 & $\begin{array}{l}\text { Flint Hills of Kansas and recently } \\
\text { bought paintings of the area }\end{array}$ & Grayson - retirement \\
\hline 2 & $\begin{array}{l}\text { post rock and wire fences are } \\
\text { another salute to the area. }\end{array}$ & Grayson - midlife \\
\hline 3 & $\begin{array}{l}\text { needlepointed the fraternity's coat } \\
\text { of arms }\end{array}$ & Grayson from wife - midlife \\
\hline 4 & fraternity award & Grayson - retirement \\
\hline 5 & model of Air Force plane he flew & Grayson - young adult \\
\hline 6 & $\begin{array}{l}\text { photo of my Swedish family (wife's } \\
\text { side) }\end{array}$ & Grayson - young adult \\
\hline 7 & small Scandinavian knickknacks & Wife's - young adult \\
\hline 8 & photo of Grayson & Grayson from wife - midlife \\
\hline 9 & photograph albums & Grayson's wife - midlife on \\
\hline 10 & small bear figurine from Alaska & Grayson - retirement \\
\hline 11 & small Greek pottery & Grayson - midlife \\
\hline 12 & image of Provence, France & Grayson - midlife \\
\hline 13 & mountain photographs & Grayson - retirement \\
\hline 14 & books & Grayson - childhood on \\
\hline 15 & box of cassette tapes & Grayson - midlife on \\
\hline 16 & Santa figures crafted by friends & Grayson - midlife \\
\hline
\end{tabular}


17 desk Grayson - midlife

18 small figurine of favorite dog, Grayson - retirement

Rufus, a Corgi

19 computer Grayson

20 large wooden chest Grayson - childhood

21 bedroom furniture Grayson - childhood 


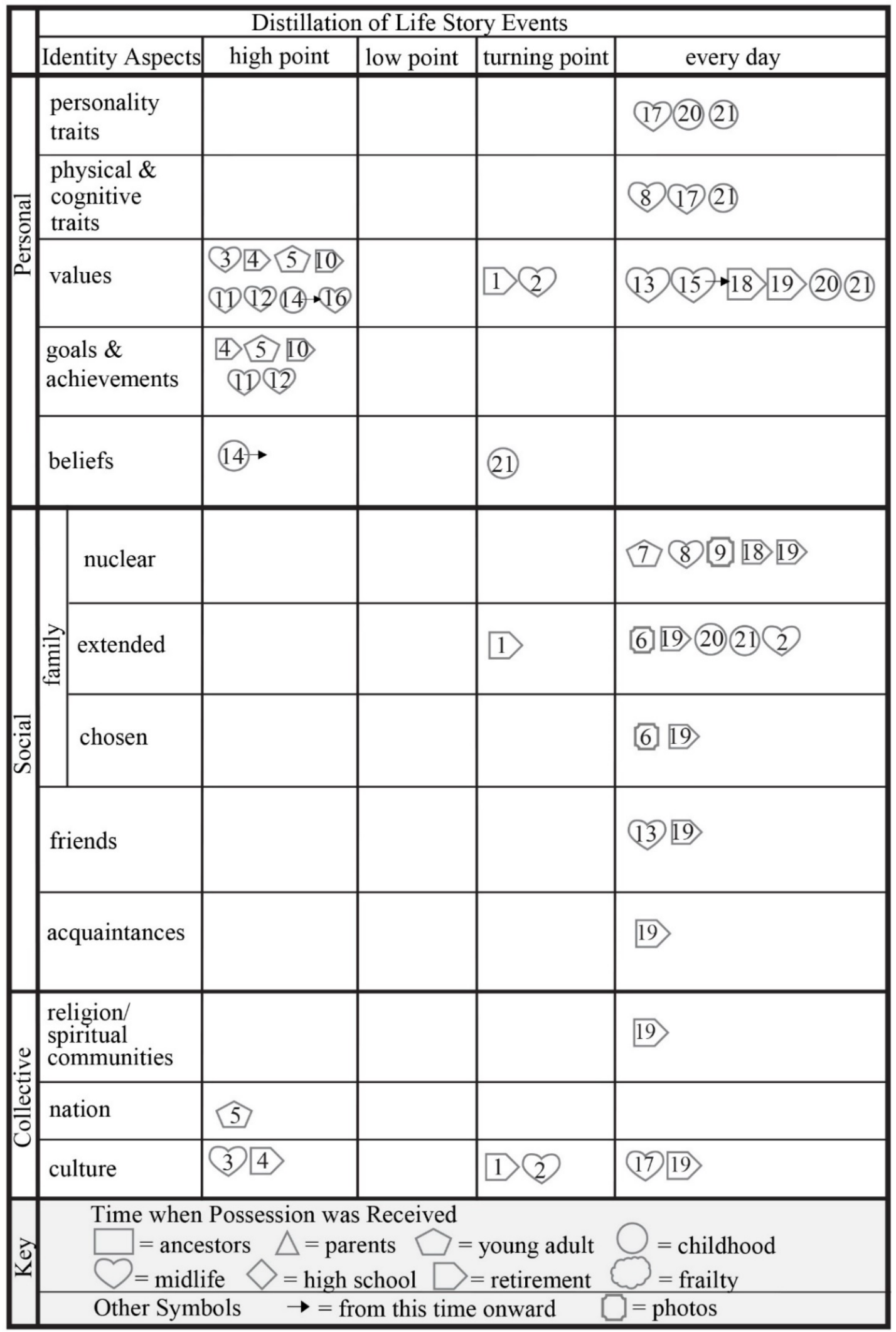

Figure 21. Grayson Life Story Possession Analysis (LSPA \#7). 

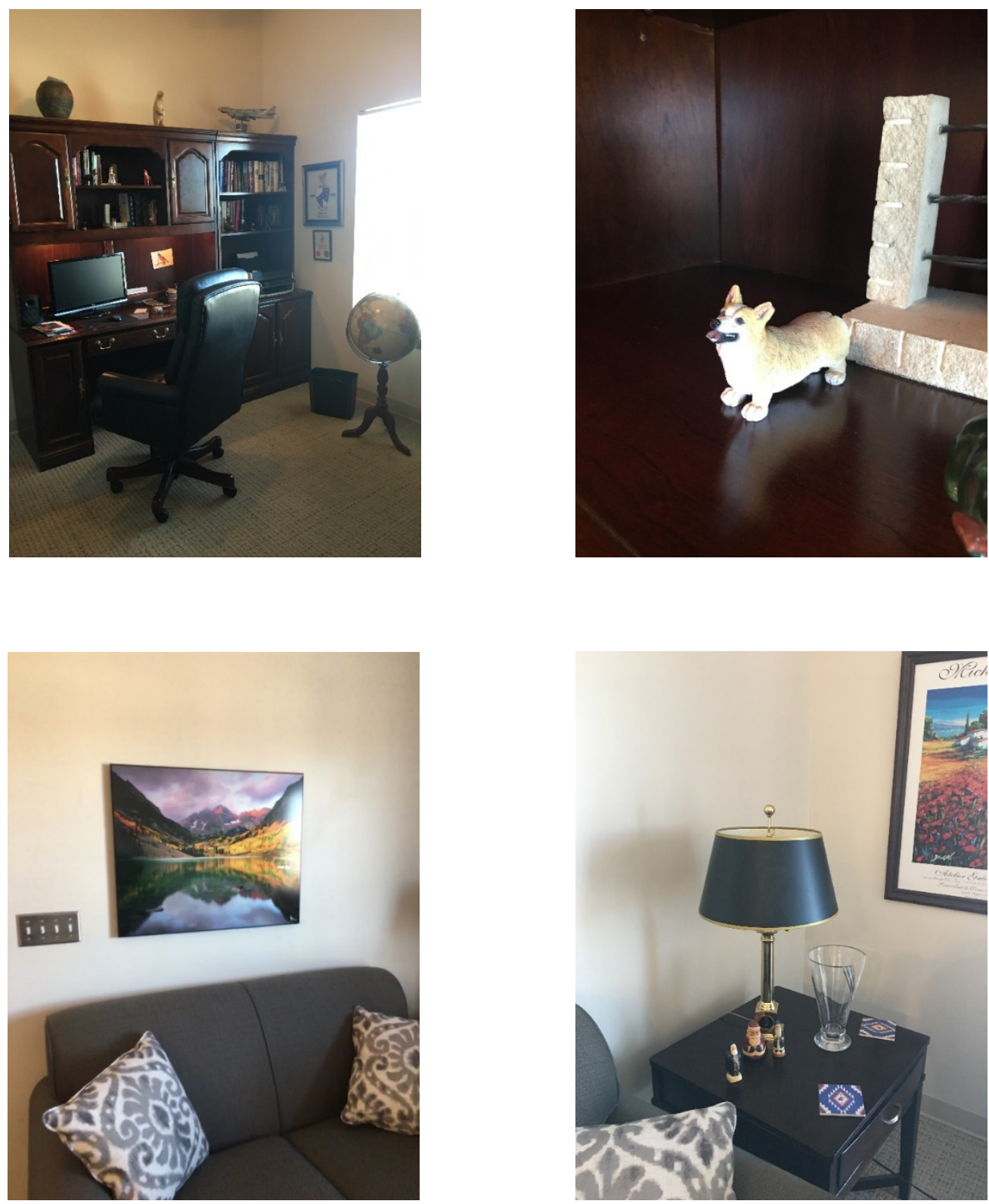

Figure 22. Photographs of Grayson's storied possessions: upper left—desk with small figurines, fraternity needlepoint, computer, bear, Greek pottery, model plane; upper right — Rufus figurine; lower left—mountain photograph; lower right—Santa figurine, fraternity award, Provence illustration.

Identity meanings, related in life span stories, embedded in the possessions

Grayson moved to his new residence. There are three themes of meaning embedded in 
the possessions Grayson moved into his senior apartment: 1) living in the present, 2) fraternity and family, and 3) not homey.

Living in the present. Grayson intentionally created a fresh space embedded with the meaning of being a single older man. Living room furniture is all new with one embedded layer of meaning: moving into the present. He kept his desk that incorporates meanings of business and work. It takes up a large portion of the second room, which is a study rather than a second bedroom. Photographs are not displayed but in albums boxed in the closet. He chooses not to display older photographs and has not received new ones from his children. His bed is a single bed from childhood.

Fraternity and family. Small decorative objects are scattered throughout the apartment. These possessions are embedded with meanings of family and fraternity, but they are small, and easily moved from place to place. The exception to this is the large wooden chest in his bedroom.

Not homey. Grayson's décor possessions do not create the homey, middle-class aesthetic that means family and comfort (McCracken, 2005). Although his furniture looks comfortable, it is not worn or mismatched. His fine art is well chosen for meanings embracing the environment of his childhood. There is no clutter. Rather there is a place for everything and everything is in its place.

Household Case Study \#8: Mary. Mary moved from living with her adult daughter in a single-family house (SFH-AC) to a one-bedroom senior apartment (SA). It was her second downsizing move (DSM) as seen in Table 18. Below is Mary's life story. Table 18 Mary's Profile 


\begin{tabular}{|c|c|c|c|c|c|c|c|c|c|c|}
\hline $\begin{array}{l}\text { Nom } \\
\text { de } \\
\text { Plume }\end{array}$ & YOB & Age & MS & $\begin{array}{l}\text { Prior } \\
\text { Years }\end{array}$ & $\begin{array}{c}\text { Prior } \\
\text { Sq. } \\
\text { Ft. }\end{array}$ & $\begin{array}{l}\text { Prior } \\
\text { Type }\end{array}$ & $\begin{array}{l}\text { Current } \\
\text { Sq. Ft. }\end{array}$ & $\begin{array}{r}\text { Current } \\
\text { Type }\end{array}$ & DSM & $\mathrm{P} \#$ \\
\hline Mary & 1932 & 85 & W & 45 & 1,500 & $\begin{array}{r}\text { SFH- } \\
\text { AC }\end{array}$ & 510 & SA & 2 & 13 \\
\hline
\end{tabular}

Mary's extended family lived on a cattle ranch in a large farmhouse surrounded by deep porches with rocking chairs. She was named Mary Twyla on the porch in her grandmother's arms. After high school, she became a nurse and married a United States career Marine. They were the country mouse and the city mouse. When they got married and left her hometown and family, she decided to never say that she missed home. They lived on many bases, in many duplexes, and she had other young married wives as neighbors each time they relocated. One early morning one of the neighbors came to the door and told Mary she was getting a divorce and moving back home. Mary was confused because all the wives knew they were marrying military men and would be relocated often. 'It was so sad. I never did say, 'I want to go home,' because I really never did."

They moved every two or three years. Mary and her husband believed Jennifer, their only daughter, had as much say in the family decisions as they did. They were not going to be authoritarian, controlling parents; instead, they would be a team, both in Jennifer's education and in their relocations. When Jennifer was little, they began moves by showing her maps of the city they were going to and talking about the fun things they would do. They made moving an adventure. Jennifer never minded going to a different school.

When her husband retired from the Marines, the family voted together to move close to his family of origin because Jennifer was not around relatives growing up. Mary 
vividly remembers driving off the freeway toward their destination, "To me, it's like a camera inside. When we were driving off the freeway, we had a big rainbow. We wondered what was on the other side of the rainbow for us. The colors were just right there, and the car just went under it."

Mary continued nursing at a new hospital. Jennifer became a volunteer candystriper at the hospital and later became a nurse working at the same place as her mother. A photograph of Jennifer in her striped uniform hangs on Mary's apartment wall.

After their final move, they purchased their first house. Mary's new neighbor was an older woman who lived by herself-Mary's current age now. Her neighbor's daughter came over with a knickknack shelf and said her mother, who was downsizing, wanted Mary to have it. Looking back, Mary thinks her neighbor was very sad about downsizing. "It was like her heart was hurting as she was doing it. Like, I don't want to do it, but I have to do it." Mary was pleased that she did not feel as sorrowfully during her own household disbandment.

After Mary's husband died, she lived on in their house for a while, but eventually Jennifer said she did not want her to live there any longer. It was time to downsize. Mary decided to take something from each part of the house, as memory keepers. She took one of the loveseats and one of the tables from the great room where they had two love seats, a big couch, and a tapestry. There are photographs hidden neatly away in the table that she and Jennifer will sort later. She kept a little cabinet and trimmed the legs to fit under the window in her new living room. The buffet is from her breakfast area in their house. A chair is from her dining room. 
The ottoman that folds out into a bed has a different story. It was purchased for Mary's new apartment as a bed for Jennifer when she wants to spend the night. A chair from her previous bedroom holds a TV. Her grandsons bought a new recliner saying, "Grandma, you need a chair, so you can raise your feet up." Her bedroom furniture and her parents' walnut end table are very important to her. Her sister has the matching table. Family photographs are also very important. They hang next to paintings Mary has recently been creating. 
Table 19

Mary's Objects Identified in Narrative

\begin{tabular}{lll} 
Item \# & Type & Ownership \\
\hline 1 & love seat & Mary - midlife \\
2 & wooden cabinet & Mary - midlife \\
3 & wooden table & Mary - midlife \\
4 & chair & Mary - midlife \\
5 & drawings & Mary - frailty \\
6 & recliner & Mary - frailty \\
7 & framed family photographs & Mary - childhood on \\
8 & end table & Mary's parents \\
9 & ottoman & Mary - frailty \\
10 & bedroom suite & Mary - midlife \\
11 & curio cabinet with figurines & Mary - midlife on \\
12 & whatnot-stand & Mary - midlife \\
& &
\end{tabular}




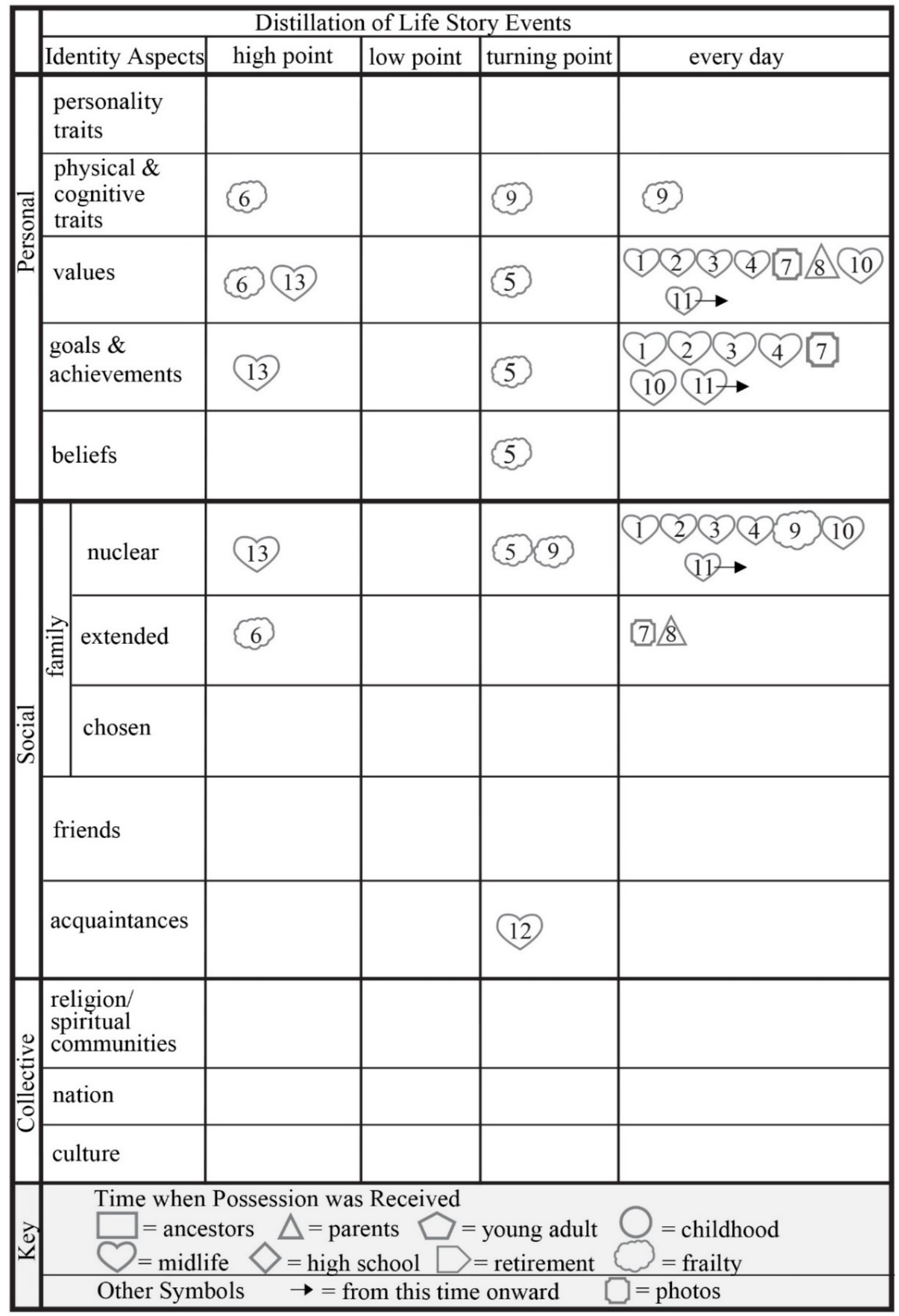

Figure 23. Mary Life Story Possession Analysis (LSPA \#8). 


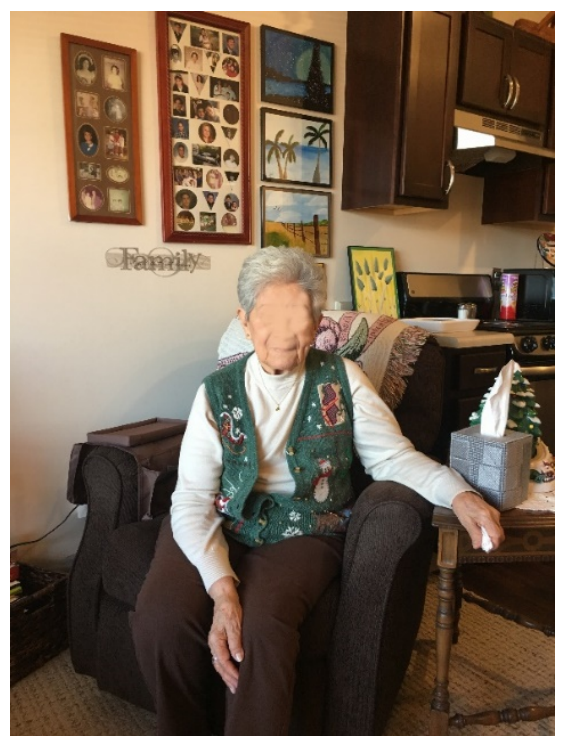

Figure 24. Photograph of Mary's storied possessions: family photos, end table, recliner, and paintings by Mary.

Identity meanings, related in life span stories, embedded in the possessions Mary moved to her new residence. There are two themes of meaning embedded in the possessions Mary moved into her senior apartment: 1) family and 2) values past place.

Family. Each of Mary's possessions is embedded with the meanings of family as a harmonious working team that cares for one another and as an object of pride. The recent paintings she created are signed so her daughter will have them after Mary is dead and will be able to remember her.

Values past place. Each piece of furniture was chosen to represent a room in her previous house. The embedded meaning is intentional remembrance of nuclear family enacted within home. 
Household Case Study \#9: Paulo and Pauline. Paulo and Pauline moved from living independently in a single-family house (SFH-I) into a two-bedroom senior independent living (SIL) apartment. It was their first downsizing move (DSM) as seen in Table 20. Below is Paulo and Pauline's life story.

Table 20

Paulo and Pauline's Profile

\begin{tabular}{lrrrrrrrrrr}
\hline $\begin{array}{l}\text { Nom } \\
\text { de }\end{array}$ & & \multicolumn{1}{c}{$\begin{array}{c}\text { Prior } \\
\text { Plume }\end{array}$} & YOB & Age & MS & $\begin{array}{r}\text { Prior } \\
\text { Years }\end{array}$ & $\begin{array}{c}\text { Ft. } \\
\text { Frior } \\
\text { Type }\end{array}$ & $\begin{array}{r}\text { Current } \\
\text { Sq. Ft. }\end{array}$ & $\begin{array}{r}\text { Current } \\
\text { Type }\end{array}$ & $\begin{array}{l}\text { M } \\
\text { M\# }\end{array}$ \\
\hline Paulo+ & 1933 & 84 & M & 26 & 2,800 & SFH-I & 984 & SIL & 1 & 24 \\
Pauline & 1936 & 81 & M & 26 & 2,800 & SFH-I & 984 & SIL & 1 & 24 \\
\hline
\end{tabular}

Paulo and Pauline's ancestries are integrated into the United States' midnineteenth century western expansion and the development of its inland waterways. They were tangibly connected to their family's past through heritage furniture and furnishings that were handed down four generations before being ensconced in their retirement apartment.

Pauline's grandfather was born in the northeast and by the time he was twelveyears old, he was working on the river. He had few material possessions when he moved west. He built a candy factory that delivered sweets locally and shipped product to department stores in Chicago. His family became financially prosperous. Prosperity allowed the family to purchase luxury items, exemplified by Pauline's mother platinum trimmed bone china.

Paulo's grandfather was one of eight children born to a farmer in the northeastern United States. Unable to provide him with land for a farm, his family sent him to work in 
a bank at a frontier outpost on the Missouri river where Paulo's grandmother's family owned a mill and a horse corral. After Paulo's grandparents married, they built a house close to the river. Their furniture arrived by steamboat from the east. Seeing an opportunity, they complemented the mill and corral businesses with steamboat and wagon train enterprises. They expanded the mill, and when the other businesses became obsolete, the mill economically maintained the financial prosperity of their descendants.

Toward the end of his life, Paulo's grandfather became interested in learning about his European heritage. In Paulo's study, is a copy of the book his grandfather wrote compiling the family's historical information. Occasionally, Paulo rereads the book, always finishing with a realization about the caliber of people who built the United States, "They were all hardworking, dedicated, religious people." Along with this family history, Paulo kept books that had been handled and read by multiple generations of ancestors.

When I asked Paulo about his most precious possession, he told me it was his treasure box because it was filled with memories that began as a very young child. During that time, his family rebuilt their house. His grandfather gave him money to buy the furnishings for his bedroom. When they were shopping, Paulo saw the treasure box. "I fell in love with it. It was my secret box as I was growing up." The treasure box was in the study in their retirement apartment directly across from Paulo's primary chair.

Paulo worked at the family flour mill until he joined the Navy and fought in the Pacific during World War II. As a bachelor, his mother told him he needed to buy a nice piece of furniture for his apartment, and he purchased a high-quality chest. 
After Paulo met and married Pauline, the first thing they bought for the house was a dining room table. Pauline also bought double-sided, drop-leaf table from one piece of wood. They kept the chest, drop-leaf table, and dining room table after their household disbandment. Pauline said she pleaded with her interior designer to appropriately place the dining room table. "I love my table, and no one wanted it." Initially, the designer said it wouldn't fit. Pauline did not want the space to look ridiculous or crammed, but she didn't want to leave it behind and was relieved when the designer arrived at a solution.

Pauline expressed to me that her most precious possession was an armoire, a signed piece, given to her by Paulo's aunt and prominently displayed. The fact that it was signed made it monetarily valuable, but the meaningfulness of the armoire came from the relationship Pauline had with the aunt. "I loved her. It was just too bad she wasn't my mother-in-law. She had no children. I just absolutely adored her, and she loved me too. She told my mother she thought of me as a daughter."

Paulo ad Pauline moved often during Paulo's active career. Those experiences were advantageous for the technical aspects of relocating, but they did not help with the emotional grief of losing heritage pieces that neither her children nor grandchildren wanted. Many times, Pauline told me that it "killed" her to lose four generations of beautiful furniture. However, once they determined what was necessary, they embraced the pioneering aspect of their ancestors. Pauline built a mental wall, placed her lost furniture on the other side of it, and made a conscientious effort to move on. Paulo said, "When we sat down, we decided, 'This is what we're going to do. This is the next part of our life." They chose a continuing care retirement center that was under construction. Five days after they moved, their furniture was in place, the kitchen was arranged to 
Pauline's liking, and artwork was hung on the walls. One of the pieces was painted by a famous Midwestern artist who gave it to Paulo's parents as a wedding gift at the turn of the twentieth century. Another had belonged to Paulo's aunt.

From the Paulo and Pauline's perspective, they moved into a place with other likeminded residents. They labeled them as "Midwestern," a definition they said including being friendly, courteous, and helpful. They never felt they had to force their way into a social group. Paulo summed it up, "I know all of the people here since we were really the pioneers of this place." They said they were at home. 
Table 21

Pauline and Paulo's Objects Identified in Narrative

\begin{tabular}{|c|c|c|}
\hline Item \# & Type & Ownership \\
\hline 1 & heritage furniture and furnishings & ancestors \\
\hline 2 & dining room chairs & Pauline's grandmother \\
\hline 3 & area rug & Pauline's mother \\
\hline 4 & child-sized, mahogany corner chair & Paulo's father \\
\hline 5 & stuffed teddy bear from & elderly Paulo \\
\hline & granddaughter & \\
\hline 6 & family genealogy book & Paulo's grandfather \\
\hline 7 & inherited books & both parents \& grandparents \\
\hline 8 & Iliad & Pauline's copy \\
\hline 9 & childhood treasure box & young child Paulo \\
\hline 10 & chest-of-drawers & young child Paulo \\
\hline 11 & antique desk & both ancestors \\
\hline 12 & boxes of photographs & both family \\
\hline 13 & chest-of-drawers & bachelor Paulo \\
\hline 14 & dining room table & both newlyweds \\
\hline 15 & double drop-leaf table & both \\
\hline 16 & silver candlesticks & Paulo's newlywed parents \\
\hline 17 & silver coffee $\&$ tea service & newlyweds \\
\hline 18 & silverware collection & newlyweds onward \\
\hline
\end{tabular}


19

20

21

22

23

24
Waterford crystal collection

hardwood shelf

signed armoire

Wedgwood

painting

painting newlyweds onward

Paulo's mother

Paulo's aunt

Paulo's aunt

Paulo's newlywed parents

Paulo's aunt 


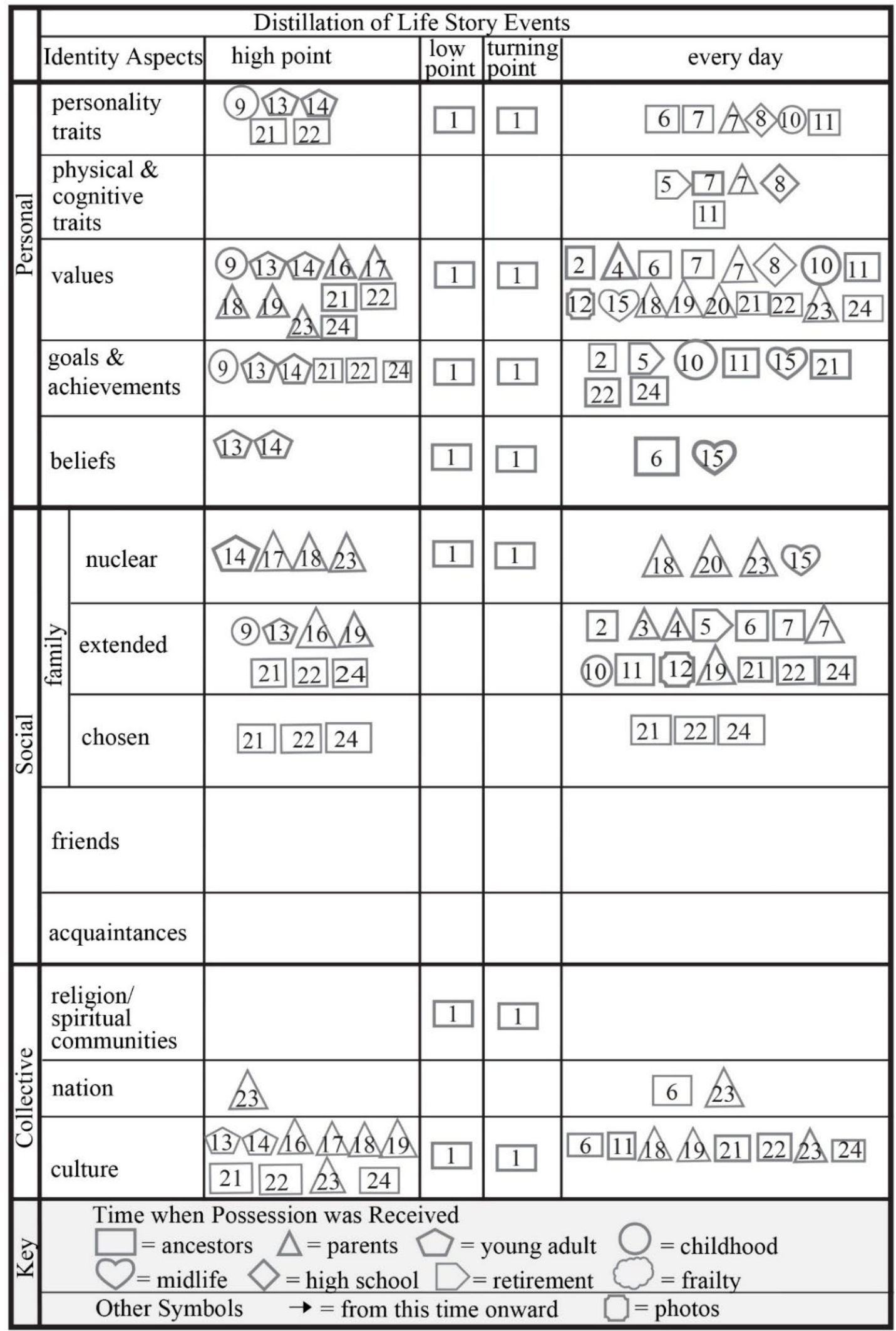

Figure 25. Pauline and Paulo's Life Story Possession Analysis (LSPA \#9). 

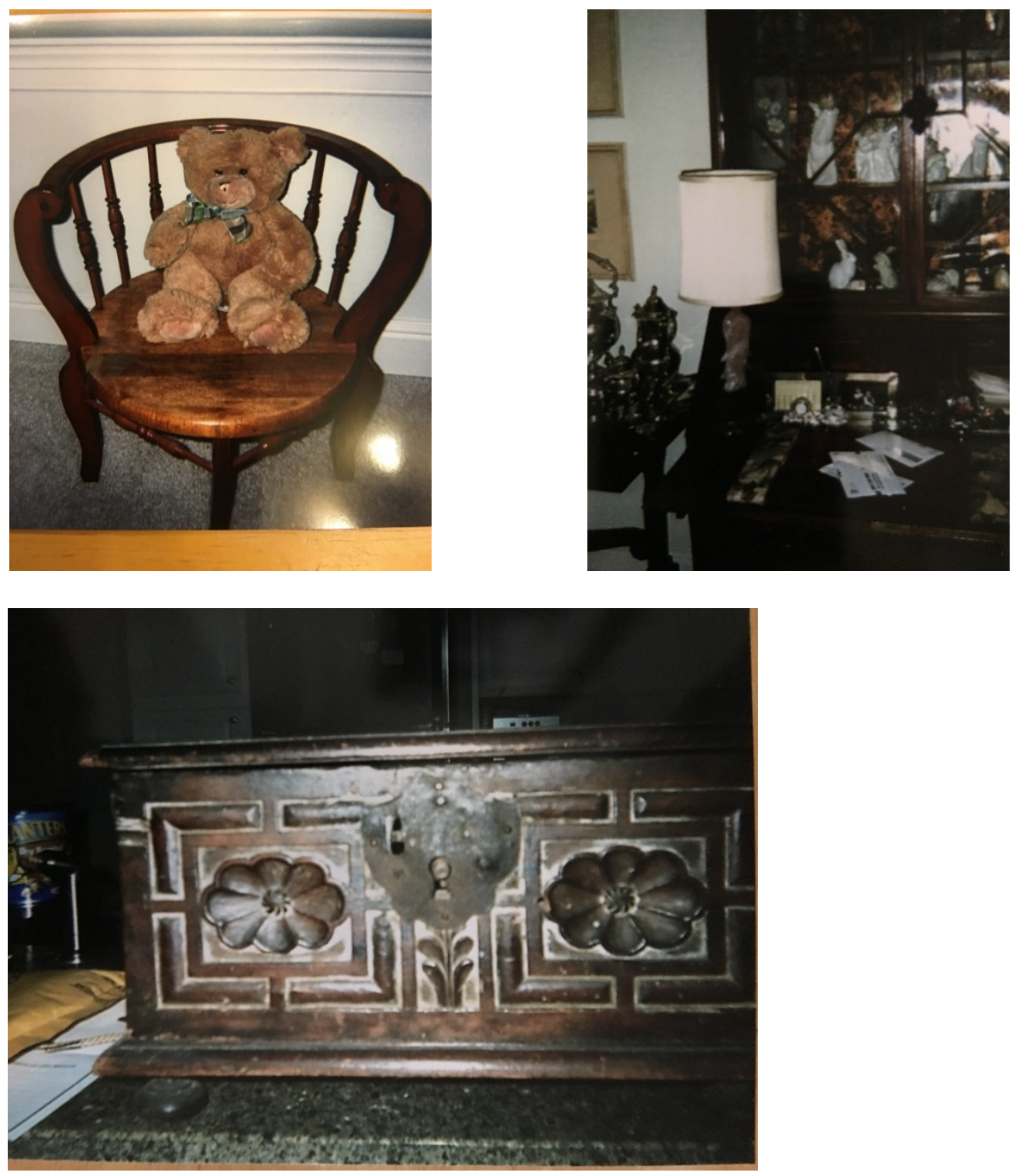

Figure 26. Pauline and Paulo's storied possessions: upper left—father's childhood mahogany corner chair with get-well bear from granddaughter; upper right — signed armoire and Lladró and Limoges figurines; lower left—Paulo's childhood treasure chest.

Identity meanings, related in life span stories, embedded in the possessions Paulo and Pauline moved to their new residence. I interpreted four themes of meaning embedded in the possessions Pauline and Paulo brought to their retirement apartment 
after disbanding their household: 1) made of the right stuff, 2) microcosm of previous life, 3) remnant of absence, and 4) turning toward the positive.

Made of the right stuff. Paulo told me he and Pauline valued the "hardworking, dedicated, religious people" from whom they descended and believed themselves to be the same caliber as demonstrated through the provenance of and safe passage given to their heritage possessions. These hardwood items connected them to the pioneers who, through these valued characteristics, pushed into the remote regions of the unsettled United States during the westward expansion of the mid-nineteenth century. This meant that, during a new frontier in their lives, they could push past the unseen future of household disbandment and successfully pioneer the newly constructed retirement community.

Microcosm of previous life. The antique desk kept in active working order demonstrated the volunteer work in which Paulo was involved. It meant that he continued to live in a microcosm of experience similar to his executive business life before retirement. It meant he was useful and important to society. Pauline's books, Waterford crystal, and silver collections meant she continued to live a quiet interior life as someone of status situated in a wealthy environment. The existence of the collections, accumulated over her adult life, demonstrated that her investment of time was still of value. The dining room table continued to allow for the family gatherings that had daily anchored their family through their married lives. It meant the potential for active family communication still existed even though they no longer owned the house in which they used to gather.

Remnant of absence The heritage items in the apartment were a remnant of the collection that represented four generations of family. Their presence was a visual 
reminder that the participants had been unable to provide safe passage into extended family houses for most of the collection. These items were unwanted by family. The remnant meant that the absence of the remainder needed to be walled off in the participant's mind as thinking about it "killed" her.

Turning toward the positive. Disbandment of the heritage collection of furniture was a low point in the participants' lives. During this low point, they used the characteristics demonstrated to them by their forefathers; Pauline told herself she needed to "move one." This meant the low point became a turning point. They embraced the "next part of their lives" (Paulo) and evaluated their experience as having done well. 
Household Case Study \#10: Robert and Elsie. Robert and Elsie moved from living independently in a single-family house (SFH-I) into a two-bedroom senior apartment (SA). It was their first downsizing move (DSM) as seen in Table 22. Below is Robert and Elsie's life story.

Table 22

Robert and Elsie's Profile

\begin{tabular}{|c|c|c|c|c|c|c|c|c|c|c|}
\hline \multicolumn{11}{|c|}{ Prior } \\
\hline $\begin{array}{l}\text { Nom de } \\
\text { Plume }\end{array}$ & YOB & Age & MS & $\begin{array}{l}\text { Prior } \\
\text { Years }\end{array}$ & $\begin{array}{l}\text { Sq. } \\
\text { Ft. }\end{array}$ & $\begin{array}{l}\text { Prior } \\
\text { Type }\end{array}$ & $\begin{array}{l}\text { Current } \\
\text { Sq. Ft. }\end{array}$ & $\begin{array}{r}\text { Current } \\
\text { Type }\end{array}$ & DSM & P\# \\
\hline & & & & & & SFH- & & & & \\
\hline Robert+ & 1934 & 83 & M & 12 & 1,800 & I & 957 & SA & 1 & 17 \\
\hline Elsie & 1942 & 75 & M & 12 & 1.800 & $\begin{array}{r}\mathrm{SFH}_{\mathrm{I}} \\
\end{array}$ & 957 & SA & 1 & 17 \\
\hline
\end{tabular}

Robert is sixth of seven generations of the Duncan family in America. He has a crest that belonged to Hugh Duncan, born in 1794. Robert is also the great-great nephew of President William McKinley, and when he asked Elsie to marry him, he gave her President McKinley's wedding ring as her own. McKinley was wearing it the day he was assassinated.

Elsie connections to past are also important and run deep as evidenced in her love of antiques and the items she chose to keep. When they disbanded their house, Elsie sold her bone china place settings but kept an English bone china large soup tureen from her German grandmother. Her grandparents bought the tureen in England and took it to Germany, and from Germany it came to the United States. She also has a few flow blue porcelain pieces from her great aunt's family. From her antebellum family, Elsie has an antique table. A map case is also very special. Her great uncle built it out of wood, and a friend of his did the metal work. 
Their marriage is the second for them both. Robert was an ordained Episcopal priest for fifty-four years and a public library administrator who lived in twenty-four places over his life time. He has two children from his first marriage. One child has passed, and he does not see the other often. Two photographs of them are on his dresser.

Elsie had difficulty both in her first marriage and in raising her children. She has a good relationship with one of her children, but he is not able to visit as often as both would like. When Elsie separated from her first husband, she became a state library consultant. She met Robert on an escalator at an airport after attending a library conference. They went for drinks and exchanged life stories. They continued seeing each other at national conferences, and finally married twenty-one years ago. Elsie bought a new bed when they were dating; it has special meaning because Robert shared it with her. They keep their wedding announcement from twenty-one years ago along with Elsie's wedding photograph on their dresser, a chest-of-drawers built in Pennsylvania in 1830.

Books are living entities in Robert and Elsie's lives. Robert was an ordained Episcopal priest for fifty-four years and a public library administrator who lived in twenty-four places over his life time. Elsie is a writer. She was a children's librarian and supervisor for twenty-five years; she wrote books and gave workshops for teachers and librarians that were used throughout the United States. She was on the Caldecott Committee and is a Caldecott Award recipient. Along with their living room furniture and dining area, their few remaining bookcases fit in their living area. Many boxes of books were lost when they were being physically moved from one place to the other, and their absence is still felt deeply. 
When Robert lost his job due to political reasons, Elsie became the primary financial provider. She worked in various library systems. They moved around the country, but after three bad work experiences, she decided to retire early and moved back to where Elsie grew up. Only a sister-in-law still lives close. Connections in their new residence have not come easily. Although Elsie has several photo albums she put together, they threw away many photographs during disbandment. There was no room for them, and Elsie's philosophy about photos is different research indicates for most older adults (Ekerdt \& Sergeant, 2006). "You have to cut your losses. We don't take very many photos. The other thing is so many people who are probably here are the ones that cling on to the importance of their families. They would be the ones that would have these poster size pictures of their kids all over the place"

They chose the senior apartment facility because it was affordable, new, and aesthetic. Robert easily adjusted to their new place; Elsie, however, does not think she will ever adjust. She views most of the other residence in the senior apartments are as less intellectual, educated, or as literary as their previous friends.

Art brings enjoyment, though. Elsie said, "We like art. We might have a little photo here or there, but I don't cling onto that." Art books reside on the lower shelf of a table in the living room. The second bedroom is Elsie's studio; the walls are covered with art images including Egyptian paintings they bought in Egypt, a George O'Keefe print, and a print of the Girl with the Pearl Earring.

Robert and Elsie fill their days with their past times. Robert describes himself as having a happy disposition and good health. He is a newshound and enjoys watching TV. Elsie lives a "life of the mind and not the body," although she considers herself a foodie 
and cooks often. She brought as many favorite kitchen utensils and machines as would fit in their new space. Her "saving grace" is writing though, especially her poetry. She considers it very close to a spiritual experience because it addresses her emotional side.

On Elsie and Robert's kitchen counter is a vase made by a friend which they try to keep filled with fresh flowers. Sun shines through the glass and lights it up. It is a reminder that things with meaning are important to them. "There's so many things that have significance for us. It isn't that we just went out and bought it in a store. Like Ikea stuff. That's not us."

Although their new apartment might not be ideal for Elsie, Robert feels that any place in which they live together would be home. 
Table 23

Robert and Elsie's Objects Identified in Narrative

\begin{tabular}{|c|c|c|}
\hline Item \# & Type & Ownership \\
\hline 1 & $\begin{array}{l}\text { crest belonged to Hugh Duncan } \\
\text { c. } 1794\end{array}$ & Robert's ancestors \\
\hline 2 & Elsie's wedding ring & Robert's ancestors \\
\hline 3 & our wedding announcement & Elsie and Robert - midlife \\
\hline 4 & art & Elsie and Robert - midlife \\
\hline 5 & photographs & Elsie and Robert - midlife \\
\hline 6 & photo albums & Elsie and Robert - midlife \\
\hline 7 & Egyptian paintings & Elsie - midlife \\
\hline 8 & Georgia O'Keefe print & Elsie - midlife \\
\hline 9 & Caldecott award & Elsie - midlife \\
\hline 10 & Published poetry & Elsie - midlife \\
\hline 11 & books \& bookshelves & Elsie and Robert - childhood on \\
\hline 12 & Constitutional Congress book & Robert - young adult \\
\hline 13 & English bone china & Elsie's grandmother \\
\hline 14 & map case & Elsie's great uncle \\
\hline 15 & gate-leg table & Robert's ancestors \\
\hline 16 & master bed & Elsie - midlife \\
\hline 17 & Robert's chair & Robert - midlife \\
\hline
\end{tabular}




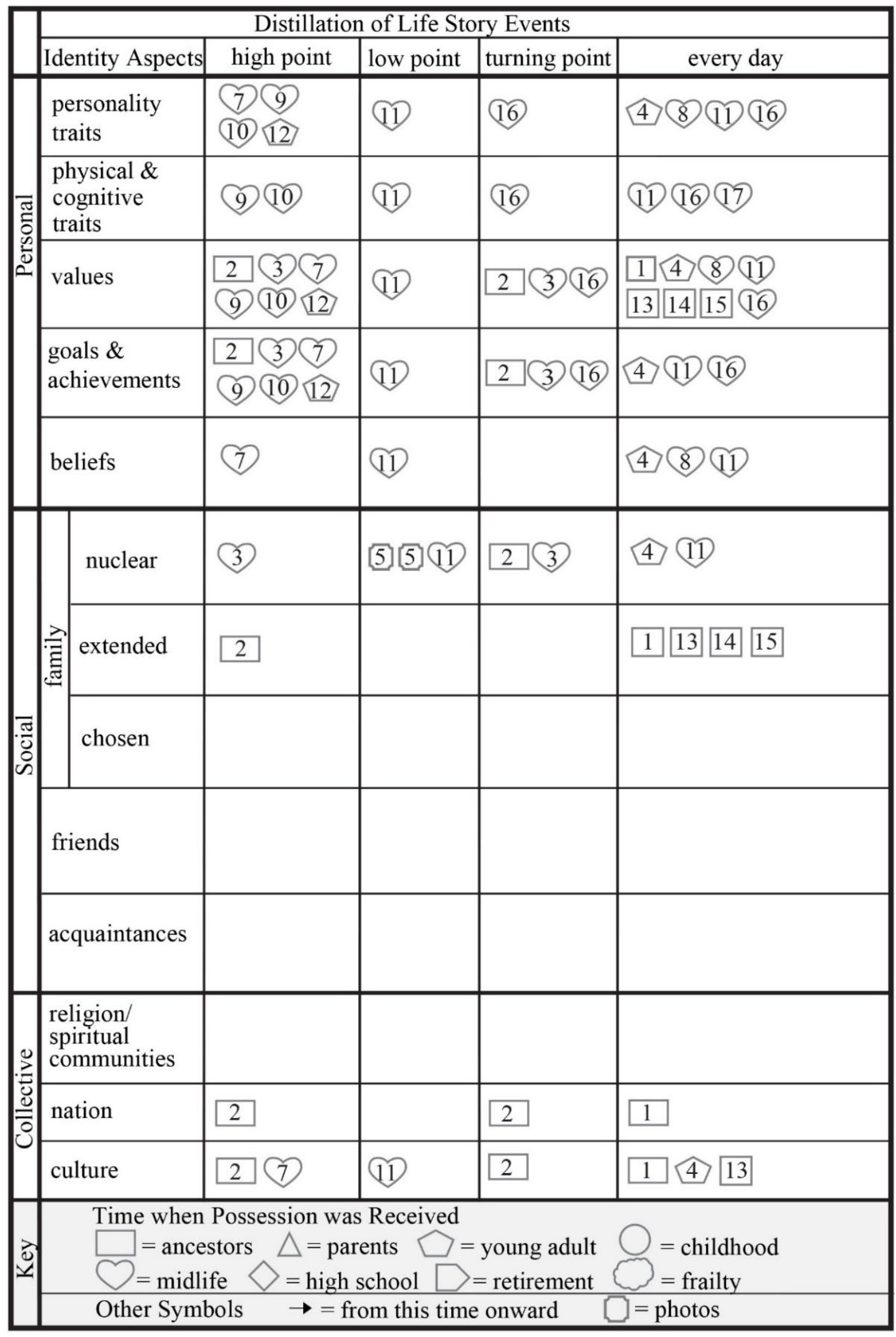

Figure 27. Robert and Elsie's Life Story Possession Analysis (LSPA \#10). 

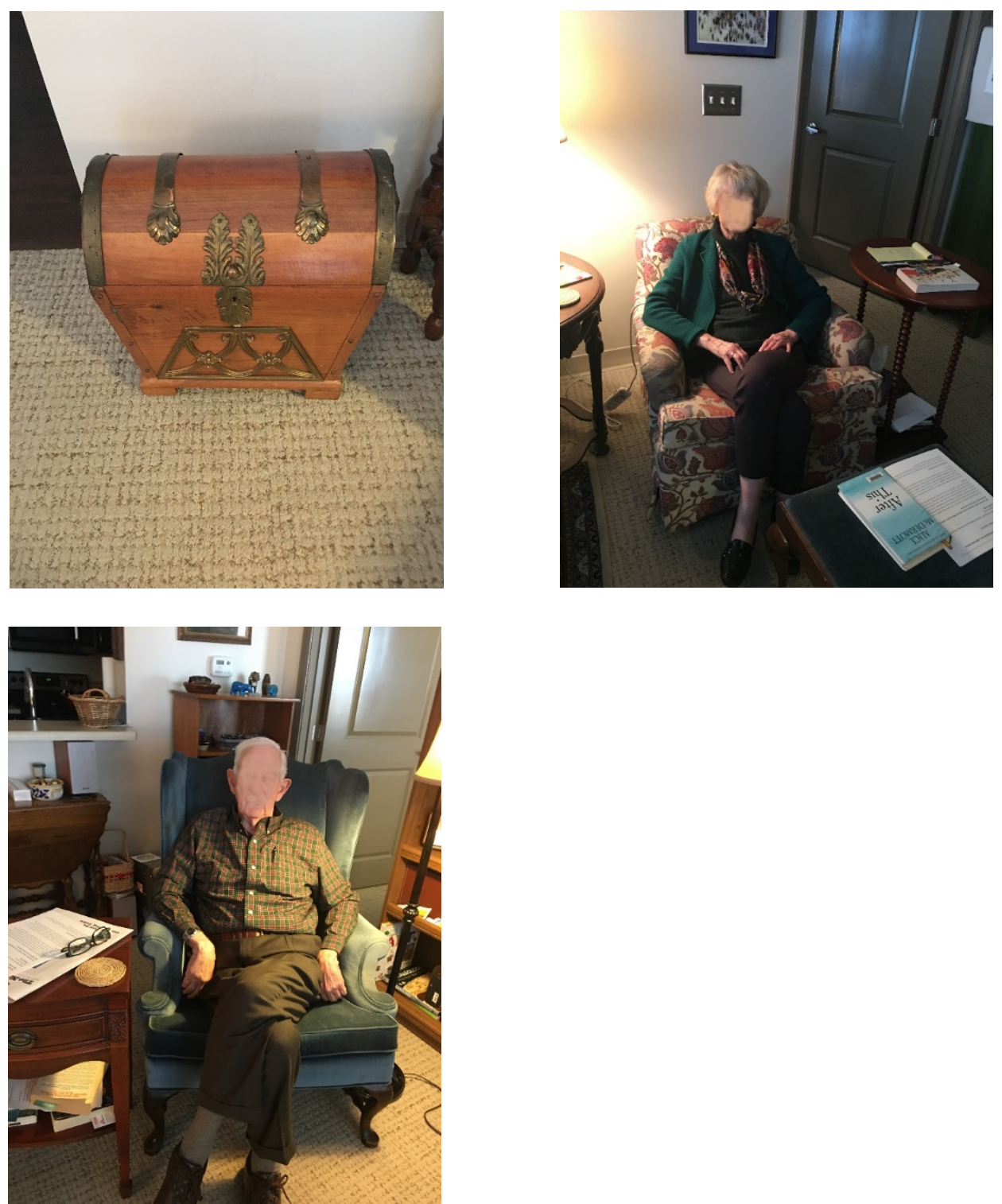

Figure 28. Robert and Elsie's storied possessions: upper left-great-uncle's handcrafted map case; upper right_—Elsie in her chair with antique tables and painting; lower left_Robert's chair with antique tables and bookcase.

Identity meanings, related in life span stories, embedded in the possessions Robert and Elsie moved to their new residence. There are three themes of meaning 
embedded in the possessions Robert and Elsie moved into their senior apartment: 1) historical family, 2) readers and a writer, and 3) art aficionados.

Prominent historical family. Possessions are embedded with the meaning that Robert and Elsie are members of historical families whose members played a prominent role in the community. This meaning of family dominates current meaning of family, which overall is one of disappointment, as seen in the positioning of a few photo albums on the lowest bookshelf amidst numerous art books, a few small photographs of children displayed in the privacy of the bedroom, and their narration of current family. that

Readers and a writer. Books are present in all three of the major rooms in the apartment. Bookcases dominate the living room, and books are scattered on pieces of furniture. Books written by Elsie are present.

Art aficionados. Fine art or replications of fine art in illustrations or posters are prominently displayed on the walls. The Caldecott Award is embedded with the meaning of being a recognized illustrator of children's books. Sculpture is embedded with the meaning of an artist creating it for them; the cover of Elsie's most recent book is illustrated by a graphic artist employed by a large greeting card company. The meaning embedded within the meaning combines the pride of being a writer with the pride of having the illustration. 
Household Case Study \#11: Gina. Gina moved from living independently in a single-family house (SFH-I) into a one-bedroom senior apartment (SA). It was her second downsizing move (DSM) as seen in Table 24. Below is Gina's life story.

Table 24

Gina's Profile

\begin{tabular}{|c|c|c|c|c|c|c|c|c|c|c|}
\hline $\begin{array}{l}\text { Nom } \\
\text { de } \\
\text { Plume }\end{array}$ & YOB & Age & MS & $\begin{array}{l}\text { Prior } \\
\text { Years }\end{array}$ & $\begin{array}{c}\text { Prior } \\
\text { Sq. } \\
\text { Ft. }\end{array}$ & $\begin{array}{l}\text { Prior } \\
\text { Type }\end{array}$ & $\begin{array}{l}\text { Current } \\
\text { Sq. Ft. }\end{array}$ & $\begin{array}{r}\text { Current } \\
\text { Type }\end{array}$ & DSM & $\mathrm{P} \#$ \\
\hline & & -5 & & & $500-2$ & SFH- & 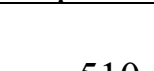 & & 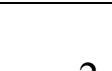 & 0 \\
\hline
\end{tabular}

Gina was more interested in the time "after" her divorce than the "before." Except for her mother's crystal and china, books, and some photographs, our interviews discussed no items from her childhood or early adulthood.

Gina had grown up in church. She had played by the rules, married someone she met there, and had three children - two boys and a girl. Her husband was headmaster at the boys' school. She developed a strong Tupperware business eventually making more money than her husband. She saved for the future and the children's college funds. Their family looked like the American dream.

Until her husband packed his bags, emptied all her savings and checking accounts, and ironically took all the children's photographs with him. He sued her for divorce. Because legally there were no uncontested divorces in their state, he had to demonstrate significant reason. He said she was an unfit mother and a bad wife. Her neighbors were called as witnesses. They testified that her children's clothes had dirt on them when they were playing outside, and their toys cluttered the house. 
He remarried four months after the divorce. The church they attended sent her a letter saying she was no longer welcome. The custody agreement allowed her ex-husband to have the children for Wednesday nights and Sundays, so they could attend church services with him. He paid child support but not alimony. Gina was no longer living the American dream, but she knew how to work and live frugally. She had her mother as an example. A registered nurse, she had worked throughout Gina's childhood.

She was hired at an advertising company, the only female salesperson. Eventually she managed her own accounts. She traveled to their businesses and increased sales. She was surprised when her boss called her into the office and said, "You are the best salesperson we have, but sales have decreased overall. These men need their income to provide for their families. You're so good, you'll be able to find work elsewhere."

She was worn down by the misogynistic small town. Nine years after her divorce, Gina shook the dust off her feet and moved to a large metropolitan area. She researched the local high schools and bought a house near the best one. She became a successful realtor and an interior decorator. Adept at finding bargains, Gina restored furniture to its original glory. Collecting antiques, she crafted a French country house and grew lavender. A lover of impressionism, she added paintings to her walls. Her sister, an artist, painted a large canvas depicting Gina lying on her side full of life. She hung the painting in her bedroom. Her many books, pets, and art helped her escape life's stress.

Both sons and her daughter worked their way through college becoming financially successful, caring adults. They went where their jobs, education, and other interests took them. Gina basked in their glory. She was please when her son and 
daughter-in-law asked her to move to their city. "Why don't you come here? We want you to be with us and not so far away. If anything happened to you, it's too far away."

Her lifestyle and status changed. While she was working, Gina enjoyed her own status. After she moved, she was delighted to realize she was recognized as the mother of a local celebrity. His status gave her status. Knowing she loved the opera and art museums, he bought her two season tickets. Although she sold her car when she moved, she kept her driver's license. Other women in the apartments have cars but no longer drive, so sometimes she drives them in their own cars. She also cooks less. One meal a day is provided by the establishment, and her son and daughter-in-law pick her up nearly every Sunday for lunch. It is a pleasure to have grandchildren nearby with whom to bake cookies.

After disbandment, one of the large pieces she moved was too tall to fit in the tiny apartment, and it was hauled to charity. Crystal and pieces of her mother's china are displayed above the small wall of kitchen cabinets. Plant cuttings from her garden grow by the window. Most of her books were donated to the facility's library, but those she kept are under chairs, the sofa, and in an antique cradle. She had stored her Christmas decorations and winter clothes under her bed by raising it on blocks. When getting into the tall bed became a problem, Gina investigated additional basement storage. But moving had come with invisible strings. Her daughter-in-law, Brenda, wanted to exhibit more control than Gina liked, particularly regarding her possessions. Brenda thought Gina had moved too many things. She refused to pay for additional storage. But as she learned to do throughout her life, Gina maintained control over the situation by finding a 
small part time job, and now pays for the storage herself. For the time being, she has that string has been cut. 
Table 25

Gina's Objects Identified in Narrative

\begin{tabular}{|c|c|c|}
\hline Item \# & Type & Ownership \\
\hline 1 & restored furniture & Gina - midlife on \\
\hline 2 & collected antiques & Gina - midlife on \\
\hline 3 & lavender & Gina - midlife on \\
\hline 4 & impressionistic paintings & Gina - midlife on \\
\hline 5 & Painting of Gina by sister & Gina - midlife \\
\hline 6 & framed photographs & Gina - midlife on \\
\hline 7 & crystal & Gina's mother \\
\hline 8 & china & Gina's mother \\
\hline 9 & plant cuttings & Gina - retirement \\
\hline 10 & books & Gina - childhood on \\
\hline 11 & chairs & Gina - midlife \\
\hline 12 & sofa & Gina - midlife \\
\hline 13 & antique cradle & Gina - midlife \\
\hline 14 & family photographs & Gina - childhood on \\
\hline 15 & antique steamer trunk & Gina -midlife \\
\hline 16 & seasonal decorations & Gina - midlife on \\
\hline 17 & framed needlepoints & Gina -midlife \\
\hline 18 & recipes & Gina - young adult on \\
\hline
\end{tabular}




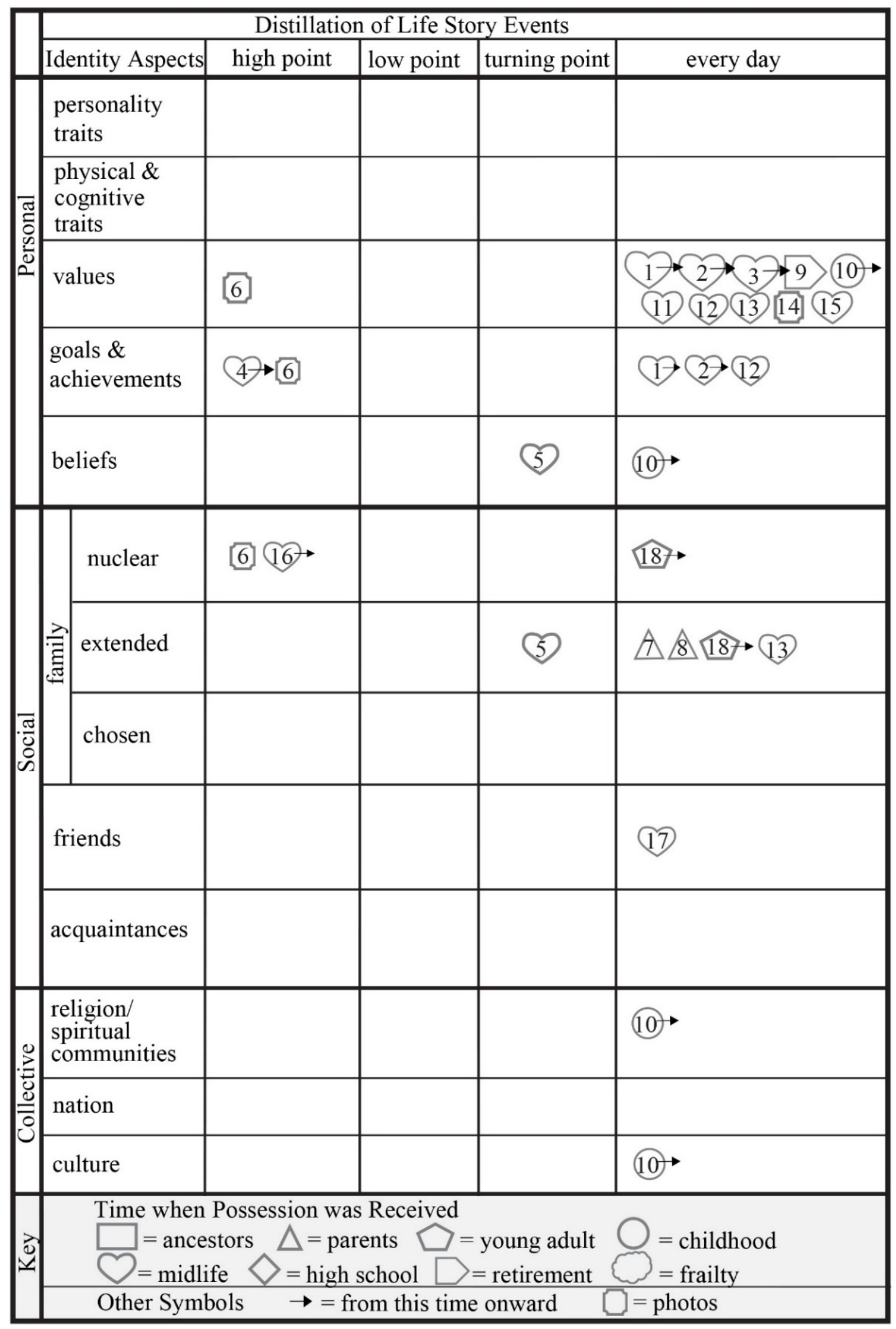

Figure 29. Gina Life Story Possession Analysis (LSPA \#11). 

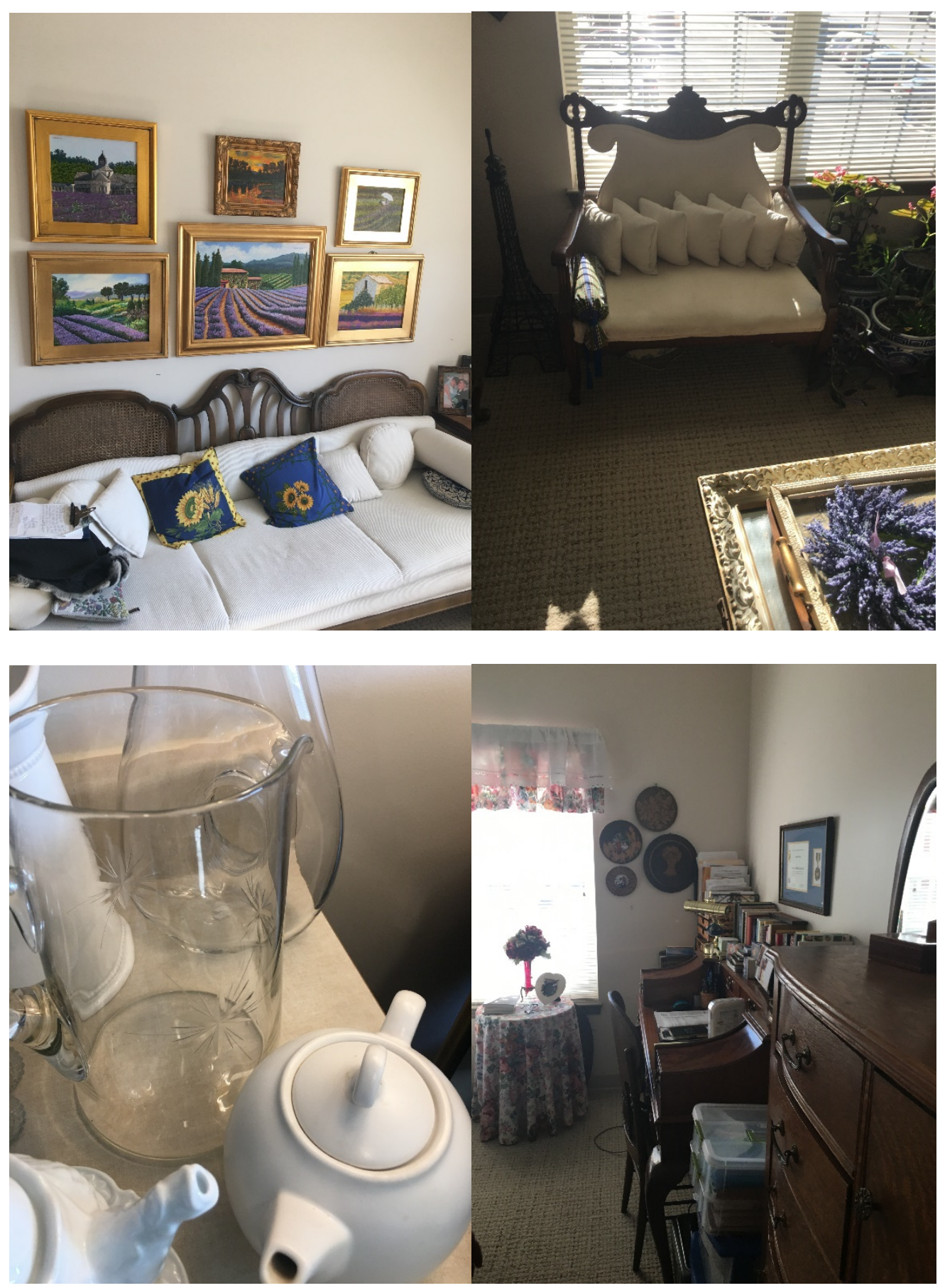

Figure 30. Gina's storied possessions: upper left—refurbished sofa and fine art; upper right — refurbished chair, cuttings from plants, lavender; lower left -mother's crystal and tea pot; lower right—refurbish desk and chest of drawers, books.Identity meanings, related in life span stories, embedded in the possessions Gina moved to her new 
residence. There are three themes of meaning embedded in the possessions Gina moved into her senior apartment: 1) reclaimed, 2) power of the maternal, and 3) cultured.

Reclaimed. Most of the furniture pieces in Gina's apartment were castoffs reclaimed by her. She invested significant psychic attention (Csikszentmihalyi \& Rochberg-Halton, 1981) into each of the pieces as she repaired, refinished, and reupholstered broken objects changing them into functional, beautiful possessions. These pieces along with the painting above her bed are embedded meanings of being reclaimed and made beautiful.

Power of the maternal. Photographs of her socially successful children and their families prominently displayed in silver frames and the crystal and china belonging to her mother are embedded with the strength of the maternal relationship in Gina's life. Additionally, her daughter's investment in helping choose each of the possessions Gina brought to her new place is embedded in each of the objects. Her late-mother is an anchor to Gina and Gina is an anchor to her children. These are embedded and layered meanings.

Cultured. Furniture pieces and décor objects are embedded with traditional highstatus culture. Fine art in the impressionistic style was personally sought out, chosen, and displayed with intentional organization. Gina did not reclaim just anything. She reclaimed cultured objects. 
Household Case Study \#12: Claire. Claire moved from living independently in a single-family house (SFH-I) into a two-bedroom senior apartment (SA). It was her first downsizing move (DSM) as seen in Table 26. Below is Claire's life story.

Table 26

Claire's Profile

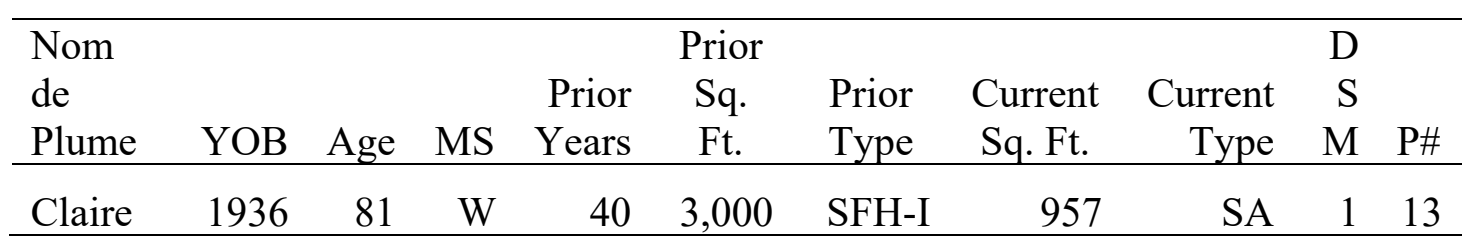

Claire was raised as an only child. Her extended family was cloaked in mystery. Many things she grew up believing were true were not. "When I was very young, I used to have questions, but my mother said it wasn't any of my business. She would never talk to me about family, and I never, never, never understood to this day." Both of her maternal grandparents died by the time Claire was five. Claire's father had been adopted, and she did not meet her only living grandparent, her dad's father, until she was seventeen.

Claire married and had three children but was widowed young. She lived by herself for forty years as her children spread throughout United States. Although it was exhausting, she loved her job. It required her to do research, which she enjoyed. She became a computer nerd not by choice, but because she was the first one in the office to learn how to use a computer. She discovered she liked it and bought her own computer in 1991. As with many others, the world got larger when the internet arrived.

As a naturally curious adult, Claire became deeply involved in discovering her genealogy. She had always resented not knowing about her extended family, and she 
finally spoke with her dad's half-brother. Her research led her to the facts she desired. When her father was nine, his mother had died, and he was given to his maternal grandparents to raise. He lived with them and an abusive aunt who he hated. When his grandfather died, his grandmother took her father and uncle back to live in her home in Copenhagen. One of the largest mysteries of her life was solved. After Claire's own father passed away, she inherited framed chocolate advertisements from Denmark that hat belonged to her great-grandmother. Her uncle had brought them back from Europe and given them to her father. The chocolate pictures meant a lot. They were tangible evidence that she had family history.

Claire worked for fifty-two years. She put in twelve to sixteen hours a day, traveling all but one week of the year. When it was time to retire, she was ready.

I visited with Claire a year after she relocated to an unfamiliar large metropolitan area to be close to one of her daughters. She was sensitive to the fact that she could no longer walk completely upright and needed the assistance of a walker, but she was proud of her apartment. She had lived in a two-story, 3,000 square feet house located in a much smaller city several hours away. She missed her home of forty years but acknowledged she could not live there after her sudden, unexpected stroke. Claire's daughter investigated over fifty places for her to move to. Together they toured six of them and decided upon one, The Fairbanks. All three of her children participated in her relocation, and she is "very happy in her little apartment."

Claire's out-of-town daughter is an interior designer and took charge of creating a beautiful and comfortable place for her mother. She chose items from Claire's existing furniture, hung the great-grandmother's chocolate pictures on the wall, and had new 
drapery installed before Claire arrived. The arrangements surprised Claire's only son, who did not understand why she purchased so much new furniture. She was thrilled to tell him, "I didn't buy one stick of anything!" Her children helped disband her previous house. They took some things, but most items were given away. Her in-town daughter was given the responsibility of storing Claire's physical photographs in her basement, which they hope to go through one day.

Claire's osteoarthritis caused her more problems after her stroke. She has "fierce back pain" but good days mix with the bad. "It's terrible to get old, but there's not much one can do about it." Her doctor, who is also a good friend, told her he could not stop her from experiencing the effects of aging, which she found hard.

In her senior apartment, she has two computers on her desk. She has three, altogether, but one is archaic, and she does not use it. When she talked about her computers, Claire said, "It's my life. I also use my iPad. I belong to a couple book clubs, and I read on the computer. I'm a news junkie. I just want to know what's going on in the world." After she recovered from her stroke, Claire appreciated things differently. "Home is just having the things that I like around me," she told me. She loves to sit and read or watch the world go around on the NASA channel for hours. Although others might think she is "absolutely nuts," Claire sees it as something she has always done-research. 
Table 27

Claire's Objectives Identified in the Narrative

Item \# Type Ownership

\begin{tabular}{lll}
\hline 1 & Furniture when she redid house $\quad$ Claire - midlife
\end{tabular}

$2 \quad$ Four pictures from Europe Claire's great-great-grandmother

3 Art class collectibles: two bowls, Claire's mother candy jar, glass shoe, and blue vases

$4 \quad$ Small painting Claire's boss - midlife

5 Clear, small vase with broken top Claire from her husband-young celebrating oldest daughter's birth life

6 A miniature porcelain horse that was Claire from a friend - midlife a gift from a friend.

$7 \quad$ A curio cabinet with collections $\quad$ Claire - midlife

8 Seven etchings bought because she Claire - midlife loved them

$9 \quad$ Etching given by Lloyd's of London Claire - midlife

10 Technology Claire - retirement

11 Books Claire - childhood on

12 CD \& DVD collections Claire-midlife on
13
Photographs
Claire_-childhood on 


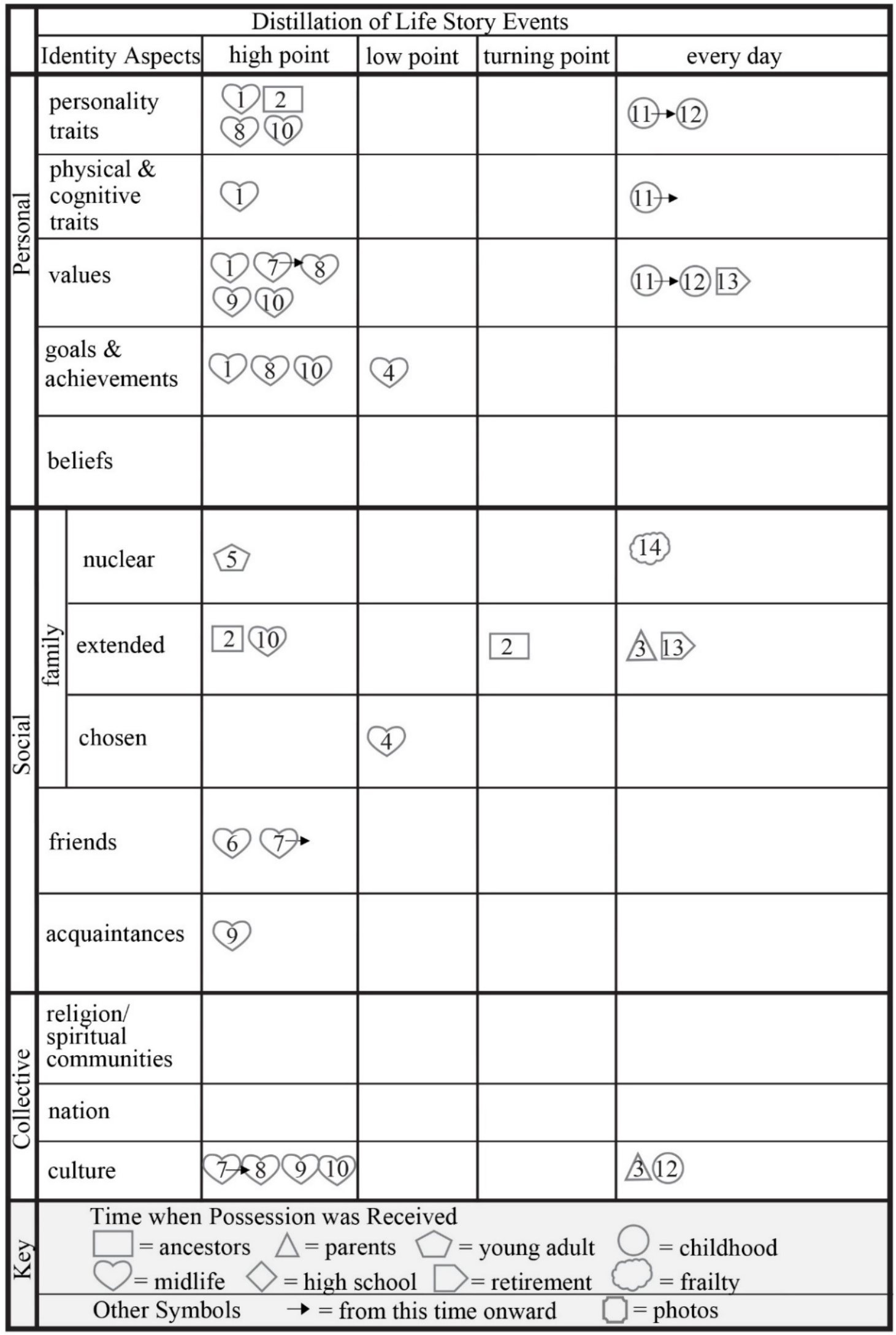

Figure 31. Claire Life Story Possession Analysis (LSPA \#12). 

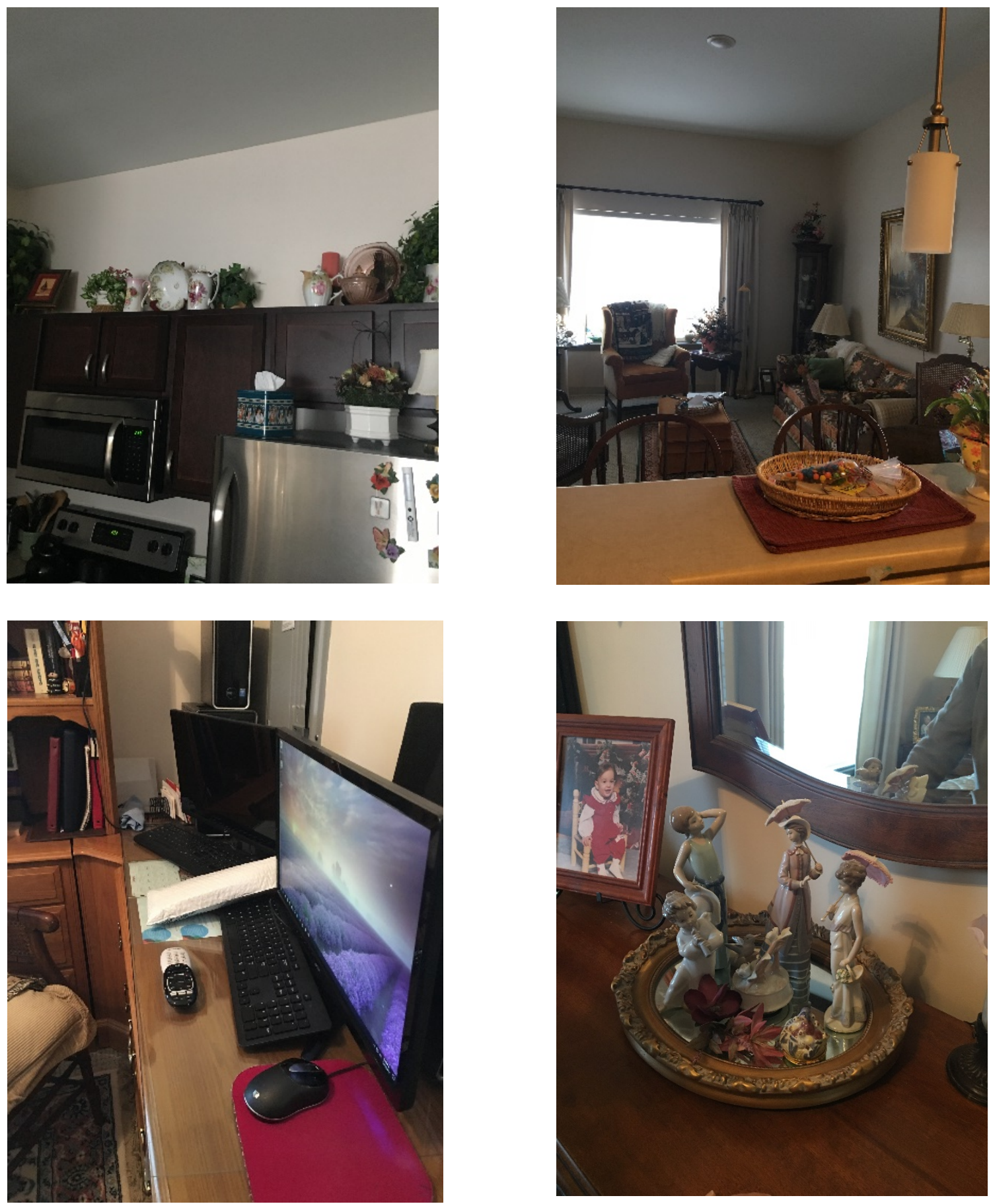

Figure 32. Photographs of Claire's storied possessions: upper left-painting by boss, mother's china; upper right—living room with drapery from daughter and furniture from house, painting; lower left—computer, books; lower right—photograph, Lladró figurines. 
Identity meanings, related in life span stories, embedded in the possessions

Claire moved to her new residence. There are three themes of meaning embedded in the possessions Claire moved into her senior apartment: 1) researcher, 2) independent, and 3) family and friends.

Researcher. Through research Claire extends herself into the world. She is fascinated by discovery and surrounds herself with precious possessions that represent her family discoveries and relational connections. Her favorite items collectively mean that Claire found out what was going on in her family and in the world. These possessions mean that Claire now has an extended family to which she belongs.

Independent. Claire purchased all her furniture after she became a widow. As a career woman she supported herself and traveled the world. Possessions purchased during those experiences are embedded with her successful independence.

Family and friends. Claire has many possessions given to and created by family and friends. Her children helped her move and arranged her furniture. Her daughter chose her drapery. All these items are embedded with the meaning that she is a valued family member and friend. 
Household Case Study \#13: Donna. Donna moved from living independently in a single-family house (SFH-I) into a two-bedroom apartment (A). It was her first downsizing move (DSM) as seen in Table 28. Below is Donna's life story.

Table 28

Donna's Profile

\begin{tabular}{|c|c|c|c|c|c|c|c|c|c|c|}
\hline $\begin{array}{l}\text { Nom } \\
\text { de } \\
\text { Plume }\end{array}$ & YOB & Age & MS & $\begin{array}{l}\text { Prior } \\
\text { Years }\end{array}$ & $\begin{array}{c}\text { Prior } \\
\text { Sq. } \\
\text { Ft. }\end{array}$ & $\begin{array}{l}\text { Prior } \\
\text { Type }\end{array}$ & $\begin{array}{l}\text { Current } \\
\text { Sq. Ft. }\end{array}$ & $\begin{array}{r}\text { Current } \\
\text { Type }\end{array}$ & DSM & $\mathrm{P \#}$ \\
\hline Donna & 1936 & 81 & W & 46 & 1,370 & $\begin{array}{r}\text { SFH- } \\
\text { I }\end{array}$ & 930 & A & 1 & 13 \\
\hline
\end{tabular}

Donna's father was an alcoholic. His disease dominated her childhood. High school became a haven for her. She was very social. Academics played a far secondary role. She liked being friendly to everyone, not just her best friends or social circle, and she loved playing the piano. Her parents bought a second-hand upright, so she could practice at home. Daily, immediately after school, she taught her fingers what keys to play. She was joyous. One day she was stunned when she came home, and there was no piano. Her mother said the piano was too heavy for the living room floor, so her father took it away. This made no sense to Donna. She said losing the piano was the most traumatic experience of her life.

Years after the piano's disappearance, Donna discovered her father and his friends had stolen it. They took it to the neighborhood bar where they regaled each other with old Irish tunes. This characterized home life with her parents: unacceptable and sometimes cruel behavior hidden behind lies, fighting, and betrayal. High school was different. Donna reigned as a social star and was voted homecoming queen. Her boyfriend, Rocky, 
the star basketball player, was also homecoming king. After high school, they married. Donna never wanted a career.

Rocky provided a good living for them. He was the quintessential salesman, wining and dining potential clients. They had two healthy children, a boy and a girl, and a nice house. Rocky was a good handyman and fixed things as they broke or when Donna wanted something special created. The basement was his woodshop with tools hanging on the walls. She loved being outside. The garden was hers, and together they developed beautiful flower beds and a pond where she loved to watch dragonflies.

Rocky, like her father, was an alcoholic. Somehow it felt as though she ended up back where she started. After a heart attack, Rocky gave up smoking and drinking. Donna became involved in a program that helped the families and friends of alcoholics and slowly began making changes in her attitudes, behavior, and thinking. Daily she read inspirational literature. Her marriage improved. However, one winter while he was drying his hands at the kitchen sink, Rocky collapsed. Donna called 911, but he died in her arms.

She was devastated by his loss. Sometime later she watched the movie Dragonfly (Shadyac, 2002) in which a doctor communicates with his late wife through a dragonfly. Donna experienced several such instances, during which she felt Rocky was helping her, specifically with things around the house, in the garden, or with her financial budget. One such experience happened in his basement woodshop. She treasured these meaningful experiences. Connecting them with the movie plot made dragonfly images symbolic for Donna. Her son is a metal sculptor and made several dragonfly pieces for her garden. As she approached her eightieth birthday, Donna began finding household maintenance burdensome. She moved into a two-bedroom apartment, so family members 
can stay the night when they want. She has wall hangings with positive wordstranquility, harmony, balance, and Chinese writing that meant good life given to her by a Chinese friend. She said these inspirational words help her to "keep things harmonious even when I disagree with friends and family."

I interviewed Donna twice in her apartment and asked her to tell me about her life and her possessions. She showed me the photo album she was given for her eightieth birthday. She said photo albums in general helped her remember past events and family. When she moved, she boxed most of her albums and put them in her closet. Her refrigerator is covered with photographs that she consistently updates.

On her fireplace mantel, Donna has a plaque with the Serenity Prayer. It has been her daily prayer for over twenty-five years. She tries to live more positively all the time saying she had to "really work at it forever; it's so easy for me to fall back into the negativity I was raised with.” She also has angels. When she looks at angels, she feels peaceful. One angel is an urn with her good friend's ashes, which is also on the mantlepiece. She put her husband's photograph on her nightstand next to her bed. He had provided financially for her, even after his death. "When I look at my husband's picture, it reminds me that I couldn't live here if it weren't for him.”

Donna can see her small patio garden from her dining room table. She loves her son's artwork, his metal sculptures, especially his dragonflies, which are now in her tiny garden on the back patio. They remind her of the living dragonflies that frequented the household pond; they remind her of her husband and the many times she felt his presence after he died. There are stepping stones in the garden with sayings on them: "Life is not measured by the breaths we take, but by the moments that take our breath away" and 
"Water your spirit by faith." Donna placed the stones, so she could see them from inside as well as when she sat outside, surrounding herself with chosen thoughts of serenity. 
Table 29

Donna's Objects Identified in Narrative

\begin{tabular}{|c|c|c|}
\hline Item \# & Type & Ownership \\
\hline 1 & photo albums & Donna from her life \\
\hline 2 & family photographs on refrigerator & Donna from her life \\
\hline 3 & framed photographs from $80^{\text {th }}$ party & Donna \\
\hline 4 & wall hanging — tranquility & Donna \\
\hline 5 & wall hanging_harmony & Donna \\
\hline 6 & wall hanging_balance & Donna \\
\hline 7 & stepping stones - Chinese good life & Chinese friend \\
\hline 8 & Plaque-Serenity Prayer & Donna \\
\hline 9 & "Life is not measured by the breaths & Donna \\
\hline & we take, but by the moments that & \\
\hline & take our breath away." & \\
\hline 10 & "Water your spirit by faith." & Donna \\
\hline 11 & angel (urn) & good friend \\
\hline 12 & dragonflies & made by son \\
\hline 13 & Photograph of husband as a younger & Donna \\
\hline
\end{tabular}




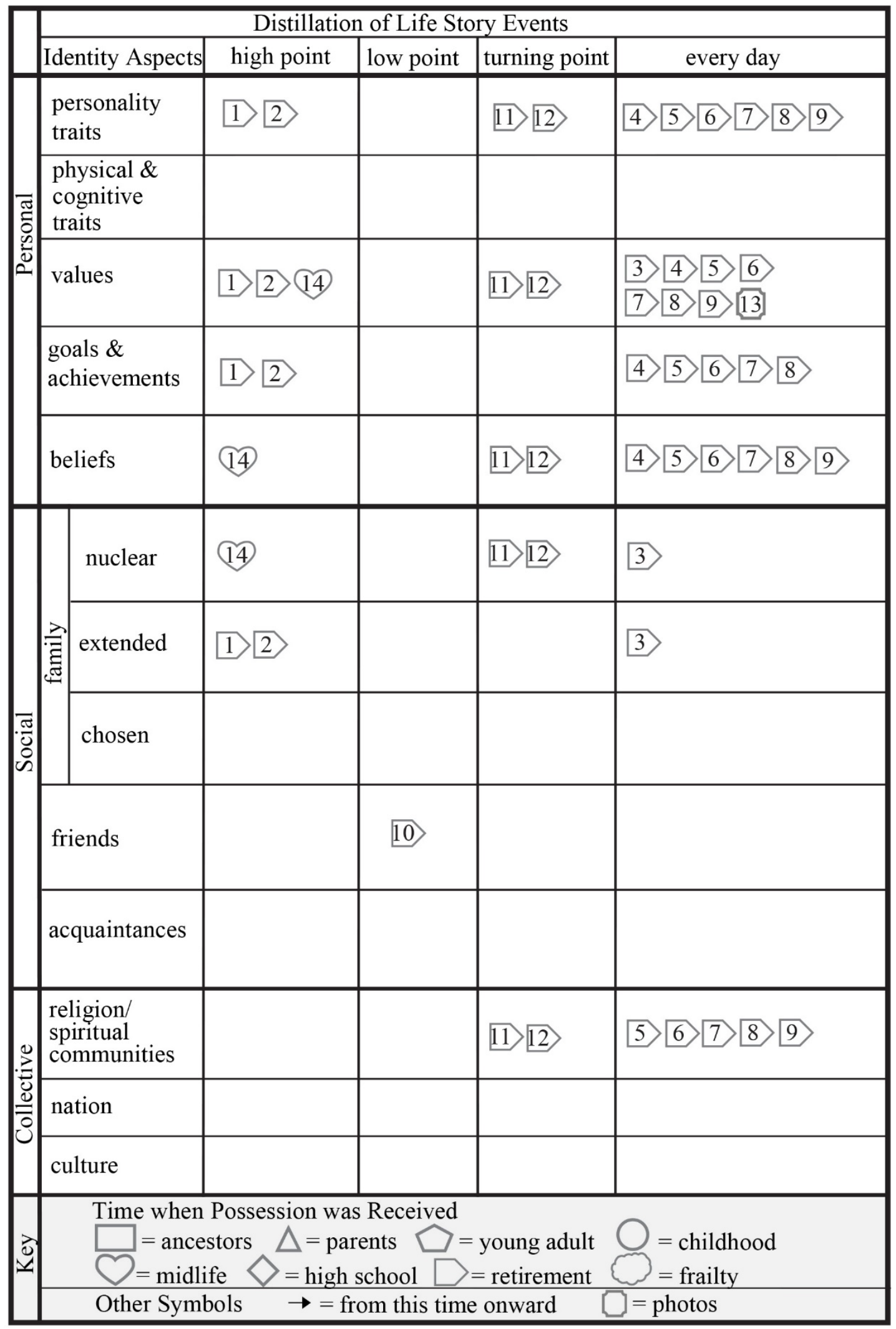

Figure 33. Donna's Life Story Possession Analysis (LSPA \#13). 

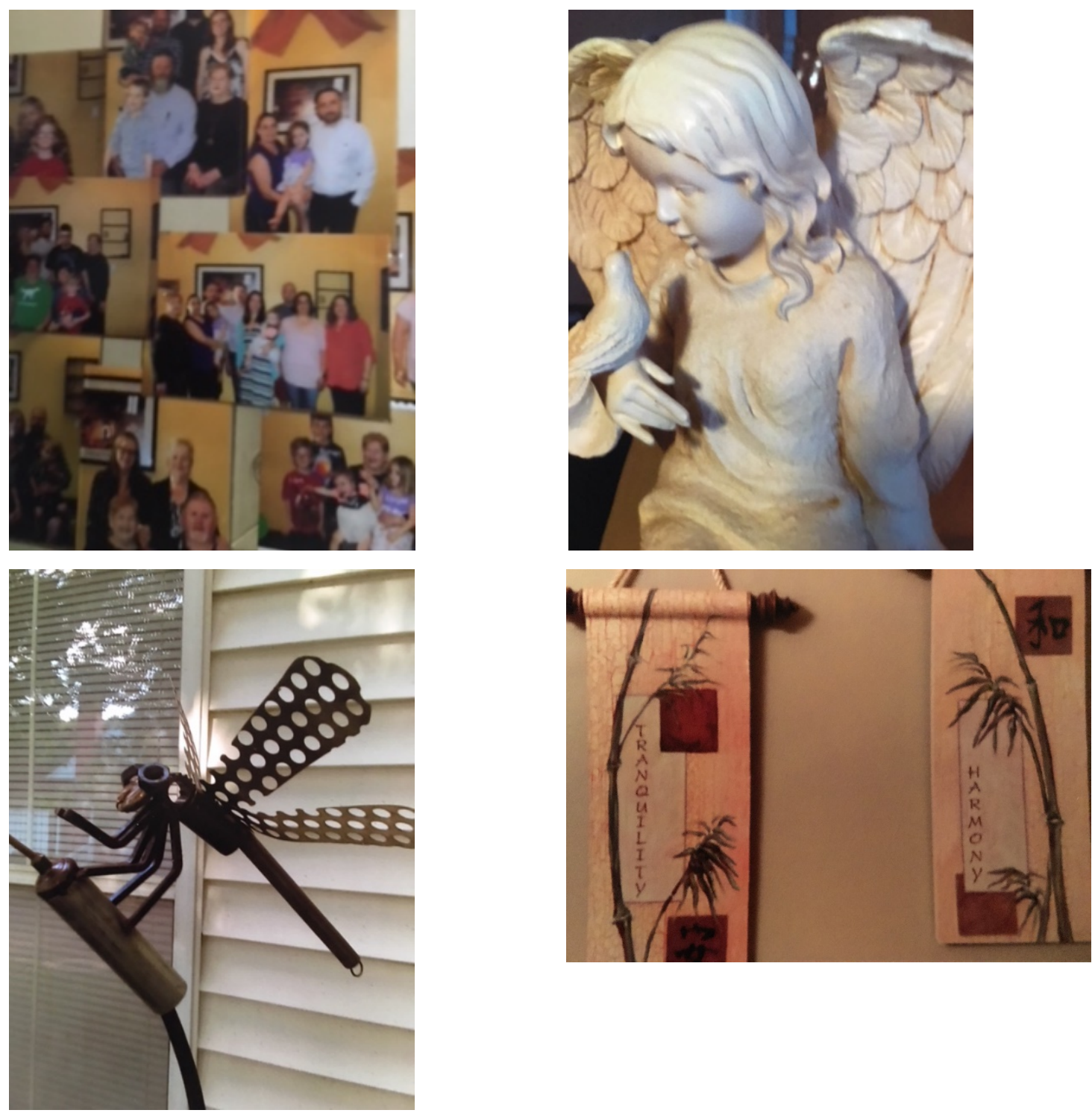

Figure 34. Photographs of Donna's storied possessions: upper left—photo collection of family during $80^{\text {th }}$ birthday celebration; upper right — angel cinerary urn; lower left—son's dragonfly metal work; lower right—wall hangings with inspirational words.

Identity meanings, related in life span stories, embedded in the possessions

Donna moved to her new residence. There are three themes of meaning embedded in the possessions Donna moved into her traditional apartment: 1) turns to the positive, 2) embraces family, and 3) remembers family and friends. 
Turns toward the positive. Donna displays inspirational word to remind herself to live positively in the present. The possessions in her garden are embedded with the meaning of growth.

Embraces family. Photographs of family gatherings remind her of family. They are her most precious possessions because they mean all her family was able to get together despite difficulties and celebrate her life.

Remembers family and friends. Dragonflies and angels are embedded with symbolic meanings of her husband, his care for her, and a dear imperfect person who was still her friend. 
Household Case Study \#14: Nina and Oliver. Nina and Oliver moved from living independently in a single-family house (SFH-I) into a two-bedroom cooperative senior community (CSC) apartment. It was their second downsizing move (DSM) as seen in Table 30. Below is Nina and Oliver's life story. Table 30Nina and Oliver's Profile

\begin{tabular}{|c|c|c|c|c|c|c|c|c|c|c|}
\hline $\begin{array}{l}\text { Nom } \\
\text { de } \\
\text { Plume }\end{array}$ & YOB & Age & MS & $\begin{array}{l}\text { Prior } \\
\text { Years }\end{array}$ & $\begin{array}{c}\text { Prior } \\
\text { Sq. } \\
\text { Ft. }\end{array}$ & $\begin{array}{l}\text { Prior } \\
\text { Type }\end{array}$ & $\begin{array}{l}\text { Current } \\
\text { Sq. Ft. }\end{array}$ & $\begin{array}{r}\text { Current } \\
\text { Type }\end{array}$ & DSM & P\# \\
\hline Nina + & 1936 & 81 & M & 20 & 3000 & $\begin{array}{r}\text { SFH- } \\
\text { I } \\
\text { SFH- }\end{array}$ & 1,440 & CSC & 2 & 28 \\
\hline Oliver & 1938 & 79 & M & 20 & 3000 & I & 1,440 & $\mathrm{CSC}$ & 2 & 28 \\
\hline
\end{tabular}

Nina was born in a small Midwest town and grew up in a home with Christian values and teachings. She attended a one room school house until she went to high school. Her father was a factory manager following in the career footsteps of his father in the dairy industry. After high school, Nina went to a small conservative Christian college in Illinois more to stay in step with her own upbringing than out of commitment to the articulated values. After graduation she moved to Chicago and worked as an office assistant. At the height of the Playboy empire, she began working for Hugh Heffner enjoying the parties and collective energy.

Oliver grew up in a middle-class working family in a steel manufacturing community. He served in the Navy during the Korean Conflict. When he left the Navy, he went to work for the State Department and was posted to Japan. He became fluent in a several languages and was an avid reader. It was in Japan he met Nina, who, had begun working for the State Department as well. 
Throughout their careers, Oliver and Nina were posted to countries all over the world. While they were in Asia, they adopted their only child, a daughter, Merida. A tight bond was created between the three of them. Although their semi-nomadic lifestyle overseas was filled with professional social engagements, it was also relatively lonely.

The three loved to shop. It was a way to engage with the various cultures, and they accumulated most of their household objects together. Their first major purchases were Persian rugs on their honeymoon in Singapore. These culturally significant rugs increased in value over the years, and they warmed the floors of their senior living apartment. Rattan living room furniture was purchased after many years of living in furnished apartments. They added a custom print made for them by a famous artist while they lived in Japan. It was Oliver's most precious possession. Bookcases housed an extensive book collection.

When they began disbanding, Oliver, a book lover, sold over 2,000 books from his library. In the process, he met world renowned authors and learned about book-cities, towns that supported independent, iconic, brick and mortar bookstores. Within twentyfour hours of listing one of his books online, he had over four-hundred offers. It was an unanticipated adventure and educational experience that anesthetized some of the pain of divestment.

I visited with Nina and Oliver five times, face-to-face and via email. Merida was at in-person meetings and actively participated in our conversations. She told me that when she thought about their many residences over the years, she realized that the living room arrangement was the primary element that gave her a sense of home. Throughout their moves, the furniture arrangement had always been a consistent element in their 
changing living space. During the disbandment, Merida became a recipient of many of their possessions. Unlike many adult children of her generation, she was interested in keeping her parents' precious possessions. She has not stayed in contact with girlhood friends; it is her parents' possessions which connect her to her childhood.

The distillation of their belongings was a three-year process. The most difficult aspect was the deaccumulation. When they originally retired to the gated lake community, they moved into a 3,700 square foot house, smaller than their previous residences. Many of their belongings, including what they called the chicken-chair, were stored in their detached garage, which Nina called huge. Their new apartment is 1,400 square feet with two bedrooms. Nina had disliked the corridor leading to the apartment because it reminded her of a hotel. However, when she opened the door to their apartment, she immediately felt at-home.

During disbandment, Nina and Oliver, who dislike the thought of constantly carrying cell phones, became very adept using CRAIGSLIST ${ }^{\circledR}$ and $\mathrm{eBay}{ }^{\circledR}$ to sell their belongings to people across the States. Some buyers drove thousands of miles to pick up unusual items. They incorporated family heirlooms into their apartment. Silver framed photographs of parents and other family members adorn a hardwood sofa table. A framed child's watercolor painting is both a result and a memory of Merida's childhood art lessons. Her childhood rocker is displayed. And once again, Oliver and Nina remained true to their decades long established practice and arranged the living room in the pattern that connects them all to the past. 
Table 31

Nina and Oliver's Objects Identified in the Narrative

Item \# Type Ownership

\begin{tabular}{lll}
\hline 1 & Mother's cedar chest & Nina - parents
\end{tabular}

$2 \quad$ Framed picture of doily Nina - parents

3 Mother \& Dad's table family pictures Nina - parents

4 rocking chair Nina - parents

5 quilt Nina - parents

6 stool Nina - young adult

$7 \quad$ Peruvian vintage hall tree Nina \& Oliver - midlife

$8 \quad$ Kitchen table, red oriental chairs $\quad$ Oliver - young adult

$9 \quad$ Mountain stone carving Peru Oliver \& Nina - young adult

10 Italian ceramics Nina \& Oliver - midlife

11 Parador from Philippines Nina \& Oliver - midlife

12 Magdalena Armoire Nina \& Oliver - midlife

13 Korean chest Nina \& Oliver - midlife

14 pictures our daughter drew Nina \& Oliver - midlife

15 Ceramic from Peru Nina \& Oliver - midlife

16 Hibachi and Tetsubin antiques Oliver \& Nina - young adult

17 decoupage patchwork cat Nina \& Oliver - midlife

18 Japanese chest Nina - young adult 
Woodblock print from Japan

20 living room furniture baskets

21 tea-kettle

22 Woodblock print from Japan

23 our daughter age 2 and 4

24 painting from Burma

25

26

27

28 potted plant

books

Persian rugs from Singapore

Breuer chairs
Oliver \& Nina - young adult

Nina \& Oliver - midlife

Nina - midlife

Oliver \& Nina - young adult

Oliver \& Nina - young adult

Oliver \& Nina - young adult

Nina - retirement

Oliver - childhood on

Oliver \& Nina - young adult

Oliver \& Nina - retirement 


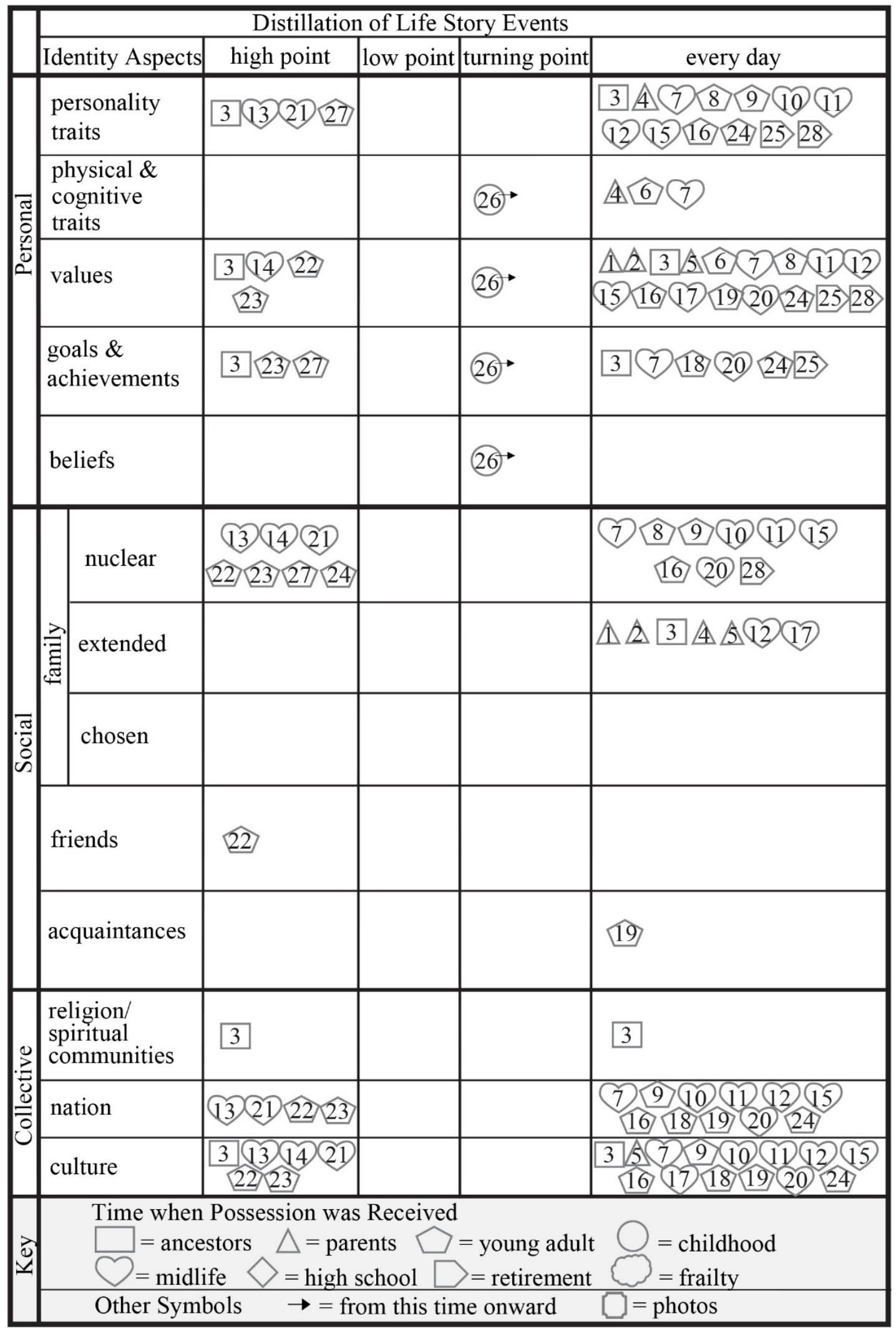

Figure 35. Nina and Oliver's Life Story Possession Analysis (LSPA \#14). 

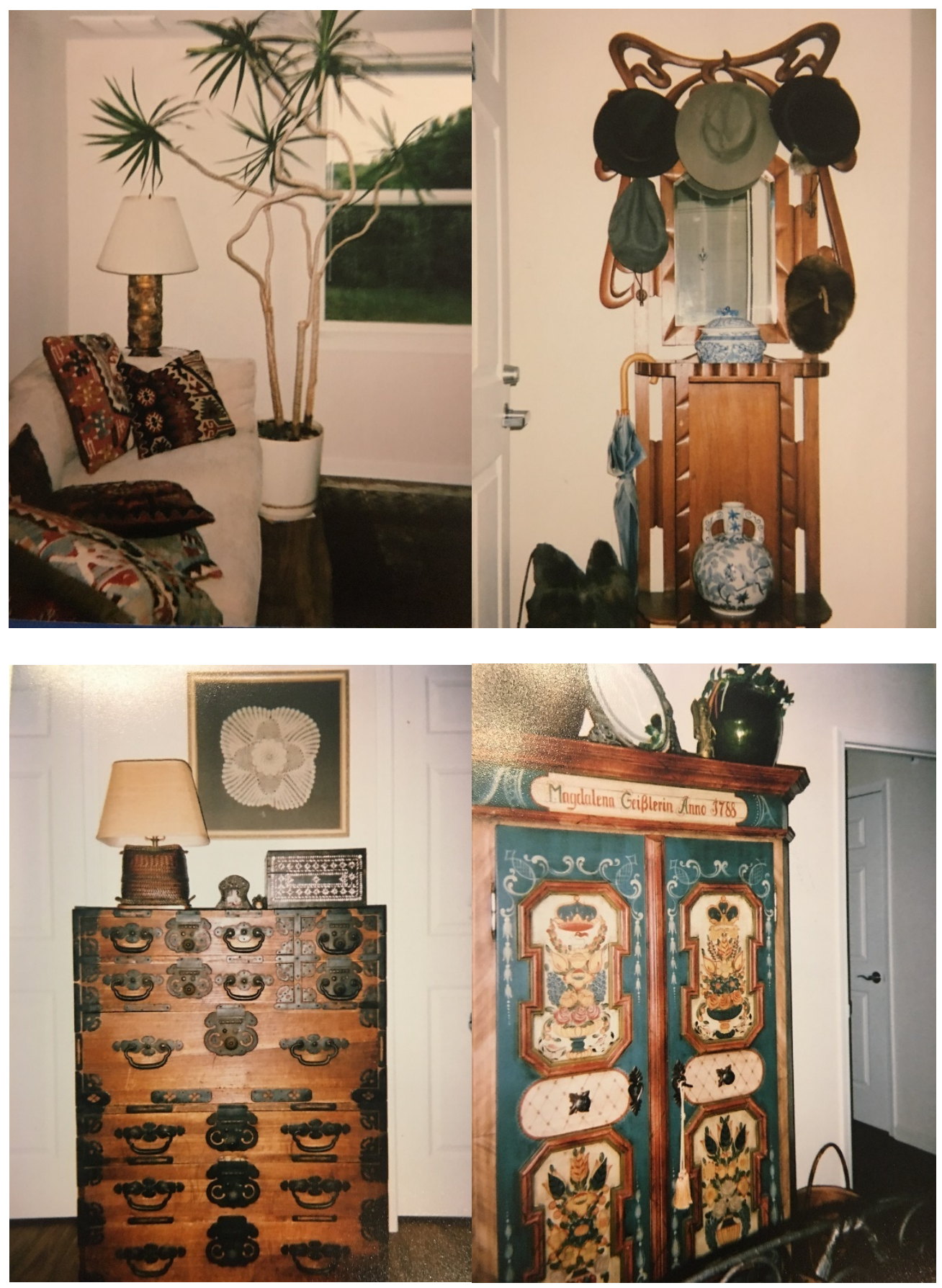

Figure 36 Photographs of Nina and Oliver's storied possessions: upper left—sofa with pillows from previous houses, 20-year-old plant; upper right-hall tree with Oliver's hats; 
lower left—Parador from Philippines, Korean chest, mother's doily; lower rightMagdalena Armoire.

Identity meanings, related in life span stories, embedded in the possessions Nina and Oliver moved to their new residence. There are three themes of meaning embedded in the possessions Nina and Oliver moved into their senior cooperative apartment: 1) international, 2) family, and 3) book collector.

International. A possession from each country they lived in was brought to their new residence. Fine art and furniture pieces are embedded with the meanings of serving their country abroad on many assignments and relationships they developed in those countries.

Family. The strength of surviving as a nuclear family isolated from extended family is also embedded in furniture pieces, Persian rugs, and the living room furniture arrangement. Extended family is embedded in photographs, a collection of letters-home, hand-crafted items, and furniture.

Book collector. Oliver is the quintessential book collector. His remaining books are embedded with the meanings of culling the collection and providing safe passage to the hundreds of books he sold online to other collectors. They embed the most painful part of disbandment for him. 
Household Case Study \#15: Susan. Susan moved from living independently in a single-family house (SFH-I) into a two-bedroom senior apartment (SA). It was her second downsizing move (DSM) as seen in Table 32. Below is Susan's life story.

Table 32

Susan's Profile

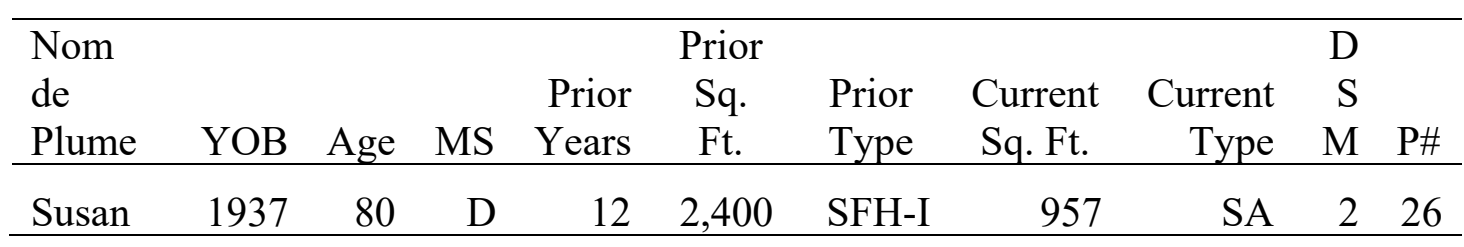

Susan was six when her father left to fight in WWII. He returned a hero with a bronze star, but shortly after he returned, it became evident he had a drinking problem. Her mother separated from her father when Susan was nine and she only saw him one more time.

Her mother got a job in the corporate offices of a factory eventually moving up to the switchboard. The company had a nationally competitive, very generous four-year college scholarship. Growing up in a single parent family, rejected by her father, Susan felt she was on the outside looking in, but she found her place in the academic arena. She excelled, applied for, and earned the prestigious scholarship. It was the only way she could attend college. Her mother used all her income providing for their daily care. There were no student loans. The scholarship paid for everything, even books, and two-thirds of room and board. She graduated high school as valedictorian and used the scholarship at an out-of-state university.

She earned her bachelor's degree in education and came back to teach in a poor rural area close to her mother's house. She drove home on the weekends because in the 
place she taught it was neither socially acceptable nor thought safe for unmarried females to spend time alone outside of work. She met her husband, Arthur, on a weekend visit home. After they married, Arthur and Susan had a daughter, Tina, and then a son, Steven. Arthur began successfully climbing the corporate ladder early in their marriage. Each promotion required a physical move. Susan was a dutiful wife but bending to the will of a controlling executive was unnatural for her. Arthur lived the domestic standards of his generation. Raised by a working, single-mother, Susan was not used to trusting a man of the house to make the decisions.

Susan continued with her education, but their serial moves made it difficult, particularly after she earned her master's degree. In an education psychology class, she taught as part of her $\mathrm{Ph}$. $\mathrm{D}$. dissertation research, she asked the college students to bring a favorite object to class and share what it meant to them. A young Vietnam veteran, who was getting his undergraduate degree in education, was in her class. He shared about his war experience explaining that when he finished his tour in Vietnam, he was disillusioned, bitter, and felt betrayed by the United States. Picking up work where he could, the vet ended up in Greece working with an old sponge diver. Together they harvested the sponges deep in the sea. Being mentored by the old diver gave the Vietnam vet the tools and guidance to come to terms with the way his country handled the war and treated soldiers. Back at home, he was studying elementary education because he wanted to help children understand about tolerance and compassion. Concluding his talk, the vet showed the class his favorite object. Turning to Susan, the returned soldier said, "I want you to have this. It's one of the sponges from Greece." 
It took her seven tenacious years and three universities to finish her Ph.D.

dissertation which she wrote by hand. She paid a secretary at Arthur's company to type it for her. She taught at universities, and at one corporate posting in the northeast, she ran for and won a seat on the school board. She was a southern, Democratic female on a board comprised of northern, Republican males. She learned how to negotiate politics and help others see it her way. Her marriage, unhappily, ended in a painful divorce.

One day after separation from her husband, Susan was in a friend's great room sharing about her deep woundedness. She mentioned how difficult it was to sleep in bed by herself. Her friend, a sympathetic listener, had a young daughter at home. The little girl stopped watching the TV and came back with a stuffed, Pot Belly Bear. She said, "Here, Miss Susan, you take Pot Belly Bear home with you. Sleep with him, and then you won't be lonely in your bed."

Susan used Pot Belly when she taught, explaining that he was a continual reminder that God's angels come in all different sizes. She became the founder and executive director of a county residential school for at-risk teenagers. She wrote new guidance policies for the city. Susan also traveled internationally with friends, visiting Thailand, China, and Africa for mission trips.

Susan retired to take care of her mother who eventually died from cancer. Her children and grandchildren were successful in their schooling and careers and actively involved in Susan's life. Because her daughter is a medical doctor, Susan decided to relocate closer to her when she turned eighty. Self-described as the healthiest eighty-year old she knows, Susan exercises daily, still drives, and travels with friends and family. 
When she disbanded her Southern home and relocated, she put her mother's hope chest by her bed to remind her that when life feels hopeless, one can always look for something a little bit better. Pot Belly sits on her bed, and the Greek sponge has a place of honor and practicality on her bathroom vanity. 
Table 33

Susan's Objects Identified in Narrative

\begin{tabular}{|c|c|c|}
\hline Item \# & Type & Ownership \\
\hline 1 & $\begin{array}{l}\text { furniture bedroom set, desk, } \\
\text { furniture, entertainment center, end } \\
\text { tables, corner knickknack shelf, } \\
\text { corner curio }\end{array}$ & Susan and her mother - retirement \\
\hline 2 & framed photographs & $\begin{array}{l}\text { Susan's family and friends - midlife } \\
\text { on }\end{array}$ \\
\hline 3 & photo albums & Susan - parents on \\
\hline 4 & Pot Belly Bear & Susan - midlife \\
\hline 5 & memorabilia from Africa & Susan - midlife on \\
\hline 6 & book from Africa & Susan - midlife \\
\hline 7 & $\begin{array}{l}\text { story lady (Native American story } \\
\text { teller pottery) from gentleman } \\
\text { friend }\end{array}$ & Susan - midlife \\
\hline 8 & mother's bird figurines & Susan - mother's \\
\hline 9 & bird house from friend & gift from friend - midlife \\
\hline 10 & painting from South Bend, Indiana & Susan - young life \\
\hline
\end{tabular}


11 nativity scenes made by mother

12

13

14

15

16

17

18

19

23

24 memorabilia from Thailand

wooden painted eggs from

Ukrainian friend

PhD diploma

children's books commemorating

civic work

computer

memorabilia from Rhode Island

memorabilia from China

mother's hope chest

hat from Paris

Greece sponge from veteran

lamp filled with beach shells

beaded necklaces from trip to Holy

Land from one of the beaches

keeshond figurine-Susan’s dog
Susan - mother's

Susan - retirement

Susan - midlife

Susan - young life

Susan for civic work - midlife

Susan - retirement

Susan - midlife

Susan from mission trip - retirement

mother's young life

from Paris - midlife

Susan - midlife

Susan - retirement

Susan - retirement

Susan's dog - midlife 
25 different copies of the Bible and my Susan - young life

books for study

26 personal journals written over Susan - young life on

lifespan 


\begin{tabular}{|c|c|c|c|c|c|}
\hline & \multirow{2}{*}{\begin{tabular}{|l|} 
Identity Aspects \\
\end{tabular}} & \multicolumn{3}{|c|}{ Distillation of Life Story Events } & \multirow[b]{2}{*}{ every day } \\
\hline & & high point & low point t & turning point & \\
\hline \multirow{5}{*}{$\mid$} & \begin{tabular}{|l} 
personality \\
traits
\end{tabular} & 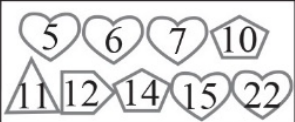 & & & (22) \\
\hline & \begin{tabular}{|l|} 
physical \& \\
cognitive \\
traits \\
\end{tabular} & (6) 14,15 & & 19 & 25 \\
\hline & values & $\begin{array}{l}7) 10 \text { 14 } 11 \\
12,15,18 \text { (22) }\end{array}$ & & & 1 (2) 31322,24 \\
\hline & $\begin{array}{l}\text { goals \& } \\
\text { achievements }\end{array}$ & $\begin{array}{c}14)(15)(17) \\
(20) 23\end{array}$ & & (4) & 25 \\
\hline & beliefs & $\begin{array}{l}5015 \\
23 \\
23\end{array}$ & & & $2 5 \longdiv { 2 6 }$ \\
\hline \multirow{5}{*}{ 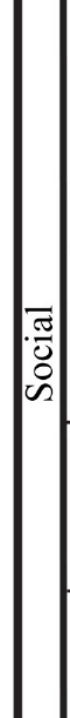 } & nuclear & 10 & & & (2) (24) \\
\hline & 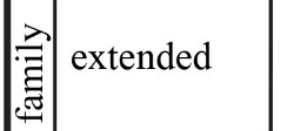 & 14 & & & (2) 3 - 819 \\
\hline & chosen & & & & \\
\hline & friends & $\begin{array}{l}(5)(6) \\
12.15\end{array}$ & & (4) & (2) (3) 9 \\
\hline & acquaintances & (5) 15 (17) & & (21) & (2) 3 (13) 16 \\
\hline \multirow{3}{*}{$\begin{array}{l}1 \\
0 \\
0\end{array}$} & $\begin{array}{l}\text { religion/ } \\
\text { spiritual } \\
\text { communities }\end{array}$ & (5) (7) 10 & & 25 & \\
\hline & nation & (17) & & & $16)$ \\
\hline & culture & (5) 7 10 12 & & & (13) 19 \\
\hline & \multicolumn{4}{|c|}{$\begin{array}{l}\text { Time when Possession was Received } \\
\begin{array}{|l}\square=\text { ancestors } \triangle=\text { parents } \square=\text { young adult } \\
\bigcirc=\text { midlife } \triangle=\text { high school } \square=\text { retirement } \\
\text { Other Symbols } \rightarrow=\text { from this time onward }\end{array}\end{array}$} & $\begin{aligned} &=\text { childhood } \\
&=\text { frailty } \\
& \bar{J}=\text { photos }\end{aligned}$ \\
\hline
\end{tabular}

Figure 37. Susan's Life Story Possession Analysis (LPSA \#15). 

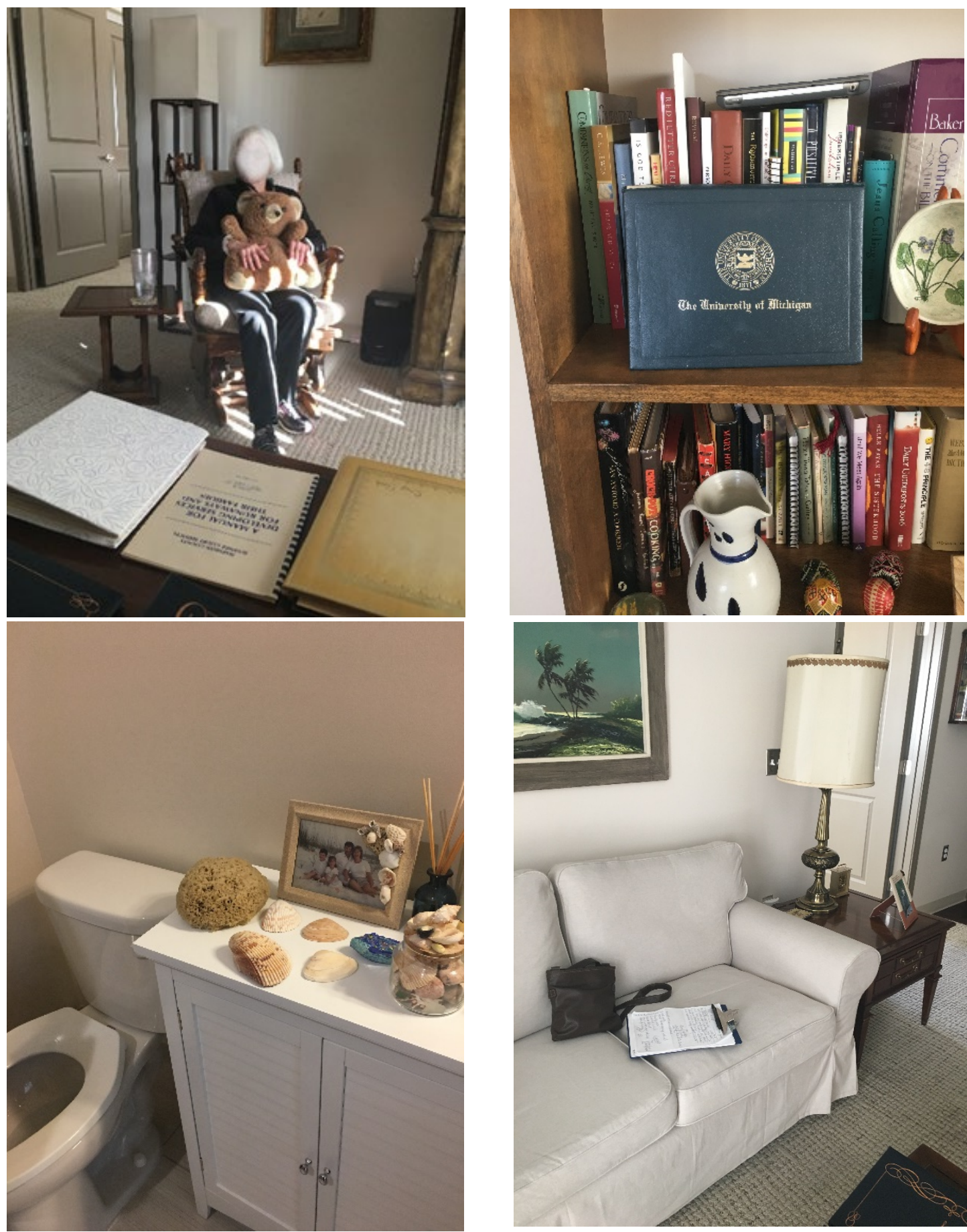

Figure 38. Photographs of Susan's storied possessions: upper left—Susan's chair, Pot

Belly Bear, photograph albums, and publish policy written by Susan; upper right- $\mathrm{PhD}$ 
diploma, study books, painted eggs; lower left—sponge and sea shells, family photo; lower right— beach painting, furniture.

\section{Identity meanings, related in life span stories, embedded in the possessions}

Susan moved to her new residence. There are four themes of meaning embedded in the possessions Susan moved into her senior apartment: 1) life of the sea, 2) surviving family, and 3) believer, and 4) educated professional.

Life of the sea Susan's favorite place is the beach. Fine art, décor, and collections are embedded with her love of the sea. One of her most precious possessions is embedded with the meaning of coming out of the sea as a redeemed person.

Surviving family Family is the highpoint of Susan's life. Her possessions are embedded with the meanings of family surviving being broken as seen in Pot Belly Bear, her mother's hope chest, and the beech scene painting.

Believer Souvenirs from mission trips, her Bible, study books, nativity sets, and journals are embedded with meanings of her active faith. Her divorce was a turning point in her life that she survived through work and her faith, a meaning embedded in the physicality of her Bible and narrated in her journals.

Educated professional. Susan's Ph.D. and the published city policy she developed for high risk teenagers are both embedded with the meaning of her success as an academic, educator, and administrator. 
Household Case Study \#16: Bernard and Abbie. Bernard and Abbie moved from living independently in a single-family house (SFH-I) into a smaller single-family house (SFH-I) in which they continue to live independently. It was their second downsizing move (DSM) as seen in Table 34. Below is Bernard and Abbie's life story. Table 34

Bernard and Abbie's Profile

\begin{tabular}{lrrrrrrrrrr}
\hline $\begin{array}{l}\text { Nom de } \\
\text { Plume }\end{array}$ & YOB & Age & MS & $\begin{array}{r}\text { Prior } \\
\text { Years }\end{array}$ & $\begin{array}{c}\text { Prior } \\
\text { Sq. } \\
\text { Ft. }\end{array}$ & $\begin{array}{l}\text { Prior } \\
\text { Type }\end{array}$ & $\begin{array}{c}\text { Current } \\
\text { Sq. Ft. }\end{array}$ & $\begin{array}{r}\text { Current } \\
\text { Type }\end{array}$ & $\begin{array}{r}\text { S } \\
\text { P\# }\end{array}$ \\
\hline Bernard+ & 1945 & 72 & M & 11 & 4,200 & SFH-I & 2,450 & SFH-I & 2 & 18 \\
Abbie & 1946 & 71 & M & 11 & 4,200 & SFH-I & 2,450 & SFH-I & 2 & 18 \\
\hline
\end{tabular}

A precocious child, Abigail disliked playing with dolls. It was knowledge and productivity which brought her contentment. Her grandmother, who Abbie adored, came to live with them when she was 18 months old. Abbie's aunt had various homes in far-off places - Germany, Tripoli, Japan — and took care to build a relationship with Abbie through the Hummels she collected for her. Abbie's father was an astute businessman who owned five appliance stores throughout the city. Her mother had a remarkable determination characterized by the plant she received when she was sixteen years old and had managed to keep alive throughout Abbie's childhood.

Bernard grew up in the same city as Abbie. His father was an electrician and his mother an artist and a fastidious stay-at-home mom. She vacuumed the house every day, a trait she passed on to her son. An artist who paid attention to color, she also had a love for music and collected 78 rpms. But Bernard, like Abigail, felt stifled in his childhood. "When I lived at home, and we lived in a pretty small house, I had to share a bedroom 
with my sister. I didn't want that. I wanted us to move so bad, bugging my parents to move, and they didn't."

Unbeknownst to either, Bernard and Abbie attended the same junior high, but it wasn't until high school that they became aware of each other's existence. Abbie, who had never really felt happy, fell head over heels and life changed. Not surprising to anyone, they married shortly after graduation.

After they married, Bernard and Abbie moved into public housing. Ironically, within a couple of years, Bernard's parents finally moved into that larger house about which he was always nagging them. Abbie and Bernard, with their two young children, Scott and Caitlin, moved to the same area as his parents.

The desire to move waned and ebbed in Bernard and Abbie's fifty years of married life. "We had a lot of houses.... I guess we get tired of houses fast." Abbie and Bernard moved into the largest house they owned after their son married. It was their favorite house. They lived there for fourteen years, but once both their children had their own places, Abbie and Bernard began the process of downsizing after the onset of health issues. Bernard began having hip problems. Abbie's knees caused her pain. Although downsizing was arduous, it allowed them to secure a meaningful retirement goal.

Abbie and Bernard wanted to spend time with their younger grandchildren, but their daughter lived outside the city. Abbie and Bernard moved from their suburban area into a more rural area six or seven minutes away from their daughter, Caitlin's house. The new house had much less storage, which forced the issue of the surplus of unopened boxes. Prior to moving, Abbie and Bernard systematically and rigorously went through each of the boxes, categorizing, sorting, and allocating belongings. 
Abbie and Bernard chose to keep meaningful family items such as the ninety-fiveyear-old plant that Abbie's mother received when she was sixteen, Bernard's greatgrandmother's handmade stool, his mother's bedroom painted-hurricane lamp, and Abbie's great-grandmother's lemonade pitcher. Another sentimental item was a set of acrylic grapes they received as a wedding present. "Even though I started thinking, "Those [grapes] look a little tacky," I wouldn't get rid of them because they have a meaning. Grandma Smith and my brother gave them to us. They're two of my favorite people." 
Table 35

Bernard and Abbie's Objects Identified in Narrative

Item \# Type Ownership

$1 \quad$ hand-crafted, tobacco-curing table $\quad$ Bernard's extended family

2 small stool, woven-reed seat, 1925 Bernard's grandmother

$3 \quad$ little table and chair Bernard's grandparent's

4 rose hurricane lamp Bernard's mother

$5 \quad$ childhood figurine, "Little Boy Bernard's dad

Blue."

6 desk Bernard's parents

$7 \quad$ toy box his dad built $\quad$ Bernard childhood

$8 \quad$ child's rocking chair $\quad$ Bernard childhood

9 painted lemonade pitcher Abbie's great-grandmother

$10 \quad 95$-year-old plant and plantstand Abbie's mother

11 secretary desk Abbie's parents

12 Hummel collection Abbie's from aunt childhood on

13 books Abbie and Bernard childhood on

14 Biblical reference books Abbie and Bernard young adult on

15 acrylic grapes in glass compote dish Abbie and Bernard young adult on

16 metal animal sculptures Abbie and Bernard midlife on

17 hand-crafted laundry room Abbie and Bernard young adult

18 pottery that our son made years ago. Abbie and Bernard's son midlife 


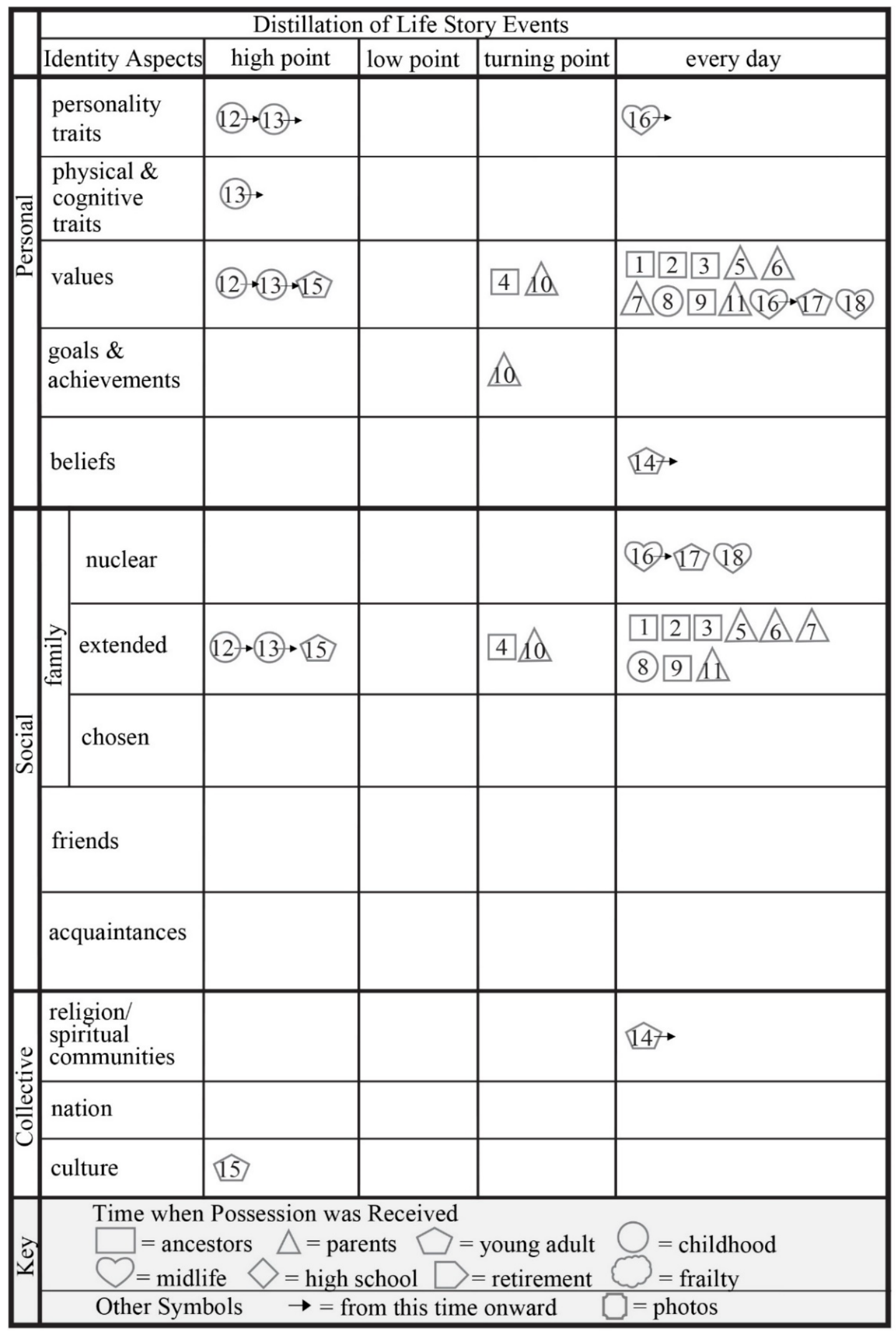

Figure 39. Bernard and Abbie's Life Story Possession Analysis (LSPA \#16). 

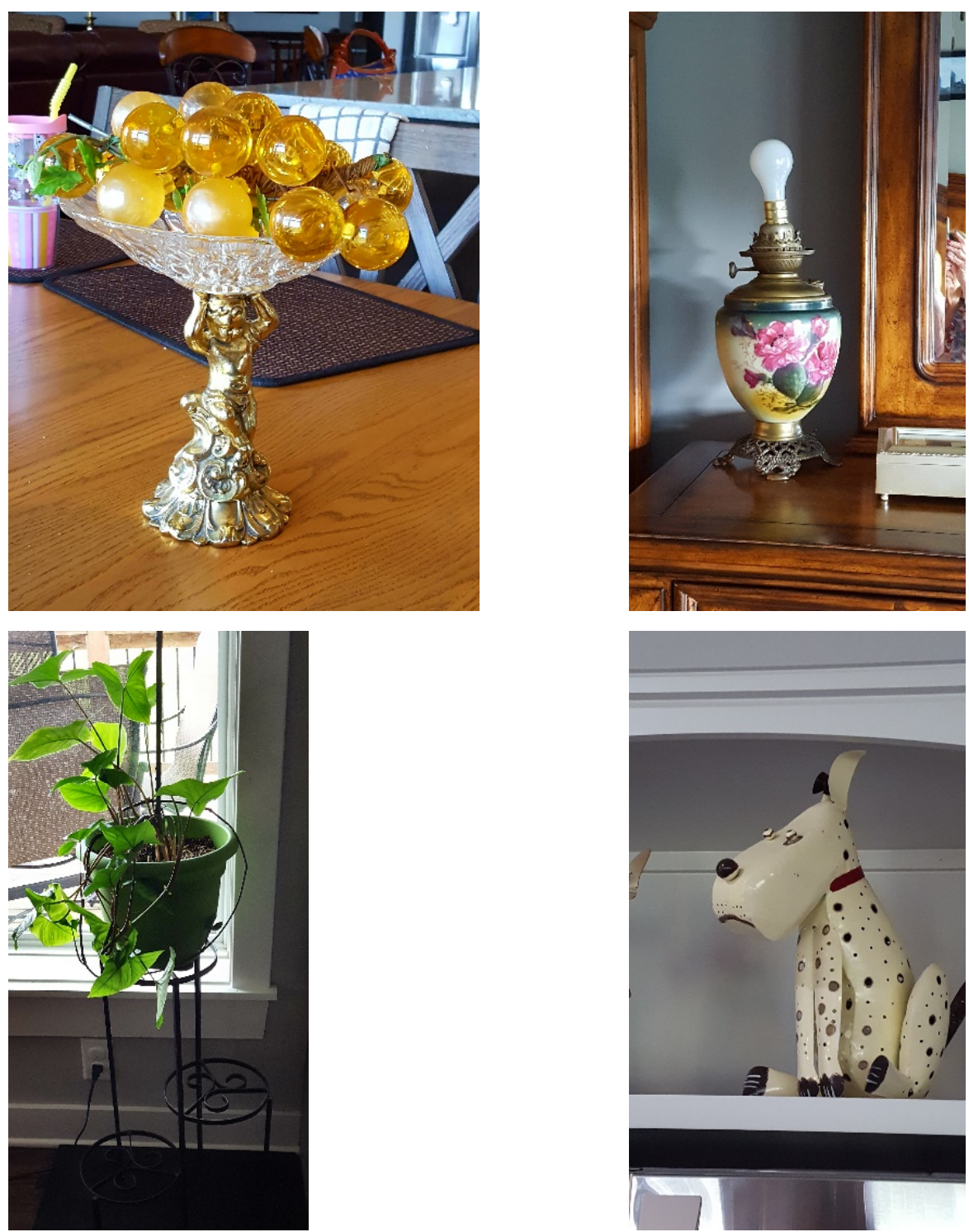

Figure 40. Photographs of Bernard and Abbie's storied possessions: upper left—acrylic grapes in compote dish; upper right—-mother's painted hurricane lamp without broken globe; lower left—mother's plant on plant stand; lower right—dog sculpture from collection.

Identity meanings, related in life span stories, embedded in the possessions Bernard and Abbie moved to their new residence. There are two themes of meaning 
embedded in the possessions Bernard and Abbie moved into their senior apartment: 1) family first and 2) collective faith.

Family first. All their possessions embed the meaning of family. Family collects together, gives gifts, provides safe passage for the past, and extends the mortality of members who have died by keeping heritage items. The house embeds the meaning of moving to be near grandchildren.

Collective faith. Abbie and Bernard are active church members and Bible teachers a meaning embedded in their Bibles, study books, and a hidden box of cassette tapes with sermons they traveled to conferences to hear.

\section{Within-Case Summary}

The sixteen within-case studies, which include twenty-three older adult participants, were analyzed to answer the research question, "What identity meanings, related in life span stories, are embedded in the possessions older adults move to their new residences?"

Findings suggest that identity meanings are richly and diversely embedded in many types of possessions. A total of seventy-nine identity meanings including personal, social, and collective identity meanings are illustrated in Figure 41. Personal identity meanings (fifty-three instances) account for over half the total. Social identity has twenty-one instances, and collective identity meanings has five instances.

In answer to the research question "What identity meanings, related in life span stories, are embedded in the possessions older adults move to their new residences," the seventy-nine identity meanings are found in thirty-five themes collected from the withincase analyses. Some themes have multiple identity meanings. For instance, one 
participant has a theme of fraternity and family. This theme has both collective-cultural and social-family meanings. Table 36 is a further analysis of the themes divided into three identity statements that begin with "I am" (twenty-four instances), "I believe" (six instances), and "I value" (five instances).

The diversity of meaning embedded within various possessions suggests that older adults have a rich sense of who they are, and they choose to bring that sense of identity into their new places. In addition to personal identity statements, family is a consistent identity theme that is expressed in all cases. This will be explored more thoroughly in the cross-case analysis. 


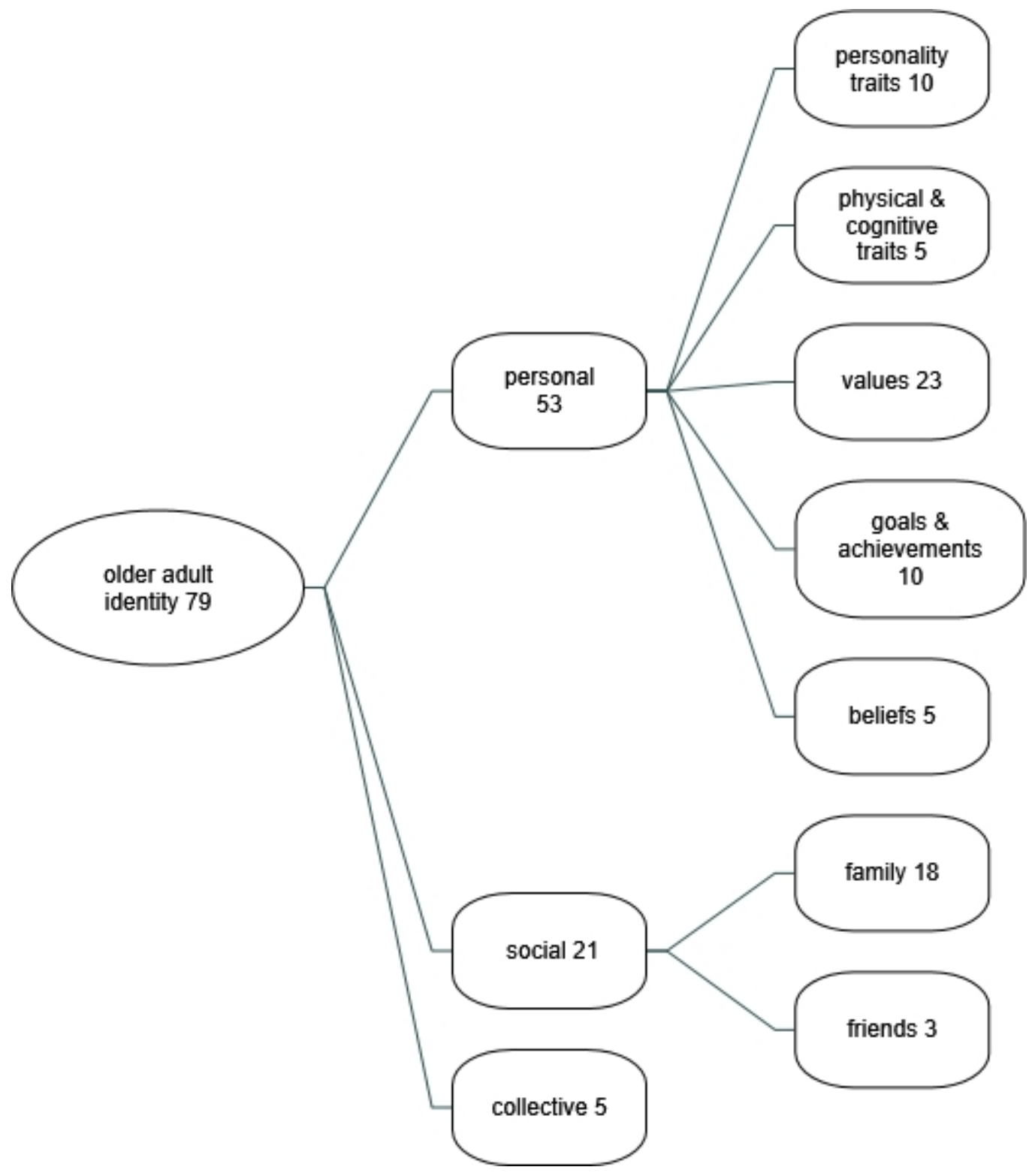

Figure 41. Coding map of collective within case identity themes based on Life Story Possession Analysis (LSPA) identity types. 
Table 36

Collective Themes Identity Statement Analysis

\begin{tabular}{|c|c|c|c|}
\hline & \multicolumn{3}{|c|}{ Personal Identity Statements } \\
\hline Theme & I am & I believe & I value \\
\hline Active and adaptable & 1 & & \\
\hline Art aficionado & 1 & & \\
\hline Believer & 1 & & \\
\hline Book collector & 1 & & \\
\hline Collector & 1 & & \\
\hline Cultured & 1 & & \\
\hline Educated professional & 1 & & \\
\hline Engaging the present & 1 & & \\
\hline Erasing emotional baggage & 1 & & \\
\hline Expandable & 1 & & \\
\hline Power of the maternal & 1 & & \\
\hline Surviving family & 1 & & \\
\hline Independent & 1 & & \\
\hline International & 1 & & \\
\hline Joyful in the unique & 1 & & \\
\hline Living in the present & 1 & & \\
\hline Living routines & 1 & & \\
\hline Made of the right stuff & 1 & & \\
\hline Not homey & 1 & & \\
\hline Reader and a writer & 1 & & \\
\hline Reclaimed & 1 & & \\
\hline Researcher & 1 & & \\
\hline Resisting rejection & 1 & & \\
\hline Turning toward the positive & 2 & & \\
\hline Books matter & & 1 & \\
\hline Collective faith & & 1 & \\
\hline Family matters & & 1 & \\
\hline Organization is less important than abundance & & 1 & \\
\hline Relationships matter & & 1 & \\
\hline Work is life & & 1 & \\
\hline Family & & & 8 \\
\hline Friends & & & 3 \\
\hline Life of the sea & & & 1 \\
\hline Created microcosm of previous life & & & 2 \\
\hline Memories of the past & & & 3 \\
\hline
\end{tabular}




\section{Cross-Case Themes: Embedded Family Meanings and Storied Possessions}

Below are themes found through the cross-case analysis that examined themes, similarities, and differences across the sixteen household cases (Mathison, 2011). These themes answer the second research question: "How do post-disbandment older adults embed the meaning of family when making place?"

Findings suggest older adults' relationships to their possessions are understood through life stories. These stories focus on salient points in their lives, quite often embedded with meaning of family. The storied possessions then contribute to late-life placemaking by temporally moving residents through chosen memories that incorporate family into their new residences. These memories represent low points, highpoints, and everyday events that occurred throughout their lives. An older adult participant, Susan, said, "In essence, if I had to capture it...everything that I brought pretty much has a story or is a symbol." An apropos quote from Myerhoff fills out Susan's statement and is seen in Kay's (2016) book, subtitled Life-Story Objects and Their Makers:

There are elderly people all over America, waiting only to be asked about their stories and folk art. Their memories and works are stored in boxes, in cellars, in trunks, in attics... needing only a witness to bring to the light, a recipient to complete the interchange that is requisite to all cultural transmission. (p. 16) As in folk art pieces mentioned above, embedding objects with stories occurs with other possession as well. Ekerdt et al. (2012a) found that "storytelling on behalf of possessions commonly conveys their histories" (2012a). It occurs with all types of possessions and is the reason that I term them storied possessions. 
The essence of these storied possessions fit into four themes: low points - the presence of loss, high points — pinnacle moments, and ordinary events — moments of everyday engagements.

Low points: The presence of absence. In a recent state eulogy, the declaration was made, "absence is tangible like the silence after a mighty roar" (USA Today, 2018). That is the essential meaning of this theme which I divide into two categories, 1) embedding and 2) adjusting.

Embedding loss into storied possessions: Signs and symbols. The terminology of signs and symbols refers to the Jung's (1964) definitions in Chapter 2.

Signs of loss. Signs, as noted by Jung (1964), have meanings that are culturally constructed, and therefore, understood without explanation from the older adult. Tangible signs of loss may be interpreted through standard cultural meanings as in the cinerary urns present in two households: one contains the ashes of a friend, the other contains a son's ashes. When showing me his son's urn, Leon said,

This is the son that was killed in the motorcycle accident. His widow had the urns prepared and shared them with us. She gave them to our oldest son, and he sent one to us, one to his brother, and one to his sister. He called us and told us, "Now it's on the way." We got the box. I told Bridgette, I said, "I can't open it." So, we called a very good friend of ours, a former pastor; he said, "Come on." So, we went up and talked to him, and he talked us through it. He said, "Now open it." Leon's account not only holds an implicit description of an object which became a storied possession, it is also a clear example of how the embedding and layering of stories can occur in a crucible of loss for older adults. Leon tells of the widow preparing 
and sharing the ashes, the older son sending the ashes and heralding their coming, the pastor shepherding the parents through the experience of holding their son's transformed body for the first time. The story embeds meanings within the urn about what death means in their family and community. Because cinerary urns are culturally understood (Cerezo-Román, Wessman, \& Williams, 2017), there is tacit meaning; however, the story concentrates and personalizes the meaning which is emphasized in Leon's heartfelt statement, "This $i s$ the son that was killed" [emphasis mine]. Leon holds within the cinerary urn the presence of absence.

Tillie's shadow box is also a storied possession with an obvious meaning of loss. It contains both a newspaper article about the fire that destroyed her ancestral home and birthplace, as well as artifacts from the house.

This is the home I grew up in when my grandparents built it in 1903, and this was later years. And it's very hard to see, but there are three of these stars that were on the house. Well, the house and everything burned. The stars are about all that's left of the place. And let's see, I think my sister has one star. And then, maybe one of their daughters, I can't remember for sure. But this was the article that was in the newspaper telling about the house burning. And I was the only one of nine kids that was born in that house.

Displaying the box brings those events from the distant past into her present place and allows continuity of family meanings. When the shadow box is eventually separated from its family of origin, the vividness of meaning will diminish. However, because the newspaper describing the fire and the associated loss is an integral part of the box, the meaning of the loss will continue to be present. However, for Tillie there is an emotional 
ache associated with the shadow box; for future owners, the box will remain a sign of loss, but the experiential meaning of presence of absence will be lost.

Symbols of loss. Unlike signs, storied possessions are embedded with symbolic meanings that are not recognized by outside observers. They are "something more than its obvious and immediate meaning” (Jung, 1964). The meanings will remain hidden unless the owner discloses them. Many of these possessions have previously embedded meanings that became layered with newer meanings of loss.

The LuRay Pastels pottery collection Bridgette and Leon have is an example of this type of storied possession. Bridgette was given her first place-settings during her wedding shower in 1958, and the collection increased through the years.

I did bring my collection of LuRay pottery. A dear friend, Ada, gave me a gravy boat that was attached to a plate. She remembered I collected it. I would not part with that for any amount of money. I just wouldn't do it. I wouldn't sell that because she gave it to me. She had a daughter who was killed, hit by a drunk driver and killed on the day before my birthday. Every year Ada and I got together on my birthday until we started getting sick and all that. But we still talked. After her husband died, she told me that was very hard, losing her husband, but it isn't anything like losing a child. I couldn't help her really. But after our son died, then I knew what she meant. I knew what she meant. I'm not getting rid of that LuRay pottery.

Purbrick (2016) suggests that wedding china has a multiplicity of culturally layered meanings including family longevity and fecundity. As friends contributed pieces to her collection, Bridgette deepened this meaning to include friendship, especially 
friendship that encompasses sympathy for another's loss. It wasn't until her own son died, however, that the pottery took on a meaning of personal loss. Bridgette now understood the depth of losing a child. The pottery was a physical reminder of an emotional connection between two women who lost their children. Bridgette knows that, unlike the urn with her son's ashes, her living children will probably not want the pottery; however, she cannot sell it. The negotiated presence of absence means too much to her; unlike Tillie's shadow box, this deeply personal symbolic meaning of loss, layered onto an established cultural meaning, will perish.

When his mother died, Bernard and Abbie received one of her precious possessions.

We've had it ever since Bernard's mother passed away. His sister always said, "She went kicking and screaming into that good night." She was an old way's person. She didn't want a microwave. She didn't embrace, of course technology wasn't real big by then— but it was coming, and she didn't like that stuff. She was an artist."

Abbie mentioned her sister-in-law's reference of Dylan Thomas' poem "Do Not Go Gentle Into That Good Night" (Thomas \& Jones, 2003). The concluding stanza of the poem encourages parents to resist death: "And you, my father, there on the sad height, Curse, bless, me now with your fierce tears, I pray. Do not go gentle into that good night. Rage, rage against the dying of the light" (Thomas \& Jones, 2003, p. 239). The lamp embeds meanings of life, death, and loss of a mother.

Grayson has figurines that incorporate his late-wife's Scandinavian family, which he refers to as his family, and a tiny Corgi dog. When he showed me the dog, he said, 
"This is our dog." Of note is that he did not say, "This is a representation of our late dog." The figurine embodies the dog in the present, first-person plural, actively incorporating Grayson's loss of a dear pet into his current place.

Embedding loss into storied past possessions: the ghost. The second category in the theme presence of absence deals with objects that are past-possessions. They are physically absent, but the embedded meanings linger in place. I named these absent objects ghosts. One definition given by Merriam-Webster for the term ghost aptly describes the meanings of several possessions: "a faint shadowy trace" (MerriamWebster, 2018c).

This shadowy trace can be seen in Monica's hutch. Within the birth cohorts represented by participants, it was culturally appropriate to pass a china hutch to the next generation (Ekerdt \& Sergeant, 2006; Jones \& Ackerman, 2016). Monica’s hutch was passed to her by her mother, a capable, well-mannered woman who understood social norms and provided a stable childhood for Monica.

Monica: My life up to then was back when children could ride the bus to town, and go to the movies, and things like that and no one worried about it and all. There were five big theaters downtown.

Interviewer: Do you wear hats and gloves?

Monica: Oh, yes, especially when I went with my mother.

Keeping the hutch provided a reference point to this beloved family member. Monica and Lance planned to use the pantry area as a niche to display the hutch. However, it was a fraction too big for the space, and relatives did not want it. Realizing that the hutch must be sold rather than being transported to their new residence was 
emotionally challenging for Monica. A crockpot, kitchen towels, and other kitchen detritus occupy what was to be a place of honor. To Monica and Lance, the presence of these items is the presence of absence. This meaning is layered into their gestalt of the pantry space itself. Their photo journal included the entry shown in Figure 42.

\begin{tabular}{|l|l|l|l|}
\hline Photo 25 & $6 / 13 / 2017$ & pantry & $\begin{array}{l}\text { You must get the story of how the china cabinet } \\
\text { ALMOST fit! }\end{array}$ \\
\hline
\end{tabular}

Figure 42. Excerpt from Lance and Monica's photo journal.

When they showed me the photograph of their pantry and physically pointed to it in their apartment, they told the story of the china hutch. In effect, it is a ghost story creating a momentary atmosphere of loss and longing (Bille et al., 2015). Monica articulated her thoughts on desire versus need regarding the items she no longer has.

By the time I was deciding what to leave behind, I guess I was grieving, I really wasn't thinking too well. But, we have everything we need. It's just the little things that my mother, or my grandmother, or somebody else left me that I wish I had.

Similar sentiments were expressed by Paulo and Pauline. They were happy with their move even though some of their heritage furniture did not fit into their new space. Leaving the heritage pieces was the low point of their moving transition. Pauline said, "It just killed me." This meaning is now layered onto the previous meanings embedded in the remaining pieces of furniture. Symbolically there is an added layer of loss, a presence of absence.

This layer also exists for Elsie and Robert when they look at empty spaces on their bookcases. The couple boxed up many books for the journey to their new home. 
Their collection represented their lives together as bibliophiles in addition to their pleasure in the individual books.

However, the boxes were lost in transit. Walter Benjamin (1999) gives a glimpse into the significance of books to bibliophiles in his essay "Unpacking My Library," when he states,

What I am really concerned with is giving you some insight into the relationship of a book collector to his possessions, into collecting rather than a collection. Every passion borders on the chaos of memories....You have all heard of people whom the loss of their books has turned into invalids....These are the very areas in which any order is an extreme act of precariousness. (p. 22)

For Elsie and Robert, true book lovers, to have gone through the original book culling, as Benjamin states a precarious process at best, only to have their recreated library aborted when the boxes were lost in the physical move, encapsulates the meaning of loss. The empty space on the bookshelves symbolizes an emotional waste and the presence of absence.

Elsie: A lot of our books got lost.

Robert: Just disappeared.

Interviewer: I'm sorry, I'm a little bit in shock. From your townhouse to here books got lost?

Robert: Yeah. Oh heck, they just never appeared. Never turned up.

Elsie: I'm not clear how that happened. I had a gentleman from our church who was helping me. [Moving] would have been terrible because we don't have family nearby to help us. He was picking up boxes, and I had them marked to go 
either here or charity, and I think they must have gotten mixed up. A lot of them. So, we lost hundreds of books. It was just awful, because we're both big readers and I'm a writer.

Elise and Roberts agree about the meaning of their missing books and commiserate together. George and Tillie, however, have a ghost storied possession which holds different meanings for them individually. George misses his uncle's rolltop desk that was spatially sacrificed to provide room for Tillie's oak hutch. "Instead of taking an ugly roll top desk that had files in it because it was 'worthless,' we brought a beautiful chest full of dishes that we never use." George did not comprehend Tillie bringing something he considered impractical at the sacrifice of a functional desk. The hutch is embedded with the meaning that his family either did not listen to him in the disbandment process or he was not able to communicate effectively. "Well, yeah. I can't get loose from the, 'Why didn't you do this?' Because I wasn't there to make it [happen]. I thought I was making it clear that this would go over, but I guess I didn't.” The hutch represents both practical and familial disfunction to George.

During our interview, however, it was clear that George was unaware of some of the layered meanings Tillie had embedded into the hutch. The first time I spoke to Tillie she was alone on the phone. She told me that during the disbandment process George was very ill in the hospital. She chose a one-bedroom apartment in part because she was unsure of his survival. In a like manner, she chose to bring the hutch filled with Franciscan Apple china that first belonged to George's mother. Over the years, Tillie and George would shop together at antique stores to add to their collection. For many years, family meals were served on the china. When the time came to choose, Tillie elected to 
take the china and hutch with their richness of meanings over the desk and its practicality. The full china hutch represented their life together. She sold much of their collection at the auction, but she kept eight place-settings. When she made the decision, she was oppressed with the possibility that she would be living in the apartment as a widow. Much like Bridgette, she was not getting rid of her china or hutch.

Within Tillie and Gray's tiny apartment, then, is a possession that represents functional loss for one spouse and a symbol of love and family for the other. These disparate layers of meaning cause friction between them, a loss of understanding. George, however, like Monica, conceded to Tillie that his desire was not the most important thing, “Well, I'm sorry. That's a dead issue, I don't know why I'm upset about it. But it's something I wanted, and I couldn't get it. But, I have you and that makes me happy."

There are powerful meanings in the theme presence of absence. Participants use these meanings to make places that incorporate their loss. The presence of absence does not prohibit a sense of home. George discusses the ambivalence of this:

Interviewer: Do you think of the apartment as home? Or do you think of it as a place that you live?

George: Well, it's home. Yeah. I don't like it, but it's home. But I lived in many apartments when I was a kid growing up. I never had a room until I was 16 years old.

George does not view home as an idyllic place that fulfills his spatial desires. He feels cramped in the space and does not like it. The place is still home to him. It is filled with storied possessions that represent family. Although this is the reason it is cramped, 
he chooses the possessions over the space. Tillie, his nuclear family, is there, and that makes him happy.

George's loss does not preclude development of meaningful place. The same thing can be said of the others, as well. Presence of absence indicates that older adults choose to incorporate loss into their new places. Theirs is not a homogenized sense of place with only positive meanings but rather an authentic sense in which both living and dead members are incorporated in the ongoing visual and spatial negotiations of what it means to live with family.

Adjusting. Turning points, within the findings were represented by possessions that demonstrated an adjustment after the older person experienced divorce and death. The turning point is internal, but the action is external - a change in direction. Estroff Marano and Yusim (2018, p. 57), when studying turning points, made the statement, "Transformational moments sit somewhere on the boundary between logic and emotion. Insight alone, no matter how brilliant, rarely leads to profound change" (Estroff Marano \& Yusim, 2018, p. 57).

To identify if participants had objects with embedded turning point meanings, I looked for a directional change on the part of the participant. Many cases had possessions associated with turning points. I entitle these possessions representations of adjustment. These objects symbolize demarcations in time when the participant detached from a previously held vantage point. Fern is a participant who made a directional change in relationship to her family.

Fern did not feel fully supported by her nuclear family. She was orphaned early in life. Later, she married a good man, but he "was not a family man." Living in her 
daughter's house was the first time she personally experienced the full support of her immediate family. At ninety-years-old, Fern changed an old belief associated with her late husband who was adamantly opposed to alternative lifestyles. Fern began to fully embrace gay men as chosen family. She regularly sings karaoke in gay bars with a female impersonator named "Cher." She has accessories for these performances, and her photographs are replete with pictures of the impersonator. She uses Facebook to stay in communication with her chosen family. Her photographs and costumes are prized possessions demonstrating a turning point in her life. They are embedded with the meaning that she has not stopped learning or living.

Another participant is Gina. As discussed in her case study, Gina's husband divorced her when she was a young woman with small children. He immediately married another woman. During that time, the church she attended rejected her as well. It was a very difficult time. Sometime later she posed for a portrait painted by her sister shown in Figure 43. The woman in the painting is reclining on her side, breasts partially exposed, with a smile playing at her lips. She is looking directly at the viewer. The artist used a painting technique called chiaroscuro, which is a dramatic effect that contrasts areas of light and dark. A woman fully accepting her sensuality is portrayed in light surrounded by darkness. Gina's emergence as a rejected woman to an accepted woman is embedded in this representation of adjustment. She learned how to successfully operate in the career world outside of the domestic domain she had previously occupied. Raising her children as a single mother was difficult, but their support and acceptance of her was meaningful. 


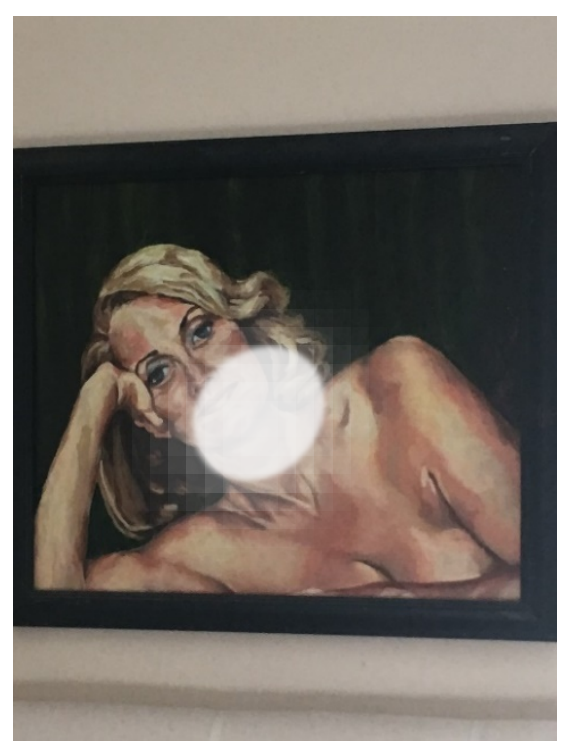

Figure 43. Painting of Gina.

Grayson moved because he needed a fresh start. The grief of losing his wife was overwhelming, and he needed a new place. He sold almost everything and started over. Although he no longer considers the Flint Hills of Kansas his home, he was raised in that region. After he moved, he bought paintings of the Flint Hills to decorate his apartment. The paintings are embedded with the beauty of his youth, a time before he met his wife. Grayson turned back to the images of his childhood to help him move away from grief.

A final representation of adjustment is Susan's Pot Belly Bear, Figure 44. It was given to her by a four-year-old child at the time of her divorce twenty-five years ago. She was having difficulties sleeping alone, and the little girl told her the bear would help her not to be lonely. The stuffed bear is a storied possession that marks the turning point for Susan of not only sleeping alone but being single. It has been on her bed through many moves. 


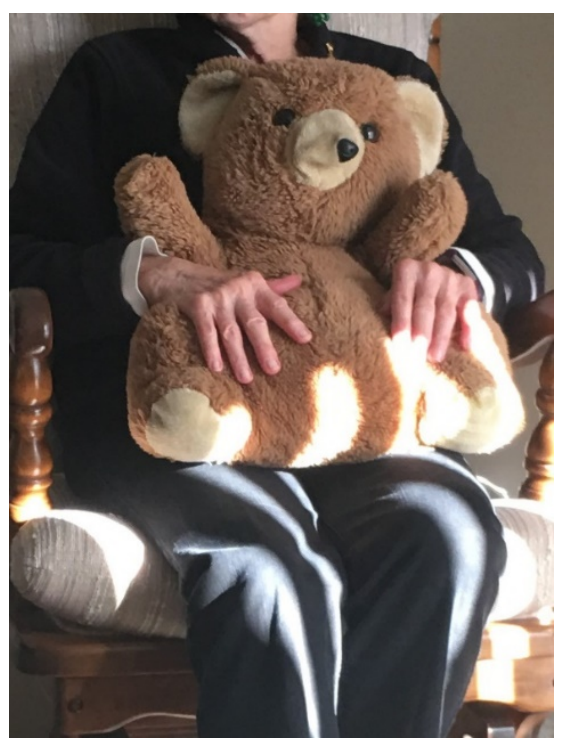

Figure 44. Pot Belly Bear.

Participants embed possessions with representations of these adjustments. Estroff Marano and Yusim (2018) suggest that "Life provides turning points of many kinds, but the most powerful of all may be character-revealing moments. They go right to the heart of who we are" (p. 52). Objects embedded with these meanings help participants remember the ways they positively adjusted to changes in their families.

High points: Pinnacle representations. The meaning-making properties of life stories vary from event to event (Bauer, Graham, Lauber, \& Lynch, 2018, p. 3). Highly positive emotional experiences allow older adults to feel, "Wow! This is cool!" (McAdams, 2008, p. 252). High points are peak experiences that involve emotions of joy, excitement, and love (Cox \& McAdams, 2014; McAdams, 2008). They connect to objects I entitled pinnacle representations to signify embedded high point meanings.

Joy. Joy is evoked by the prospect of possessing what one desires, wellbeing, success, or good fortune; it is associated with bliss, happiness, delight, and felicity (Merriam-Webster, 2018d). Joyful memories occurred throughout participants' life spans 
and included births, birthdays, graduations, weddings, anniversaries, and in one case, finding family.

As discussed in Claire's case study, her mother discouraged any inquiries about their family of origin. Claire grew up feeling adrift from ancestral lineage. Eventually, through perseverance, Claire discovered extended family. There are four framed illustrations of European chocolate hanging in Claire's apartment that belonged to her great-grandmother. The illustrations are storied with her grandmother's death, her father's adoption, voyages back and forth from Copenhagen, the discovery of the illustrations, and ultimately, the finding of family. Claire no longer feels adrift; she has what she desired.

Another group of joyful objects are a quilt, a photographic family tree, and a clock all representing fiftieth wedding celebrations. Lance and Monica have a blue and white quilt hand stitched by his sister for their fiftieth wedding anniversary hanging on the study wall. At the head of George and Tillie's bed is Tillie's photographic family tree. The photographs encompass the extended families of each of her parents' nine children and were taken when the entire family gathered for her parents' fiftieth wedding celebration. Bridgette and Leon have a small clock given to them by a chosen family member. It sits on the bureau next to their son's cinerary urn.

Bridgette: Something else is this little clock. Max and Charlotte gave that to us on our 50th wedding anniversary. They're friends.

Leon: He's almost a son. 
Bridgette: Yeah, he and our oldest son went to school together, and they wrestled together. They went out together. They stayed overnight at each other's houses.

Leon: Both in the Navy together.

Bridgette: And when they married, their wives became good friends. We went out to Max's house for Thanksgiving. He stops by every once in a while, just to kind of check on us. I told him one night, I said, "Max, I love you like one of my own." And he said, "I know you do, and I do, too." He is just absolutely the sweetest kid.

Participants also have possessions from weddings. Robert and Elsie's wedding announcement is prominently displayed in their bedroom. Showing it to me, they told me the story of their encounter on an elevator and their long-distance courtship. Paulo and Pauline have the silver and Waterford crystal collection they began when they married. They also have silver candlesticks given to their parents as a wedding present almost a hundred years ago.

Participants memorialized births and birthdays with possessions which became storied. When their oldest daughter was born, Claire's husband brought flowers to the hospital. She kept the vase; the edge chipped during Claire's recent move adding another layer to the storied possession. Nina has a Michael Graves tea-kettle that delighted her when she originally saw it in the store. Her family went back later and surprised her with the tea-kettle for her birthday. It's been on her stove ever since. Donna's eightieth birthday party was a large celebration that required months of planning. She was happy with the success of her plans. 
The pictures in this album are from my party. That was when the whole family came, which is very hard to get. I just knew someone's going to get sick. Chicago, St. Louis, yeah, and South Dakota. Yeah, all my kids, my grandkids, my brother and sister, and my brother's wife. They gave me a surprise 70th birthday party. It was a big surprise, so I told everybody on my 80th I was going to have a party and invite everybody and pay for everything.

Excitement. Events that produce excitement in participants' families are associated with the fun of positive adventures. Boxes and chests quite contained this type of excitement. Paulo's most prized possession is the treasure box he purchased with money given to him by his grandfather. Cole's music boxes coalesce his wood working skills, his love for music, and the fun he had traveling with his wife.

Cole: Yeah, they're a lot of fun; I probably had 100 boxes. Just brought small ones with me, but we had floor models and uprights. They're real good ones, and they were fun. We traveled internationally with the Musical Box Society that we got formed, and it was great. We were active, and this is an example of one of them. They're just beautiful and they sound so good. I got a big one beautiful sounding with a good diameter. The big fat ones are the best ones.

Interviewer: When you traveled with the group was it to buy music boxes or to go to the places where the music was?

Cole: Oh, just for fun. We traded them, we had a meeting, a sales meeting every year where we would bring them and sell them.

Oliver and Nina lived in different countries throughout the world for their careers. When they disbanded their household, they kept pieces from each of the countries where 
they lived. The Korean chest is noticeable for its intricate hardware. They purchased it one Thanksgiving when they could not get back to the States for the holidays. Rather than staying home and feeling lonely, the family went on an adventure to nearby Korea and purchased two chests. The chests began their story during this adventure, but through the years, layers of stability have been added as seen in the account of the furniture by Oliver and Nina's only child, Phoebe.

I have a few of their things in my apartment. What's nice is now, in a way, I still kind of feel a little bit more at home, because I have their other coffee table that I grew up with. I have their other Korean chest that I had growing up. Certain things that they've always had in their house. And their apartment is full of what I've grown up with. That's what's nice.

The furniture weaves the excitement of living in different countries with the stability of family. In another case, Susan's family experienced excitement when they purchased a painting from a southern artist who was selling out of the back of his car. Later the painting was an important possession to Susan during her divorce.

Susan: This is the oldest painting. I got it in the divorce; I would not dare let Hershel have it. This is the itinerant artists that were in Florida. They're called the Highwaymen. They were African American painters, and they sold their paintings out of the back of their cars.

Interviewer: Oh, my goodness.

Susan: And we saw one in a gift shop, and it wasn't exactly what we wanted, so we drove across the State of Florida with our children, and little children of 
course then, in the car, to find the artist. He opened his trunk and he had a number of different paintings.

Interviewer: What a great story.

Susan: And so, we picked this one. And as I said, I loved the beach. Lots of shells are in my bathroom that I use. So, I was fortunate enough that Hershel didn't fight with me over it and I got to keep that one.

Other storied possessions illustrating excitement are photographs and illustrations of fighter planes flown by WWII pilots which line the hallways of Fern and Leah's house. Additionally, there are Persian rugs purchased in Singapore by Oliver and Nina on their honeymoon. The excitement embedded in the possessions is inherent in the stories about family adventures even though other layers are also embedded within the objects. This demonstrates the complexity of the multiple meanings symbolized in one possession.

Love. Love is the final subcategory of possessions embedded with high points experiences. Love can be a nebulous word, so in sorting and coding, I looked for objects that commemorated positive family relationships. Following McAdams (2008, p. 252), if I could interpret and paraphrase the participant's interaction as "Wow! This is cool-my family loves me," "I love my family," or "my family loves each other," I coded the possession to love. More possessions fit into this high point meanings than the in joy or excitement.

My family loves me. Many different types of possessions including books, photographs, furniture pieces, and decorative art objects are linked to being loved by 
family. For instance, Abbie's grandmother recognized she was a precocious child and bought her books that encouraged her interests.

Yeah. I know. I'm thinking about my childhood, and I think I had a good childhood, but I wasn't exceptionally happy. I wasn't troubled or exceptionally sad, but I don't know. I think I enjoyed doing things that you had to be older to do. I enjoyed reading.... The children's books downstairs - a lot of those I had when I was a child. I have my little blue book, red book, and green book of birds. I loved the Audubon Society. I need to rejoin it. I was in the junior Audubon Society, and my grandmother bought those books for me.

Monica's wedding photo sits on a chest of drawers that her father built for her when she was young. Tillie has a quilt that was pieced and stitched for her by all the women in her family. Mary has a recliner that her grandson went out of his way to make sure fit her correctly. Tillie has a lift chair purchased by her children to save wear and tear on her knees. Grayson's wife needlepointed his fraternity's coat of arms for him, and George has the grandfather clock Tillie bought him for Christmas. All these possessions as well as the signed armoire that Paulo's aunt gave to Pauline and Abbie's acrylic grapes from her brother and grandmother represent being loved by family. They are precious possessions embedded with stories of love, some of which brought tears to the eyes of the participants when they told the stories.

I love my family. All participants had photographs in their new residences of family members. Most had boxes of photographs in their closets waiting to be sorted into albums. Grayson had albums his late-wife assembled and complained that he did not have 
up to date photographs of his grandchildren. Framed photographs were usually in places of prominence, and participants told stories of their children, brothers, and sisters.

Objects other than photographs also demonstrated the participants' love for family. Nina has a framed doily crocheted by her mother and a large armoire with her grandmother's named painted on it. Fern's wedding ketubah, Grayson's small figurines representing his wife's family of origin, and a framed drawing done by Nina and Oliver's young daughter are other examples. Participants spoke lovingly about the characteristics of the people embedded in the objects. Tillie talked about how her mother fixed her hair. She loves the hair brush and comb set because of the relationship it has to her mother. I love mother's dresser set. Dad gave that to her before they were married, which is early 1928. It has another box, which is a powder box. This one was the hair receiver. My mother saved the hair, and then she had this little roll, it was in a net, and she pinned it right back here. Oh my. I love that.

My family loves each other. Looking at a photograph taken with her four siblings before their parents died, Fern told me she did not remember being poor until she looked at the photo. Three of the five children are still living and in their nineties. Looking at a more recent photograph, Fern spoke with pride about how they all take care of one another, something that amazed her daughter. Fern's oldest brother calls her and her sister every Saturday afternoon to check on them.

Fern: I kept thinking, you have to know from where I came from, and when my mother died, it was tough. It broke up the family and, well my father told the older boy and my sister, take care of your brothers and sisters. 
Leah: It's amazing through so many generations that the three of them still stay in touch.

High points in participants' life stories vary not only from event to event but also from person to person and object to object (Bauer, Graham, et al., 2018, p. 3). Experiences that involve the emotions of joy, excitement, and love connect to a wide variety of pinnacle representations. Nina made a statement that seems ubiquitous for all possessions, "Well, it has multiple meanings."

Ordinary events: Moments of everyday engagement. Participants structure their everyday lives with routines, mundane activities, and habitual occurrences that are enacted through place and material culture. Everyday life experiences are punctuated by high and low points that were reviewed in previous themes. Between high and low points in life, there are ubiquitous, temporal experiences that fill the interstitial spaces of the day. Luborsky et al. (2011) found that, "stories fix on mundane daily details and commonsensical aphorisms" (2011, p. 244). The quotidian nature of these experiences does not exempt them from representation within material culture. Everyday objects contribute to the meanings of family for the older adults. The prosaic family meanings derived from these categories bring the distant past near through storied interactions and allow participants to visualize themselves in the context of everyday family. Everyday family meanings are layered onto the cultural meanings previously imbued in the objects (Tischleder, 2005). “Objects, whether precious or not, remain amongst the living, activated by the safety, comfort, and security offered up by the 'living' domestic space" (Myzelev, 2017, p. 202). I incorporate these popular, "activated" meanings from material 
culture with the findings from participant interviews. This illuminates the depth of meaning through which the participants view these possessions.

Categories in the theme moments of everyday engagement are 1) being historically relevant, 2) being together, and 3) melding family with aesthetics.

Being historically relevant. Various possessions, secured in meaning and place, are used to prevent or restrict dislocation of participants from their familial relevance to the history of the U.S. (Stobart \& Rothery, 2014). Belk (2013) suggests there is a strong desire to bask in the magnificence of past eras and that collections from these eras allow owners, "as if by magic," to possess their magnificence. Many participants displayed this desire by photographing, writing about, and discussing their antiques and heritage furniture.

Apart from Bernard and Abbie, whose births were concurrent with the beginning of the Baby Boomer generation (1945 and 1946 respectively), all participants were part of the Great or silent generations and born between 1923 and 1942. Their grandparents and parents were impacted by the Civil War and the westward expansion of the United States, events that continue to color the material culture of America (Salazar-Porzio, Troyano, \& Safranek, 2017; S. S. Smith \& Carpenter, 2018). Additionally, they experienced firsthand the incorporation of a consumer driven culture into American society (Breen, 2017; Stowe, 2017). Within their possessions, consequently, there are layers of meaning about what it entailed to be a socially respected family in the United States from the mid-nineteenth-century onward.

Paulo described the Midwestern characteristics of his ancestors as inclusive, friendly, helpful, courteous, hardworking, dedicated, and devout. Pauline and he have 
incorporated these characteristics into their family identity as shown by their continuing volunteer work. Though retired, Paulo works from his desk on projects for their retirement community. Moving possessions with this embedded meaning, transformed the older adults' impersonal, smaller residences into settings rich with family meanings that reinforce their historical relevance (Fleming, 1974, p. 169). Paulo and Pauline's furniture originated three generations before their births. They, as well as Lance and Monica, owned pieces that traveled on steamships and covered wagons to the Midwest and Texas. Covered wagons had little storage space which illustrates the importance this furniture had for the pioneers who brought the pieces west (Taylor \& Warren, 2012). Monica's ancestors were ranchers, and she has her grandfather's rocking chair from an historically prominent Texas ranch.

Robert and Elsie have possessions from the twenty-fifth President of the United States, William McKinley, who led the nation during the Spanish-American War and promoted American industry from1897 until his assassination in 1901. Robert talked to me about Elsie's wedding ring, "The ring she has on her finger was the same ring he had when he was assassinated. That was McKinley's wedding ring." They also had heritage furniture including their Civil War era dining table and a gate-legged table. Walnut gatelegged tables appeared in the British American colonies during the formation of America's first true style, the William and Mary Period, circa 1690-1720 (Hayden, 1906).

These types of possessions symbolize the participants' heritage and affirm their family ties to the history of the United States.

Heritage items have additional embedded social meanings that could not be bought or learned (Stobart \& Rothery, 2014). Although aristocracy and social caste 
systems were not promoted (ideally) as American, the status of inheritance is still relied upon for embedded meaning. Robert and Elsie, as well as other participants, created places in which "old and new coexisted through the differential construction and use of domestic space" reminiscent of elite European country houses (Stobart \& Rothery, 2014, p. 385). This can be seen in Elsie's discussion of a family crest, which is a sign of titled ancestors, in the same conversational thread as a pioneer family's chest.

Elsie: Robert is sixth of seven generations of Duncans in America. They're largely Scotch-Irish from Northern Ireland. This crest belonged to Hugh Duncan born in $1794 \ldots$... You bring with you what you want to not lose.

Paola and Pauline also have a family crest. Crests elaborately display family lineage and resultant status. They proclaim that a family is woven into the history of a particular society. Stobart and Rothery (2014) suggest that crests have a social patina which adds a layer of meaning onto the family.

...patina indubitably remained a central pillar of their material culture. This meant inherited goods, but also the inscription of pedigree onto material objects in the form of crests and arms - a process which added layers of meaning and made them integral to what Lewis calls an 'ecology of signs' that communicated the importance of family as lineage" (Stobart \& Rothery, 2014, p. 387).

Robert and Elsie had an interesting twist to their historically relevant theme in that they connected it with status. This was especially important to Elsie. She stated that she lost everything she called home when she and Robert disbanded their house filled with books, antiques, and Persian carpets. They moved into a region she considered "an 
industrial stepsister" to the wealthier part of town with less educated, more conservative residents.

Interviewer: Elsie, it's sounding like this is not home for you.

Elsie: Right.

Interviewer: Is there anything that could make this home?

Robert: Me.

Elsie: I don't know. Wish we had lots of money. If we were in a place that had better food and a different kind of clientele. So that can't be possible here.

Although Robert could make a home place with Elsie, she could not create that place meaning for herself in their new residence. By calling upon embedded meanings in her antiques and heritage pieces, she was able to cocoon in a self-constructed status-place that she mentally isolated from the other apartments in the facility. This demonstrates Belk's previously mentioned magic. Elsie magically imbued furniture pieces with the status of historically important family members so that she and Robert had status uncontaminated by its surroundings.

The material of wood. In addition to the eminence of iconic eras and personalities, heritage and antique furniture carry a meaning associated with its primary material, wood. Wood as a material is historic (Brinberg, Bumgardner, \& Daniloski, 2007). "Wood has always been the basic material for furniture; it has in fact never had a serious rival. Its preeminence is the result of many virtues" (Aronson, 1965, p. 464). Culturally, objects 
made from wood are considered valuable, stable, natural, and authentic (Perry, 1999). Cedarwood is an example of this.

Cedar chests that belonged to participants' mothers were also part of their new residences. There was an historical period when these chests were considered practically and symbolically important pieces of furniture for household routines. Practically, from pre-revolutionary America, cedar was a rich resource with natural oils that served as an insecticide. In 1632 red cedar was noted as not only good for commercial production of furniture but also sacred, "Cedar, of this sorte there is abundaunce; and this wood was such as Salomon used for the building of that glorious Temple at Hierusalem ... This wood cuts red, and is good for bedsteads tables and chest...” (Back \& Rabak, 1922, p. 2). The odoriferous wood protected sacred contents from insects and fungus (Baker, Grant, \& Malakar-Kuenen, 2018). Practically, this was important in a pre-synthetic fiber society, but after the advent of synthetics, the sacred symbolism was reenacted for the purity of young women planning their future domestic lives (Goggin, 2017).

During the time when the mothers of participants were born, the chest began being marketed to America's middle class as a hope chest (Walters, 2012). Lane Furniture Company ran ads suggesting that young women should buy cedar chests to keep treasured memories such as those associated with senior proms, wedding ceremonies, and children's births from being erased by time (Sujan, Bettman, \& Baumgartner, 1993). Additionally, the hope chest was a preparation for marriage. "The custom of providing a chest for the plenishing of a prospective bride, a hope chest, appears universally in most civilizations" (Aronson, 1965, p. 174). Young women began collecting the material items needed to set up a house: kitchen and bed linens, cookbooks, 
utensils, etc. Older female family members and friends helped contribute items; some from the past and some new (Mecum \& Balzano, 2011). McAra (2017) refers to hope chests as "boxes of accoutrements containing memories and prophecies" (p. 168). The chest became a representation of historic preservation, practical preparation for domestic responsibility, and future hope (Walters, 2012).

Elaine's most precious possession was the hope chest her father made for her. For many years, family quilts were housed in it. Before her death, she was able to give the chest safe passage to her granddaughter. Although Elaine was the mother of four sons, she was able to continue the cultural history of passing on the cedar chest to a female in a following generation. Contrarily, Lance inherited his grandmother's chest, and it resides in Monica and his master bedroom closet. Nina uses her mother's chest to store current day woolens. Grayson kept little furniture from his house of four decades, but he has the chest at the foot of his bed. He uses it daily to put on his shoes.

The meaning of historical relevance in everyday family engagement is perhaps best illustrated through these chests and is exemplified by Susan's statement, "This was mother's cedar chest, so she's (emphasis mine) on the other side of the bed from Pot Belly.... [Mother received it] in the day when everyone who got married got a cedar chest. So that came with me." Stories of hope chests detail cycles of family life with embedded memories of young women who became wives and mothers. After their deaths, the hope chests embodied maternal family history and were passed on in anticipation of cultural replication.

Hope chests are no longer an item of cultural relevancy, and heavy wood furniture and antiques are not a current trend. Radkau and Camiller (2012) suggest, "The natural 
properties of the various kinds of wood have always been noted but they represented potentials that were variously used and appreciated in different cultures and epochs. Wood inspires culture; it does not determine it" (p. 19). This quote applies to participants of the study. They appreciated hope chests, wood, and their families' historical contribution to the United States. This relevancy was important to them as is demonstrated by their possessions that symbolize their heritage and affirm their family ties to the history of the United States.

Being together. Participant narratives suggest family members seek out each other's companionship and engage in activities together. One of the ways this is enacted is around tables, a furniture piece that speaks to social and cultural expectations. Tables represent sharing common interest and emphasize the importance of family members to one another. "The language of furniture is not entirely obvious, of course. It is a language of connotation as well as denotation, of suggestion as well as statement, of symbol as well as sign" (Abercrombie, 1990, p. 77).

Participants actively raised their families during a time when the dining room table was a sign of nightly middle class family togetherness (Cinotto, 2006). Parents were educated then as now that eating together promotes "positive conversations and parental monitoring that can strengthen connections among family members. Resilient families who build positive connections may be more likely to work through conflict and maintain relationships with one another" (Patel, 2017, p. v). Dining room tables were prized possessions for these reasons.

Tillie chose to keep her own oak dining room furniture over older heritage pieces. She and George enjoyed having the heritage pieces at the house they moved from, so 
much so, that they built a large room to have adequate space for the pieces in their previous home. However, although she valued older, she left those pieces behind when they moved and instead retained the newer oak pieces. The complex crux indicates a subtlety of meaning. She had used the newer oak furniture to daily feed her family and memories of large gatherings were embedded in the table.

We had a dining room set of furniture that George's uncle had given us. They were antiques, but I wanted my oak hutch and the oak chairs. They were newer. They weren't antiques, but I just felt that really-I just love this oak. It has another leaf, so it could be a lot longer too. And when we had a lot of company, we had both tables stretched out as far as they'd go.

Families gather around dining room tables. "The way the [dining room] space was organized and negotiated was crucial to middle-class perceptions of the role of dining both in everyday life and for special occasions" (Rich, 2006, p. 293). Keeping the dining room table after household disbandment serves as a reminder of those spatial gatherings. Symbolically, the dining room itself is an "expression of values" (Wood \& Beck, 1990, p. 5); it suggests the family achieved enough status to have a formal dining room in which members came together, conversed, and children were socialized (Heneghan, 2003; Wood \& Beck, 1990).

After Abbie and Bernard disbanded their house, they no longer had a formal dining room. They kept a smaller dining room table and hutch from one of their previous houses for the eating area adjacent to their kitchen. It serves as their current family gathering area and embeds memories of past engagements. Additionally, from Bernard's childhood house, they have a hardwood desk that symbolizes the importance of a dining 
room to not only Abbie and himself, but to his parents as well. He grew up in a small house without a formal dining room typical of post-WWII blue collar families. Bernard's parents had used the desk to partition off a space in the living room for a named dining room. "It was a pretty small area, but it had a dining table. We never sat at it to eat. We used to sit in the kitchen." In Bernard's case, his family used the kitchen to gather for meals, but they created an unused symbolic dining room.

It speaks to the value Bernard's parents placed on what Rich (2006) calls a middle-class "bourgeois love of order and specialization" that began to be privileged in the late nineteenth-century (p. 292). His parents' desire for a dining room is embedded in the desk. Borden (2006) suggests architecture should be considered, " a "space of flows' - not as objects, but the interrelations between things, spaces, individuals and ideas" (p. 50) and ties this to Simmel's concept of boundary which is not "a spatial fact with sociological consequences but a sociological fact that is formed spatially" (p. 51). Using a desk, Bernard's parents spatially formed a dining room and sociologically grounded their middle-class status.

Throughout Bernard's childhood, he "begged" his parents to buy a larger house. After Abbie and he married, they upsized houses routinely; they had large hearth-areas adjacent to kitchens and formal dining rooms. Though these are rooms of their past, keeping Bernard's parent's desk reminds Bernard that he achieved the larger houses he coveted as a child.

Pauline's dining table was extremely important to her "I love my table, and no one wanted it. Jim [the interior designer] wasn't going to include it in the move. That just killed me. I said, 'Jim, please.' Finally, Jim said, "I think it'll go in there." For Pauline, 
the meaning of her dining room table not only resides in the high point of its acquisition, as reviewed previously, but also in the simple routine of daily dinner-time experiences. Attendance and conversation at these family engagements were required. For Pauline, appropriate engagement and family connectivity during the evening meal was a social imperative she fully achieved. After their move, Paulo and she generally took their evening meal in the dining hall of their retirement community; however, the meaning in the table was too important for it to be discarded.

Nina and Oliver did not keep their dining room table. Instead they kept a table Oliver purchased before they were married. They did, however, keep a parson's table that belonged to her parents. Atop the fruitwood table, Nina created a vignette of family photographs, framed in silver, representing many generations. Like the wood from which the table was formed, her family was stable, rural, and authentic. Looking at the photograph she'd taken of the table, Nina told me the story of growing up far from town and attending a one room schoolhouse; living the farthest away, she was the first child picked up by the school bus every morning.

Dusting the twisted table legs of her parents' parson's table had been Nina's job during her school years. She remembers sitting many Saturday mornings on the floor in front of the table with her dusting cloth. Nina's description of her parents invoked the same the Midwestern characteristics Paulo described. They were devout, loving people who lived far from the city limits and believed in hard work. Although much of Nina and Oliver's apartment is furnished with a collection of furniture from their world travels, this piece represents her extended family in a special way. It embeds meanings that include 
what it is to be parented by loving, industrious people in rural America at the dawn of the twentieth century.

Melding family with aesthetics. Older adults have various ways of aesthetically personalizing their residences with remembrances of family (Oswald \& Wahl, 2013). These variations are seen in the incorporation of collectible, decorative, and fine art décor that family members have gifted them or purchased with them. Fine art is considered a visual object, skillfully created to be aesthetically contemplated and admired (Merriam-Webster, 2018b). Paintings and sculpture are included as fine arts. Though some paintings are financially valuable, participants did not suggest it was this value alone that made the paintings prized. Stories embedded in the paintings involve meanings of family: the members, generosity, interests, careers, friendships, and beginnings. They demonstrate the delight participants have in fine arts.

Delight in fine art, however, was not expressed as being more important than the delight experienced by other décor objects. Décor objects kept through disbandment were not prized for their aesthetic value alone just as they were not valued strictly for financial reasons. Rather, the inherent value of the décor was its storied temporal metamorphosis caused by association with others. Decorative art is distinguished from fine art by being functional as well as visually interesting (Merriam-Webster, 2018a). It may include vases, textiles, furniture, tableware, and objects known for their skillful product design.

There is a distinction between decorative art and collectible art. Collectible art is mass produced and often uses "highly clichéd and stylized symbols to evoke an emotional response, not an aesthetic response" (Burton, 1989, p. 45). Décor is linked to 
aesthetic choice (Li, 2017). Voltaire (as cited in Meskin \& Robson, 2015) made the following analogy regarding physical and aesthetic taste.

This sense, this capacity for discriminating between different foods, has given rise, in all known languages, to the metaphorical use of the word "taste" to designate the discernment of beauty and flaws in all the arts. [...] In common with physical taste it is sensitive to what is good and reacts to it with a feeling of pleasure, it refuses with disgust what is bad [...] and sometimes it needs practice to develop discrimination. (p. 1)

Aesthetic taste was a mark of the elite, those who could financially afford status as patrons of the arts. "Philosophies of taste select an idealized image of a privileged, educated person (man, actually), who is held to represent the best of human nature and whose preferences should guide others" (Korsmeyer, 2017, p. 22). The industrial revolution, however, brought about production of decorative arts that could be purchased by the middle class. The hobby of collecting decorative objects began in the Victoria era (1837-1901) (Anderson, 2018). During this time, England aggrandized their worldwide imperialism stating, "the sun never sets on the British Empire," (Robertson, 2017). Astute purchasers had access to identity markers previously reserved for aristocrats: cultured, well-travelled, and of good taste (Webb, 2009).

Previously established elements of taste were not always incorporated into collectible and decorative arts. Aesthetic critiques apply the epithet Victorian clutter to describe this stylistic time frame with attendant bad taste (Brooker \& Stone, 2013; Havenhand, 2006; Logan \& Beer, 2001; Valis, 2002). The dichotomy of good and bad 
taste continues in contemporary material culture as seen in a recent description of the specific demographic one collectible art company targets.

Not discerning art aficionados, but the unsophisticated sentimental mother with a station wagon full of kids. The traditional American Midwesterner who didn't frequent art galleries, but who would like to think of herself as loving art. These women had diminutive Lladró figures praying in their curio cabinets at home, and Norman Rockwell ornaments hanging from their Christmas trees. (Kuskey \& Gilois, 2014, p. 27).

Although older adult participants have collectible, decorative, and fine art, the former is more represented than the latter. Kant separated aesthetic beauty from emotions (Gage, 2011), but a modern aesthetic as represented by Leddy (2017) suggests that a conceptual definition of art should include the subject-object interaction, i.e., the experience generated by art, “...only through toggling between contemplation and engagement can we obtain a full experience of art, nature, or of the everyday" (p. 72).

These thoughts illuminate participants' interaction with their décor whether collectible, decorative, or fine art. Many used the word love to describe their emotional interactions with these possessions. Participants' contemplation and engagement with their décor involve stories about how they received the objects. Family is melded with aesthetic décor through the giving or shopping process. Participants routinely described their décor objects as gifts from family and friends. They also received objects from the collections of family members who were deceased. The gift-giver is embedded into the story of the gift. 
Collectible arts. Participants' decorative art possessions have historic meanings originating in the material culture of the item. Original meanings were foundations for additional layers of family meanings. A good example is Hummel figurines. Based on the drawings of artist Berta Hummel, these objet d'art were produced by a German porcelain company in 1935. During WWII United States service people bought and sent them home. Interest in the figurines grew when people began to travel again worldwide after the war (M.I. Hummel Company, 2011).

Abbie: Well, I got my first Hummel when I was six years old from Aunt Mabel who lived in Germany. She was my favorite aunt because she was single during my childhood. She always worked abroad and came home in the summers. She stayed at our house quite a few times. She was fun and played with us and everything. I remember one time she was hiding in the closet and jumped out. My poor little sister was about four. It scared her to death. She started crying. Mabel was so sorry. I kept getting Hummels from Mable, and then Bernard gave them to me for gifts for quite some time. But I haven't acquired any in the last would you say 20 years maybe?

Bernard: Yes.

Abbie: The Hummel plates were from Bernard's grandmother, and she had this really big Hummel. She gave that to us. Did she give it to us before she passed?

Bernard: Yes.

Abbie's story weaves narrative rich in temporal family meanings involving her aunt, sister, husband, and husband's grandmother. It exemplifies Belk's suggestion that 
collectible art "can contribute to the creation of identity in areas like the dimensions of time, space and gender" Rotenberg (2014) suggests that collections contribute to turning a house into a home; additionally they enable the possessors to enact identities of “sophisticated collector” (p. 43). Abbie's Hummel collection has been contributing to her meanings of home since she was six years old. Her family helped her become a sophisticated collector through the Hummels. The figurines are also imbued with what it meant to be a favorite aunt, a loving husband, and a benevolent grandmother.

Claire's Lladró collection is a similar example. Lladró figurines are produced in Spain and marketed in similar manner to Hummels. Although Claire's collection is significantly smaller than Abbie's Hummel collection, it is also embedded with the sophisticated collector identity and links to family. She suggests that one figurine belongs to both her granddaughter and her. The Lladró figurines in her residence are linked to the one she gave to her granddaughter.

Claire: This one, I got in London. This one was a gift. This one was a gift. This one, I bought. This was a gift. Then, this one, I bought. I have another one that's not here. It's my granddaughter's.

Russell and Rosa (2012) suggest that sharing possessions enacts communion. Sharing makes the recipient part of the extended self and allows it to commiserate and rejoice with the other's losses and gains. This type of sharing typically occurs with family and friends.

Many households had curio cabinets to display their collections. These furniture pieces were originally devised as stages for displaying collectible art that highlighted the owners' social status (Anderson, 2018; Myzelev, 2017). Created to display objects that 
were difficult to procure, their emergence was synchronous with collecting as a Victorian hobby (Anderson, 2018). Unlike curio cabinets enclosed with glass doors, knickknack shelves, also known as étagères, have open shelves. Anderson (2018) likened Victorian era étagères to household shrines depicting stories about the owners. Some participants had étagères in addition to their curio cabinets. Both étagères and curio cabinets had singular pieces in addition to larger collections. Many pieces were possessions inherited from mothers. Susan and Claire both had bird figurines that belonged to their mothers.

Decorative art. As stated, decorative art is functional as well as visually interesting (Merriam-Webster, 2018a). Participant possessions include furniture, tableware, and objects known for their skillful product design.

Bridgette, Fern, and Nina and Oliver had furniture pieces that fit into the category of decorative arts. Bridgette owns a small table with a chair appropriately scaled to the table, but they were purchased separately. She bought them both because of their aesthetic and functional characteristics.

Interviewer: Why did you choose to keep the little table and chair?

Bridgette: I had the chair, and it's this nasty shade of green. My feet touched the floor when I sat in it. I've always been short. One day I went by [a store], and they had that ugly old green table. It was just the same color as the chair, and they're both about as ugly as you can get. But I just think they're the cutest things I ever saw. I loaded my paper dolls into that bureau and then we couldn't get the drawer open, there were so many paper dolls. I have dolls and jacks. I have crayons.

Interviewer: From your childhood? 
Bridgette: Some of the jacks were. Just things that I liked, and I wanted to have them around for the grandkids when they came. Matter of fact, Leon gave me a new box of crayons for Christmas. I asked him.

The functionality and aesthetics of the table and chair are interwoven with Bridgette's personal and family identity. She used the largest closet in their new place to create an enclosed space for the table and chair, a small play area for herself and her grandchildren with the support of her husband.

Fern and Nina and Oliver had chairs that were designed by famous furniture makers. Fern has two red Womb ${ }^{\mathrm{TM}}$ chairs designed by Eero Saarinen for Knoll@: one in the living room and one in her daughter and son-in-law's master suite. They eat dinner together in the living room and often visit in the master suite. Fern's chairs demonstrate that she is an integral member of the family. Her daughter, a furniture representative, who works in the design community, chose modern, bright red, comfortable chairs to help her mother feel stylish and up-to-date.

Paulo and Pauline have Wedgwood® blue-and-white jasperware. Josiah Wedgewood's fashionable tableware designs appealed to the international style conscious market including the Queen of England during the late eighteenth century. Wedgwood's title "Potter to Her Majesty" increased the popularity of his tableware (Shepherd, 2014, p. 73). After his designs for the royal family became mass marketed, purchasers were able to imitate the royal family and distinguish themselves from lower classes (Shepherd, 2014). Paulo and Pauline's families of origin gained their family wealth through the manufacturing industry. Paulo's aunt purchased the Wedgwood, which she later gave to Pauline. When Paulo and Pauline moved into the retirement community, Pauline 
displayed it on a wooden shelf given to them by his mother. The Wedgwood was imbued with cultural status and layered with meanings of family.

Fine art. Many participants owned fine art, however, the objects discussed below represents gifts from Paulo and Pauline's extended family, Lance's wife, Gina's sister, and Fern's sister-in-law. An additional silk screen painting was purchased by Oliver and Nina together. In each of these instances, the objects are storied and represent meaningful people and places to the older adults.

Paulo and Pauline owned two paintings, one was a wedding gift to Paulo's parents from a well-known Midwest painter and another belonged to his aunt by different artist. These were framed and prominently displayed. Lance owned a Russell print "Bronc for Breakfast" that Monica bought him honoring his father's history as a cowboy. They also owned an abstract painting they purchased in the Alaskan town where one of their son's lived. Gina owned a large portrait of herself painted by her sister and discussed in the previous section on representations of adjustment. Oliver and Nina owned a silk screen painted by a Japanese artist who became one of their friends when they lived in Japan. Because they met and married in Japan, it is a place of family beginnings for them. The painting is Oliver's most prized possession and is the focal point of their living room. Fern's bedroom wall is adorned with two paintings from her sister-in-law's collection. “These two are from Sophie's collection. She was friends with Sammy Davis Jr.'s wife. So, these are actually paintings that Sammy Davis Jr.'s wife did.” Fern's daughter also explained a silk painting Fern owned.

Leah: And what we tried to do was embrace more things that were from Mom's place. This was a particular silk painting that she and dad had. 
Fern: That was given to us in 1956 by his Nationalist Chinese students that he taught English to in Taiwan.

Fern's example demonstrates how she uses aesthetic décor to personalize her place with storied possessions that incorporate her late-husband and sister-in-law. She, as other participants do, uses everyday objects to contribute meanings of family in her new place.

Meanings derived from melding family with aesthetics, being together, and being historically relevant allow participants to call to mind their previous everyday family interactions. These family meanings, layered onto the cultural meanings previously imbued in the objects, help participants create meaningful places in their new residences.

\section{Cross-Case Summary}

Answer to the second research question: "How do post-disbandment older adults embed the meaning of family when making place?" was developed in three themes-1) low points: the presence of absence, 3) high points: pinnacle representations, and 4) ordinary events: moments of everyday engagements. These themes, as seen in Figure 45, suggest post-disbandment older adults make place by integrating family into their new residences through the storage and display of possessions that connect them to storied points in their lives embedded with the meaning of family. The storied possessions then contribute to late-life placemaking by temporally moving residents through chosen memories that incorporate family into their new residences. These memories represent low points, high points, and everyday events that occurred throughout their lives. 


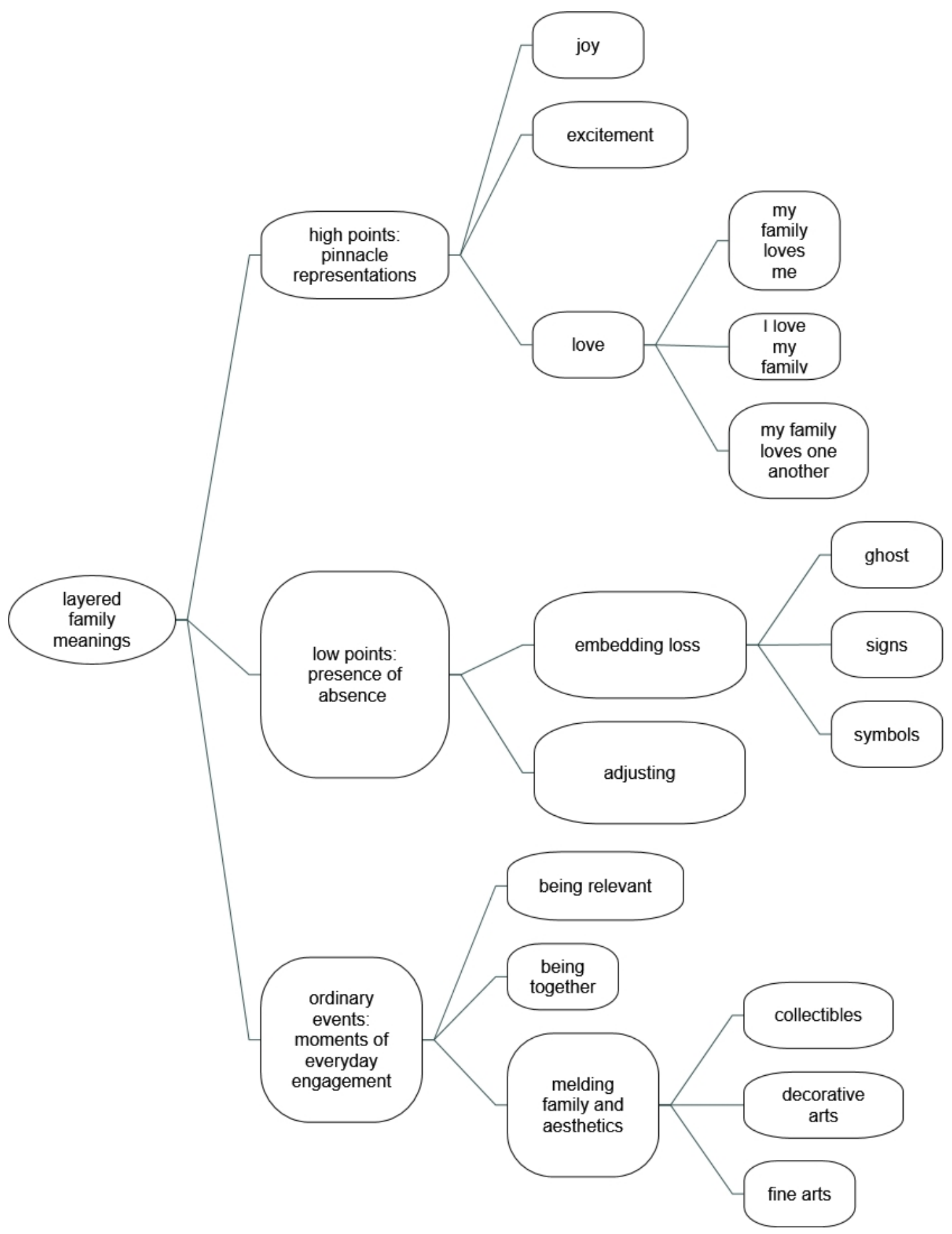

Figure 45. Map of layered family meanings with four themes -low points, high points, and ordinary events. 
All participants had possessions which related to everyday meanings as opposed to the other themes. This theme was followed in frequency by high point meaning. Low point and turning points were evidenced but it far fewer numbers. Low points were associated with disbandment and death. Turning points were related to death and divorce. Storied possessions in these themes tended to have fewer disclosed layers. 


\section{Chapter Five: Discussion}

"Clients and colleagues are invited to bring their eyes closer and closer until the model is the only thing in view and the imagined space is no longer subordinate to that of the room it is displayed in" (Wigley, 2011, p. 385). Wigley is talking about a building model, but his quote also aptly describes the way older adult participants use their possessions to model their lives and overlay stories upon anonymous spaces. Vignettes and individual possessions display a gestalt that demonstrates the life currently lived. In this way, the place is painted with a brush dipped into the meaning of one's life- $-\mathrm{a}$ culmination of past experiences, events, and people.

Owners of storied possessions have visceral responses to their objects; belongings trigger memories of moments of time embedded in them. This is perhaps why the process of disbandment and placemaking is a crucible from which meaning emerges. For this study's participants, disbandment embodies the significance of choosing future over past as they struggled with what needed to be discarded or given away. As one participant said, "I felt like there were so many parts of me that were just gone." When safe passage could not be given, there was grief, a feeling of, "It just killed me.” Contrarily, storied possessions that were given safe passage provided a balm, concurring with Ekerdt and Sergeant's findings, "Family members who receive property and possessions may be a vehicle for the continuity of individual identity or the conservation of ancestral stories" (2006, p. 2).

The embedding of narrative life stories into the physicality of objects creates sensory meaning - the visual accompanied with voice and touch, immaterial with material. The power of this distilled meaning, however, becomes too much for some who 
help in the disbandment placemaking process. Ekerdt and Sergeant (2006) noted the exasperation a daughter experienced, "Mother was attached to all her things, and she had a story about everything that we packed. So, we had to listen to a nonstop story of her talking all the time, and that's very tough to be around" (p. 8). This then is the crux of the issue. To be processed, there is history that must be told, but the hearing is difficult.

Sometimes stories are burdensome to hear because the content is painful. This was true in the cinerary urns and symbols of grief participants discussed. More often, however, it is the quotidian nature of many storied possessions that makes listening tedious, the "nonstop story" of everyday life.

For the disbandment process to be successful on the level of future placemaking, however, the stories must be told. If the hearing is sacrificial, so is the telling - at the end some possessions will be forfeited. The telling is a release. When Bernard stood at the dumpster with his mother's warped LPs, it was the story of her love for music he released. The story migrated over to the hand painted lamp Bernard kept, joining the story of his mother being an artist. Shortly after he and Abbie moved, Abbie cried when a housecleaner broke the globe of the lamp, but in their search for a replacement globe, stories will be told about his mother's grit and determination. Layers of meaning are being added to the lamp.

The number of kept possessions represented in this study is the distillation of lives. Approximately three hundred possessions were discussed, but the stories represented are exponential. The layers are vast. Participants spanned three generations: The Greatest Generation, silent generation, and baby boomers. Which of the three holds societal status is signaled by current rules of punctuation. Perhaps the name of the 
Greatest Generation is capitalized, when the others are not, because we symbolically denote the increasing rarity and thus value of their stories as this cohort now occupies less than one-percent of our current US population (Statista, 2018). Speaking with participants from this generation, I was aware that their stories, with childhood depression era and WWII life experiences, will not to be heard much longer. Consequently, it was a privilege to hear about such things as the bullet lodging in Cole's unopened parachute during an aerial dogfight. Soon it will be possessions, the bullet rather than Cole, that conserve the ancestral stories.

These possessions will tell of the depths of economic depression and the heights of the good life experienced in the explosion of consumer culture that occurred after WWII (Leach, 2011). Participants were all born in America before 1950, a time differentiated from previous eras by a dynamic economy that provided more income, confidence, and possessions (Leach, 2011). They experienced the rise and domination of a consumer culture that fulfilled the goals of Paul Mazur of Leman Brothers, "We must shift America from a needs to a desires culture. People must be trained to desire, to want new things even before the old have been entirely consumed" (de Beistegui, 2016, p. 2). As American materialism progressed, thought leaders from Fromm (2013) to Csikszentmihalyi and Rochberg-Halton (1981) expressed concerns. McCracken (2005) responded to one writer's classification of Americans as "devouring beasts" by saying, "It is time to take a more intelligent view and to see that consumer goods capture us because they capture the meanings with which we construct our lives" (pp. 3,4).

It is no wonder older adult participants in this study expressed a dynamic tension between having and being. When I asked a participant about the ways her possessions 
helped her make home, she responded, "In every way. I'm sorry to say because we should say 'As long as we have Jesus and each other.'” Her feelings of guilt are echoed by others; however, their collective-lived experiences are unique. They came of age during a cultural evolution that also aligned with increased life expectancy. Decades of ongoing material prosperity, for the first time in history, cultivated the potential to live for many years in one's chosen abode surrounded by prized possessions (Stafford, 2016). Older adults also discard significantly fewer items from their houses than younger adults (Ekerdt \& Baker, 2014a). Living longer with a greater accumulation of belongings, participants are the vanguard for intensity of disbandment experiences. Even so, I found these older adults to be resolute in action, goal oriented, and generally positive. Their capacity for courage and resilience inspires me, as it should. Each of us, if we live long enough, will face similar experiences. It is to our benefit that others have paved the way that we might have greater understanding when our times come. This benefit was one of my original goals in pursuing the study. By passing on gained understanding about older adult experiences and perspectives of post-disbandment placemaking, I intended to benefit those who are practically associated with the experience.

Continuing this discussion for the remainder of the chapter, I will review my research design to answer the research questions posed in the introduction chapter, show support of the answers with the findings reviewed in the previous chapter, and explain how the answers connect to the literature chapter and fit into the bigger picture. Based on Maxwell (2012), there are five interactive components of my research design. I review them in the following order: research questions and answers, conceptual framework, 
trustworthiness with methods, and goals. I follow with my strengths and limitations, implications, and suggestions for future research.

\section{Research Questions and Answers}

Embedded identity meanings. My first question asks, "What identity meanings, related in life span stories, are embedded in the possessions older adults move to their new residences? Within the thirty-five themes collected from the within-case analyses, I interpreted seventy-nine identity meanings. These included personal identity (53 instances), social identity (21 instances), and collective identity meanings (5 instances). Three identity statements also emerged from the thirty-five themes that begin with "I am" (twenty-four instances), "I believe" (six instances), and "I value" (five instances). The diversity of meaning embedded within various possessions suggests older adults have a rich sense of who they are, and they choose to bring that sense of identity into their new places. This concurs with studies suggesting possessions contribute to post-disbandment older adult identities as fluid in nature (Lovatt, 2016), autonomous, individual, and dignified (Nord, 2013). My study adds a granular level to the analysis of identity meanings that are embedded in post-disbandment older adults' possessions.

The lack of social-acquaintance and collective-national identity meanings within the themes may be explained with the theory of socioemotional selectivity (Baltes \& Carstensen, 1996). As mentioned in Chapter Two, the theory suggests emotional goals are increasingly important to people as they age. To maximize emotionally meaningful experiences, older adults actively restructure their social and collective relationships. Emotionally close relationships are retained while more superficial social relationships are discontinued (Carstensen et al., 1999). This would explain the lack of development of 
social-acquaintance and collective-national identity meanings in favor of family meanings.

Family identity in the creation of place.My second question asks, "How is the meaning of family identity, which is embedded within possessions, used to create meaningful places?" Four themes developed-1) low points: the presence of absence, 2) turning points: representations of adjustment, 3) high points: pinnacle representations, and 4) ordinary events: moments of everyday engagements. Presence of absence indicates that older adults incorporate loss into their new residences. Participants also include possessions that represent difficult adjustments such as death and divorce. These objects help them remember the ways they positively adjusted to changes in their families. High points in participants' life experiences involve joy, excitement, and love. Meanings derived from melding family with aesthetics, being together, and being historically relevant allow participants to call to mind their previous everyday family interactions. These family meanings are layered onto the cultural meanings previously imbued in the objects.

The storied possessions contribute to late-life placemaking by temporally moving residents through chosen family memories representing low points, turning points, high points, and everyday events that occurred throughout their lives. Lovatt (2016) suggests that, "Rather than the meaning of home being inherent in objects, or felt subjectively by residents, meaning is generated through ongoing, everyday interactions between the two" (Lovatt, 2016, p. 58) . My findings concur with this statement. When older adults are trying to make sense of their everyday lives, interactions with their storied possessions visually and narratively illustrate their family memories and stories. The possessions help 
them with the breakup of their household and reconstruction of their identity with the embedded family narrative. In this way storied possessions provide internal narrative coherence in understanding how older adults relate to their families in their new places.

Sense of home. As mentioned in my findings, 21 of 23 participants established a sense of home. This was a surprise to me. I anticipated that household disbandment was such a significant disruption to place that it could not be reestablished in the limited time remaining for the older adults. I did not take into consideration the inherent agency of placemaking or the tenacity of character and previous experiences of the three birth cohorts represented. Although arduous, household disbandment was not my participants' "first rodeo." In my introduction, I make the statement that dwelling is a learning to be athome that involves the creation of meaning. Rowles (2017) refers to it as being in place. I also make the statement that it is a process that occurs throughout the individual life span up until we die.

There is perhaps a tendency to see older adults as dotty because they are elderly, even if one would not say so out loud. It is the undercurrent in the daughter's quote above, "We had to listen to a nonstop story of her talking all the time." When we view Lawton and Nahemow's competence press model (1973), we must remember to look at the competence and press rather than assume an incompetence. I discovered in my research that all my participants were capable of making place, even home. Koss and Ekerdt (2016) suggest third-age older adults are consciously aware of relocations they will make as they enter the fourth-age. They capably consider and plan their options. This concurs with Lovatt's (2016) research conclusion that post-disbandment older adults, as during other stages of the life course in other settings, can still be at home because home 
is a made place, an interaction. She goes further and "challenges conceptualizations of older people's homes — and older age itself_-as somehow unknowable and unfamiliar" (Lovatt, 2016). I assert it is in the gap between unknowable and knowable and unfamiliar and familiar that storied possessions are most meaningful. Stories require a teller and a hearer - the unknowable becomes known, the unfamiliar-familiar.

Two of my household cases did not fit the dominant pattern (Colvin et al., 2018) and did not make home. One participant made a place of isolation and the other made a place of rejection. Within community placemaking research, a term is used for spaces that are not concerned with identity or defined as relational or historical: non-places (Bagnall et al., 2018). For this study, I borrow the term from community research and consider both the spaces of these two outliers as non-places.

In one instance, the participant felt rejected as a mother, and she was out of place. For the other, the participant was out of place because she did not feel she belonged in the socioeconomic community in which she located. In both cases, participants created nonplaces based on their symbolic and subjective place meanings wrapped up in postdisbandment residences, their place and possession attachments, and their life story narratives. There was increased complexity in one of the household cases because the spouse did make home. These findings suggest that possessions in and of themselves, even if chosen carefully, cannot make a sense of home if other symbolic meanings are more important to the older adult and dominate the process. These different choices, and the powerful agency of placemaking, need to be acknowledged. This concurs with studies suggesting being oneself is an aspect of agency connected to being at-homeness at the end of one's life (Saarnio, 2018; Saarnio et al., 2016). In both of my household non-place 
cases, neither of the participants felt she could be herself in the place she physically resided.

\section{Conceptual Framework-Storied Possessions Model}

In Chapter Two, I discuss my conceptual framework which includes four concepts viewed through the lens of symbolic interaction. The concepts are: older adult identity, embedded meaning in possessions, narrative life stories, and late-life placemaking Adding the findings from my study to this framework, I created the Storied Possessions Model which I explain below.

The interactions of the self are at the center of the storied possessions model, Figure 46. They are fashioned throughout lived experiences and are often expressed narratively. Narrative construction not only disseminates knowledge and shares experiences, it also facilitates understanding of the world and one's place in it (J. Bruner, 1990). Through narrative interactions with one's self and others in social and collective groups, self-identities develop and continue operating in the social context. These interactions are represented by the four arrows moving out from the center through the personal identity, social identity, and collective identity.

Additionally, there are identity interactions with objects that embed layers of meaning and create storied possessions. Storied possessions contribute to meaningful places. This is the outer circle of the model following Belk's suggestion, "Possessions central to self may be visualized in concentric layers around the core self' (1988, p. 152). Double arrows are shown leading into and out of meaningful place because place reciprocates by adding meaning to self-identities and objects. 


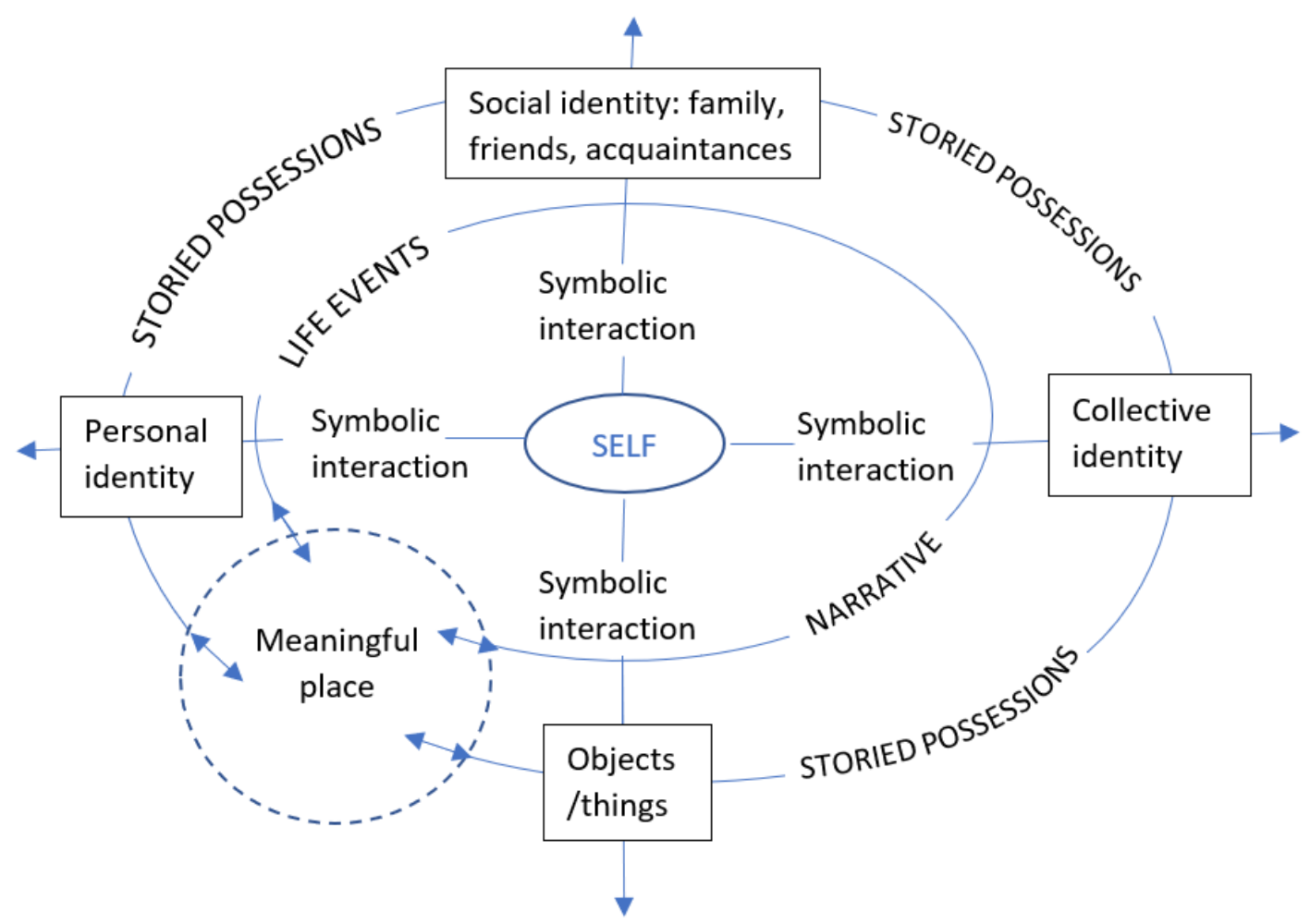

Figure 46. Storied possessions model showing symbolic interactions of life events in narrative form between the various identities of self in the social context and storied possessions leading to meaningful place.

When storied possessions are brought into environmental space, the space becomes a meaningful place through the possessions' meanings and the older adult's continuing engagement with them. This model concurs with conceptual thoughts in the literature regarding place: it is a geographic location having material form and invested with specific meanings (Gieryn, 2000) as well as a psychical force that shapes older adult lives with the remembrance of people and events temporally anchored (Schieffelin, 2018). Fuller and Atkinson (2016) view place as an "integration of physicality, functionality, community and spirituality and given an enacted/enacting form as place- 
making" (p. 233). Most recently Rowles (2018) suggests placemaking is a blending of the physical location and older adult identity.

\section{Interior Design Knowledge}

I include this section because one of my goals for this research was to add understanding that informs interior design theory. This directly relates to the aspect of the agency of making home. Theoretically, interior designers are unable to make home for other people. It is an interaction undertaken by the person wanting a home, even in, if not especially in, post-disbandment. Older adults need to be free to create meaningful places or non-places. Practically, for interior designers, this means creating spaces that afford places for older adults.

\section{Trustworthiness}

The multiple-case holistic case study research allowed me to answer my research questions and address the trustworthiness of my research design. I collected rich data that I triangulated using within-case analysis, cross-case analysis of the within-case findings, and an additional cross-case analysis.

\section{Goals}

I began this study wanting to achieve greater understanding of post-disbandment older adults' use of their possessions in late-life placemaking, the perspective (feelings \& opinions) of older adults after household disbandment about their senior apartments, and how older adults used their possessions to extend their identity within new environments to create meaningful places. I also wanted to add research that informs interior design theory as mentioned above. I achieved these goals. 


\section{Limitations and Strengths}

Limitations. The participants are not representative of the older population at large for several reasons. The cities in which they live were chosen for researcher convenience. All participants are middle-class, American Caucasians; all completed high school, many had master's degrees, and one female participant had a Ph.D.; no older adults within the LGBTQ community are represented. Consequently, a limitation of the study is the lack of diversity within the demographic.

An additional limitation is, with four exceptions, all participants are third-age older adults who are in general good health and have at least fair mobility with assistance. The four fourth-age older adults had the advantage of having significant family support. None of the participants were frail older adults with restricted social support. Answers to the research questions could significantly change with a larger inclusion of frail fourthage older adults. As a qualitative multiple-case holistic case study with sixteen cases and a sample population of twenty-three, I did not aim to provide generalizability across the population. Instead my goal was to provide descriptions of each case under study and themes from the cross-case analysis. Therefore, the small population size is not viewed as a limitation regarding the findings.

Strengths. This study developed an analytic tool that enables a more granular level of meaning than discussed in previous studies and may be helpful to other researchers. Additionally, a model that highlights the importance of story in postdisbandment placemaking was developed. Other strengths include a pool of participants who lived in two states, four different cities, and sixteen households in a variety of housing options. Three generational birth cohorts are represented with divorced, 
widowed, and married males (9) and females (14). The inclusion of the Greatest Generation birth cohort allowed representation of a population with material culture meanings that are quickly vanishing and spanned many generations. This contributed to the richness of material culture meanings within possessions.

\section{Implications}

Storied possessions are rich in meaning. This complexity is one aspect of the reported frustrations of working together on downsizing events; they are inherently problematized due to the complexity of multiple layers. The fact that some meanings are hidden does not negate their existence within storied possessions or their impact on owners. Disbandment and subsequent placemaking are connected through these possessions. Understanding the meanings may allow greater success in future placemaking. This emphasizes the importance of viewing disbandment and future placemaking as one holistic event.

Although the effects of individual age-related declines dictate much in the disbandment process, privileging the personal agency of older adults, to the degree possible, allows for authentic versions of placemaking.

An additional implication is a continuum of what and how many possessions older adults choose to keep. Participants who only furnished their apartments with possessions from past homes were confused by residents who started fresh with newly purchased items. It is helpful to remember that just as there is not only one meaning embedded in an object, there is not one way of placemaking for post-disbandment older adults. The places are as idiosyncratic as the possessions. 


\section{Suggested Future Research}

Various changes in Table 2 could produce future research. While continuing to focus on the possession - placemaking connection, studying persons displaced by career moves or marital status at earlier ages, would extend understanding to other groupings of individuals.

Changing the current residential type to include a facility case study investigating residents' use of possessions to tell life stories to other residents would increase understanding of post-disbandment placemaking.

Looking at the types of places older adults make when they are dissatisfied with the possessions they kept from disbandment would add a complementary perspective to this study. Additionally, looking at digital versus physical possessions is important intergenerationally. For instance, with the increase of digital technology, there is a different aspect in meaning making. Generations born or raised during the age of digital technology are known as digital natives. Digital natives are familiar with electronic resources (materials accessed electronically in digital format). These include electronic books (e-books). The display and preservation of photographs has also migrated to digital media. Because books and photographs, to varying degrees, were important to all participants, safe passage of these possession was important to them. Future research understanding the difference in the granular level of meaning of physical versus digital books and photographs in multiple generations of family, therefore, would be beneficial.

Continuing in this vein, including a greater emphasis on family relationship research and post-disbandment placemaking with possessions would also be beneficial as family was a significant aspect for participants in this study. 


\section{Conclusion}

This concludes the analysis and synthesis of my findings. I reviewed my research design including research questions and answers, conceptual framework, trustworthiness with methods, and goals. Although dynamic tensions existed in the disbandment experience between older adults, helpers, and possessions, participants from three birth cohorts were found to use their possessions to overlay stories upon anonymous spaces and create meaningful places. This is one way older adults remain connected to the meaningful past while engaging in the present. 


\section{REFERENCES}

Abercrombie, S. (1990). A philosophy of interior design: Harper \& Row.

Addington, A., \& Ekerdt, D. J. (2014). The Reproduction of Gender Norms Through

Downsizing in Later Life Residential Relocation. Research on Aging, 36(1), 3-21. doi:10.1177/0164027512463084

Ahmed, V., Opoku, A., \& Aziz, Z. (2016). Research methodology in the built environment: a selection of case studies: Routledge.

Altheide, D. L. (2000). Identity and the Definition of the Situation in a Mass - Mediated Context. Symbolic Interaction, 23(1), 1-27.

Ames, K. L. (1995). Death in the dining room and other tales of Victorian culture: Temple University Press.

Anderson, A. (2018). The bric-á-braquers étagère or whatnot: Staging 'artistic' taste in the 'aesthetic' house beautiful. In H. Kingstone \& K. Lister (Eds.), Paraphernalia! Victorian Objects: Taylor \& Francis.

Aronson, J. (1965). The Encyclopedia of Furniture (3rd Revised ed.): Crown Publishers.

Ashton, M. C., Lee, K., \& De Vries, R. E. (2014). The HEXACO Honesty-Humility, Agreeableness, and Emotionality factors: A review of research and theory. Personality and Social Psychology Review, 18(2), 139-152.

Bachelard, G. (1969). The Poetics of Space (M. Jolas, Trans.). Boston: Beacon Press. Back, E. A., \& Rabak, F. (1922). Red cedar chests as protectors against moth damage: US Dept. of Agriculture. 
Bagnall, A., South, J., Di Martino, S., Southby, K., Pilkington, G., Mitchell, B., .. . Corcoran, R. (2018). A systematic review of interventions to boost social relations through improvements in community infrastructure (places and spaces).

Baker, B. P., Grant, J. A., \& Malakar-Kuenen, R. (2018). Cedarwood Oil Profile.

Bauer, J. J., Graham, L. E., Lauber, E. A., \& Lynch, B. P. (2018). What growth sounds like: Redemption, self - improvement, and eudaimonic growth across different life narratives in relation to well - being. Journal of personality.

Bauer, J. J., King, L. A., \& Steger, M. F. (2018). Meaning making, self - determination theory, and the question of wisdom in personality. Journal of personality.

Beckett, C., \& Maynard, A. (2011). What are values. Social work: A reader, 129-135.

Belk, R. (1988). Possessions and the extended self. Journal of Consumer Research, 15(September), 139-168.

Belk, R. (1990). The role of possessions in constructing and maintaining a sense of past. ACR North American Advances.

Belk, R. (1992). Attachment to Possessions. In I. Altman \& S. M. Low (Eds.), Place Attachment (pp. 37-55). New York: Plenum Press.

Belk, R. (2013). Collecting in a consumer society: Routledge.

Bengtson, V. L., \& Allen, K. R. (2009). The life course perspective applied to families over time. In P. Boss, W. J. Doherty, R. LaRossa, W. R. Schumm, \& S. K. Steinmetz (Eds.), Sourcebook of family theories and methods (pp. 469-504): Springer.

Benjamin, W. (1999). Unpacking my library: A talk about book collecting. In D. Bassin (Ed.), Female Sexuality: Contemporary Engagements (pp. 21-28): J. Aronson. 
Bennett, E. V., Clarke, L. H., Kowalski, K. C., \& Crocker, P. R. (2017). From pleasure and pride to the fear of decline: Exploring the emotions in older women's physical activity narratives. Psychology of sport and exercise, 33, 113-122.

Berger, A. A. (1997). Narratives in popular culture, media, and everyday life: Sage.

Bergman, N. U. (2007). Understanding space, place and leisure of women over 85 living in the community.

Berkeley, G. (2009). Principles of human knowledge and three dialogues: Oxford University Press.

Bettcher, T. M. (2008). Berkeley: A Guide for the Perplexed. London: Continuum.

Bhattacharya, H. (2008). The SAGE Encyclopedia of Qualitative Research Methods. In (pp. 465-467). Thousand Oaks

Thousand Oaks, California: SAGE Publications, Inc. Retrieved from http://sk.sagepub.com/reference/research. doi:10.4135/9781412963909

Bignante, E. (2010). The use of photo-elicitation in field research. Exploring Maasai representations and use of natural resources. EchoGéo(11).

Bille, M., Bjerregaard, P., \& Sørensen, T. F. (2015). Staging atmospheres: Materiality, culture, and the texture of the in-between. Emotion, space and society, 15, 31-38.

Borden, I. (2006). Thick edge: Architectural boundaries and spatial flows. In M. Taylor \& J. Preston (Eds.), Intimus: Interior design theory reader (pp. 49-55). West Sussex, England: Wiley-Academy Press.

Boschetti, M. A. (1995). Attachment to Personal Possessions. Journal of Interior Design, $21(1), 1-12$. 
Boyle, G. J., Matthews, G., \& Saklofske, D. H. (2008). The SAGE Handbook of Personality Theory and Assessment: Personality Measurement and Testing: SAGE Publications.

Brandtstädter, J., \& Greve, W. (1994). The aging self: Stabilizing and protective processes. Developmental review.

Breen, T. H. (2017). "Baubles of Britain": the American and consumer revolutions of the eighteenth century. In Colonial America and the Early Republic (pp. 197-228): Routledge.

Brinberg, D., Bumgardner, M., \& Daniloski, K. (2007). Understanding perception of wood household furniture: application of a policy capturing approach. Forest Products Journal. 57 (7/8): 21-26., 57(7/8).

Brockmeier, J. (2009). Reaching for Meaning:Human Agency and the Narrative Imagination. Theory \& Psychology, 19(2), 213-233. doi: $10.1177 / 0959354309103540$

Brooker, G., \& Stone, S. (2013). From organisation to decoration: an interiors reader: Routledge.

Brown, C., \& Lowis, M. J. (2003). Psychosocial development in the elderly: An investigation into Erikson's ninth stage. Journal of Aging Studies, 17(4), 415-426.

Bruner, J. (1990). Acts of Meaning: Harvard University Press.

Bruner, J. (1991). The narrative construction of reality. Critical Inquiry, 18(1), 1-21.

Buck, P. S. (2013). My several worlds: a personal record: Open Road Media.

Burnes, D., Henderson Jr, C. R., Sheppard, C., Zhao, R., Pillemer, K., \& Lachs, M. S. (2017). Prevalence of financial fraud and scams among older adults in the United 
States: A systematic review and meta-analysis. American journal of public health, 107(8), e13-e21.

Burton, D. (1989). Collectible aesthetics. Art Education, 42(6), 42-45.

Buys, L., Burton, L., Cuthill, M., Hogan, A., Wilson, B., \& Baker, D. (2015). Establishing and maintaining social connectivity: An understanding of the lived experiences of older adults residing in regional and rural communities. Australian Journal of Rural Health, 23(5), 291-294.

Campbell, J. J. (Producer). (2010, June 30). Symbolic Interactionism. Retrieved from https://www.youtube.com/watch?v=1rOgqwD2OjQ\&t=218s

Carstensen, L. (2006). The influence of a sense of time on human development. Science, 312(5782), 1913-1915.

Carstensen, L., Isaacowitz, D., \& Charles, S. (1999). Taking time seriously: A theory of socioemotional selectivity. American Psychologist, 54(3), 165-181. doi:10.1037/0003-066X.54.3.165

Carter, M. J., \& Fuller, C. (2016). Symbols, meaning, and action: The past, present, and future of symbolic interactionism. Current Sociology, 64(6), 931-961.

Casey, A. M. (2018, July 14). Mom shows me how to live in the present. Dallas Morning News.

Cast, A. D., \& Stets, J. E. (2016). The Self. In Handbook of Contemporary Sociological Theory (pp. 343-365): Springer.

Cerezo-Román, J., Wessman, A., \& Williams, H. (2017). Cremation and the Archaeology of Death: Oxford University Press. 
Charmaz, K. (2011). A Constructivist grounded theory analysis of losing and regaining a valued self. In F. J. Wertz, K. Charmaz, L. M. McMullen, R. Josselson, R. Anderson, \& E. McSpadden (Eds.), Five Ways of Doing Qualitative Analysis: Phenomenological Psychology, Grounded Theory, Discourse Analysis, Narrative Research, and Intuitive Inquiry (pp. 165-204). NY, NY: Guilford Press.

Chatters, L. M., Taylor, H. O., Nicklett, E. J., \& Taylor, R. J. (2018). Correlates of Objective Social Isolation from Family and Friends among Older Adults. Paper presented at the Healthcare.

Chaudhury, H., \& Oswald, F. (2018). Annual Review of Gerontology and Geriatrics, Volume 38, 2018: Environments in an Aging Society: Autobiographical Perspectives in Environmental Gerontology: Springer Publishing Company.

Cinotto, S. (2006). "Everyone would be around the table": American family mealtimes in historical perspective, 1850-1960. New directions for child and adolescent development, 2006(111), 17-33.

Clark-Ibáñez, M. (2004). Framing the social world with photo-elicitation interviews. American behavioral scientist, 47(12), 1507-1527.

Colman, A. W. (2015a). belief. In.

Colman, A. W. (2015b). trait. In A. W. Colman (Ed.), A Dictionary of Psychology: Oxford University Press.

Colvin, C. J., Garside, R., Wainwright, M., Munthe-Kaas, H., Glenton, C., Bohren, M. A., ... Lewin, S. (2018). Applying GRADE-CERQual to qualitative evidence synthesis findings - paper 4: how to assess coherence. Implementation Science, 13(1), 13. doi:10.1186/s13012-017-0691-8 
Connelly, F. M., \& Clandinin, D. J. (2006). Narrative inquiry. In J. Green, G. Camili, \& P. Elmore (Eds.), Handbook of complementary methods in education research (pp. 375-385). Mahwah, N.J.: Lawrence Erlbaum.

Cornish, P., \& Saunders, N. J. (2013). Introduction. In Bodies in Conflict (pp. 21-28): Routledge.

Costanza, R., \& Folke, C. (1997). Valuing ecosystem services with efficiency, fairness, and sustainability as goals. In G. C. Daily, K. Bawa, S. Postel, L. Kaufman, C. H. Peterson, S. Carpenter, S. Alexander, K. Lagerquist, P. Dayton, \& L. Goulder (Eds.), Nature's Services: Societal Dependence On Natural Ecosystems (pp. 4968): Island Press.

Cox, K., \& McAdams, D. P. (2014). Meaning making during high and low point life story episodes predicts emotion regulation two years later: How the past informs the future. Journal of Research in Personality, 50, 66-70.

Creswell, J. W. (2009). Research design: Qualitative, quantitative, and mixed methods approaches (3rd ed.). Thousand Oaks: Sage.

Creswell, J. W. (2013). Qualitative Inquiry and Research Design: Choosing Among Five Approaches: SAGE Publications.

Creswell, J. W., \& Miller, D. L. (2000). Determining validity in qualitative inquiry (Vol. 39).

Crotty, M. (1998). The foundations of social research: Meaning and perspective in the research process: Sage.

Csikszentmihalyi, M., \& Rochberg-Halton, E. (1981). The meaning of things: Domestic symbols and the self. New York: Cambridge University Press. 
Czaja, S. J., Boot, W. R., Charness, N., Rogers, W. A., \& Sharit, J. (2017). Improving social support for older adults through technology: findings from the PRISM randomized controlled trial. The Gerontologist, 58(3), 467-477.

de Beistegui, M. (2016). Desires we live by. Paper presented at the Forum for European Philosophy Blog.

de Lange, A. H., Van Yperen, N. W., Van der Heijden, B. I., \& Bal, P. M. (2010). Dominant achievement goals of older workers and their relationship with motivation-related outcomes. Journal of vocational behavior, 77(1), 118-125.

Diehl, M., \& Wahl, H. W. (2014). Annual Review of Gerontology and Geriatrics, Volume 35, 2015: Subjective Aging: New Developments and Future Directions: Springer Publishing Company.

Donahoe, J. (2011). The place of home. Environmental Philosophy, 8(1), 25-40.

Dunkel, C. S., \& Harbke, C. (2017). A review of measures of Erikson's stages of psychosocial development: Evidence for a general factor. Journal of Adult Development, 24(1), 58-76.

Edensor, T. (2002). National identity, popular culture and everyday life: Bloomsbury Publishing.

Eisenberg, R. (2014). The Next Housing Crisis: Aging Americans' Homes. Retrieved from https://www.forbes.com/sites/nextavenue/2014/09/02/the-next-housingcrisis-aging-americans-homes/\#6f4038e22edc

Ekerdt, D. J. (2014). Possessions as a Material Convoy. In J. Twigg \& W. Martin (Eds.), Routledge Handbook of Cultural Gerontology. London: Routledge. 
Ekerdt, D. J., Addington, A., \& Hayter, B. (2011). Distributing possessions: Personal property can become a social matter. Generations, 35(3), 34-40.

Ekerdt, D. J., \& Baker, L. A. (2014a). The material convoy after age 50. The Journals of Gerontology Series B: Psychological Sciences and Social Sciences, gbu003.

Ekerdt, D. J., \& Baker, L. A. (2014b). The material convoy after age 50. Journals of Gerontology Series B: Psychological Sciences and Social Sciences, 69(3), 442450.

Ekerdt, D. J., Luborsky, M., \& Lysack, C. (2012a). Safe passage of goods and self during residential relocation in later life. Ageing \& Society, 32(5), 833-850.

Ekerdt, D. J., Luborsky, M., \& Lysack, C. (2012b). Safe passage of goods and self during residential relocation in later life. Ageing and society, 32(05), 833-850.

Ekerdt, D. J., \& Sergeant, J. F. (2006). Family things: Attending the household disbandment of older adults. Journal of Aging Studies, 20(3), 193-205.

Ekerdt, D. J., Sergeant, J. F., Dingel, M., \& Bowen, M. E. (2004). Household disbandment in later life. The Journals of Gerontology Series B: Psychological Sciences and Social Sciences, 59(5), S265-S273.

Emlet, C. A., Harris, L., Pierpaoli, C. M., \& Furlotte, C. (2018). “The Journey I Have Been Through": The Role of Religion and Spirituality in Aging Well Among HIV-Positive Older Adults. Research on Aging, 40(3), 257-280.

Encyclopedia of Case Study Research. (2010). doi:10.4135/9781412957397

Enz, K. F., \& Talarico, J. M. (2016). Forks in the road: Memories of turning points and transitions. Applied Cognitive Psychology, 30(2), 188-195. 
Eshelman, P., \& Evans, G. (2002). Home Again: Environmental Predictors of Place Attachment and Self-esteem for New Retirement Community Residents. Journal of Interior Design, 28(1), 1-9. doi:10.1111/j.1939-1668.2002.tb00368.x

Estroff Marano, H., \& Yusim, A. (2018). Character's turn. Psychology Today, 9.

Ewens, B. A., Hendricks, J. M., \& Sundin, D. (2017). Never ending stories: visual diarizing to recreate autobiographical memory of intensive care unit survivors. Nursing in critical care, 22(1), 8-18.

Farber, N., Shinkle, D., Lynott, J., Fox-Grage, W., \& Harrell, R. (2011). Aging in place: A state survey of livability policies and practices.

Fearon, J. D. (1999). What is identity (as we now use the word). Unpublished manuscript, Stanford University, Stanford, Calif.

Fegg, M. J., Wasner, M., Neudert, C., \& Borasio, G. D. (2005). Personal values and individual quality of life in palliative care patients. Journal of pain and symptom management, 30(2), 154-159.

Ferraro, K. F., \& Wilmoth, J. M. (2013). Gerontology: Perspectives and issues: Springer Publishing Company.

Fleming, E. M. (1974). Artifact study: A proposed model. Winterthur Portfolio, 9, 153173.

Flick, U. (2013). The SAGE handbook of qualitative data analysis: Sage.

Fowler, C. (2010). From identity and material culture to personhood and materiality. In The Oxford handbook of material culture studies.

Fromm, E. (2013). To have or to be? : A\&C Black.

Fuller, S., \& Atkinson, S. (2016). Wellbeing and Place: Taylor \& Francis. 
Gabrielson, M. (2018). Challenges and Achievements Regarding Outreach to Lesbian, Gay, Bisexual, and Transgender Elders: Perspectives from Nursing. In Critical Gerontology Comes of Age (pp. 104-123): Routledge.

Gage, M. F. (Ed.) (2011). Aesthetic Theory: Essential Texts. New York: W. W. Norton. Gagliardi, P. (2017). Symbols and artifacts: Views of the corporate landscape: Routledge.

Gale, C. R., Ritchie, S. J., Cooper, C., Starr, J. M., \& Deary, I. J. (2017). Cognitive ability in late life and onset of physical frailty: the Lothian Birth Cohort 1936. Journal of the American Geriatrics Society, 65(6), 1289-1295.

Galford, G. (2018). Architecture as a device of control: Themes of prison life with focus on solitary confinement. (Ph.D.), The University of Missouri - Columbia, Columbia, MO.

Giasson, H. L., Liao, H.-W., \& Carstensen, L. L. (2018). Counting down while time flies: implications of age-related time acceleration for goal pursuit across adulthood. Current opinion in psychology.

Gieryn, T. F. (2000). A space for place in sociology. Annual review of sociology, 26(1), 463-496.

Gilleard, C., \& Higgs, P. (2015). Connecting Life Span Development with the Sociology of the Life Course: A New Direction. Sociology. doi:10.1177/0038038515577906

Given, L. M. (2008). The Sage Encyclopedia of Qualitative Research Methods: A-L ; Vol. 2, M-Z Index: Sage.

Glas, G. (2006). Person, personality, self, and identity: a philosophically informed conceptual analysis. Journal of Personality Disorders, 20(2), 126-138. 
Goggin, M. (2017). The Needle as the Pen: Intentionality, Needlework, and the Production of Alternate Discourses of Power. In Women and the Material Culture of Needlework and Textiles, 1750-1950 (pp. 29-46): Routledge.

Golant, S. M. (2015). Aging in the Right Place.

Gott, M., \& Ingleton, C. (2013). Do old people matter? Retrieved from https://blog.oup.com/2013/01/do-old-people-matter-ageism-palliative-end-life$\underline{\text { care/ }}$

Gram-Hanssen, K., \& Beth-Danielsen, C. (2004). House, home and identity from a consumption perspective. Housing, Theory \& Society, 21(1), 17-26.

Hagestad, G. O., \& Settersten, J. R. A. (2017). Aging: It's Interpersonal! Reflections From Two Life Course Migrants. The Gerontologist, 57(1), 136-144. doi:10.1093/geront/gnw117

Halfon, N., \& Hochstein, M. (2002). Life course health development: an integrated framework for developing health, policy, and research. The Milbank Quarterly, $80(3), 433-479$.

Harmeling, C. M., Palmatier, R. W., Fang, E., \& Wang, D. (2017). Group marketing: Theory, mechanisms, and dynamics. Journal of Marketing, 81(4), 1-24.

Hartup, W. W., \& Stevens, N. (1997). Friendships and adaptation in the life course. Psychological bulletin, 121(3), 355.

Haslam, S. A., Cornelissen, J. P., \& Werner, M. D. (2017). Metatheories and metaphors of organizational identity: integrating social constructionist, social identity, and social actor perspectives within a social interactionist model. International Journal of Management Reviews, 19(3), 318-336. 
Havenhand, L. K. (2006). American Abstract Art and the Interior Design of Ray and Charles Eames. Journal of Interior Design, 31(2), 29-42.

Hayden, A. (1906). Chats on old furniture: a practical guide for collectors: T. Fisher Unwin.

Hedges, D. (2017). Transitions in life: early stages. In Poetry, Therapy and Emotional Life (pp. 33-44): CRC Press.

Heidegger, M. (1971). Building dwelling thinking: poetry, language, thought. Translated from the German by Albert Hofstadter. In: New York: Harper Colophon Books.

Heisler, M. (2017). Eliciting Personal Values of Patients with Multiple Chronic Conditions: Why and How. In: Springer.

Hendricks, J., \& Cutler, S. J. (2018). Leisure in life-course perspective. In R. A. Settersen (Ed.), Lives in Time and Place and Invitation to the Life Course: The Problems and Promises of Developmental Science. New York, NY: Routledge.

Heneghan, B. T. (2003). Whitewashing America: Material culture and race in the antebellum imagination: Univ. Press of Mississippi.

Hiles, D. (2008). In L. Given (Ed.), The SAGE encyclopedia of qualitative research methods (pp. 891-892). Thousand Oaks, California: SAGE Publications, Inc. Retrieved from http://sk.sagepub.com/reference/research. doi: $10.4135 / 9781412963909$

Hill, R., Betts, L. R., \& Gardner, S. E. (2015). Older adults' experiences and perceptions of digital technology:(Dis) empowerment, wellbeing, and inclusion. Computers in Human Behavior, 48, 415-423. 
Humphrey, H. H. (1976). Address to Democratic National Convention (Speech). http://www2.mnhs.org/library/findaids/00442.xml

Hutchison, E. D. (2014). Dimensions of Human Behavior: The Changing Life Course: SAGE Publications.

Inclezan, D., Zhang, Q., Balduccini, M., \& Israney, A. (2018). An ASP Methodology for Understanding Narratives about Stereotypical Activities. arXiv preprint arXiv:1804.09855.

IRB. (2018). Standard Operating Procudre for Exempt Process Case Reports. Retrieved from Columbia, Missouri:

https://research.missouri.edu/policies/files/SOP_Exempt_Process_Case_Reports.p $\underline{\mathrm{df}}$

Jaspers, E. D., \& Pieters, R. G. (2016). Materialism across the life span: An age-periodcohort analysis. Journal of Personality and Social Psychology, 111(3), 451.

Joint Center for Housing Studies of Harvard University. (2015). Projections \& implications for housing a growing population: Older households 2015-2035. Retrieved from Harvard University:

Jones, J., \& Ackerman, M. S. (2016). Curating an infinite basement: understanding how people manage collections of sentimental artifacts. Paper presented at the Proceedings of the 19th International Conference on Supporting Group Work.

Jørgensen, C. R. (2010). Invited essay: Identity and borderline personality disorder. Journal of Personality Disorders, 24(3), 344-364.

Jung, C. G. (1964). Man and his symbols: Laurel. 
Kay, J. (2016). Folk Art and Aging: Life-Story Objects and Their Makers: Indiana University Press.

Kelly, W. W. (2018). The ubiquitous baseball cap: Identity, style, and comfort in late modern times. Journal of Consumer Culture, 18(2), 261-278. doi: $10.1177 / 1469540517744693$

Kennedy, S., \& Mitchell, L. (2017). Shine: Penguin UK.

Kiliçkiran, D. (2004). Migrant homes: Ethnicity, identity, and domestic space culture. In S. Menin (Ed.), Constructing place: mind and the matter of place-making (pp. 99110). New York, NY: Routledge.

Kleine, S. S., \& Baker, S. M. (2004). An integrative review of material possession attachment. Academy of Marketing Science Review, 1(1), 1-35.

Kondo, M. (2018). KonMari. Retrieved from https://konmari.com/

Kondo, M., \& Zeller, E. (2015). The Life-changing magic of tidying up: Findaway World LLC.

Korsmeyer, C. (2017). Taste and other senses: Reconsidering the foundations of aesthetics. The Nordic Journal of Aesthetics, 26(54).

Koss, C., \& Ekerdt, D. J. (2016). Residential reasoning and the tug of the fourth age. The Gerontologist, gnw010.

Kuskey, G. E., \& Gilois, B. (2014). Billion Dollar Painter: The Triumph and Tragedy of Thomas Kinkade, Painter of Light: Hachette Books.

Lal, S., Suto, M., \& Ungar, M. (2012). Examining the potential of combining the methods of grounded theory and narrative inquiry: A comparative analysis. The Qualitative Report, 17(21), 1. 
Lawton, M. P., \& Nahemow, L. (1973). Ecology and the aging process. In A. P. A. T. F. o. Aging, C. Eisdorfer, \& M. P. Lawton (Eds.), The Psychology of Adult Development and Aging (pp. 619-674). Washington, DC: American Psychological Association.

Leach, W. R. (2011). Land of Desire: Merchants, Power, and the Rise of a New American Culture: Knopf Doubleday Publishing Group.

Leddy, T. (2017). A Dialectical Approach to Berleant's Concept of Engagement. ESPES, $6(2), 72-78$.

Lee, S., Johnson, R., Fenge, L.-A., \& Brown, K. (2017). Safeguarding Adults at Risk of Financial Scamming. Safeguarding Adults Under the Care Act 2014:

Understanding Good Practice, 240.

Leonard, L., Perkins, H., \& Thorns, D. (2004). Presenting and creating home: the influence of popular and building trade print media in the construction of home. Housing, Theory \& Society, 21(3), 97-110. doi:10.1080/14036090410000480

Lewin, K. (1939). Field Theory and Experiment in Social Psychology: Concepts and Methods. American Journal of Sociology, 44(6), 868-896.

Li, L. (2017). Analysis of the Influence of Visual Aesthetics on Interior Design. Boletín Técnico, ISSN: 0376-723X, 55(19).

Lin, T., Ankudowich, E., \& Ebner, N. C. (2017). Greater perceived similarity between self and own-age others in older than young adults. Psychology and Aging, 32(4), 377.

Lincoln, Y. S., \& Guba, E. G. (1985a). Establishing trustworthiness. Naturalistic inquiry, $289,331$. 
Lincoln, Y. S., \& Guba, E. G. (1985b). Naturalistic inquiry (Vol. 75): Sage.

Lindley, S., \& Wallace, J. (2015). Placing in age: Transitioning to a new home in later life. ACM Transactions on Computer-Human Interaction (TOCHI), 22(4), 20.

Livesley, W. J., \& Larstone, R. (2018). Handbook of personality disorders: Theory, research, and treatment: Guilford Publications.

Loeffler, T. (2018). Looking back, paddling forward: perspectives on outdoor expedition participation over the lifespan. Journal of Adventure Education and Outdoor Learning, 1-13.

Logan, T., \& Beer, G. (2001). The Victorian Parlour: A Cultural Study: Cambridge University Press.

Lovatt, M. (2016). Everyday life in older people's residential homes from a material culture perspective. University of Sheffield,

Low, S. M., \& Altman, I. (1992). Place attachment: A conceptual inquiry. In I. Altman \& S. M. Low (Eds.), Place Attachment. New York: Plenum Press.

Luborsky, M. R., Lysack, C. L., \& Van Nuil, J. (2011). Refashioning one's place in time: Stories of household downsizing in later life. Journal of Aging Studies, 25(3), 243-252.

Luchetti, M., \& Sutin, A. R. (2018). Age differences in autobiographical memory across the adult lifespan: older adults report stronger phenomenology. Memory, 26(1), $117-130$.

M.I. Hummel Company. (2011). About M.I. Hummel. Retrieved from https://web.archive.org/web/20110721192337/https://www.shophummel.com/abo ut hummel 
Marcoux, J.-S. (2001). The 'Casser Maison'ritual constructing the self by emptying the home. Journal of Material Culture, 6(2), 213-235.

Margolis, M. F. (2018). From Politics to the Pews: How Partisanship and the Political Environment Shape Religious Identity: University of Chicago Press.

Mason, J. (2002). Qualitative researching: Sage.

Mathison, S. (2011). Cross-Case Analysis. In S. Mathison (Ed.), Encyclopedia of Evaluation. Thousand Oaks, California.

Maxwell, J. A. (2005). Qualitative Research Design: An Interactive Approach: Sage Publications.

Maxwell, J. A. (2012). Qualitative Research Design: An Interactive Approach: SAGE Publications.

McAdams, D. P. (2008). Personal narratives and the life story. Handbook of personality: Theory and research, 3, 242-262.

McAra, C. (2017). Hope Chest. Girlhood Studies, 10(3), 168-183.

McCormack, B. (2017). Negotiating Partnerships with Older People: A Person Centred Approach: A Person Centred Approach: Routledge.

McCracken, G. (1986). Culture and Consumption: A Theoretical Account of the Structure and Movement of the Cultural Meaning of Consumer Goods. Journal of Consumer Research, 13(1), 71-84.

McCracken, G. (2005). Culture and consumption II: markets, meaning, and brand management. Bloomington, IN: Indiana University Press.

McGhee, G., Marland, G. R., \& Atkinson, J. (2007). Grounded theory research: literature reviewing and reflexivity. Journal of Advanced Nursing, 60(3), 334-342. 
Mecum, L., \& Balzano, W. (2011). Women's and Gender Studies News \& Notes. In (No. 44/Fall 2010-Fall 2011 ed.): Wake Forest University.

Menin, S. (2004). Constructing place: mind and the matter of place-making: Routledge.

Merriam-Webster. (Ed.) (2018a) Merriam-Webster Dictionary.

Merriam-Webster. (Ed.) (2018b) Merriam-Webster Dictionary.

Merriam-Webster. (Ed.) (2018c) Merriam-Webster Dictionary.

Merriam-Webster. (Ed.) (2018d) Merriam-Webster Dictionary.

Merriam-Webster. (Ed.) (2018e) Merriam-Webster Dictionary.

Merriam, S. B., \& Mohamad, M. (2000). How Cultural Values Shape Learning in Older Adulthood: The Case of Malaysia. Adult Education Quarterly, 51(1), 45-63. doi:10.1177/074171360005100104

Meskin, A., \& Robson, J. (2015). Taste and acquaintance. The Journal of Aesthetics and Art Criticism, 73(2), 127-139.

Meyer, M. H., \& Daniele, E. A. (2016). Gerontology: Changes, Challenges, and Solutions [2 volumes]: Changes, Challenges, and Solutions: ABC-CLIO.

Miller, S., \& Schlitt, J. K. (1987). Interior Space: Design Concepts For Personal Needs. New York: Praeger Paperback.

Moschis, G. P. (2007). Life course perspectives on consumer behavior. Journal of the Academy of Marketing Science, 35(2), 295-307. doi:10.1007/s11747-007-0027-3

Myzelev, A. (2017). Material Cultures, 1740 - 1920: The Meanings and Pleasures of Collecting: Taylor \& Francis.

Neumann, J. (2008). Kurt Lewin - 'Field Theory Rule'. Retrieved from http://www.tavinstitute.org/projects/field-theory-rule/ 
Nicolaisen, M., \& Thorsen, K. (2017). What are friends for? Friendships and loneliness over the lifespan-From 18 to 79 years. The International Journal of Aging and Human Development, 84(2), 126-158.

Nisan, M. (1999). Identity and Civilization: Essays on Judaism, Christianity, and Islam: University Press of America.

Noonan, J. (2008). Ontology. In L. Given (Ed.), The SAGE encyclopedia of qualitative research methods (pp. 578-581). Thousand Oaks, California: SAGE Publications, Inc. Retrieved from http://sk.sagepub.com/reference/research. doi:10.4135/9781412963909

Nord, C. (2013). A day to be lived. Elderly peoples' possessions for everyday life in assisted living. Journal of Aging Studies, 27(2), 135-142.

Nurmi, J.-E. (1992). Age differences in adult life goals, concerns, and their temporal extension: A life course approach to future-oriented motivation. International Journal of Behavioral Development, 15(4), 487-508.

Oswald, F., \& Wahl, H.-W. (2013). Creating and sustaining homelike places in residentail environments. In G. D. Rowles \& M. Bernard (Eds.), Environmental Gerontology: Making Meaningful Places in Old Age (pp. 53-77): Springer Publishing Company.

Padgett, D. K. (2016). Qualitative methods in social work research (Vol. 36): Sage Publications.

Palinkas, L. A., Horwitz, S. M., Green, C. A., Wisdom, J. P., Duan, N., \& Hoagwood, K. (2013). Purposeful sampling for qualitative data collection and analysis in mixed 
method implementation research. Administration and Policy in Mental Health and Mental Health Services Research, 1-12.

Patel, S. (2017). Substance Use: Family Meals, Conversations, and Family Cohesion. California State University, Sacramento,

Pattinson, S., Nicholson, J., \& Lindgreen, A. (2017). Emergent coopetition from a sensemaking perspective: A multi-level analysis. Industrial Marketing Management.

Perry, G. (1999). Gender and Art: Yale University Press.

Peteet, J. R., Zaben, F. A., \& Koenig, H. G. (2018). Integrating spirituality into the care of older adults. International Psychogeriatrics, 1-8. doi:10.1017/S1041610218000716

Phoenix, C., \& Sparkes, A. C. (2009). Being Fred: Big stories, small stories and the accomplishment of a positive ageing identity. Qualitative Research, 9(2), 219236.

Pickett, M. C. (2016). Toward a Future Adult Learning Community: If Socrates Had a PC.

Ponzetti, J. (2003). International encyclopedia of marriage and family: Macmillan Reference USA.

Popenoe, D. (1993). American family decline, 1960-1990: A review and appraisal. Journal of Marriage and the Family, 527-542.

Price, L. L., Arnould, E. J., \& Folkman Curasi, C. (2000). Older consumers' disposition of special possessions. Journal of Consumer Research, 27(2), 179-201. 
Price, L. L., Arnould, E. J., \& Folkman Curasi, C. (2000). Older consumers' disposition of special possessions. Journal of Consumer Research, 27(2), 179-201.

Purbrick, L. (2016). The Wedding Present: Domestic Life Beyond Consumption: Taylor $\&$ Francis.

Quan-Haase, A., Mo, G. Y., \& Wellman, B. (2017). Connected seniors: how older adults in East York exchange social support online and offline. Information, Communication \& Society, 20(7), 967-983.

Radkau, J., \& Camiller, P. (2012). Wood: A History: Wiley.

Rantz, M. J., Skubic, M., Miller, S. J., Galambos, C., Alexander, G., Keller, J., \& Popescu, M. (2013). Sensor technology to support aging in place. Journal of the American Medical Directors Association, 14(6), 386-391.

Rapoport, A. (2005). On using "home" and "place": Springer Publishing Company, New York.

Ray, M. (2018). Material Culture. In T. K. Bhutia \& M. Ray (Eds.), Encyclopaedia Britannica: Encyclopædia Britannica, Inc. Retrieved from https://www.britannica.com/topic/material-culture.

Raymond, C. M., Kyttä, M., \& Stedman, R. (2017). Sense of Place, Fast and Slow: The Potential Contributions of Affordance Theory to Sense of Place. Frontiers in Psychology, 8(1674). doi:10.3389/fpsyg.2017.01674

Resnik, D. B. (2011). What is ethics in research \& why is it important. Paper presented at the The national. 
Rich, R. (2006). Designing the dinner party. In M. Taylor \& J. Preston (Eds.), Intimus: Interior design theory reader (pp. 292-296). West Sussex, England: WileyAcademy Press.

Ritchie, J., Lewis, J., Nicholls, C. M., \& Ormston, R. (2013). Qualitative research practice: A guide for social science students and researchers: Sage.

Robertson, E. (2017). Minstrels, missionaries and the Minster: Race, imperialism and the historic city. In Chocolate, women and empire: Manchester University Press.

Rose, D. (2018). Physical Activity Instruction of Older Adults, 2E: Human Kinetics.

Rose, G. (2014). On the relation between 'visual research methods' and contemporary visual culture. The sociological review, 62(1), 24-46.

Rotenberg, R. (2014). material agency in the urban material culture initiative. Museum Anthropology, 37(1), 36-45.

Rowles, G. D. (2017). Being in place: Identity and place attachment in late life. In M. W. Skinner, G. J. Andrews, \& M. P. Cutchin (Eds.), Geographical Gerontology: Perspectives, Concepts, Approaches: Taylor \& Francis.

Rowles, G. D. (2018). Housing for Older Adults. In Environmental Psychology and Human Well-Being (pp. 77-106): Elsevier.

Rubinstein, R. L., \& de Medeiros, K. (2005). Home, self, and identity. In G. D. Rowles \& H. Chaudhury (Eds.), Home and identity in late life: International perspectives (pp. 63-80). New York, NY: Springer Publishing Company.

Rubinstein, R. L., \& Parmalee, P. A. (1992). Attachment to place and the representation of the life course by the elderly. In I. Altman \& S. M. Low (Eds.), Place Attachment (pp. 139-160). New York: Plenum Press. 
Russell, W. B., \& Rosa, L. (2012). Shared Possessions/Shared Self. In The Routledge Companion to Identity and Consumption: Routledge.

Saarnio, L. (2018). Enabling at-homeness for older people despite their severe ilness and impending death: Inst för neurobiologi, vårdvetenskap och samhälle/Dept of Neurobiology, Care Sciences and Society.

Saarnio, L., Boström, A. M., Gustavsson, P., \& Öhlén, J. (2016). Meanings of at homeness at end - of - life among older people. Scandinavian journal of caring sciences, 30(2), 312-319.

Sabar, G., \& Sabar Ben-Yehoshua, N. (2017). 'I'll sue you if you publish my wife's interview': ethical dilemmas in qualitative research based on life stories. Qualitative Research, 1468794116679727.

Salazar-Porzio, M., Troyano, J. F., \& Safranek, L. (2017). Many Voices, One Nation: Material Culture Reflections on Race and Migration in the United States: Smithsonian Institution.

Samanta, T. (2017). Bridging the gap: theory and research in social gerontology. In Cross-Cultural and Cross-Disciplinary Perspectives in Social Gerontology (pp. 3-22): Springer.

Schieffelin, B. B. (2018). Language socialization and making sense of place. The Sociolinguistics of Place and Belonging. Perspectives from the Margins, 29-56.

Schwaba, T., \& Bleidorn, W. (2018). Individual differences in personality change across the adult life span. Journal of personality, 86(3), 450-464. 
Sergeant, J. F., \& Ekerdt, D. J. (2008). Motives for residential mobility in later life: Postmove perspectives of elders and family members. The International Journal of Aging and Human Development, 66(2), 131-154.

Settersten, R. (2018). Lives in Time and Place and Invitation to the Life Course: The Problems and Promises of Developmental Science: Routledge.

Shadyac, T. (Writer). (2002). Dragonfly. In T. Shadyac, G. Barber, R. Birnbaum, \& M. Johnson (Producer). USA: Spyglass Entertainment.

Shaw, D. (2013). A New Look at an Old Research Method: Photo - Elicitation. TESOL Journal, 4(4), 785-799.

Shepherd, R. E. (2014). Going Up the Country: A Comparison of Elite Ceramic Consumption Patterns in Charleston and the Carolina Frontier.

Sherman, E., \& Dacher, J. (2005). Cherished objects and the home: Their meaning and roles in late life. In G. D. Rowles \& H. Chaudhury (Eds.), Home and identity in late life: International perspectives (pp. 63-79). NY, NY: Springer Publishing Company.

Silverman, D. (2015). Interpreting qualitative data: Sage.

Silverstein, M., \& Bengtson, V. L. (2018). Return to Religion? Predictors of Religious Change among Baby-Boomers in their Transition to Later Life. Journal of population ageing, 11(1), 7-21.

Sinclair, T. J., \& Grieve, R. (2017). Facebook as a source of social connectedness in older adults. Computers in Human Behavior, 66, 363-369.

Smith, G. V., \& Ekerdt, D. J. (2011). Confronting the material convoy in later life. Sociological inquiry, 81(3), 377-391. 
Smith, S. S., \& Carpenter, B. S. (2018). Discursive Materials of Racism and the Arts in Education: Narratives, Performances, and Material Culture. In The Palgrave Handbook of Race and the Arts in Education (pp. 177-185): Springer.

Sneed, J. R., \& Whitbourne, S. K. (2001). Identity processing styles and the need for selfesteem in middle-aged and older adults. The International Journal of Aging and Human Development, 52(4), 311-321.

Srivastava, P. (2017). Supernatural and Religious Beliefs among Rural and Urban Older Adults. Journal of Psychosocial Research, 12(1), 11.

Stafford, G. E. (2016). Aging alone in the family home: Exploring place attachment and personal adaptation. University of Missouri--Columbia,

Statista. (2018). Resident population in the United States in 2017, by generation (in millions). Retrieved from https://www.statista.com/statistics/797321/uspopulation-by-generation/

Stephan, Y., Sutin, A. R., Bosselut, G., \& Terracciano, A. (2017). Sensory functioning and personality development among older adults. Psychology and Aging, 32(2), 139.

Stobart, J., \& Rothery, M. (2014). Fashion, heritance and family: new and old in the Georgian country house. Cultural and Social History, 11(3), 385-406.

Stone, L. (2008). Epistemology. In L. Given (Ed.), The SAGE encyclopedia of qualitative research methods (Vol. 2, pp. 265-268). Thousand Oaks, California: SAGE Publications, Inc. Retrieved from http://sk.sagepub.com/reference/research. doi:10.4135/9781412963909 
Stowe, W. W. (2017). Going Abroad: European Travel in Nineteenth-Century American Culture (Vol. 4841): Princeton University Press.

Sujan, M., Bettman, J. R., \& Baumgartner, H. (1993). Influencing consumer judgments using autobiographical memories: A self-referencing perspective. Journal of Marketing research, 422-436.

Swank, J. M., Smith - Adcock, S., \& Puig, A. (2017). “Finding Beauty in Everyday Life” : A Photo - Elicitation Study of Play Across the Life Span. Adultspan Journal, 16(1), 3-17.

Swinburn, J. (2013). You die twice. JohnSwinburn.com. Retrieved from $\underline{\text { http://johnswinburn.com/you-die-twice/ }}$

Taylor, L., \& Warren, D. B. (2012). Texas Furniture, Volume One: The Cabinetmakers and Their Work, 1840-1880: University of Texas Press.

Thomas, D., \& Jones, D. (2003). The Poems of Dylan Thomas: New Directions.

Thomsen, D. K., \& Pillemer, D. B. (2017). I know my story and I know your story: Developing a conceptual framework for vicarious life stories. Journal of personality, 85(4), 464-480.

Tilley, C. (2006). Objectification. In C. Tilley, W. Keane, S. Kuechler, M. Rowlands, \& P. Spyer (Eds.), Handbook of Material Culture: SAGE Publications.

Ting-Toomey, S., \& Dorjee, T. (2018). Communicating Across Cultures, Second Edition: Guilford Publications.

Tischleder, B. (2005). Literary Interiors, Cherished Things, and Feminine Subjectivity in the Gilded Age. ESC: English Studies in Canada, 31(1), 96-117. 
Umanath, S., \& Berntsen, D. (2017). Some personal life events are more prominent than others: Younger and older adults agree on which life events matter most. Memory Studies, 1750698017754250.

USA Today (Writer). (2018). George W. Bush's full speech at the memorial service for John S. McCain [Video file]. In USA Today (Producer). youtube.com.

Valis, N. (2002). The culture of cursilería: bad taste, kitsch, and class in modern Spain: Duke University Press.

Vignoles, V. L., Schwartz, S. J., \& Luyckx, K. (2011). Introduction: Toward an integrative view of identity. In Handbook of identity theory and research (pp. 127): Springer.

Vollmer, J. L., Schulze, P. A., \& Chebra, J. M. (2005). The American Master Bedroom: Its Changing Location and Significance to the Family. Journal of Interior Design, 31(1), 1-13. doi:10.1111/j.1939-1668.2006.tb00413.x

Waldersen, B. W., Wolff, J. L., Roberts, L., Bridges, A. E., Gitlin, L. N., \& Szanton, S. L. (2017). Functional goals and predictors of their attainment in low-income community-dwelling older adults. Archives of physical medicine and rehabilitation, 98(5), 896-903.

Walters, D. (2012). Securing tradition: Researching the origins of the hope chest through Medieval European, Italian Renaissance, and Early American Forms. (Departmental Honors), Lycoming College,

Webb, J. D. (2009). Golden Age collecting in America's Middle West: Chester and Clara Congdon's Glensheen Historical Manor and Raymond Wyer's An Art Museum. Journal of the History of Collections, 22(1), 99-113. 
Wendt, A. (1994). Collective identity formation and the international state. American political science review, 88(2), 384-396.

Wertz, F. J., Charmaz, K., McMullen, L. M., Josselson, R., Anderson, R., \& McSpadden, E. (2011). Five Ways of Doing Qualitative Analysis: Phenomenological Psychology, Grounded Theory, Discourse Analysis, Narrative Research, and Intuitive Inquiry: Guilford Press.

Wheeler, E. (2017). On the stability of identity interacting with the impermancence of time. In J. D. Sinnott (Ed.), Identity Flexibility During Adulthood (pp. 3-17): Springer.

White, C. L., \& Beaudry, M. C. (2009). Artifacts and personal identity. In International handbook of historical archaeology (pp. 209-225): Springer.

Wigley, M. (2011). Inside the inside. In L. Weinthal (Ed.), Toward a New Interior: An Anthology of Interior Design Theory (pp. 383-393). New York, NY: Princeton Architectural Press.

Williamson, E., Lyle, S., Darton, F., Griffiths, F., \& Lamb, S. (2017). From data collection to intervention development: A qualitative study of older people's experiences of living with neurogenic claudication. Musculoskeletal Science \& Practice, 28, e18-e19.

Winterrowd, E., Canetto, S. S., \& Benoit, K. (2017). Permissive beliefs and attitudes about older adult suicide: a suicide enabling script? Aging \& mental health, 21(2), 173-181.

Wood, D., \& Beck, R. (1990). Do's and Don'ts: Family Rules, Rooms, and Their Relationships. Children's Environments Quarterly, 2-14. 
Yin, R. K. (2017). Case Study Research and Applications: Design and Methods (Kindle Ed.): SAGE Publications.

Young, A. (2017). What Are the Facilitators and Barriers to Participation in Meaningful Occupations of Retired Community Based Older Adults? 


\section{Appendix A}

\section{Answers to Reflexivity Questions Spring 2017}

\section{What are my experiences with this type of research and my topic?}

As I write this, I have just spent a week with my parents who raised me with a solid value system that was ethical and centered around a strong work ethic, honesty, and "do no harm" to your fellow man. Both my parents are octogenarians, although my father will turn 90 next year. I flew into town to help with their taxes, but my mother, who is frail, had a medical episode that resulted in an emergency room visit and overnight hospitalization. I am intimately involved in the details of their lives and their home environment. My parents are hoarders, and the characteristics I described in my conceptual framework about people with hoarding disorder applies to them. When I am not in the same city helping them, it is easier for me to be objective and detach from the domino effect of their disorder. This week, however, I had to tell the caseworker at the hospital what the home health aides, who will be coming to my parents' house, need to expect: an overwhelming odor of dogs, feces, and urine and pathways lined with piles of boxes, trash, and furniture.

This is horrendously sad to me, and I've spent years dealing with false guilt and shame. My natural default is to deal with things by how I feel about them or how they fit into my personal value system, and I process experiences via my five senses in a literal, concrete fashion. It is perhaps a major reason I became an interior designer though I did not understand my need for environmental control at the time. I've always enjoy creating order and structure and am very good at tasks which require these kinds of skills. In this way, I tend to be externally focused. I used these skills when I was the primary person 
who assisted my in-laws and my great-aunt in their late-life household disbandment. These experiences contributed to profound feelings of frustration with them and sadness and regret for them. In addition to my personal background, I spent 30 years professionally helping my interior design clients with place making. In 2009, I began pursuing my graduate degree. My master's thesis, a study using grounded theory, involved understanding how householders contributed to their sense of home using physical attributes of their houses. My pilot study, for this dissertation research, investigated the feelings and opinions of older adults involved in household disbandment.

\section{How will I position myself in my research?}

I usually have very well-formed ideas about social etiquette and responsibilities and I express my opinions when I am asked for them. I have a strong moral code. I value contact with friends and family, responsibility, dependability, security, stability, beauty, productivity, order, kindness, generosity, decisiveness, proactivity, assertiveness, and intimacy. I am motivated by connecting, creating quality relationships, and having purpose. Although I am genuinely interested and highly supportive of others, I have a strong need to be liked, and to be in control. Being both an interior designer and a department chair allows me positions of control and helping people decide what to do. I read others to understand their point of view. To be more pleasing to others, I can be somewhat of a chameleon, changing my own manner to match that of the people I am with at the time.

As a research interviewer, I can use some of these skills, but I need to position myself as the person seeking answers rather than the one providing them. I need to listen empathetically and critically (without moral judgment), and not give my opinions. When 
I transcribed my pilot study interviews, I became aware of the amount of interjections I made into the participants' narratives. I want to listen more and talk less this time.

\section{What do I suppose is going to happen during my research and why?}

Based on my previous research, I will initially find the obvious. It will take deeper questioning and analysis to get to new "meat of the topic." This is one of the reasons I want to incorporate narrative inquiry and a focus on temporality. It will be tempting to force my preconceptions on the data, but I will ask myself, "What am I not seeing?" There will be many ways the process of relocation and place making is accomplished, but there will be underlying patterns that will contribute to categories for my theoretical framework.

\section{What do I value about the research I am doing?}

I value the notion of people dwelling and trying to be at home. I value independence for others as well as for myself. I care about older people and their last living experiences. I am passionate about the value of interior design as a profession and want to see theoretical depth added to it.

\section{Why is it important to me?}

My research is important for all the values I listed in the above question. In hindsight, I was insensitive in the way I handled the disbandment of my great-aunt's house. She was frail and needed to move, but she had lived independently and had been a professional woman for many decades. At the time of the move, she entered the hospital for brain aneurysm, and it was likely she would die on the operating table. I flew across the country, leaving my preschooler, sold the house, and packed up what I wanted her to take if she survived. I made unilateral decisions. She did survive the surgery. I loaded her 
onto a plane and admitted her to a very nice assisted living facility that she called a "hell hole." Although I was more compassionate as I assisted my in-laws, there were still things that I didn't understand until afterwards when I read the literature during my graduate work. I want to add to the literature and the understanding of the phenomenon, which will eventually contribute to interior design practice. In part, I am performing a "living amend" to my aunt who I harmed in her disbandment process. On a more concrete level, it goes without saying that my research is vital to the completion of my doctorate degree.

\section{Why did I choose it?}

I chose grounded theory research because of my own perspective on the construction of meaning. I chose my topic because of my values and the importance I attribute to honoring the aged. Additionally, I asked the "so what" question. In addition to the research being important to me, it is important to a world experiencing population aging. There are more people entering very old age. It is important for us as a society to understand implications of the late life relocation process.

\section{What types of actions and decisions have I taken to get to this place in my research?}

I am a driven person. I did not get my $\mathrm{PhD}$ in the normal life course time frame. Academia is my second career. Interior design was my first. For the last decade, I've made "short term sacrifices for long term gains." Two years ago, I relocated away from my home and family to stay in a position at which I was already experienced rather than take a different job that had a steeper learning curve. I wanted to spend time on my research rather than on learning a new position. The difficulty of this is my years remaining are less than the years that have gone before. It alters the dynamics of short- 
term sacrifice for long term gains. There have been more sacrifices than I expected, consequently the research has a greater value to me. I want to do it right. I want to do it well. 


\section{Appendix B}

\section{Recruitment Script}

When I become aware of a potential participant (through the selection procedures identified in the body of the proposal), I will ask the person who gave me her/his name to let the potential participant know I will be calling them. Afterwards I will call the person and use the following script.

Hello . My name is Heather Carter. Our mutual

friend suggested I call you. She/he said you would be interested in talking to me about my research study. I am working on a dissertation study as part of the requirements for a doctoral degree, and I'm very interested in knowing more about the experiences of older adults who have moved in the last 18 months. Are you still interested in visiting with me?

Great! I'd like to ask you just a few questions now and maybe then see if we can make an appointment to visit later. Is that ok? Great!

\begin{tabular}{|c|c|}
\hline \multicolumn{1}{|c|}{ Question } & \multicolumn{1}{c|}{$\begin{array}{c}\text { Qualifying } \\
\text { Answer }\end{array}$} \\
\hline Are you retired and 65 or over? & Yes \\
\hline When did you move? & $\begin{array}{c}\text { In the last 18 } \\
\text { months }\end{array}$ \\
\hline $\begin{array}{c}\text { Was your move related to either anticipated } \\
\text { or actual health conditions? }\end{array}$ & Yes \\
\hline $\begin{array}{l}\text { And lastly, did you have to downsize a great } \\
\text { deal, even most of your household possessions, } \\
\text { when you moved? }\end{array}$ & Yes \\
\hline
\end{tabular}

If one of the answers rules out the person from participating, I will discontinue asking further questions and let them know that although I appreciate their willingness to 
help, his/her situation is slightly different than the one I am studying. I will ask them if they know of anyone else who might want to help who meets all the qualifications.

If all the answers allow the person to participate, I will continue:

I am looking for people such as you to interview for this research about your relocation experience and specifically about the possessions you kept when you downsized and moved with you. This would involve two different meeting times over the course of a couple or several months. The first meeting will only take $15-20$ minutes. The second meeting will be about 90 minutes.

What I would like to do initially, is perhaps set up a time for me to meet with you at your home so that we could meet and talk about and my research process and you can decide if you want to participate. I have a consent form that you do not have to sign (Appendix G), but I'll leave it with you, so you know that I'm connected with the University of Missouri. It will have additional phone numbers to call if you have any questions.

Are you agreeable to set up our first meeting? 
Appendix C

Recruitment Poster

Available on following page. 


\section{NEEDED: RESEARCH PARTICIPANTS}

To understand how older adults decided what possessions they kept when they downsized and how those possessions have helped them in their new residences

WHEN

Spring-Fall 2017

WHERE

Kansas City \&

Dallas Metro Areas

Senior, Assisted, Independent

Living \& Residential Apartments

CONTACT

Researcher-Heather Carter

Cell: 913-486-3355

linkedin.com:

Heather Carter

heathercarlilecarter@gmail.com

Facebook Messenger:

m.me/heathercarlilecarter
AGES 65 \& UP

DISSERTATION TOPIC Meaningful possessions in the moving experiences of older adults

INTERVIEWS

- 45-90 minutes

- Non-disruptive

- Recorded

- Confidential

PARTICIPANT

REQUIREMENTS

- Retired

- Moved in last $18 \mathrm{mo}$.

- Downsized residence

- Moved due to agerelated limitations (anticipated or actual)

RESULTS

If desired, participates will receive results

COMPENSATION

Participants will add understanding to this area. No compensation will be provided. 


\section{Appendix D}

\section{Initial Meeting Protocol Form}

Storied Objects: Post-Household Disbandment Older Adult Place-Making through

Meaningful Possessions

\section{Senior Interview Protocol}

Institution: $\underline{\text { University of Missouri-Columbia }}$

IRB No.

Interviewee (Pseudonym)

Interviewer: $\underline{\text { Heather Carlile Carter, } \mathrm{PhD}(\mathrm{abd})}$

Date:

Time:

Place:

Documents Obtained:

\section{Possessions and Post-Household Disbandment Relocation Photographs}

\section{Introductory Protocol}

Thanks so much for being willing to participate in this research that focuses on understanding your apartment relocation. As we talked about when we last spoke, I want to understand how your possessions have helped you during your moving process. This is our first of three meetings if you decide to participate.

Overall, what I would like you to do is think about the possessions you brought with you to your new apartment. If you're agreeable, I'd like you to take photographs of your things that are meaningful to you and record in a journal a brief description of the object and a short narrative about your thoughts when taking the photo. You may use your cell phone and send me the digital images, or I have a disposal camera here to leave with you and a postage paid self-addressed envelope to send it back to me when you are finished. After I receive the photographs, I will print them for our second meeting. At that meeting, I will interview you about the photographs you took. Basically, I will want to know the story of these possessions, about what makes them things you kept when you downsized. After we visit, I'll have the audio recording of our interview transcribed, and I will send it to you to make sure it says what you want it to say. I will analyze that transcript along with other people's transcripts to see what kind of themes emerge. 
I'm hoping to interview about 30 people. After I've been interviewing for a while, I anticipate that the same themes will continue to emerge from what people have been saying. That's when I will schedule the third meeting. I'll meet with groups of about 8 participants at a time and together we will look at the photographs and the themes to see if they make sense. If you are uncomfortable showing other people any of the things in your photographs, we can come up with a sketch and a general description to use in the group meeting. That will be our last meeting. Does this make sense to you and is it something in which you'd like to participate? Do you have questions?

[If the person does not want to participate, I will gently end the meeting and leave. If s/he does want to participate, I will continue.]

Here is a consent form that explains my research process. You don't need to sign anything. This is for your information only. Let me know if there is something you don't understand. Basically, this document states that: (1) all information will be held confidential, (2) your participation is voluntary, and you may stop at any time if you feel uncomfortable, and (3) I do not intend to inflict any harm. Thank you for your agreeing to participate.

Today I'm going to go over the photographs I want you to take. Here is the camera (if participant asked for a camera) and a list of photographing tips that might be helpful and directions on what to do with the camera when you finish (or digital photos if participant is using a cell phone). Please do not include any people in your pictures - just photos of your personal possessions that you moved with you into your new apartment. Do you have any questions?

Great; after I get the camera (or digital images) from you, I will print them for our interview, which will be our second meeting. Let's go ahead and set up a meeting date in about two weeks. When is a good time for you? I'll touch base in about a week to confirm our appointment and check to see if you have any questions about the photographs. Thanks so much for helping me with this research!

[Sheet with tips on photographing and sending digital images follows in Appendix E] 


\section{Appendix E}

\section{Tips for Taking Photographs of Objects \& Sending Digital Images}

1. Do not take any photographs with people in them.

2. Make sure the lens on the camera is clean.

3. Use the orientation (portrait or landscape) that includes the entire object in the view finder.

4. Get closer to the object you are photographing instead of zooming in

5. Make sure the object has enough light on it, so you can see the details that you like.

6. If your hands shake, put the camera (or cell phone) on a table or something else that is stable before you take the picture.

\section{Directions for sending me the disposal camera}

- After you finish taking photographs, put the camera in the self-addressed stamped envelope I gave you when we met

- Pop the envelope in the mail

- Call me at 913-486-3355 to let me know you've sent it

- If something happens to the envelope or the camera before you can send me the camera, please call me, and I will replace it or them.

\section{Directions for sending me the digital images from your cell phone or iPad}

After you finish taking photographs, email the digital images to me or attach them to a text message. Call me at 913-486-3355 after you send them.

- How do I attach pictures and files to a text message?

- Open a new message and click on the attachment button.

- Choose your desired file format in the new window.

- Next, pick the picture or file (depending on your operating system) you want to send.

- Insert 913-486-3355 (or my name if you have me saved as a contact) as the recipient and include your name in the text.

$\circ$ Send.

You can send 4 attachments per message, $10 \mathrm{MB}$ maximum per attached picture or file. You will need to send additional texts to include all the images.

\section{Directions for sending me the digital images as an email attachment}

You can share your digital photos from the comfort of your computer with email programs that support attachments. To send photos in Microsoft Outlook Express: 
1. Connect to the Internet and fire up Outlook Express: If you use a different e-mail program, log on \& try these steps as well.

2. Choose File $\rightarrow$ New $\rightarrow$ Mail Message: A blank mail window appears.

3. Enter recipient's name, e-mail address, \& subject information. (It's the same as when you normally send an e-mail.)

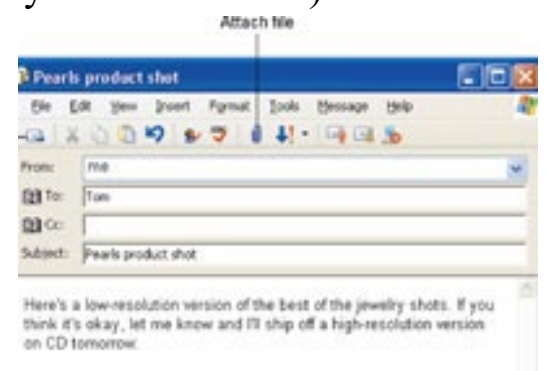

4. Choose Insert $\rightarrow$ File Attachment or click the Attach File button on the toolbar. A dialog box appears. Most programs provide a toolbar button to attach files.

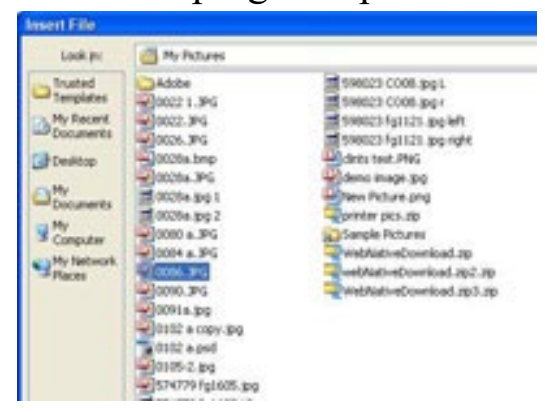

5. Track down the image file IN YOUR PHOTOS OR DOCUMENTS that you want to attach. Select it \& click Attach. You are then returned to the message composition window.

6. Choose File $\rightarrow$ Send Message or click the Send button to launch that image into cyberspace.

From : http://www.dummies.com/photography/digital-photography/photosharing/sharing-digital-photos-as-e-mail-attachments/ 


\section{Appendix F}

\section{Meeting 2 Interview Protocol with Interview Questions}

Storied Objects: Post-Household Disbandment Older Adult Place-Making through

Meaningful Possessions

\section{Senior Interview Protocol}

Institution: University of Missouri-Columbia

IRB No.

Interviewee (Pseudonym):

Interviewer: $\underline{\text { Heather Carlile Carter, } \mathrm{PhD}(\mathrm{abd})}$

Date:

Time:

Place:

Documents Obtained:

\section{Possessions and Post-Household Disbandment Relocation Interviews}

Introductory Protocol

To facilitate my note-taking, I'm going to record our conversations today on my $i P h o n e$ and $i P a d$. Only the research team on this project will be privy to the recording and that includes a transcriber and me. The recording will be eventually erased after it is transcribed.

Here is a consent form that explains the interview process we will have today. You don't need to sign anything. This is for your information only. Let me know if there is something you don't understand. Essentially, this document states that: (1) all information will be held confidential, (2) your participation is voluntary, and you may stop at any time if you feel uncomfortable, and (3) we do not intend to inflict any harm. Thank you for your agreeing to participate.

This interview won't last longer than ninety minutes. During this time, I'll ask you some questions, but mostly I want to learn from you and hear about your experience. 
Feel free to share something with me that I don't ask about if you think it matters to me understanding your moving experience.

In a couple of days, I'd like to give you the complete transcript of your interview so that you can verify that what is written is what you said. I can either email you a copy or send it through the postal service. Which would you prefer? (Get email address if that choice is made.)

Introduction

I asked you to talk with me today because you are someone who can share about the process of downsizing and moving from the perspective of an older adult, and I want to understand how your possessions helped you during the process. My study isn't judging your experiences. I'm just trying to learn more about how you are trying to make this place your home, and hopefully improve interior designers' understanding of what it's like for seniors to go through their possessions and move to a smaller location.

\section{A. Interviewee Background}

How long have you been living here?

B. Precipitation of the move

Probe 1: Would you talk to me a little about the reasons you decided to downsize your belongings and move into this new place? 
TRANSITION: “Thanks, for sharing. This is very helpful. Now do you mind telling me more about the actual process?"

C. Understanding the process

Probe 2: How did you decide what to move with you and what not to keep?

TRANSITION: "Wow, that's a tremendous amount of emotional and physical energy."

D. Changes in spatial environment and sense of home

Probe 3: How do you feel your new space? 
TRANSITION: "Spatial changes really matter to the way we operate in our homes. Let's look at other changes for a moment."

E. Reviewing photographs

Probe 4: Would you please show me the 10 photographs you selected from all the photographs you took and tell me the story of each of these possessions?

TRANSITION: "I'm always interested at the relationships we have with our things."

F. Contribution of possessions to place-making

Probe 5: Talk to me about ways your things may have changed the way you feel about this apartment. 
TRANSITION: “Thank you so much for sharing your personal story with me. I think this subject is both meaningful and important and I believe it will only be more so as our society continues to age. What you've shared is very beneficial to my research."

Post Interview Comments and/or Observations:

\section{Closure}

- REMEMBER to thank interviewee

- assure confidentiality

- ask permission to follow-up 
Field Notes: 


\title{
Appendix G
}

\section{CONSENT FORM TO PARTICIPATE IN A RESEARCH STUDY}

\author{
Researcher's Name(s): Heather Carlile Carter
}

Project Number:

Project Title: Storied Objects: Post-Household Disbandment Older Adult Place-Making through Meaningful Possessions

\section{INTRODUCTION}

This consent may contain words that you do not understand. Please ask me to explain any words or information that you do not clearly understand.

You are being asked to participate in a research study. This research is being conducted to get a better understanding of a senior's perspective on moving into an apartment during the latter part of life after downsizing and how an older adult's remaining possessions help make the new space meaningful. When you are invited to participate in research, you have the right to be informed about the study procedures so that you can decide whether you want to consent to participation. This form may contain words that you do not know. Please ask me to explain any words or information that you do not understand.

You have the right to know what you will be asked to do so that you can decide whether or not to be in the study. Your participation is voluntary. You do not have to be in the study if you do not want to. You may refuse to be in the study and nothing will happen. If you do not want to continue to be in the study, you may stop at any time without penalty or loss of benefits to which you are otherwise entitled.

Please tell me if you do not want to participate or if you want to stop answering questions after we begin the interview.

\section{WHY IS THIS STUDY BEING DONE?}

The purpose of this research is to get a better understanding of the way older adults use their remaining processions to make a new place after downsizing most of their other possessions and moving into apartments during the latter part of their lives. 


\section{HOW MANY PEOPLE WILL BE IN THE STUDY?}

About 30 people will take part in this research for a pilot study for my dissertation research, which is being done through the University of Missouri in Columbia, Missouri.

\section{WHAT AM I BEING ASKED TO DO?}

You will be asked to answer questions and tell me about your experience with downsizing your possessions and moving to an apartment. You will also be asked to take photos of the possessions that you brought with you into your new space that help make it "home" to you. If I ask a question you do not want to answer, just let me know that you want to skip that one. If you do not want to take photographs, please let me know.

\section{HOW LONG WILL I BE IN THE STUDY?}

This study will take approximately 3 - 6 months for me to complete. During that time, we will meet two more times. The next time will be for an interview that will last approximately 90 minutes. You can stop participating at any time without penalty.

\section{WHAT ARE THE BENEFITS OF BEING IN THE STUDY?}

Your participation will benefit environment and behavior researchers who are trying to understand the needs of seniors.

\section{WHAT ARE THE RISKS OF BEING IN THE STUDY?}

There are no reasonably foreseeable risks or discomforts associated with this study. If at any time you are uncomfortable continuing to discuss you moving experience, please let me know you want to discontinue answering questions.

\section{CONFIDENTIALITY}

Information produced by this study will be stored in my locked files within a locked office and on a password protected computer and identified by a pseudonym. All participants will be given pseudonyms during data transcription. Information contained in your records may not be given to anyone unaffiliated with the study in a form that could 
identify you without your written consent, except as required by law. Audio recordings will be password protected. The password will change every three months. No printed documents will have participants' actual names.

In addition, if photographs, audiotapes or videotapes were taken during the study that could identify you, then you must give special written permission for their use. In that case, you will be given the opportunity to view or listen, as applicable, to the photographs, audiotapes or videotapes before you give your permission for their use if you so request.

\section{WHAT ARE MY RIGHTS AS A PARTICIPANT?}

Participation in this study is voluntary. You do not have to participate in this study.

\section{WHO DO I CONTACT IF I HAVE QUESTIONS, CONCERNS, OR COMPLAINTS?}

Please contact Ruth Brent Tofle, PhD, Phone: (573) 882-6035 E-mail: Phone: (573) 8826035

E-mail: tofler@missouri.edu if you have questions about the research. Additionally, you may ask me questions, voice concerns or complaints at any time 913-486-3355 or hec2pc@mail.missouri.edu.

\section{WHOM DO I CALL IF I HAVE QUESTIONS OR PROBLEMS?}

If you have any questions regarding your rights as a participant in this research and/or concerns about the study, or if you feel under any pressure to enroll or to continue to participate in this study, you may contact the University of Missouri Campus Institutional Review Board (which is a group of people who review the research studies to protect participants' rights) at (573) 573-882-3181 or irb@missouri.edu.

If you choose to participate, please keep this copy of the Informed Consent form for your records. No signatures are required as it would be the only document linking you to the study. 


\section{Appendix H}

\section{EXAMPLE OF COMPLETED PHOTO JOURNAL}

\begin{tabular}{|c|c|c|c|}
\hline Photo 1 & Date & ${ }^{\text {Description }}$ & $\begin{array}{l}\text { Thoughts about the object when taking photograph } \\
\text { ITIS FUN, I LOVE MH RECORDS } \\
\text { MUSIC IS ENJOYABLE } \\
\text { REMINDSME OF PLACES, THINGS, Plople }\end{array}$ \\
\hline Photo 2 & Date & $\begin{array}{l}\text { Description } \\
\text { PHory E } \\
\text { ALBUIMS }\end{array}$ & $\begin{array}{l}\text { Thoughts about the object when taking photograph } \\
\text { ILOVE PHOTOS, I THINK OF FRIENDJ } \\
\text { ANO WHERE I'VE BFEN } \\
\text { WHEN I RECAL MEMORIFS FGAME } \\
\text { CET ALBUMS OVT AND FIND PNOTOS }\end{array}$ \\
\hline Photo 3 & & $\begin{array}{l}\text { Description } \\
\text { MODEL } \\
\text { AIR } \\
\text { PLANES }\end{array}$ & $\begin{array}{l}\text { Thoughts about the object when taking photograph } \\
\text { FUN TO BUILD M,DEZS OUT of } \\
\text { BALSA WOOD } \\
\text { LIKE TO SEE THEM FLY } \\
\text { BUILO THEM ALLMYLIFE }\end{array}$ \\
\hline Photo 4 & $5 \mid 18$ & $\begin{array}{l}\text { Description } \\
\text { FRAMED } \\
\text { PHOTOS }\end{array}$ & $\begin{array}{l}\text { Thoughts about the object when taking photograph } \\
\text { OF EXPERIENCES, FRIEND, FAM ILW. } \\
\text { MANY ARENOT AROVNO ANYMORE } \\
\text { TAEY BRINGBACK MEMORIES }\end{array}$ \\
\hline Photo 5 & Date $3 / 28$ & $\begin{array}{l}\text { Description } \\
\text { Books }\end{array}$ & 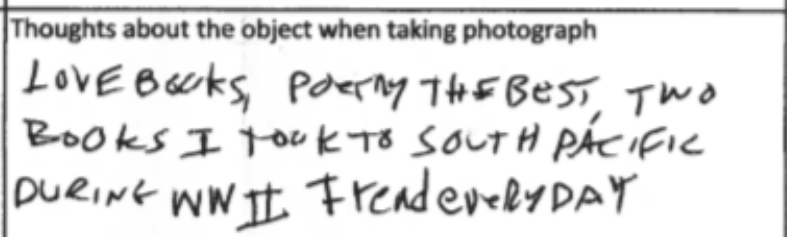 \\
\hline Photo 6 & $\xi 128$ & $\begin{array}{l}\text { Description } \\
\text { TRAIN } \\
\text { SET UP } \\
\text { HOU SES }\end{array}$ & $\begin{array}{l}\text { Thoughts about the object when taking photograph } \\
\text { ALWAYS MAD MUDELTRAINS } \\
\text { BLT TOO DIFFILUT TO RE BVILD IT. }\end{array}$ \\
\hline Photo 7 & $5 \ln 8$ & $\begin{array}{l}\text { Description } \\
\text { Tools }\end{array}$ & $\begin{array}{l}\text { Thoughts about the object when taking photograph } \\
\text { LOVE BUILOING AND REPAN,NG } \\
\text { THINCS, YOL AWWAYS NEEDTD HAVE } \\
\text { TOCLS. }\end{array}$ \\
\hline
\end{tabular}




\section{Vita}

Heather Carlile Carter was born on November 10, 1960 in Fairbanks, Alaska the second of four daughters to a civil engineer and a mathematician. When she was twoyears-old, her father took a job with the United States Bureau of Reclamation in Denver, Colorado where Heather spent the remainder of her childhood.

She attended Abilene Christian University in West Texas and received a BS degree in Interior Design in 1984. After working for an international development corporation in Kansas City, she began her own interior design business in 1987. Better Homes and Gardens published one of her projects in 1993. Heather earned her NCIDQ certification in 2007 and LEED AP certification in 2009. She is a professional member of ASID and IIDA.

Heather earned a MS in the University of Missouri's Architectural Studies program with an emphasis in Environment and Behavior in 2012. In 2018, she completed her PhD in Human Environmental Sciences with an emphasis in Architectural Studies also from the University of Missouri - Columbia. She is a member of Environmental Design Research Association (EDRA) and the Interior Design Educators Council (IDEC).

Heather began teaching in 2008 when she was hired to develop a new interior design Bachelor of Arts program in Kansas City. In 2015, She began commuting to Dallas as the Program Coordinator of Interior Design for the Art Institute of Dallas, overseeing the CIDA reaccreditation visit in 2016 and teaching a variety of classes from beginning through upper levels. Heather lives in Kansas City with her husband of thirtysix years. She has two adult daughters. 